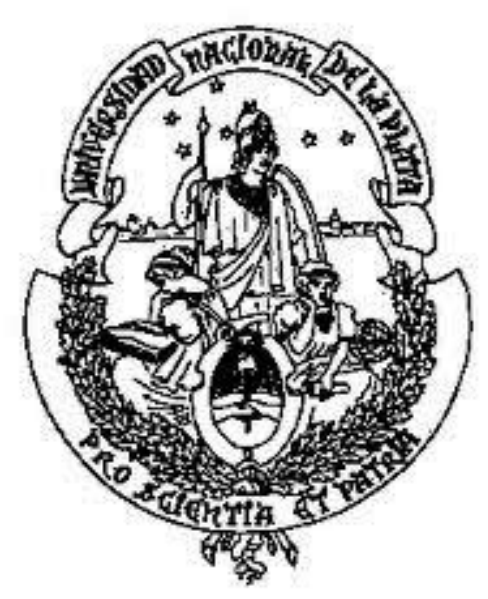

UNIVERSIDAD NACIONAL DE LA PLATA

FACULTAD DE CIENCIAS EXACTAS

DEPARTAMENTO DE CIENCIAS BIOLÓGICAS

Trabajo de Tesis Doctoral

\title{
UTILIZACIÓN DE PASTAS COMO ALIMENTOS FUNCIONALES
}

\section{CRISTINA S. MARTINEZ}

Director Dra. María Cristina Añón

Codirector Dr. Alberto Edel León

Año 2010 
A mis padres Susana y Chicho

A mi esposo Martín

A nuestro primer hijo Agustín A nuestro segundo hijo por nacer 


\section{Agradecimientos}

Con la alegría de llegar a la recta final, se vienen a la memoria innumerables momentos que han transcurrido durante la realización de esta tesis, e inmediatamente aparecen en mi pensamiento aquellas personas sin las cuales esto no hubiera sido posible. Mi más sincero agradecimiento a todos los que de una u otra forma me ayudaron a alcanzar este trascendental logro.

A la Dra. María Cristina Añón por distinguirme en ser su tesista, por su valiosa dirección y por su desinteresado apoyo y tiempo, a pesar de la dificultad de la distancia.

Al Dr. Alberto León, por haberme dado la oportunidad de realizar esta tesis, por su función de codirector, por sus inestimables consejos y por su permanente ayuda y apoyo. Un especial agradecimiento no solo por haberme brindado una excelente formación a nivel científico y profesional, sino por todas sus enseñanzas a nivel personal y su calidez humana.

Al Dr. Pablo Ribotta por su constante predisposición y ayuda para sortear los inconvenientes que tuve que superar durante este trabajo.

A la Dra. Gabriela Pérez por su desinteresada colaboración, consejos y por todo el apoyo dado durante este tiempo.

A la Fundación YPF por haberme otorgado la beca de la Fundación Estenssoro que me permitió la realización de esta tesis.

A la Facultad de Ciencias Agropecuarias de la Universidad Nacional de Córdoba por haberme facilitado un lugar de trabajo para el desarrollo de este estudio.

Al Centro de Investigación y Desarrollo en Criotecnología de Alimentos (CIDCA) de La Plata por haberme permitido realizar parte de mi trabajo en sus laboratorios.

Al Centro de Excelencia en Productos y Procesos de Córdoba (CEPROCOR), que prestó sus instalaciones y equipos para realizar algunas de las determinaciones que formaron parte de este trabajo.

A la Secretaría de Ciencia y Técnica de la Universidad Nacional de Córdoba por el apoyo económico para el desarrollo de este estudio. 
A la Agencia Nacional de Promoción Científica y Tecnológica por el financiamiento a través del Préstamo PICTR2005-33882.

A la acción CYTED por el financiamiento del Proyecto de Cooperación Internacional PANXTODOS, 106AC0301.

A mis más antiguas compañeras y amigas, Eugenia, Paola, Lorena, Mariela y a las más nuevas, Gabriela y Malena, por estar siempre a mi lado para brindarme su ayuda y colaboración, por disfrutar conmigo todos los lindos momentos, así cómo apoyarme en los tiempos más difíciles. A Andrés por sus inteligentes aportes. A Alicia por su contagiosa alegría y sus consejos.

A mis hermanos, muy especialmente a Fernando por escucharme, aconsejarme y animarme para alcanzar este logro a pesar de los $1600 \mathrm{~km}$ que nos separan.

A mis padres, para los cuales no existen palabras de agradecimiento, por su incondicional apoyo; por animarme y contenerme en los momentos más difíciles, y por hacer suyos mis logros y metas alcanzadas. Por la ayuda brindada con Agustín, por todas las horas que lo cuidaron y mimaron.

Mi más infinito agradecimiento para Martín, mi esposo, compañero, consejero, amigo y excelente padre, por su inestimable apoyo y compresión para sobrellevar todo mis viajes y ausencias que implicó la realización de este trabajo.

A Agustín, por ser el sol de cada día desde que llegó a nuestras vidas, porque con su pequeñita presencia, divinamente alegre y divertida, nos da la más inmensa fuerza como para superar cualquier inconveniente.

A nuestro segundo hijo, que Dios acompañe su crecimiento y bendiga el momento de tenerlo en nuestros brazos. 


\section{Índice}

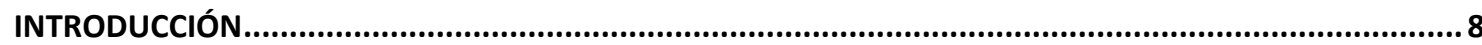

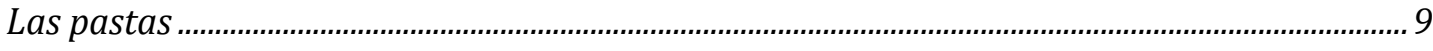

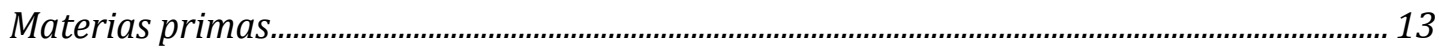

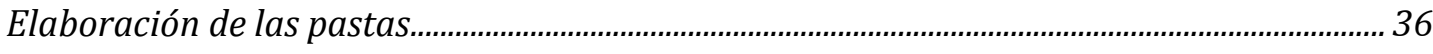

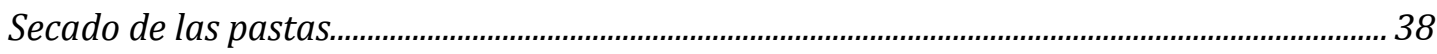

Comportamiento de las pastas durante la cocción ............................................................................. 42

Propiedades funcionales y nutricionales de las pastas............................................................... 44

Propiedades funcionales inherentes a la estructura de las pastas .............................................. 45

Propiedades funcionales de la harina de amaranto................................................................ 48

Propiedades funcionales de la harina de soja............................................................................. 50

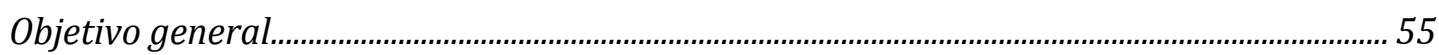

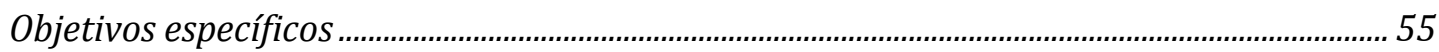

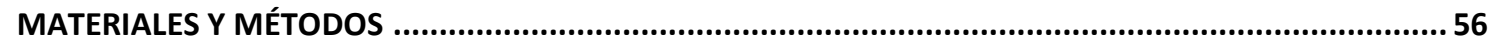

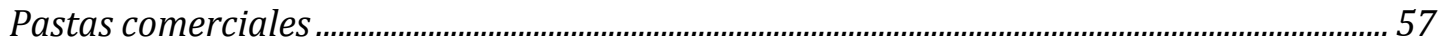

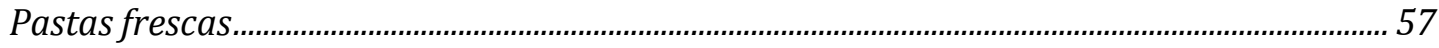

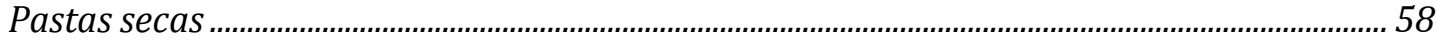

Evaluación de las harinas ................................................................................................................. 60

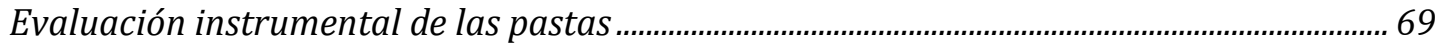

Determinación de isoflavonas por HPLC en las harinas y en las pastas cocidas..................... 81

Determinación de escualeno por HPLC en las harinas y en las pastas cocidas........................ 81

Almidón resistente, soluble y total ................................................................................................... 83

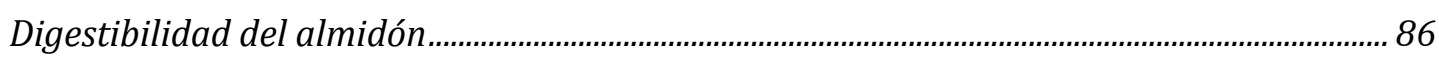

Digestibilidad de proteínas......................................................................................................... 88

Evaluación sensorial de las pastas....................................................................................................... 89

Análisis estadístico ……................................................................................................................................. 93

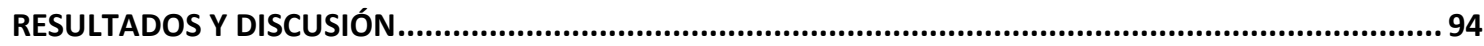

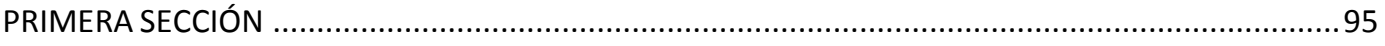

ESTUDIO DE LOS PARÁMETROS QUE DEFINEN LA CALIDAD DE LAS PASTAS .............................................. 95

Composición de las muestras........................................................................................................... 96

Propiedades de cocción de las pastas .......................................................................................... 97

Color de la pasta cruda y cocida …............................................................................................... 99 
Evaluación sensorial...................................................................................................................101

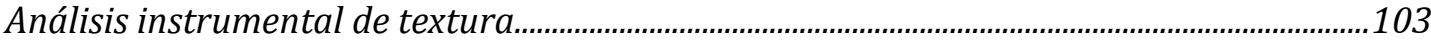

Correlación entre la evaluación sensorial y el análisis instrumental de textura ...................108

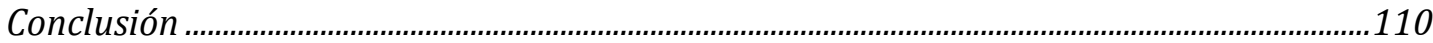

SEGUNDA SECCIÓN

EVALUACIÓN DEL EFECTO DEL ALMIDÓN Y DEL GLUTEN SOBRE LA CALIDAD DE LAS PASTAS LAMINADAS ELABORADAS CON HARINA DE TRIGO PAN

Composición química de la harina de trigo, del almidón y del gluten ......................................112

Características de las pastas frescas.............................................................................................113

Conclusión …...............................................................................................................................119

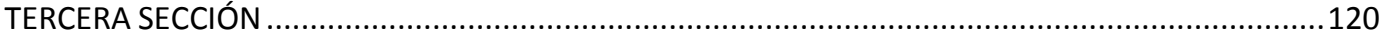

EVALUACIÓN DEL EFECTO DE HARINAS CON DIFERENTES CARACTERÍSTICAS SOBRE EL COLOR DE PASTAS FRESCAS ....120

Caracterización de las harinas utilizadas .......................................................................................121

Determinación del color de las pastas......................................................................................127

Relación entre la composición química y el color de las harinas y de las pastas..................128

Relación entre las fracciones proteicas y el color de las harinas y de las pastas ..................129

Relación entre diferentes cantidades de agua añadida a la masa y el color de las pastas

Conclusiones.

CUARTA SECCIÓN

OBTENCIÓN DE PASTAS DE CALIDAD TECNOLÓGICA Y SENSORIAL ACEPTABLES, ELABORADAS CON HARINA DE AMARANTO Y HARINA DE SOJA A FIN DE OTORGARLES PROPIEDADES FUNCIONALES Y MEJORAR SU CALIDAD NUTRICIONAL

Caracterización de las harinas.

Elaboración de las pastas 138

Comportamiento durante la cocción. 141

Evaluación instrumental de la textura de las pastas secas.........................................................142

Evaluación instrumental de la textura de las pastas cocidas ....................................................144

Propiedades reológicas de las pastas cocidas..............................................................................145

Color de las pastas cocidas .......................................................................................................151

Microscopía electrónica de barrido (SEM) de las pastas secas y cocidas.................................153

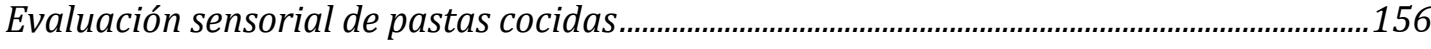

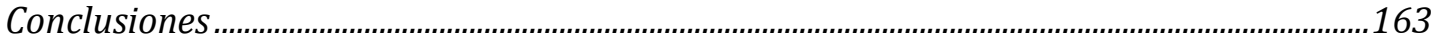

QUINTA SECCIÓN

DETERMINACIÓN DE LOS COMPONENTES CON PROPIEDADES FUNCIONALES APORTADOS POR LA HARINA DE AMARANTO 
LOS COMPUESTOS CON PROPIEDADES FUNCIONALES APORTADOS POR LA HARINA DE AMARANTO Y POR LA HARINA DE SOJA, FUERON AISLADOS, IDENTIFICADOS Y CUANTIFICADOS TANTO EN LAS HARINAS COMO EN LAS PASTAS ELABORADAS CON ELLAS. SOBRE ESTAS ÚLTIMAS, ADEMÁS SE EVALUÓ LA CALIDAD NUTRICIONAL.

EL COMPUESTO IDENTIFICADO Y CUANTIFICADO EN LAS PASTAS ELABORADAS CON HARINA DE AMARANTO FUE EL ESCUALENO, MIENTRAS QUE EN LAS ELABORADAS CON HARINA DE SOJA SE HIZO LO PROPIO CON LAS ISOFLAVONAS........166

Determinación del escualeno

Extracción de las isoflavonas de la harina de soja y de las pastas sustituidas con ésta y su determinación por HPLC..

Evaluación de la calidad nutricional de las pastas elaboradas con harina de amaranto y harina de soja.

Conclusiones.

CONCLUSIONES GENERALES 


\section{INTRODUCCIÓN}




\section{Las pastas}

Las pastas alimenticias son productos que se consumen en todo el mundo, que se caracterizan por ser un alimento tradicional y de gran aceptación debido a su conveniencia, palatabilidad y cualidades nutricionales (Petitot et al., 2009a). Dentro de las muchas razones que justifican la popularidad de la pastas, se destacan, entre las más importantes, su ajustado perfil nutricional, y el hecho de ser una fuente importante de carbohidratos complejos y moderada de proteínas y de algunas vitaminas. Por ejemplo, una porción de $55 \mathrm{~g}$ de pastas secas contiene aproximadamente 210 calorías y presenta 75 por ciento de carbohidratos. Las directrices dietéticas publicadas por el Departamento de Agricultura de Estados Unidos de América (USDA) y por Health Canada, muestran que los productos a base de granos, como lo son las pastas, deben ser una parte importante de una dieta saludable. Además las pastas son un valorado bien de consumo, y como tal, se venden bien en buenos y malos tiempos económicos. En el caso de las pastas secas envasadas, se las puede considerar como un alimento prácticamente no perecedero, si se conservan de manera adecuada y se destacan por ser fáciles de cocinar, pudiéndose preparar una extensa variedad de platos a partir de las diferentes formas y tamaños disponibles (Marchylo \& Dexter, 2001).

En nuestro país, se las define de la siguiente manera: "Con el nombre genérico de pastas alimenticias o fideos se denomina a los productos no fermentados obtenidos por el empaste y amasado mecánico de sémolas o semolín o harinas de trigo ricas en gluten o harinas de panificación o por sus mezclas, con agua potable, con o sin la adición de substancias colorantes autorizadas a este fin, con o sin la adición de otros productos alimenticios de uso permitido para esta clase de productos..." (CAA, 2009/10a).

La producción mundial de pastas ronda los 12 millones de toneladas por año. Italia, que elabora más de 3.160 .000 toneladas, es el principal país productor (26\%). Luego le siguen Estados Unidos cuyos 2.000 .000 de toneladas representan el $16 \%$ del total mundial, y Brasil que fabrica 1.500 .000 toneladas (12\%). Las 370.000 toneladas que produce nuestro país, en su mayor parte correspondiente a pastas secas envasadas, lo ubican en el noveno puesto del ranking mundial. De acuerdo al consumo interno anual per cápita, el cual promedia los $8,5 \mathrm{~kg}$, el país se sitúa en el puesto № 12 del mundo, siendo Italia, por lejos, el mayor consumidor de pastas alimenticias con $26 \mathrm{~kg}$ per cápita, por año. Los principales destinos de exportación son Chile, Brasil, Estados Unidos y Angola (Lezcano, 2009).

En Argentina, la elaboración de pastas alimenticias comprende unas 1500 empresas, pero el $95 \%$ de ellas son establecimientos pequeños, a menudo familiares, dedicados a producir 
pastas frescas. Las 80 firmas productoras de pastas secas son las que abastecen la mayor parte del mercado interno. La oferta es amplia y variada, puesto que la tecnología que se aplica y la formulación de la masa posibilitan gran número de productos con diferentes formatos.

El ingrediente de elección por excelencia de la pasta es la sémola de trigo candeal, obtenida de la molienda de granos de trigo durum (Triticum durum Desf.). Desafortunadamente, el trigo durum requiere de condiciones climáticas relativamente estrictas, no pudiendo ser cultivado en áreas demasiado frías o demasiado cálidas y húmedas.

En Argentina el trigo durum se cultiva desde el Sudeste hasta el Sudoeste de la Provincia de Buenos Aires y parte de La Pampa y los productores suelen trabajar por contratos o integrados verticalmente a industrias elaboradoras de pastas. Se trata de algunas empresas elaboradoras de pastas que poseen su propia producción primaria de trigo candeal, incluyendo su molienda (Lezcano, 2009).

A lo largo de los últimos diez años la producción de trigo durum ha representado solo el $1 \%$ de la cosecha triguera total. Cuando el trigo candeal presenta un precio elevado, poca oferta y disponibilidad, o en regiones alejadas de las zonas donde se cultiva, este es reemplazado parcial o totalmente por trigo pan (Triticum aestivum L.) para elaborar las pastas, resultando en productos de buena calidad excepto por la pérdida del color amarillo y la resistencia a la sobre-cocción, características de las pastas elaboradas a partir de sémola de trigo candeal (Hoseney, 1994a).

Si bien se puede producir sémola a partir de trigo pan, ésta se encuentra más acotada que la producción de la harina "0000" o "000", dado que para producirla, los molinos harineros deben contar con equipos especiales denominados sasores o purificadores de sémolas (Lezcano, 2009).

Considerando las limitaciones antes mencionadas, es frecuente encontrar pastas elaboradas a partir de harinas de trigo pan, especialmente en aquellos productos destinados a consumidores que priorizan el costo sobre la calidad.

\section{Variedades de pastas}

Las formas básicas de las pastas alimenticias, tales como espaguetis, lasaña, macarrones, y otros tipos de pastas cortas, no han cambiado mucho a lo largo de los siglos. Del mismo modo, la pasta se sigue haciendo con los mismos ingredientes: sémola de trigo candeal, sémola de trigo pan o harina o una combinación de estos, agua e ingredientes opcionales tales como 
huevo, espinaca, tomate, morrones, hierbas y otros (Marchylo \& Dexter, 2001). Se pueden encontrar pastas con cientos de formas y tamaños diferentes, pudiendo ser clasificadas como pastas largas (fetuccini, linguini, etc.), y pastas cortas (fideos coditos, tirabuzón, moños, etc.). Asimismo, de acuerdo al tipo de proceso, las pastas pueden ser laminadas (fideos cinta) o extrudidas (espaguetis) (Figura I.1).

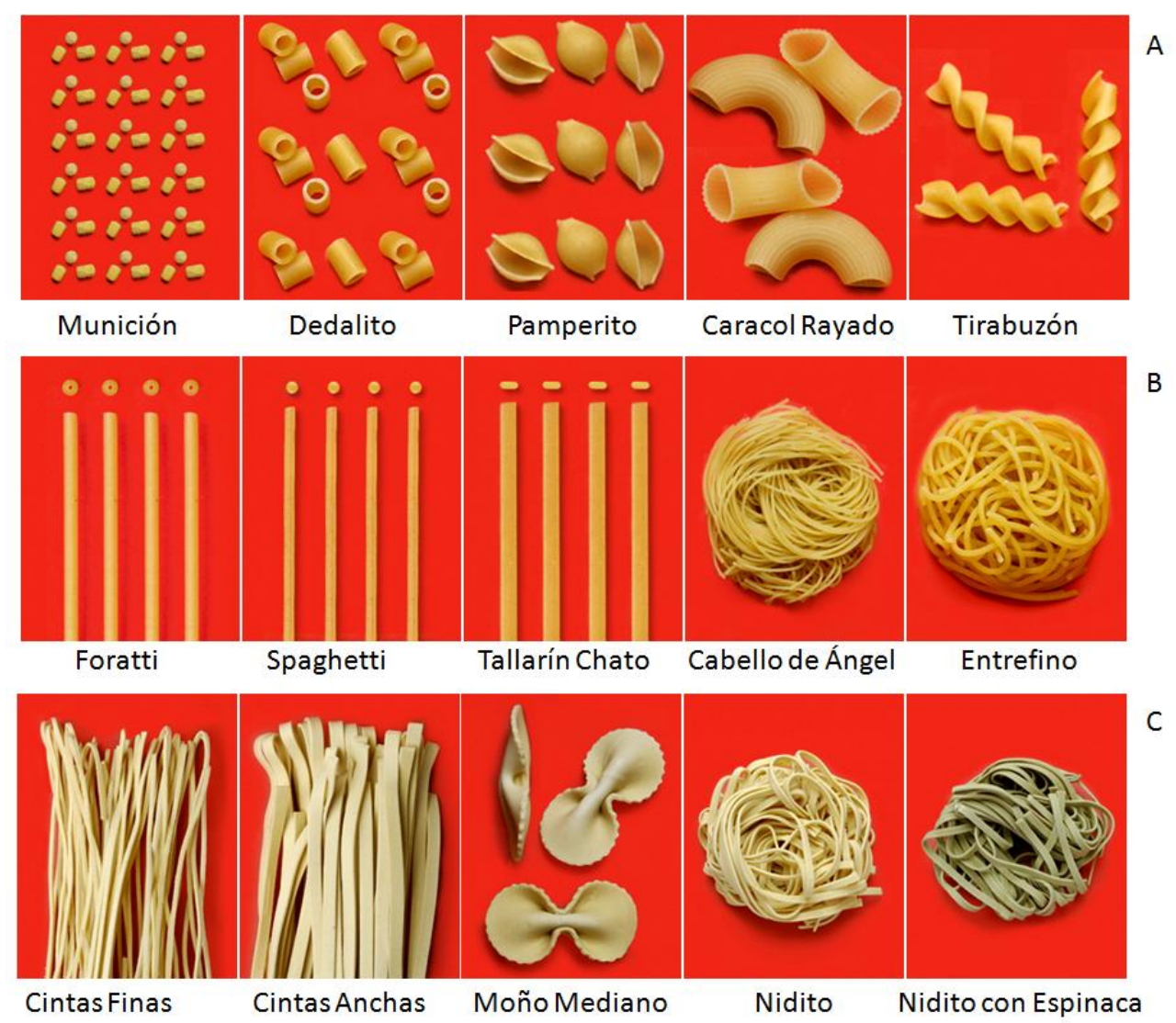

Figura I.1 - Pastas extrudidas cortas (A), pastas extrudidas largas (B), pastas laminadas (C). (http://www.pastaspolo.com.ar).

Dependiendo del trigo usado y del proceso de elaboración se pueden distinguir dos grandes grupos: los noodles y las pastas propiamente dichas. Los noodles son generalmente elaborados a partir de trigo pan (Triticum aestivum L.) usando un proceso de laminado y cortado; mientras que las pastas son procesadas por extrusión usando semolina proveniente de trigo durum (Triticum turgidum Desf.). Las diferencias entre las materias primas y el procedimiento de elaboración resultan en dos productos fácilmente distinguibles en apariencia y textura. Mientras que las pastas presentan una textura densa y firme con acentuado color amarillo, los noodles son generalmente más blandos y elásticos con una apariencia que varía entre blanco, blanco cremoso a amarillo suave (Fu et al., 2006). 
Según el contenido de agua, las pastas también pueden diferenciarse en pastas secas y pastas frescas. Las primeras se caracterizan por haber sido sometidas a un proceso de secado con posterioridad a su moldeo y cuyo contenido de agua no debe ser superior a $12,5 \%$ en peso (si bien el CAA establece un máximo de 14\% en peso, industrialmente se trabaja con un menor contenido de agua para asegurar la inocuidad del producto). En cambio, en las pastas frescas el contenido de agua no debe ser superior a 35\% peso/peso, a excepción de los ñoquis en donde se admite hasta el 55\% peso/peso (CAA, 2009/10a). Además se pueden encontrar pastas frescas elaboradas con diferentes rellenos en base a carnes, verduras, papas, quesos, ricota 0 sesos y que de acuerdo a sus características, pueden denominarse cappellettis, ravioles, panzottis, sorrentinos, tortellettis y agnolottis entre otras.

\section{Origen de las pastas}

Más allá de la difundida versión histórica que señala que Marco Polo introdujo las pastas en Europa desde China, el origen de las pastas se remonta a 1200 años a. C. en Egipto, en donde se encontró un bajo relieve de una especie de panadería en la cual se hacían rollos de masa, que se cortaban y se cocinaban. A partir de allí la pasta se extendió desde Palestina hacia el Asia Menor y luego a Grecia y Europa.

En la Edad Media las pastas estaban definitivamente incluidas en la dieta de los sicilianos, propagándose luego hacia el norte de Italia. Inicialmente la pasta era laminada, cortada en tiras y comercializada como pasta fresca. Posteriormente se descubrió que el clima de la costa de Italia era ideal para el secado y así la pasta seca se hizo rápidamente muy popular debido a su estabilidad durante el almacenamiento. La mecanización de la fabricación de las pastas comenzó durante los siglos XVIII y XIX con la invención de prensas hidráulicas y amasadoras. Los gabinetes de secado aparecieron en el siglo XX y la elaboración de las pastas siguió siendo un proceso por lotes hasta la década de 1930 cuando se introdujo la extrusión continua (Marchylo et al., 2004).

Indiscutiblemente, desde tiempos muy tempranos las pastas pertenecen a los italianos y en la actualidad son consideradas como un producto típicamente italiano, asociación en gran medida justificada por el hecho de que Italia es el principal productor, consumidor y exportador de pastas alimenticias del mundo (Marchylo \& Dexter, 2001).

\section{Origen de los "noodles"}

El origen de los noodles (fideos característicos de Asia) se remonta a 6000 años atrás en el norte de China. Algunos atribuyen su origen a una pequeña aldea de Shanxis, donde se 
elaboraban unos fideos llamados "Yu" que eran similares a los espaguetis. Los noodles se diseminaron desde China hacia otros países del sudeste asiático como Corea, Filipinas, Tailandia, Malasia y Japón. A mediados del siglo pasado se desarrollaron los noodles instantáneos, estilo ramen, en Japón en 1957, por Nissin Foods, los que fueron rápidamente adoptados como una comida de rápida y fácil preparación y que en la década del 70s inmigraron con éxito a EE.UU. (Hatcher, 2001).

En el año 2002 se destinaron 13 millones de toneladas de trigo para la producción de 54.700 millones de unidades de noodles instantáneos en el mundo, concentrando solo Asia el $75 \%$ del consumo mundial de esta clase de noodles. Este hecho resume la importancia actual de los noodles. Corea del Sur tiene el mayor consumo per cápita por año, alcanzando $83 \mathrm{~kg}$, seguido por Indonesia, Japón y Tailandia con 46, 45 y 22 kg respectivamente (Fundación Chile, 2005).

\section{Materias primas}

Se han realizado muchos trabajos científicos para tratar de entender los parámetros que influyen en el procesamiento de las pastas y en la calidad final del producto. La correcta elección de las materias primas y de las variables del procesamiento son las únicas medidas que pueden tomarse para garantizar la obtención de una pasta, que cocida al dente, sea firme, elástica, no presente una superficie pegajosa y que la pérdida por cocción sea poca o ninguna (Brunnel et al., 2010).

\section{El trigo}

Con el término "trigo" (Triticum spp) se designa a un conjunto de especies, tanto cultivadas como silvestres, que pertenecen al género Triticum. La palabra «trigo» proviene del vocablo latino triticum, que significa 'quebrado', 'triturado' o 'trillado', haciendo referencia a la actividad que se debe realizar para separar el grano de trigo de la cascarilla que lo recubre (Gómez Pallarés et al., 2007).

Existen muchos tipos de trigo, pero los más importantes comercialmente son tres. El trigo común o pan (Triticum aestivum L. subsp. aestivum, también llamado triticum vulgare) es el más ampliamente cultivado y produce harinas de calidad superior para elaborar productos leudados; el trigo club (Triticum aestivum L. subsp. compactum (Host) Mackey) posee granos blandos y con bajo contenido de proteína, por lo que produce harinas aptas para elaborar ciertos tipos de bizcochuelos y galletitas donde se necesita un gluten débil; y el trigo duro 
(Triticum turgidum L. subsp. durum (Desf.) Husn.), que en nuestro país se denomina candeal y se destina principalmente para la producción de sémolas que se utilizan en la elaboración de pastas.

De acuerdo al CAA (2009/10a), artículo 657, el Triticum aestivum o trigo pan se caracteriza por presentar un grano de forma elíptica, más o menos redondeado, de color rojizoamarillento, grisáceo o combinaciones de estos colores, de aspecto opaco, fractura almidonosa, no quebradizo; de gluten húmedo elástico y extensible; con buen o muy buen valor panadero y con un peso de 30-40 g los 1000 granos; mientras que, el Triticum durum (Candeal y Taganrock) o trigo fideos, presenta un grano de forma elíptica sensiblemente alargado, de color ámbar claro, aspecto traslúcido, fractura vítrea y gran friabilidad, con gluten húmedo, corto y duro no apto para panificación con un peso de 50-60 g los 1000 granos.

\section{Estructura del grano de trigo}

Los granos de trigo son cariópsides, de forma ovalada con sus extremos redondeados. Están formados por tres partes principales: el salvado, o parte externa, el germen o embrión y el endospermo, que es la parte más interna del grano. El germen sobresale en uno de los extremos y en el otro hay un mechón de pelos finos, el resto del grano se denomina endospermo, el cual es un depósito de alimentos para el embrión y representa el $82 \%$ del peso del grano (Figura I.2).

A lo largo de la cara ventral del grano hay una depresión (surco), una invaginación de la aleurona y de todas las cubiertas. En el fondo del surco hay una zona vascular fuertemente pigmentada. El pericarpio y la testa, juntamente con la capa de aleurona, conforman el salvado de trigo. El salvado está formado por numerosas capas ricas en vitaminas, minerales y con un alto contenido de proteínas. La capa de aleurona se localiza entre el salvado y el endospermo. El germen es la parte donde se inicia el origen de una nueva planta. El germen de trigo es una de las fuentes más ricas en vitaminas del grupo $B$ y E, y contiene proteínas, grasas y minerales. El endospermo está constituido principalmente por almidón, proteínas y, en menor medida, celulosas, y presenta un bajo contenido de vitaminas y minerales. La harina blanca está formada predominantemente por el endospermo (Gómez Pallarés et al., 2007).

La textura del endospermo puede ser vítrea (cristalina, córnea, acerada) o harinosa (almidonosa, yesosa). El carácter vítreo de los granos suele estar relacionado con un alto contenido proteico, mientras que el carácter harinoso suele asociarse con rendimientos más elevados. 


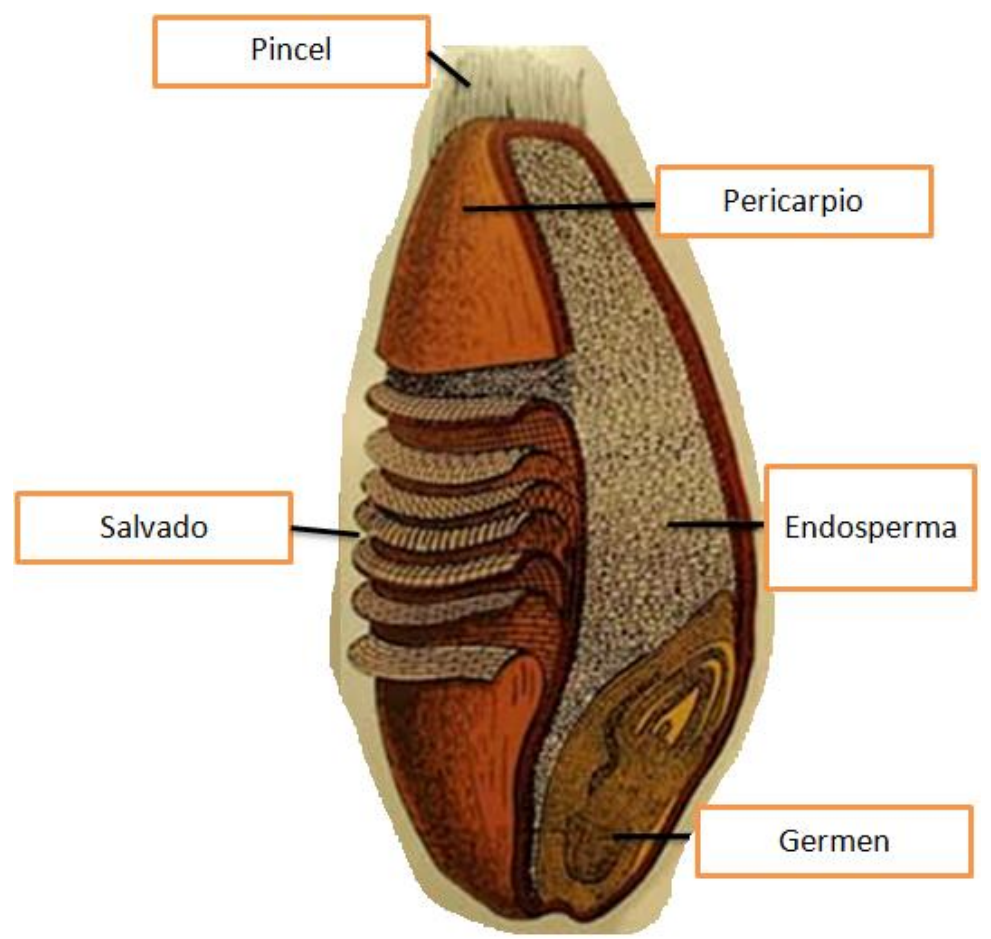

Figura I.2 - Estructura del grano de trigo.

Los granos vítreos son translúcidos y aparecen brillantes al observarlos, al contrario de los harinosos que son opacos y más oscuros bajo una fuente de luz. Esta opacidad de los granos harinosos es simplemente un efecto óptico, ocasionado por las diminutas vacuolas o fisuras llenas de aire que se encuentran en el interior de las células del endospermo o entre éstas. Estas fisuras forman superficies reflectantes internas que impiden la transmisión de la luz y dan al endospermo una apariencia blanca, que no tienen los granos vítreos en los cuales las células están totalmente llenas de una matriz formada por almidón-proteína. En los granos vítreos la luz se difracta en la interfase aire-grano, pero luego viaja a través del grano sin sufrir ninguna difracción. Debido a la presencia de estos espacios los granos harinosos son menos densos que los vítreos. A través de microscopía electrónica se ha observado que en los granos de $T$. durum existe una fuerte adherencia entre la proteína y el almidón. Los trigos duros producen una harina con mayor granulometría (sémola o semolina), que está formada por partículas de forma regular, que son, en su mayoría son células enteras del endospermo. Por el contrario, los trigos blandos proporcionan una harina muy fina formada por fragmentos irregulares de las células del endospermo y partículas planas que se adhieren unas a otras. La dureza, por otra parte, incide sobre la facilidad con que el endospermo se separa del salvado. En los trigos duros esta separación es más limpia y las células del endospermo permanecen intactas, sin embargo en los trigos blandos las células periféricas del endospermo tienden a 
fragmentarse y mientras unas se separan otras quedan unidas al salvado (Gómez Pallarés et al., 2007).

La composición del trigo puede variar según la zona y el año de cosecha. En la Tabla I.1 se presenta el rango de variación de los principales componentes en la composición química del grano de trigo (Matz, 1999).

Tabla I.1. Composición química del grano entero de trigo

\begin{tabular}{cc}
\hline Componentes & Composición Química, g/100 g* \\
\hline Agua & $8,0-18,0$ \\
Proteínas & $7,0-18,0$ \\
Lípidos & $1,5-2,0$ \\
Almidón & $60,0-68,0$ \\
Fibra Cruda & $2,0-2,5$ \\
Cenizas & $1,5-2,0$ \\
\hline
\end{tabular}

*Valores mínimos y máximos de cada componente en porcentaje.

El principal criterio de calidad del grano de trigo para elaborar harina para pastas es la dureza del grano, el contenido de proteínas, la fuerza del gluten y las propiedades de pasting del almidón (Fu, 2008).

\section{Harina de trigo}

La harina de trigo blanca proviene del endosperma del grano. Dado el repliegue (surco) que presenta el grano de trigo, es imposible eliminar las capas externas por simple abrasión y por ello, es que se opera por sucesivas trituraciones, llamadas molturación, tamizados y cernidos. De esta manera se separan diversas fracciones correspondientes a los tegumentos y capas de aleurona (salvado), el germen y el endosperma (Cheftel \& Cheftel, 1992).

La composición química del grano varía durante el proceso de molienda y la modificación más importante que se produce es una pérdida considerable de elementos nutritivos, especialmente de sales minerales y vitaminas. A partir del año 2002 rige en Argentina la ley 25.630, la cual obliga a que la harina de trigo destinada al consumo humano debe ser adicionada con determinadas cantidades de hierro, ácido fólico, tiamina, riboflavina y niacina. Además la eliminación de las capas más externas del grano provoca una pérdida prácticamente completa de las fibras presentes en el grano y una disminución del contenido de proteínas, lo que genera en consecuencia un aumento proporcional de la concentración del almidón.

La harina del endosperma representa aproximadamente el $70 \%$ del peso del grano y contiene la totalidad del almidón y gran parte de las proteínas del grano, en particular las 
glutelinas y las prolaminas, que se caracterizan por sus propiedades únicas de formar una masa viscoelástica al ser mezcladas con agua y darles energía a través del amasado. Estas proteínas pueden absorber prácticamente dos veces su peso en agua y constituir una red deformable, elástica y extensible capaz de retener $\mathrm{CO}_{2}$ durante la fermentación y posterior cocción. Por lo tanto, la calidad de la harina de trigo está determinada principalmente por la estructura molecular de las proteínas presentes, y de ellas dependen las interacciones que se establecen durante el amasado, que no solo se dan entre las proteínas y el agua para formar la red de gluten sino también interacciones con otros componentes presentes en la harina: almidón, polisacáridos no almidonosos (arabinoxilanos, arabinogalactanos) y lípidos (neutros y polares: fosfo y glicolípidos) (Carr et al., 1992; Bettge \& Morris, 2000; Lee et al., 2001).

La composición de una harina es aproximadamente un 75\% de almidón, 10\% de proteínas, $1 \%$ de lípidos, 0,3\% de fibras y 0,5\% de cenizas (Yúfera, 1998).

\section{Característica de la harina para pastas}

Considerando que la harina es la responsable del 95-98\% de los sólidos en las pastas secas, su importancia en la elaboración de éstas es elemental.

La apariencia de la harina de trigo utilizada para la elaboración de pastas evaluada por microscopía electrónica de barrido, difiere cuantitativamente de la apariencia de la sémola de trigo durum (Figura I.3). Mientras que la primera presenta una amplia gama de tamaños de partículas que incluye gránulos de almidón individuales y pequeños fragmentos proteicos, con los gránulos de almidón claramente visibles en la superficie de partículas más grandes; en la sémola se observan pocas partículas pequeñas, mostrando un aspecto mucho más compacto, en donde los gránulos de almidón están completamente encerrados en una matriz amorfa de proteínas (Dexter et al., 1979; Heneen \& Brismar, 2003).
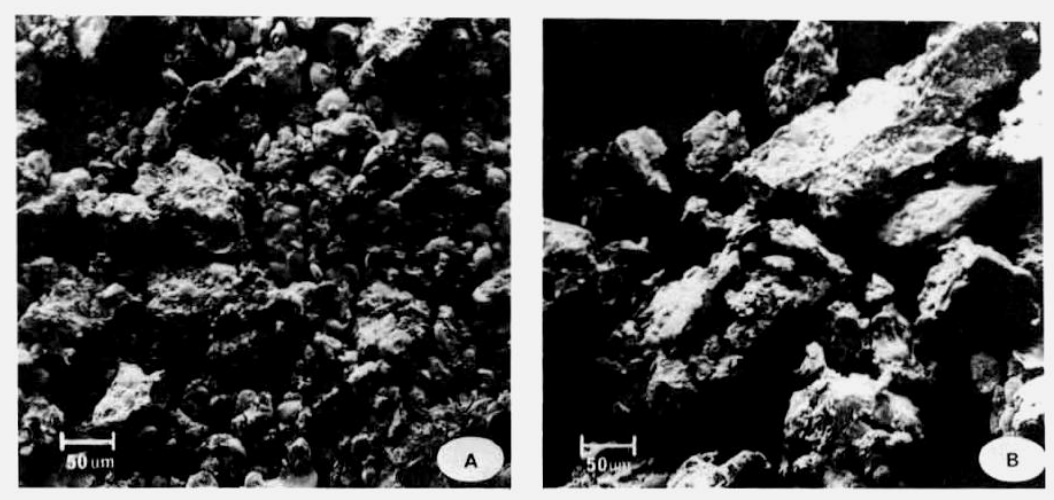

Figura I.3 - Microscopía electrónica de barrido: (A) harina de trigo pan, (B) sémola de trigo duro (Dexter et al., 1979). 
Un tamaño de partícula de la harina relativamente pequeño favorece la hidratación durante el amasado y el óptimo desarrollo de un gluten uniforme durante el laminado; de manera tal que, menos del $15 \%$ de una harina típica para pastas debe quedar retenido en un tamiz de $100 \mu \mathrm{m}$. Además la distribución del tamaño de partícula debe ser uniforme, ya que las partículas pequeñas se hidratan mucho más rápido que las más grandes, generando corpúsculos de masa de diferentes tamaños, lo que da lugar a manchas (húmedas o secas) en la lámina de masa. Por otro lado, una harina con un tamaño de partícula demasiado pequeño, puede estar indicando una alta cantidad de almidón dañado, que debido a su competencia por el agua con el gluten durante el amasado, debe ser evitado (Fu, 2008).

\section{Proteínas}

Osborne, en 1907 clasificó a las proteínas de los cereales de acuerdo a su solubilidad en cuatro tipos: albúminas, solubles en agua; globulinas, insolubles en agua y solubles en soluciones salinas diluidas; prolaminas, insolubles en agua y en soluciones salinas y solubles en alcohol al 70\% y glutelinas, insolubles en los solventes anteriormente mencionados y solubles en ácidos diluidos. Estas últimas también pueden ser solubilizadas en bases diluidas y detergentes. A los dos primeros grupos pertenecen las proteínas metabólicamente activas que se ubican en el citoplasma celular. Las gliadinas y gluteninas comprenden las proteínas de almacenamiento, las cuales conforman la mayoría de las proteínas presentes en el gluten. Aunque en trigo se usan los términos gliadinas y gluteninas, Osborne sugirió los nombres genéricos, prolaminas y glutelinas, para las fracciones equivalentes de otros cereales.

Asimismo, las proteínas de los granos de trigo se pueden dividir, más allá de la solubilidad que tengan en los distintos solventes, en base a su funcionalidad, clasificándose de este modo en dos grandes grupos: las proteínas que forman gluten y las que no lo forman. Las primeras se denominan proteínas de almacenamiento y constituyen alrededor del $80-85 \%$ del total de proteínas. Entre las proteínas no formadoras de gluten, que representan el $15-20 \%$ del contenido total de proteínas, se encuentran la mayoría de las enzimas.

\section{Proteínas que no forman gluten}

Las proteínas que no forman gluten son solubles en soluciones salinas diluidas por lo tanto corresponden a las albúminas y globulinas del fraccionamiento de Osborne. Son proteínas monoméricas, metabólicamente activas y estructurales, que se ubican en las capas más externas del grano de trigo. Su función en la panificación aún no está clara (Veraverbeke \& 
Delcour, 2002). Estas proteínas poseen un buen balance de aminoácidos, contienen proporciones relativamente altas de lisina, triptofano y metionina; tres aminoácidos que se encuentran en baja proporción en la mayoría de los cereales. La fracción de albúminas y globulinas incluye las proteínas solubles en cloroformo - metanol (CM-proteínas), enzimas, albúminas de alta masa molecular (HMW-albúminas), proteínas "triples" y otras proteínas que no son de almacenamiento. Las CM-proteínas poseen masas moleculares entre 11.000-13.000 Da y una composición de aminoácidos única con altos valores de lisina y aminoácidos no polares. Las proteínas "triples" o "triticins" son proteínas menores del endosperma depositadas en cuerpos proteicos que aparecen en las electroforesis en geles de poliacrilamida (SDS-PAGE) en condiciones no reductoras como un triplete de bandas de alto peso molecular (HMW). En presencia de mercaptoetanol o ditiotreitol se obtienen cuatro subunidades de $58.000,52.000,23.000$ y 22.000 de masa molecular (Singh et al., 1991). Mediante el fraccionamiento de las albúminas de harina de trigo por SDS-PAGE aparecen numerosos componentes proteicos. La mayoría de estas proteínas se pueden dividir en dos grupos: HMWalbúminas, y LMW-albúminas con un peso molecular aproximado de 60.000 y de 14.000 16.000 Da, respectivamente (Pogna et al., 1994).

\section{Proteínas formadoras de gluten}

Las proteínas formadoras de gluten se denominan también proteínas de almacenamiento (Kasarda et al., 1976), representan entre un $80-85 \%$ del total de las proteínas del trigo y sirven como fuente de nitrógeno durante la germinación de la semilla (Ng \& Bushuk, 1987; Larroque et al., 2000). Se encuentran en el endosperma del grano de trigo maduro donde forman una matriz continua alrededor de los gránulos de almidón. Las proteínas del gluten son insolubles en agua o en soluciones salinas diluidas y pueden ser divididas en dos grupos de acuerdo a su funcionalidad: las gliadinas monoméricas y las gluteninas poliméricas (extraíbles o no extraíbles). La composición de aminoácidos de las gliadinas y de las gluteninas es similar, se caracterizan por tener altas concentraciones de glutamina (un tercio o más del residuo total de aminoácidos) y de prolina (una séptima parte o más del residuo total de aminoácidos). Se considera en general que las gliadinas son las responsables de la viscosidad del gluten, mientras que las gluteninas son las encargadas de conferirle fuerza y elasticidad (Hoseney, 1994b).

\section{Gliadinas}

Como se mencionó anteriormente, las gliadinas son mayormente proteínas monoméricas ricas en glutamina y prolina, y además poseen un bajo nivel de aminoácidos cargados. 
Constituyen un tercio de las proteínas de la harina (Lindahl, 1990) y son clasificadas en $\alpha-, \beta-$, Y- y $\omega$-gliadinas en base a su movilidad en electroforesis a pH ácido (Shewry et al., 1986). Estas proteínas poseen una masa molecular entre $30.000-80.000$ Da y están formadas por un dominio no repetitivo rico en estructura secundaria $\alpha$-hélice y por un dominio repetitivo heterogéneo rico en estructura $\beta$-turn (Tatham \& Shewry, 1985).

Comparaciones del genoma y de las secuencias de los aminoácidos muestran que las $\alpha-\mathrm{y}$ $\beta$-gliadinas están estrechamente relacionadas y se suele referir a ambas como gliadinas tipo- $\alpha$. Las $\gamma$ - y $\omega$-gliadinas son estructuralmente distintas (Shewry \& Tatham, 1990). La $\alpha$ - y $\gamma$-gliadinas son proteínas monoméricas y consisten de 250 a 300 residuos de aminoácidos. Poseen un dominio $\mathrm{N}$-terminal repetitivo que representa entre $1 / 3$ y $1 / 2$ de la secuencia de la proteína, que es rica en residuos de prolina y glutamina, y un dominio C-terminal no repetitivo que posee residuos de cisteínas (Shewry \& Tatham, 1990). Las $\omega$-gliadinas están formadas por aproximadamente 350 residuos de aminoácidos y contienen repeticiones sucesivas de un octapéptido (Pro.Gln.Gln.Pro.Phe.Pro.Gln.Gln) y no presentan residuos de cisteína, por lo que están limitadas para formar interacciones covalentes en la masa (Tatham, 1995). Las $\gamma$ gliadinas poseen ocho residuos de cisteínas que se encuentran localizados en el dominio Cterminal y forman cuatro enlaces disulfuro intramoleculares, por lo que no son capaces de formar nuevos enlaces covalentes con otras proteínas del gluten. Las $\alpha$-gliadinas poseen seis residuos de cisteínas igualmente ubicados como en las $\gamma$-gliadinas que forman tres enlaces disulfuro también intermolecularmente. Sin embargo, estos enlaces disulfuro son importantes para retener el plegado de la estructura de las gliadinas que determina la naturaleza de las interacciones no covalentes con la red de gluteninas (Wrigley et al., 1998). Las fracciones de mayor masa molecular (entre 100.000 y 200.000 Da) están compuestas de subunidades más pequeñas (Bietz \& Wall, 1980). Las gliadinas fueron modeladas como estructuras elípticas con conformaciones extendidas mediante difracción de rayos-X de pequeño ángulo y diámetros de aproximadamente 3,2 nm (Thomson et al., 1999). Las gliadinas pueden también ser separadas por su hidrofobicidad mediante cromatografía líquida de alta performance en fase reversa (RPHPLC): las $\gamma$-gliadinas son el grupo más hidrofóbico (Wieser et al., 1987). Algunos investigadores proponen que son las responsables de la cohesividad de las masas (Hoseney, 1994b), aunque otros sugieren que controlan el potencial de volumen de pan (Khatkar et al., 2002), por lo que cobra interés el estudio de la composición y la estructura de esta fracción proteica. 


\section{Gluteninas}

Las gluteninas se encuentran formando agregados proteicos unidos por puentes disulfuro y fuerzas no covalentes intermoleculares. Su masa molecular varía desde 500.000 Da a más de 10 millones (Wieser et al., 2007). Luego de la reducción de los puentes disulfuro las subunidades de gluteninas resultantes poseen una solubilidad en alcohol similar a las gliadinas y pueden ser divididas en dos tipos: las subunidades de alta masa molecular (HMW-GS) y las subunidades de baja masa molecular (LMW-GS) (Shewry et al., 1992).

En un principio, las gluteninas fueron clasificadas en tres grupos ( $A, B$ y $C$ ) de acuerdo a su movilidad en geles de poliacrilamida (SDS-PAGE): en el primer grupo (A) se encuentran las HMG-GS con masas moleculares entre $95.000-136.000$ Da y en el segundo y tercer grupo (B y C) se encuentran las LMW-GS con masas moleculares entre $42.000-51.000$ y $31.500-35.500$ Da, respectivamente (Payne \& Corfield, 1979). Posteriormente, Jackson et al. (1983) observaron (también de acuerdo a su movilidad electroforética) que las LMW-GS podían dividirse en tres grupos, por lo que adicionó un grupo más denominado $\mathrm{D}$.

LMW-GS son un grupo complejo de proteínas que poseen la habilidad de formar enlaces disulfuro que permiten su incorporación dentro de los polímeros de gluteninas. La mayoría de las LMW-GS contienen entre siete y ocho residuos de cisteínas (Grosch \& Wieser, 1999; Wieser, 2003), seis residuos están en una posición homóloga a las gliadinas, y por lo tanto formarían puentes disufuro intramoleculares. Los residuos de cisteínas adicionales no son capaces de formar puentes disulfuro intramoleculares, probablemente por impedimento estérico, por lo que formarían puentes disulfuro intermoleculares formando agregados proteicos entre ellas y con HMW-GS (Pogna et al., 1994). En general las LMW-GS tipo-B actúan como extensores de las cadenas poliméricas crecientes ya que pueden formar dos puentes disulfuro intermoleculares, mientras que la mayor parte de las LMW-GS tipo C y D actúan como terminadores de las cadenas poliméricas crecientes ya que solo poseen una cisteína disponible para formar un puente disulfuro intermolecular (Kasarda, 1989). Muy poco se conoce sobre la estructura de LMW-GS. Tatham et al. (1987) propusieron que en el dominio Nterminal se encuentran distribuidas irregularmente estructuras secundarias $\beta$-turn, mientras que en el dominios C-terminal predomina la estructura $\alpha$-hélice. Lindsay \& Skerrit (2000), basados en imágenes de microscopia electrónica de transmisión, determinaron que las LMWGS forman estructuras agrupadas discretas, pero no fue posible determinar si esas asociaciones son covalentes o no covalentes. Aunque HMW-GS son el grupo principal de proteínas del gluten que determinan las características panaderas de la masa, LMW-GS también cumplen un importante rol. En general, LMW-GS se relacionan con la resistencia y la 
extensibilidad de la masa (Metakovskii et al., 1990; Andrews et al., 1994; Cornish et al., 2001) e incluso algunas formas alélicas causan mayores efectos sobre las propiedades de la masa que las HMW-GS (Payne et al., 1987; Gupta et al., 1989, 1994).

Las subunidades de gluteninas de alta masa molecular (HMW-GS) presentan fuertes similitudes estructurales entre ellas, pero también diferencias características. Una de las diferencias es el comportamiento en la polimerización y se relaciona con el número de grupos sulhfidrilo. En base a esta diferenciación, HMW-GS son clasificadas en dos subgrupos: subunidades tipo-X y tipo-Y. El dominio $\mathrm{N}$-terminal de las subunidades tipo-X contienen cuatro residuos de cisteínas y el dominio $\mathrm{N}$-terminal de las subunidades tipo- $\mathrm{Y}$ contienen cinco residuos de cisteínas. Además, las subunidades tipo-X tienen una menor movilidad electroforética que las subunidades tipo-y (Tatham, 1995).

En la Figura I.4 se muestra un modelo estructural basado en datos espectroscópicos detallados por Shewry et al. (2001). Los estudios muestran a las subunidades de gluteninas de alta masa molecular, como moléculas alargadas que posee una estructura $\beta$-espiral en la región central repetitiva. Mientras que los dominios $\mathrm{N}$ - y C-terminal poseen una estructura similar a las proteínas globulares, presentado $\alpha$-hélices y estructura desordenada (Figura I.5).

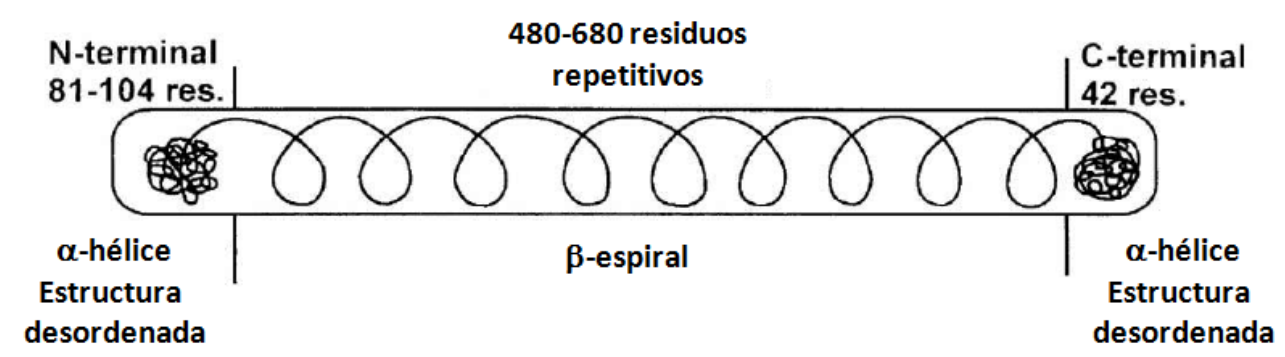

Figura I.4 - Modelo estructural de las subunidades de gluteninas de alto peso molecular (HMW), basado en estudios predictivos, espectroscópicos e hidrodinámicos (Shewry et al., 2001).

En los dominios terminales se encuentran la mayoría de los residuos de cisteínas que proveen de los sitios para la formación de puentes disulfuro intermoleculares. La estructura $\beta$ espiral de la región central presenta elasticidad intrínseca, pero la contribución a las propiedades elastoméricas del polímero no está aún dilucidada. 
Residuos adicionales de cisteína en dominios repetidos

Puede formar uniones S-S dentro de

la cadena dando lugar a polimeros más rígidos.

\section{Estructura $\beta$-espiral}

Contribuye a la elasticidad del gluten por elasticidad intrínseca y por formación de "bucles y colas" estabilizados por puentes de hidrógeno.

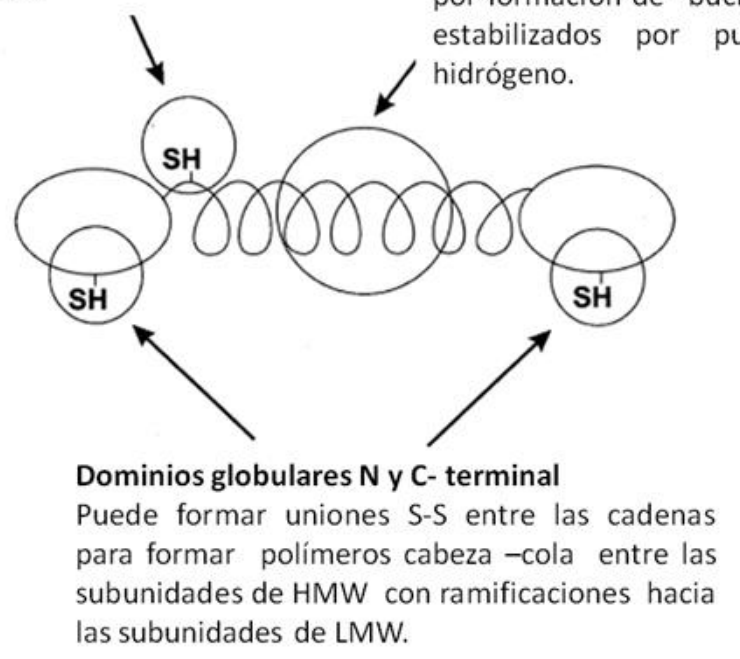

Figura I.5 - Modelos propuesto por Shewry et al. (2001) de las características estructurales de las subunidades HMW que pueden determinar la elasticidad del gluten y la masa.

\section{Macropolímero de gluteninas}

Parte de las gluteninas poliméricas pueden ser separadas como una capa de gel insoluble en SDS llamado macropolímero de gluteninas (GMP). El GMP está compuesto por agregados proteicos de gran tamaño formados por gluteninas de alto y bajo peso molecular (HMW-GS y LMW-GS) (Don et al., 2003a). Varios modelos, basados principalmente en la habilidad de las subunidades en formar puentes disulfuro intermoleculares, han sido propuestos para la estructura del GMP, pero no se ha logrado consenso aún. Hamer \& van Vliet (2000) propusieron que el GMP es un gel formado tanto por interacciones físicas como químicas. Don et al. (2003 a,b,c) afirmaron que el GMP está compuesto por partículas esféricas de gluteninas de distintos tamaños. Estos autores postulan que el tamaño de las partículas de gluteninas determina la energía requerida en el amasado para el óptimo desarrollo de la masa. El amasado modifica la forma y el tamaño de las partículas de gluteninas afectando sus propiedades físicas; durante este proceso el contenido de GMP disminuye debido a su despolimerización, mientras que durante el reposo se restablecen las interacciones y el GMP es re-polimerizado (Weegels et al., 1996 a,b, 1997 a,b). Por otro lado, Belton (2005), sostiene que las HMW-GS no son partículas, si no que componen una red enramada y físicamente entrecruzada. 


\section{El gluten}

Las propiedades de la harina de trigo para formar una masa cohesiva que puede ser horneada para producir pan o para formar pastas son derivadas de las proteínas presentes en el gluten. Las propiedades reológicas de la masa son gobernadas por la estructura del gluten y las interacciones que se establecen entre las proteínas que lo componen, particularmente entre los polímeros de gluteninas unidos por enlaces disulfuro (Lindsay \& Skerritt, 1999).

El gluten es definido como un gel formado por las proteínas de almacenamiento del grano de trigo cuando se trabaja mecánicamente una mezcla de harina y agua. Se puede obtener lavando una masa con agua para eliminar el almidón y los componentes solubles. El gluten está formado por un $80 \%$ de proteínas y un $8 \%$ de lípidos, en base seca, con un resto de hidratos de carbono y cenizas (Hoseney, 1994b), aunque dicha composición varía con el método de extracción.

Las proteínas que integran el gluten se encuentran localizadas en cuerpos proteicos en el endospermo del grano. Durante el amasado se produce la ruptura de estos cuerpos y su hidratación, formando así una red tridimensional continua en la cual se encuentra embebido el almidón. Las interacciones de tipo covalentes y no covalentes entre los polipéptidos más grandes que forman la masa producen una matriz elástica y extensible. El gluten es una mezcla compleja de proteínas que varían en su proporción, estructura y propiedades.

A pesar de los numerosos estudios realizados sobre la estructura de las proteínas del gluten y la base molecular existente, su rol en el procesamiento del pan aún no ha sido totalmente esclarecido (Shewry et al., 2001). Como se mencionó anteriormente, las subunidades de glutenina de alto peso molecular están presentes en forma de polímeros. La importancia de tales polímeros en determinar la viscoelasticidad del gluten ha sido apreciada durante muchos años, aunque su tamaño, complejidad y baja solubilidad limita el estudio detallado. La importancia de los puentes disulfuro en estabilizar estos polímeros ha sido extensamente demostrada. Hay evidencia de la formación de puentes disulfuro intermoleculares entre gluteninas de alto peso molecular, y de estas con LMW-GS (Shewry \& Thatham, 1997; Kasarda, 1999). Los enlaces disulfuro son entonces considerados esenciales para la viscoelasticidad del gluten.

La composición de aminoácidos de las proteínas del gluten muestra que aproximadamente la mitad de los constituyentes son glutamina y prolina, por lo que se supone que hay gran cantidad de puentes de hidrógeno en el sistema. Otro aporte importante son las interacciones 
hidrofóbicas, ya que aproximadamente el 35\% de los aminoácidos poseen cadenas laterales de naturaleza hidrofóbica (Hoseney, 1994b).

En la Figura I.6 se presenta un esquema de la estructura del gluten (Shewry et al., 2001) en el cual las gluteninas de alto peso molecular forman la columna vertebral del polímero, estas HMW-GS se encuentran unidas entre sí a través de puentes disulfuro intermoleculares ubicados en los extremos. Esta columna vertebral de gluteninas de alto peso molecular sirve de base para que se unan a ella las subunidades de bajo peso molecular (LMW-GS) mediante puentes disulfuro formando puntos de ramificación. Las gliadinas, consideradas como las principales responsables de la viscosidad del gluten, interactúan principalmente con los polímeros de gluteninas mediante interacciones no covalentes.

En el dominio central de las HMW-GS ocurren fuertes interacciones puentes de hidrógeno probablemente entre las amidas de los residuos de glutamina. Estas interacciones son muy importantes porque contribuyen a la viscoelasticidad de la masa (Ewart, 1989; Jeffrey \& Saenger, 1994; Belton ,1999).
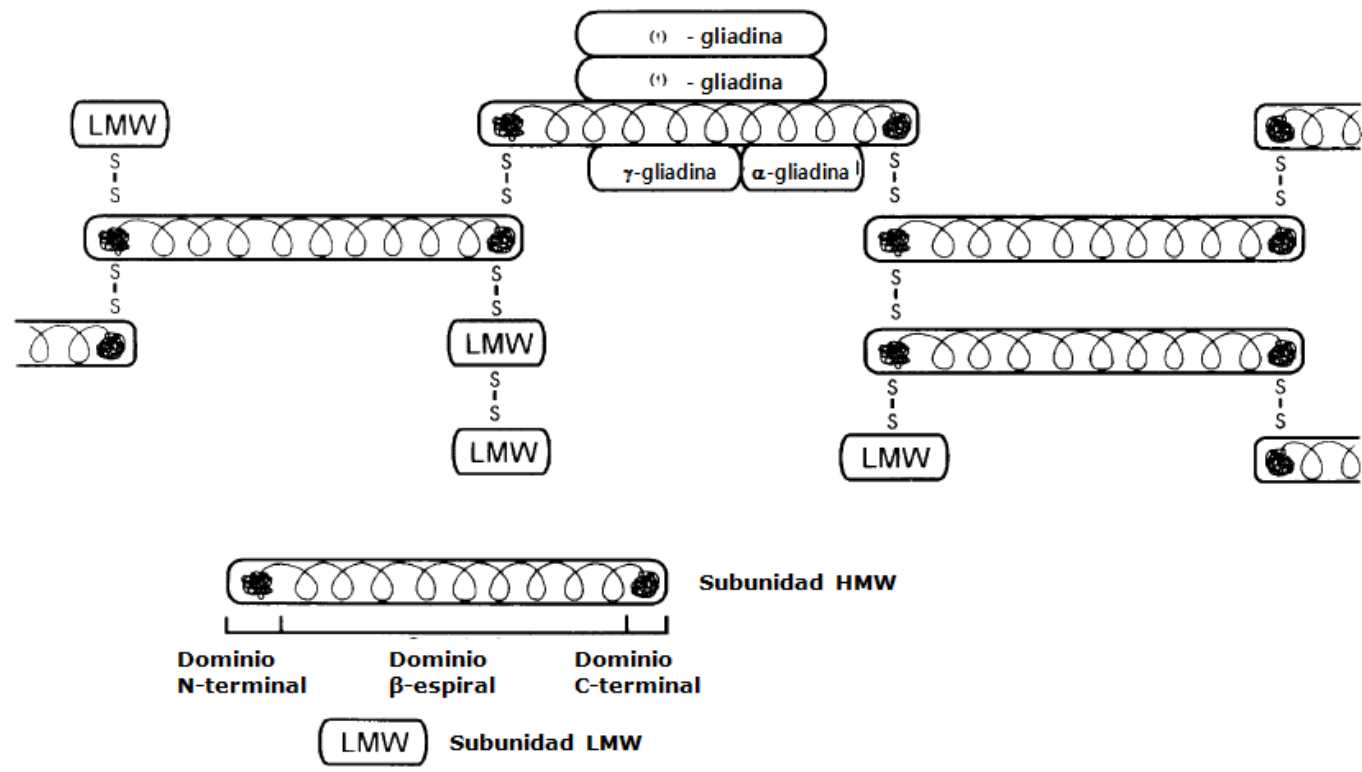

Figura I.6 - Un modelo estructural para el gluten de trigo en el que las subunidades HMW ligadas por uniones disulfuro proporcionan una columna vertebral, la cual interacciona con otras proteínas del gluten por enlaces disulfuro (subunidades LMW) y por interacciones no-covalentes (gliadinas) (Sherry et al., 2001).

Popineau et al. (1994) demostraron que en el gluten las cadenas de los polímeros de gluteninas forman estructuras $\beta$-sheet alineadas en una red extendida de puentes de hidrógeno. Posteriormente, Shewry et al. (2001) propusieron un modelo para explicar la 
elasticidad del gluten (Figura I.7), basado en una estructura de bucles y colas, loop and trains, regiones donde existen interacciones polímero-solvente y regiones con interacciones polímero-polímero, respectivamente. En este modelo las proteínas del gluten están estabilizadas por interacciones no covalentes entre moléculas paralelas. HMW-GS inicialmente presentan una conformación en forma de bucle (loop) que son estiradas durante la extensión del gluten para formar polímeros alineados en los cuales la formación de altas proporciones de estructuras $\beta$-sheet se encuentra favorecida. Por esta razón tales polímeros son altamente resistentes a la extensión.

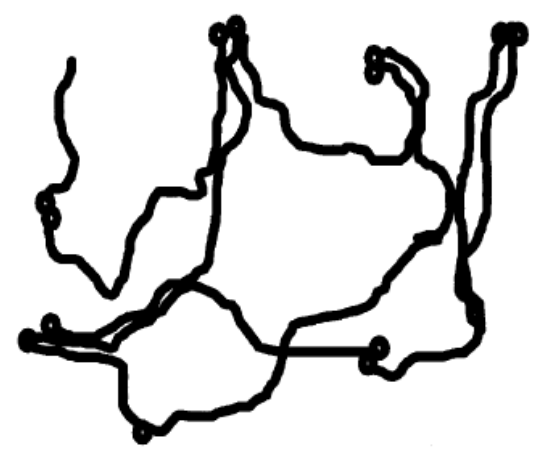

Disposición de las

subunidades HMW en la matriz de la masa antes de la extensión.๑ representa las regiones de uniones disulfuro

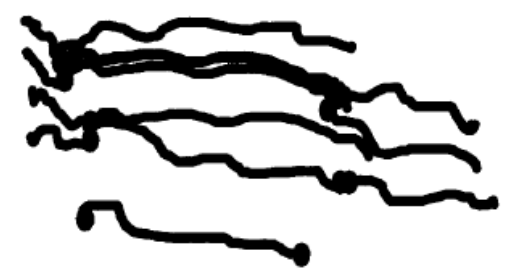

Disposición de las

subunidades después de la extensión. Se destaca la deformación en la región del bucle.

Figura I.7- Modelo para el arreglo de las subunidades HMW en la matriz de la masa antes (arriba) y después (abajo) de extensión (Sherry et al., 2001).

El estiramiento de los polímeros produce primero la deformación de los bucles (loops) y posteriormente de las colas (trains), a la vez que se rompen las interacciones no covalentes. Durante la extensión, los puentes disulfuro se rompen y se restablecen derivando en una red alineada en dirección a la extensión. Sin embargo, puede producirse la restauración del equilibrio de bucles y colas espontáneamente, resultando en la relajación de la estructura del polímero.

Estos modelos estructurales fueron extensamente relacionados con la viscoelasticidad del gluten y con la estabilidad de los polímeros (Belton, 2005; Wellner et al., 2005). Wellner et al. (2005) postularon que en algunos casos la extensión no resultaría en alineamientos favorables 
y por lo que la relajación de las conformaciones de los bucles ( $\beta$-turn) sería más rápida dependiendo del tamaño del polímero.

Mediante microscopía atómica se demostró que las moléculas de HMW-GS se alinean para formar un gran polímero ramificado previamente a la formación de puentes disulfuro, sugiriendo en parte que la habilidad de formar puentes disulfuro está direccionada por las interacciones no covalentes (Humphris et al., 2000). Anteriormente, Pezolet et al. (1992) ya habían sugerido que la elasticidad del gluten resulta de interacciones intermoleculares que involucran estructuras $\beta$-sheet. Sin embargo, Belton et al. (1995) postularon que los puentes disulfuro pueden incrementar la probabilidad de la formación de interacciones intermoleculares. Más tarde, Shewry et al. (2003) observaron que el número y el patrón de puentes disulfuro en los polímeros de gluteninas del trigo afectan la fuerza de la masa. Por lo tanto, estructuras $\beta$-sheet y puentes disulfuro contribuyen a la estabilización de los polímeros como fue propuesto por Belton (2005).

\section{Importancia de las proteínas en las pastas}

La habilidad única de la harina de trigo de formar una masa cohesiva, elástica y extensible es debido a las proteínas de gluten presentes en la harina. Tanto la cantidad como la calidad son importantes en la elaboración de las pastas (Hoseney, 1994a), considerando que las propiedades reológicas de las masas son dominadas por las proteínas (De Noni \& Pagani, 2010). Altas concentraciones de proteínas (10-14\%), con capacidad de formar una red fuerte de gluten, produce pastas de textura elástica y chiclosa. Harinas con muy baja concentración de proteínas originan pastas con pobre tolerancia a la cocción y se vuelven blandas y pegajosas. De modo que un correcto rango del contenido de proteínas es importante para las características de textura (Ross et al., 1997; Park \& Baik, 2004; Zhao \& Seib, 2005).

Además, las pastas que van a ser sometidas a un proceso de secado requieren un mayor contenido de proteínas que las pastas frescas, ya que las primeras deben soportar el proceso sin romperse (Fu, 2008). A decir verdad, la calidad de las pastas secas no solo está relacionada con el contenido de proteínas sino también con la fuerza del gluten del trigo (D'Egidio et al., 1990; Malcomson et al., 1993; Rao et al., 2001).

En la evaluación de la calidad de las proteínas de la sémolas o harinas destinadas a la elaboración de pastas se deben considerar las fracciones individuales de las proteínas (Edwards et al., 2003; Sissons et al., 2005). Las gluteninas y las gliadinas son responsables de un buen comportamiento durante la cocción de las pastas, ya que tanto la tenacidad como la elasticidad de la red de proteínas son debidas a las agregaciones proteína/proteína y 
subunidad/subunidad. Además, otras características químicas de las proteínas, tales como el número de grupos sulfhidrilo, o el contenido relativo de gluteninas de bajo peso molecular, parecen estar relacionados con la calidad de las pastas. Por lo tanto, para evaluar la calidad del trigo destinado a la elaboración de pastas, deben considerarse otros parámetros adicionales, tales como la relación glutenina/gliadina, la presencia de fracciones proteicas específicas, la hidrofobicidad superficial y las propiedades funcionales del gluten y de la masa (De Noni \& Pagani, 2010).

A diferencia de los ensayos para la elaboración de pan, los análisis químicos y reológicos usados para controlar el comportamiento de las proteínas, algunas veces no son confiables para predecir el comportamiento en la elaboración de las pastas. Se han hecho considerables esfuerzos para evaluar cuáles ensayos pueden predecir mejor la calidad de las pastas cocidas (De Noni \& Pagani, 2010).

En realidad, la evaluación de los componentes de la sémola o harina usada para la elaboración de pastas, puede ayudar a rechazar materias primas de mala calidad, pero raramente permite identificar las de buena calidad. En otras palabras, una harina con un gluten de buena calidad (evaluado en el laboratorio), no necesariamente significa una pasta de buena calidad, especialmente cuando ésta se seca a bajas temperaturas ( $D^{\prime}$ Egidio et al., 1990). En efecto, un almidón de mala calidad puede suprimir el efecto positivo de un gluten de buena calidad (De Noni \& Pagani, 2010)

\section{Polisacáridos no almidonosos}

En el grano existen polisacáridos no almidonosos denominados pentosanos (básicamente arabinoxilanos y arabinogalactanos). Los pentosanos pueden dividirse en solubles en agua (PS) y pentosanos insolubles en agua (PI) y comprenden, respectivamente, el 25 y $75 \%$ del total de estas sustancias presentes en la harina de trigo (Meuser \& Suckow, 1986). La habilidad de los pentosanos para retener agua y formar soluciones viscosas o geles por uniones covalentes probablemente afecte la distribución de la humedad entre los constituyentes de la masa, alterando la formación del gluten y las propiedades reológicas de la masa (Kim \& D’Appolonia, 1977). Se ha estimado que durante la preparación de la masa, una cuarta parte del agua agregada es retenida por los arabinoxilanos (Atwell, 1998). Durante el proceso de amasado, los arabinoxilanos insolubles en agua causan un impacto negativo ya que actúan limitando la agregación del gluten debido a impedimentos estéricos (van Oort et al., 1995) y absorben una 
gran cantidad de agua que deja de estar disponible para el desarrollo del gluten (Courtin et al., 1999; Courtin \& Delcour, 2002).

\section{Almidón}

Los granos de cereales almacenan energía en forma de almidón. El almidón se acumula en gránulos que se sintetizan dentro de los amiloplastos. Los gránulos de almidón en la harina de trigo y de otros cereales muestran una distribución de tamaño bimodal, los gránulos más pequeños (tipo-B) son esféricos con un diámetro menor a $10 \mu \mathrm{m}$, en tanto que los grandes (tipo-A) son lenticulares con un diámetro cercano a $20 \mu \mathrm{m}$ (Figura I.8). El interior de los gránulos está formado por regiones cristalinas y amorfas alternadas, por lo que el almidón es descripto como un polímero semicristalino o parcialmente cristalino (Eliasson \& Gudmundsson, 1996).

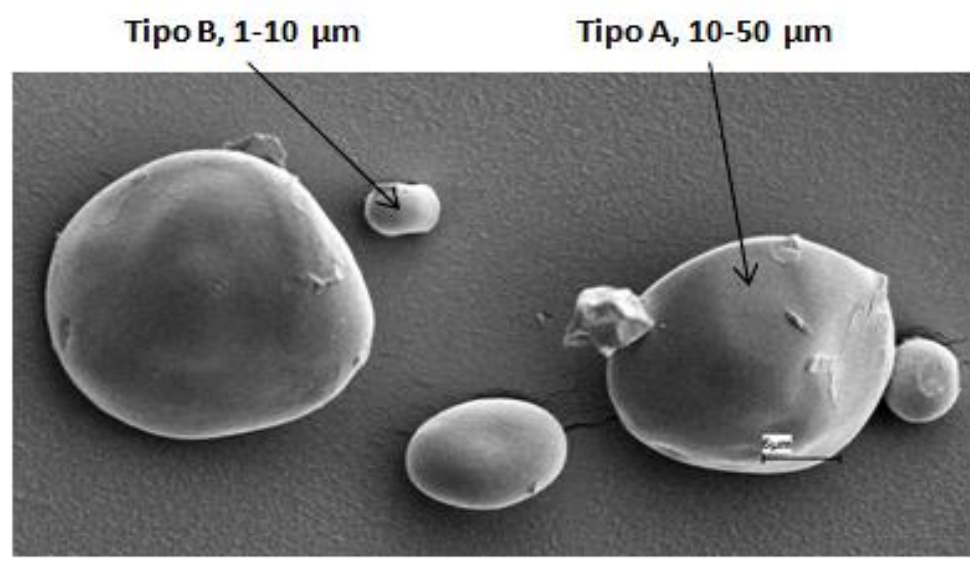

Figura I.8- Microscopía electrónica de barrido de gránulos de almidón de trigo (barra de escala: 5 $\mu \mathrm{m}$ ).

El almidón, componente mayoritario de la harina de trigo, es una macromolécula que está compuesta por dos fracciones: la amilosa y la amilopectina. La amilosa es definida como una molécula esencialmente lineal, compuesta por 500-6000 unidades de glucosa unidas por enlaces $\alpha$-(1-4), con escasos puntos de ramificación formados por enlaces $\alpha$-(1-6) (Shibanuma et al., 1994); y la amilopectina está formada por una cadena central similar a la de la amilosa pero posee ramificaciones con enlaces $\alpha$-(1-6) cada 9 a 20 unidades de D-glucosa (Whilster \& Daniel, 1984). El enlace $\alpha-1,4$ imparte a la molécula un giro natural, con lo que la conformación de las cadenas es helicoidal (Greenwood, 1976). Dentro del gránulo se puede diferenciar una zona con cierto grado de cristalinidad debido a regiones ordenadas de cadenas de 
amilopectina y una zona amorfa compuesta principalmente por las regiones ramificadas de la amilopectina y las cadenas de amilosa (Figura I.9).

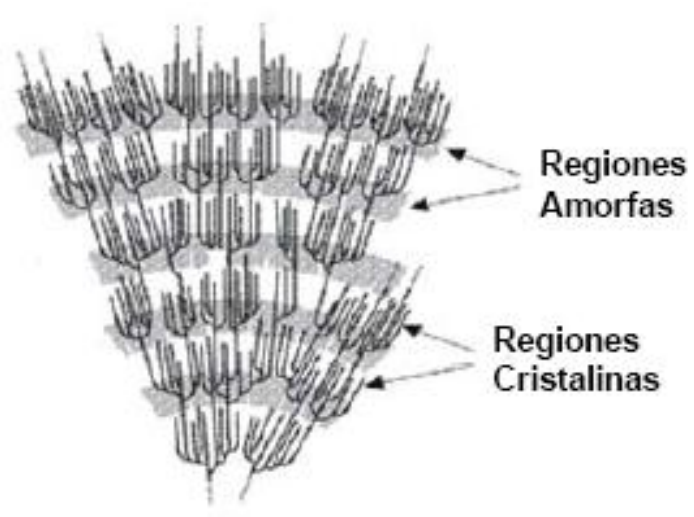

Figura 1.9 - Regiones amorfas y cristalinas del almidón.

Cuando los gránulos de almidón son sometidos a tratamientos térmicos, debido a su estado nativo parcialmente cristalino, experimentan distintas transiciones de fase, llamadas gelatinización y retrogradación (Belitz \& Grosch, 1999). Como consecuencia de la combinación de calor, humedad y tiempo durante la cocción, los gránulos de almidón se hinchan y gelatinizan (Figura I.10A). La gelatinización es la destrucción irreversible del orden molecular de los gránulos de almidón (Atwell et al., 1988). Para que ocurra este fenómeno es necesario un nivel mínimo de agua y una determinada temperatura. Durante la gelatinización, una pequeña cantidad de almidón, principalmente amilosa, es liberada en la región inter-granular lo que conduce a un aumento de la viscosidad (Figura I.10B). Además se produce el desorden de las regiones cristalinas dentro de los gránulos. Típicamente, el almidón se hidrata a temperaturas que van desde 40 a $120^{\circ} \mathrm{C}$, dependiendo del origen del almidón y del contenido de amilosa (Haralampu, 2000). Parte de la amilosa solubilizada forma complejos de inclusión con los lípidos polares de la harina de trigo. La calorimetría diferencial de barrido (DSC) se usa generalmente para estudiar la gelatinización y la retrogradación del almidón. La temperatura de transición y la entalpía de gelatinización determinadas por DSC pueden relacionarse con características de los gránulos de almidón como por ejemplo el grado de cristalinidad (Krueger et al., 1987). Altas temperaturas de transición han sido propuestas como resultado de un alto grado de cristalinidad, indicando estabilidad estructural y resistencia de los gránulos a la gelatinización (Barichelo et al., 1990). 


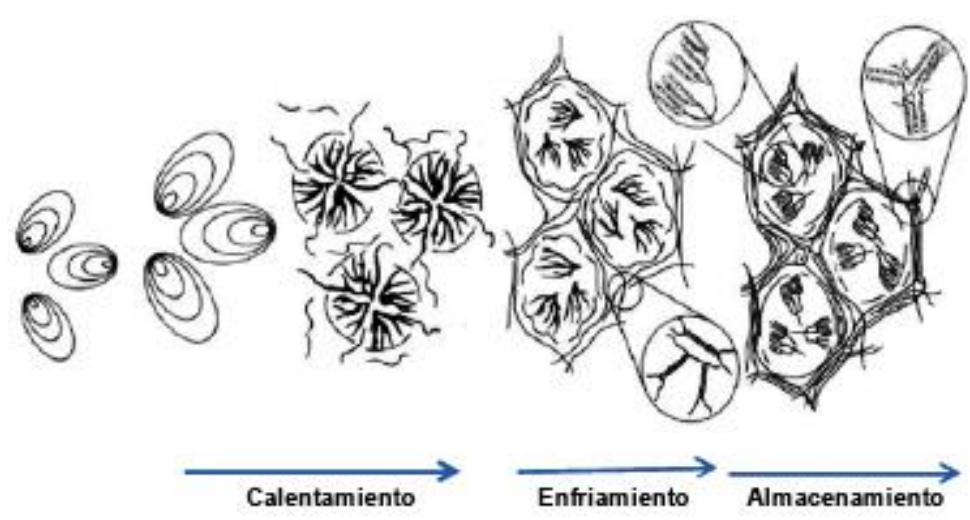

Figura I.10- (A) Hinchamiento de los gránulos de almidón a medida que absorben agua. (B) Gelatinización durante el calentamiento, ruptura de los gránulos de almidón y liberación de moléculas de amilosa. (C) Retrogradación de la amilosa durante el enfriamiento, formación de la red de amilosa. (D) Retrogradación de la amilopectina durante el almacenamiento, ordenamiento de las moléculas de amilopectina (Goesaert et al., 2005).

Durante el enfriamiento las moléculas de almidón se reasocian dando lugar a un estado más ordenado o cristalino, proceso llamado retrogradación (Atwell et al., 1988), en donde se forman estructuras compactas. La amilosa gelificada forma una red continua rodeando los gránulos de almidón hinchados y deformes (Figura I.10C), (Eliasson \& Larsson, 1993a). Estas estructuras son térmicamente muy estables y solamente pueden ser rehidratadas a $80-150^{\circ} \mathrm{C}$, dependiendo del grado y la naturaleza de la retrogradación (Haralampu, 2000). Durante la retrogradación, la amilosa lixiviada a la solución como un polímero enrollado, se reorganiza como dobles hélices estabilizadas por medio de uniones puente hidrógeno. En las hebras individuales, las hélices contienen seis unidades de glucosa por vuelta, que al retrogradar, se empaquetan en una única celda hexagonal (Figura I.11) (Haralampu, 2000). La retrogradación de la amilopectina ocurre a una velocidad mucho menor que la amilosa.

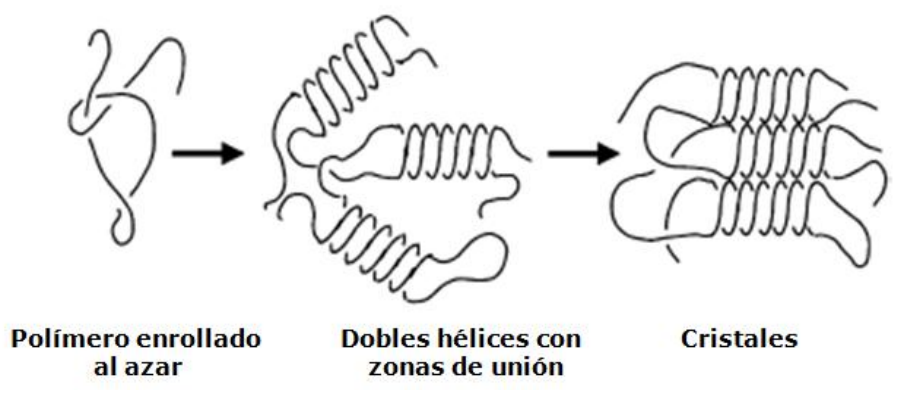

Figura I.11 - Esquema de retrogradación de la amilosa (Haralampu, 2000). 
Una fracción significativa de los gránulos de almidón (alrededor del 8\%) es dañado durante la molienda. Este daño mecánico de los gránulos generalmente afecta las propiedades del almidón (Hoseney, 1994c). En presencia de agua, el almidón dañado puede hincharse y gelatinizar a temperatura ambiente, es decir que pierde la birrefringencia óptica, la cristalinidad, forma un gel traslúcido y los glucanos solubles son lixiviados a la fase acuosa. Los parámetros de gelatinización (temperatura y entalpía determinadas por medio de la calorimetría diferencial de barrido, DSC) del almidón dañado presentan valores más bajos que el almidón no dañado, siendo este cambio más pronunciado en los trigos duros que en los trigos bandos. El almidón dañado es hidrolizado rápidamente por amilasas, por lo tanto son sustratos de las amilasas durante la fermentación (Eliasson, 2003). Además el almidón dañado absorbe dos veces su peso de agua en contraste con el almidón no dañado, el cual solo absorbe el $40 \%$ de su peso. Esta elevada capacidad de absorción de agua implica que el almidón dañado puede ser responsable de aproximadamente el 16\% de la absorción total de agua de la harina, un valor similar al de la propia proteína. De hecho la contribución que hace el almidón dañado a la absorción de agua se ha convertido en un elemento esencial de las especificaciones de la harina (Cauvain \& Young, 2001).

\section{Importancia del almidón en las pastas}

El rol del almidón en las propiedades reológicas de la masa para la elaboración de las pastas, es muchas veces subestimado con respecto al rol del gluten. Sin embargo, las características de la superficie de los gránulos de almidón puede afectar el comportamiento viscoelástico de la masa, dado que éstas determinan el tipo de interacción proteína-almidón (De Noni \& Pagani, 2010). De acuerdo a Fu (2008), las pastas elaboradas con harinas que presentan un almidón con alta capacidad de hinchamiento resultan con una textura más blanda que aquellas elaboradas con almidones con baja capacidad de hinchamiento.

Generalmente los gránulos de almidón absorben agua lentamente durante el amasado por estar envueltos por una gruesa capa de proteína-fosfolípidos, que limita el hinchamiento y la gelatinización en esta etapa, en donde la temperatura no supera los $50^{\circ} \mathrm{C}$. Consecuentemente, un almidón con buenas propiedades para la elaboración de pastas es aquel que tiene alta temperatura de gelatinización, que demore su hinchamiento y su solubilización de manera de reducir la interferencia con la reticulación de las proteínas. La presencia del gluten en sí incrementa la temperatura de gelatinización del almidón (De Noni \& Pagani, 2010). El mismo efecto se ha inferido con una gran proporción de gránulos de almidón de tamaño pequeño (5$10 \mu \mathrm{m}$ ) (Soh et al., 2006) y con una alta relación amilosa/amilopectina. La amilopectina es 
considerada como el componente del almidón con mayor responsabilidad en la pegajosidad y el agrupamiento de las pastas (De Noni \& Pagani, 2010).

Además, tanto la rotura mecánica de los gránulos (almidón dañado) que ocurre durante la molienda y la acción enzimática de la $\alpha$-amilasa, sin duda deben ser consideradas como modificaciones negativas del almidón (Matsuo et al., 1982), desde que éstas promueven la solubilización del almidón durante la cocción de la pasta (De Noni \& Pagani, 2010). Un incremento en el almidón dañado además afecta negativamente el color de las pastas, provoca una mayor pérdida por cocción y genera un hinchamiento excesivo de la superficie (Hatcher et al., 2002).

\section{Lípidos}

Los lípidos de la harina de trigo constituyen un grupo heterogéneo de compuestos con diferentes estructuras químicas y composición. Se pueden encontrar libres o unidos a algún constituyente de la harina, principalmente almidón y proteínas. Los lípidos asociados al almidón comprenden en gran parte liso-fosfolípidos que forman complejos de inclusión con la amilosa durante la gelatinización del almidón, sin embargo estos complejos también se encuentran en el almidón nativo del cereal (Morrison et al., 1993). Esta fracción de lípidos se encuentra dentro de los gránulos de almidón y solo queda disponible cuando se alcanzan las condiciones de gelatinización durante la cocción. La fracción de lípidos no asociados al almidón está constituida por cantidades similares de lípidos polares y no polares. Parte de ésta fracción corresponde a lípidos que se encuentran libres y parte asociados principalmente a proteínas. Los lípidos que se encuentran libres son polares, principalmente glico y fosfolípidos, mientras que los que se encuentran asociados son lípidos no polares, mayormente triglicéridos (Chung, 1986; Eliasson \& Larsson, 1993b).

En el patrón de ácidos grasos de los lípidos de la harina de trigo se encuentran el ácido linoleico y en menor cantidad el ácido palmítico y el ácido oleico (Eliasson \& Larsson, 1993b).

Durante el desarrollo de la masa, los lípidos que se encuentran libres se asocian a las proteínas del gluten mediante interacciones específicas y modifican las propiedades reológicas de la masa. En particular, los lípidos polares (especialmente los glicolípidos) pueden promover tanto interacciones hidrofóbicas como hidrofílicas entre el gluten y el almidón (Matsuo et al., 1986). Estas interacciones pueden mejorar la calidad de las pastas cocidas, favoreciendo la estabilidad tanto de la red de proteínas como del almidón (De Noni \& Pagani, 2010). 


\section{Pigmentos}

Los dos principales grupos de pigmentos en la harina de trigo son los carotenos y los flavonoides. Los pigmentos carotenoides se encuentran en el endosperma del grano de trigo y son responsables del color amarillo cremoso de la harina. La cantidad de carotenos varia ampliamente entre los diferentes cultivares de trigo. Estos pigmentos pueden ser fácilmente destruidos por agentes de blanqueado, agregados a la harina, como el peróxido de benzoilo, y por la enzima lipoxigenasa. Por el otro lado, los flavonoides, provenientes principalmente de la contaminación de la harina con salvado, son relativamente estables, pudiendo decolorarse a pHs ácidos y dando color amarillo a pHs alcalinos (Hoseney, 1994a).

El nivel de pigmentos naturales en la sémola o harina correlaciona altamente con el color de la pasta. El blanqueamiento de la harina destruye en gran medida los pigmentos amarillos naturales, y no es recomendado para la harina destinada a la elaboración de pastas (Fu, 2008).

La mayor tasa de extracción de la harina favorece el oscurecimiento de las pastas debido a los altos niveles de salvado y de cenizas con que resultan estas harinas. De modo que una baja tasa de extracción y bajos niveles de cenizas son preferidos para lograr pastas con una apariencia clara y brillante. Asimismo, el mayor aporte de material que no pertenece al endosperma resulta en mayor presencia de la enzima polifenoloxidasa, por estar localizada principalmente en las capas de salvado (Fuerst et al., 2006; Hatcher \& Kruger, 1993), la cual también afecta negativamente el color de las pastas, como se explica más abajo.

\section{Enzimas}

Además del gluten, entre las proteínas presentes en el grano de trigo se destacan, por su importancia funcional, las enzimas. Todas las reacciones que conforman el metabolismo de los vegetales son catalizadas por este tipo de proteínas. En el grano intacto, seco y no germinado la actividad enzimática total es muy baja, pero cambia drásticamente cuando comienza la germinación. Las enzimas que han recibido mayor atención son las que digieren el almidón. Las principales enzimas hidrolíticas que actúan sobre los hidratos de carbono presentes en los cereales son $\alpha$ y $\beta$-amilasas, enzimas desramificantes, celulasas, $\beta$-gluconasas y glucosidasas (Gómez Pallarés et al., 2007).

El trigo contiene también un gran número de enzimas proteolíticas, tanto endopeptidasas como exopeptidasas. Otro grupo importante de enzimas son las lipasas, esterasas y fosfatasas; las dos primeras se diferencian en su capacidad para hidrolizar ésteres carboxílicos a partir de moléculas insolubles o solubles en agua, respectivamente; mientras que las fosfatasas actúan sobre ésteres del ácido fosfórico. También están presentes en el grano de trigo las fitasas, que 
catalizan la hidrólisis del ácido fítico a inositol y ortofosfato libre; las lipooxigenasas, que aceleran la peroxidación de ciertos ácidos grasos insaturados por el oxígeno y las polifenoloxidasas, que oxidan los fenoles a quinonas (Gómez Pallarés et al., 2007).

A pesar que la harina contiene sólo pequeñas cantidades de enzimas, su presencia puede afectar la calidad de la pasta. Cantidades excesivas de $\alpha$-amilasa facilitan la rotura de la estructura de la pasta. Asimismo, la polifenoloxidasa también afecta la calidad de las pastas blanqueando los pigmentos amarillos de caroteno (Hoseney, 1994a).

\section{Agua}

El agua es la segunda materia prima más importante después de la harina para la elaboración de las pastas y tiene un efecto significativo sobre la calidad del producto final. El agua proporciona el medio necesario para todas las reacciones fisicoquímicas y bioquímicas que subyacen a la transformación de las materias primas en producto terminado. Sin el agua las proteínas del gluten en la harina no pueden manifestar sus propiedades viscoelásticas. Los ingredientes hidrosolubles son usualmente disueltos en el agua antes del amasado. El agua requerida para la elaboración de las pastas se optimiza con el objetivo de tener suficiente cantidad como para hidratar la harina y permitir el desarrollo de una lámina de masa uniforme, pero no demasiada, como para que la masa formada cause problemas en su manipulación y extrusado o laminado debido su pegajosidad. El nivel de absorción de agua para la elaboración de las pastas en general está alrededor de 30-38\%, basado en el peso de la harina (Fu, 2008).

Además de los requerimientos básicos sanitarios fundamentales, el agua empleada en la elaboración de pastas debe presentar ciertas especificaciones para asegurar una buena calidad del producto final. El agua varía en dureza, alcalinidad y pH, lo que afecta la hidratación de la harina, las propiedades de la lámina de masa, la gelatinización del almidón y la textura del producto terminado. Dependiendo de la cantidad y el tipo de sales minerales presentes en el agua, ésta puede ser dura, blanda, salina o alcalina. En general el agua presenta un pH entre 5,8 y 8,6 . Aguas excesivamente duras son indeseables debido a que retardan la hidratación de las partículas de harina porque aumentan demasiado la fuerza y la tenacidad de las proteínas del gluten. Los iones en el agua también tienen un impacto significativo en la gelatinización del almidón durante la cocción de las pastas. Por otro lado, aguas demasiado blandas también son objetables debido a que carecen de los minerales que ayudan al fortalecimiento del gluten, lo que resultan en masas blandas, y pegajosas. Un agua de dureza baja a media es considerada como la más adecuada para la elaboración de las pastas (Fu, 2008). 


\section{Sal}

La cantidad agregada para la elaboración de pastas está usualmente entre 1-3\%. La sal lleva a cabo tres funciones principales; la más importante es fortalecer y endurecer el gluten de la masa y mejorar las propiedades viscoelásticas (Dexter et al., 1979), lo cual es debido en parte, a su efecto inhibidor sobre las enzimas proteolíticas, aunque otras evidencias indican una interacción más directa de la sal con las proteínas de la harina. La sal puede mejorar significativamente las propiedades de laminado de la masa, especialmente a altos niveles de absorción de agua (Fu, 2008). Estos incluyen el aumento en la rigidez de la estructura del gluten para darle tenacidad y mejorar las propiedades viscoelásticas

La segunda función de la sal es realzar el sabor y mejorar las propiedades de textura de las pastas. Las pastas elaboradas con sal tienen tiempos de cocción más cortos, al aumentar la permeabilidad del agua durante la cocción (Dexter et al., 1979) y una textura más blanda y más elástica que las pastas sin sal.

La tercera función de la sal es inhibir la actividad enzimática y el crecimiento de microorganismos, impidiendo la fermentación alcohólica y ácido láctica (Dexter et al., 1979). La sal enlentece el proceso de decoloración oxidativo y el deterioro en ambientes con alta temperatura y humedad, extendiendo así la vida útil de las pastas frescas (Fu, 2008).

Asimismo, en las pastas secas la cantidad de sal agregada puede afectar la velocidad de secado, ya que el agua se evapora más lentamente cuanto mayor sea la sal agregada, previniendo así la formación de grietas durante el secado (Dexter et al., 1979).

\section{Elaboración de las pastas}

A pesar de la gran diversidad en la formulación, el tamaño y la forma de las pastas, el proceso de elaboración de pastas laminadas es notablemente constante. En general, éste comienza con una etapa de amasado, se arman las láminas, se les reduce el espesor y finalmente se forman las hebras de pasta al pasar la lámina por unos rodillos cortantes.

\section{Amasado}

El principal objetivo del amasado es distribuir los ingredientes uniformemente e hidratar las partículas de harina. En la elaboración del pan, el alto contenido de humedad ( $50 \%$ ), y el prolongado amasado y trabajo de la masa, permite un desarrollo completo del gluten cuyas propiedades funcionales están bastante explotadas y determinan la estructura global del 
producto. En la elaboración de las pastas, el amasado se realiza con un nivel de humedad mucho más bajo ( 30\%) y por corto tiempo, por lo tanto, el desarrollo del gluten es solo parcial en esta fase (De Noni \& Pagani, 2010).

Más allá de los diferentes mecanismos de las amasadoras, el amasado también está influenciado por la calidad de la harina, la cantidad de agua agregada, la presencia/ausencia y cantidad de ciertos ingredientes (especialmente sal) y la temperatura y humedad del ambiente donde se realiza. Las harinas con alto contenido de proteínas se hidratan relativamente rápido y fácilmente forman partículas de masa de gran tamaño, requiriendo menos tiempo de amasado.

Durante esta etapa la superficie de los gránulos de almidón también comienza a hidratarse, aunque sin que ocurra ningún cambio aparente en su organización interna nativa (De Noni \& Pagani, 2010). Si la harina presenta gránulos de almidón dañados, éstos tienen una mayor capacidad de absorción y competirán con el gluten por la limitada cantidad de agua en la masa. Las harinas con alto contenido de almidón dañado requieren mayor absorción de agua y tiempos de amasado más largos (Fu, 2008).

\section{Descanso}

Al amasado usualmente le sigue un tiempo de descanso de la masa. Este tiempo permite que se acelere la futura hidratación de las partículas de harina y que se redistribuya el agua en el sistema. El tiempo de descanso también favorece la relajación de la estructura del gluten facilitando su formación durante el laminado (Fu, 2008).

\section{Laminado}

A pesar que las partículas de harina están suficientemente hidratadas después del amasado y el tiempo de descanso, el desarrollo de la matriz de gluten está lejos de completarse, siendo localizada y discontinua. Es durante el proceso de laminado que la matriz del gluten se vuelve continua. El desarrollo de una matriz uniforme de gluten con un buen balance de elasticidad y tenacidad es muy crítico para asegurar buenas propiedades de procesamiento y la buena calidad del producto terminado (Calvelo, 2008).

Bajo compresión, las partículas adyacentes de endosperma se fusionan de modo que la matriz de proteínas dentro de las partículas del endosperma se continúa con la de las partículas adyacentes. El proceso de laminado tiende a lograr una lámina de masa lisa, de un espesor deseado y con una matriz de gluten continua y uniforme. La masa de las pastas laminadas debe ser los suficientemente fuerte para soportar el laminado, pero no tan fuerte 
como para causar desgarro o rotura en la lámina de las pastas. Un buen nivel de la extensibilidad de la masa asegura que la lámina no va a encogerse durante las sucesivas pasadas por los rodillos de la laminadora. Al final del laminado, la matriz de gluten está alineada a lo largo de la dirección de la lámina. (Fu, 2008).

\section{Cortado}

Una vez que la lámina es reducida al espesor deseado, ésta se corta en hebras a lo largo de la dirección del laminado, las que podrán presentar diferente ancho y forma de acuerdo a los rodillos de corte usados.

En general se acepta que la pasta cocida obtenida por laminado tiene una calidad mejor que los productos extruidos. La red de gluten alcanza mayor desarrollo por el laminado que por la extrusión (Matsuo et al., 1978; Dexter et al., 1979). También se encontró que la extrusión contribuye a la formación de una red de proteínas con numerosas discontinuidades, concluyendo que el proceso de extrusión no es apto para la producción de pasta cuando la materia prima es de mala calidad, como lo es la harina de trigo blando (Abecassis et al., 1994).

\section{Secado de las pastas}

La vida útil de las pastas puede ser significativamente prolongada si se asegura su estabilidad microbiológica y bioquímica. La forma más efectiva de alcanzar esta meta es secar las pastas hasta un contenido de humedad en el cual el crecimiento microbiológico sea imposible. Las hebras de pastas de 2-4 m de largo son colgadas en cañas pudiendo ser llevadas a una cámara de secado, o bien colocadas dentro de un túnel de secado en el cual las cañas pasan a través de diferentes secciones con ambientes controlados (Calvelo, 2008).

Las propiedades físicas más significativas en el secado de la pasta son la humedad y la temperatura del aire y la humedad y temperatura del producto. La humedad de la superficie de la pasta pasa a vapor y el cual es removido por el aire circundante. La fuerza motora para que se produzca esta remoción de humedad es la diferencia de la presión parcial de vapor de agua de la pasta respecto a la del aire. Se genera un gradiente del contenido de humedad dentro de la hebra de pasta, de modo que la humedad va a difundir, como líquido, desde el centro hacia la superficie, a lo largo de ese gradiente. En el frente de evaporación remanente, la velocidad de secado va a estar limitada primariamente por la difusión de la humedad dentro de la hebra (Fu, 2008). 
Un adecuado proceso de secado generalmente involucra múltiples etapas para minimizar cambios estructurales indeseables. Una práctica muy común es un proceso de tres etapas principales: pre-secado, secado y enfriamiento. La primera etapa toma hasta el $15 \%$ del total del tiempo de secado y es de primordial importancia para reducir el contenido de humedad de la pasta desde $32-38 \% \mathrm{p} / \mathrm{p}$ a menos de $28 \%$. Su principal función es secar la superficie de la pasta rápidamente después de haber sido cortada, para prevenir que las hebras se peguen entre sí y evitar que sufran un sobre estiramiento (Calvelo, 2008). Las condiciones para que esta compleja fase de migración y redistribución se produzca, es por ejemplo una cámara de presecado con alta humedad y alta temperatura $\left(75^{\circ} \mathrm{C}\right)$ (Professional Pasta, L1N06P044).

Se puede decir que la pasta puede encontrarse en dos estados: plástico o elástico. Cuando la pasta sale del extrusor o de la laminadora, se dice que está en estado plástico. Un cuerpo en estado plástico puede deformarse bajo la acción de fuerzas externas sin generar ninguna tensión particular en su interior, pudiendo aún permanecer con la forma adquirida como resultado de las fuerzas a las que fue sometido. Esta propiedad puede apreciarse claramente cuando la pasta en estado plástico se deforma por la acción del disco del extrusor o de la laminadora, manteniendo la forma adquirida aún después que ha cesado la fuerza a la que fue sometida. En este estado plástico, la pasta puede soportar un intenso secado sin sufrir tensiones internas que puedan ocasionarle daño, pudiendo aun mantener la deformación dada por el disco del extrusor o los rodillos cortantes, a pesar de la contracción que sufre debido a la extracción de agua (Professional Pasta, L1N06P044).

Esta primera transferencia de agua se produce a costa del almidón, el que durante la preparación de la masa absorbe 1/5 más de agua que el gluten. Luego, por ósmosis, el agua migra desde el gluten al almidón. Dado que el gluten es elástico, éste tiende a seguir las partículas de agua, desplazándose desde la parte más interna del producto, donde éste está más concentrado (debido que allí se encuentra el mayor contenido de humedad) hacia la superficie. La redistribución del gluten, que sucede cuando la pasta presenta un contenido de humedad aproximado de $26 \%$ p/p, mejora la capacidad de cocción y disminuye la pegajosidad del producto. La conservación de la capilaridad del producto es esencial para la redistribución de las partículas de agua durante la siguiente fase del proceso (Professional Pasta, L1N06P044). Debido a su naturaleza higroscópica, la sal tiene un significativo efecto sobre la velocidad de difusión de la humedad durante el secado (Fu, 2008).

A la fase de pre-secado le sucede una primera fase de secado, a una humedad y temperatura relativamente alta (por ejemplo $75-85 \% \mathrm{HR}, 30-40{ }^{\circ} \mathrm{C}$ ). En la segunda fase de secado, se aplica temperaturas más altas y aire seco (por ejemplo $40-50{ }^{\circ} \mathrm{C}, 55-60 \% \mathrm{HR}$ ) para 
completar la etapa de secado. La velocidad de la etapa de secado es inevitablemente menor que la de pre-secado, debido a que la estructura del producto se ha vuelto más rígida, su capilaridad ha disminuido, y por ende la migración de las partículas remanentes de agua desde el interior hacia el exterior es más lenta. El secado toma aproximadamente 6-8 veces más que el tiempo requerido por el pre-secado (Professional Pasta, L1N06P044).

A medida que el proceso de secado progresa y disminuye la humedad del producto hasta valores cercanos a $22-18 \% \mathrm{p} / \mathrm{p}$, el estado de la pasta cambia de plástico a elástico. Un cuerpo elástico sujeto a fuerzas de deformación va a tender a mantener su forma original hasta que la fuerza sea removida. Más allá de la deformación causada, la fuerza deformante puede generar tensiones internas en el producto. Si estas tensiones están comprendidas dentro del límite de elasticidad específico, podrán ser absorbidas precisamente por la propia elasticidad del producto, mientras que si estas tensiones exceden esos límites, el producto resultará inevitablemente dañado (Professional Pasta, L1N06P044).

Para evitar un exceso de tensión dentro del producto, durante todo el proceso de secado, se deben intercalar etapas de revenido, es decir períodos con mínima circulación de aire y alta humedad para darle tiempo a la difusión del agua desde el interior hacia la superficie de la pasta. En la fase final, el producto es gradualmente enfriado, mientras que se continúa secando. El principal problema aquí es bajar lentamente la temperatura para evitar tensiones internas de la pasta (Calvelo, 2008)

Un secado inapropiado puede dañar la estructura de la pasta, causando sobre-elongación, grietas, deformación y división de las hebras (Figura 1.12), con los problemas en la manipulación y el envasado que estos defectos generan. Además las propiedades de cocción y de textura pueden ser severamente afectadas. Si se procura secar demasiado rápido, se va a crear una gran diferencia de humedad entre la superficie y el núcleo de los fideos. Al perder la humedad, la pasta se encoge y la superficie seca tiende a contraerse sobre el núcleo húmedo. Mientras que la superficie de la pasta va a estar bajo tensión, el centro va a estar bajo compresión, pudiendo ocasionar una deformación permanente de la hebra de pasta al liberar esa tensión (Fu, 2008). 


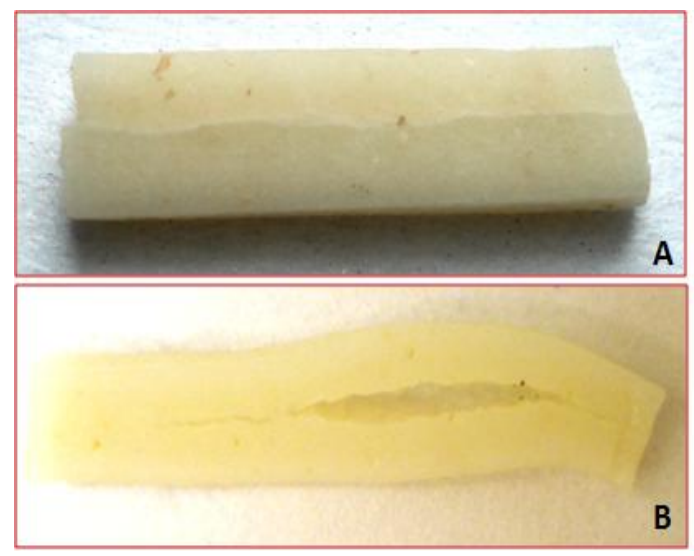

Figura I.12 - Defecto de secado: división de hebras de una pasta laminada elaborada con trigo pan, pasta seca (A), pasta cocida (B).

Existen diversas tecnologías de secado: el secado a baja temperatura (LT) $\left(<60{ }^{\circ} \mathrm{C}\right)$, el secado a alta temperatura $(\mathrm{HT})\left(60^{\circ} \mathrm{C}<\mathrm{T}<90^{\circ} \mathrm{C}\right)$ y el secado a muy alta temperatura (VHT) (T $>90{ }^{\circ} \mathrm{C}$ ). A su vez, la aplicación de altas temperaturas puede realizarse bajo dos condiciones: alta temperatura-alta humedad $(\mathrm{HT}-\mathrm{HM})\left(70-75{ }^{\circ} \mathrm{C}, 20-25 \% \mathrm{H}\right)$, o alta temperatura-baja humedad (HT-LM) $\left(70-75{ }^{\circ} \mathrm{C}, \sim 18 \% \mathrm{H}\right)$. En general la aplicación de altas temperaturas reduce los tiempos de secado y por ende aumenta la capacidad de proceso; además mejora la calidad microbiológica, el comportamiento durante la cocción y favorece el color amarillo. Sin embargo las altas temperaturas también generan una pérdida del valor nutricional por la disminución de la lisina disponible (reacción de Maillard) y aumentan desfavorablemente el color rojizo de la pasta (Calvelo, 2008).

Cuando las pastas se secan a LT $\left(<60^{\circ} \mathrm{C}\right)$, se observa una menor organización de la red de proteínas, sin modificaciones de la estructura interna de los gránulos de almidón. Cuando la pasta es sometida a un proceso de secado HT-LM, prácticamente ocurre una completa coagulación de las proteínas promoviendo la formación de una red de proteínas definitiva y se suceden cambios conformacionales en la estructura fina de los gránulos de almidón. Cuando el gluten es pobre en calidad y cantidad, los gránulos de almidón pueden hincharse de manera anormal durante el secado a HT-HM provocando rupturas en la estructura fibrilar de las proteínas y en consecuencia, resultando en un efecto perjudicial sobre la calidad de la pasta (De Noni \& Pagani, 2010). 


\section{Comportamiento de las pastas durante la cocción}

Las propiedades de cocción de las pastas secas son el resultado tanto de las características de la materia prima como de las condiciones de elaboración.

La calidad de las pastas cocidas se expresa en términos de absorción de agua, de material lixiviado durante la cocción, y de las propiedades de textura en cuanto a la firmeza y la pegajosidad. La textura de la pasta cocida es generalmente reconocida como su aspecto de calidad más importante (Brunnel et al., 2010).

Como la pasta es un sistema de humedad limitada, durante la cocción sucede una fuerte competencia por el agua entre el almidón y las proteínas. Las proteínas requieren agua para coagular de modo tal que produzcan una red elástica, al tiempo que el almidón, a través de la absorción de agua, se hincha, gelatiniza y tiende a solubilizarse. Debido a que la desnaturalización de las proteínas y el hinchamiento del almidón comienzan aproximadamente al mismo rango de temperaturas, hay una competencia física entre esos dos fenómenos durante la cocción de las pastas. Cuando las interacciones entre las proteínas de la red continua prevalecen, el material almidonoso, el cual se hidrata lentamente, queda atrapado dentro de la red, y la pasta cocida será firme, evitando la pegajosidad sobre la superficie y los consecuentes agrupamientos. Por el contrario, cuando la red de proteínas no es lo suficientemente fuerte y elástica, el almidón se hincha y gelatiniza antes que tenga lugar la coagulación de las proteínas. En este caso, la amilosa va principalmente hacia el agua de cocción, quedando la amilopectina sobre la superficie de la pasta, resultando en una textura blanda y pegajosa (De Noni \& Pagani, 2010).

En la estructura interna de una hebra de pasta cocida se puede observar un gradiente de cambios estructurales a lo largo de la sección transversal, principalmente en lo que refiere a la apariencia de los gránulos de almidón debido a sus sucesivos estados en el proceso de gelatinización (Heneen \& Brismar, 2003). Se han reconocido tres regiones concéntricas; una región externa formada por una red abierta, filamentosa, donde la gelatinización del almidón es completa, una región cerca del núcleo de la pasta, no gelatinizada y un núcleo intacto, donde el agua de cocción no llegó a penetrar (Dexter et al., 1979).

Los resultados de este estudio indican que una red de proteínas unidas por puentes disulfuro está presente en todas las pastas, proporcionando una resistencia a la tensión de las partículas y limitando el hinchamiento del almidón y su lixiviación posterior (Figura I.13). Una óptima polimerización de las proteínas durante el procesamiento y/o cocción de las pastas es fundamental para la obtención de productos de buena calidad. Cuando las proteínas han 
polimerizado con demasiada fuerza durante el procesamiento (en especial durante las severas condiciones de secado), carecen de elasticidad para hacer frente al hinchamiento del almidón durante la cocción. Esto, a su vez, se traduce en mayores pérdidas durante la cocción y pastas más pegajosas. De modo que, demasiada polimerización de las proteínas durante el procesamiento es perjudicial para la calidad de la pasta cocida. Por otra parte, cuando las proteínas son menos polimerizados durante el procesamiento (en especial durante un secado suave), la polimerización se produce sobre todo durante la cocción, y las proteínas son más propensas a seguir el hinchamiento del almidón, lo que resulta en una pasta de mayor calidad (menor pérdida por cocción y menos pegajosidad) (Brunnel et al., 2010).

Los factores claves para la cocción de las pastas son la relación entre el agua y la pasta, el tiempo de cocción y la calidad del agua de cocción. El volumen deseable del agua de cocción es 10 a 20 veces el peso de la pasta cruda húmeda. Cuando el volumen del agua de cocción no es suficiente, ésta demora más en volver a alcanzar la ebullición, las hebras quedan demasiado juntas, sin el movimiento relativo adecuado, lo que resulta en una superficie rugosa y una falta de uniformidad en la cocción de las pastas. Por el contrario, demasiado volumen del agua de cocción o un calentamiento demasiado fuerte puede dañar la superficie de las pastas debido a una intensa fricción entre sus hebras en el agua de cocción. Idealmente, el agua debe estar en un estado de ebullición leve durante todo el tiempo de cocción; tiempo que va a depender del tamaño y el tipo de pasta (Fu, 2008).

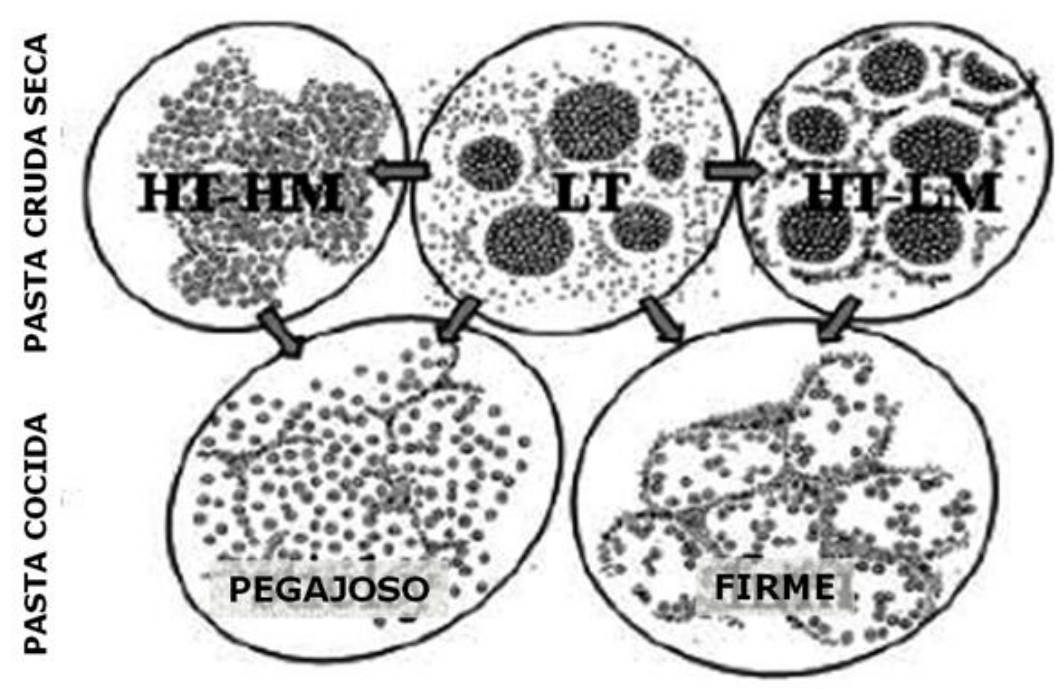

Figura I.13 - Esquema de los cambios que ocurren en la ultraestructura de pastas secas y cocidas respecto a la coagulación de proteínas, hinchamiento del almidón y la lixiviación de partículas. Círculos vacíos corresponden a las partículas de almidón; puntos negros representan las partículas de proteína (De Noni \& Pagani, 2010). 
Mientras que la dureza del agua no tiene un efecto significativo sobre la pérdida por cocción, la alcalinidad del agua sí. Las pastas cocinadas en aguas de pH 5-6 tienen la menor pérdida por cocción. Las pérdidas aumentan significativamente una vez que el agua de cocción alcanza pH 7-8. De modo que es muy importante tener en cuenta el pH del agua de cocción (Fu, 2008).

\section{Propiedades funcionales y nutricionales de las pastas}

En los últimos años las pastas se han vuelto más atractivas por sus propiedades nutricionales ya que se trata de un producto de bajo índice glucémico (Björck et al., 1994; Barkeling et al., 1995; Brand-Miller et al., 2009) y con escaso aporte de grasa y de sodio (Ovando-Martinez et al., 2009).

La Organización Mundial de la Salud y la Food and Drug Administration de Estados Unidos (FDA), han considerado a la pasta como un alimento apropiado para el agregado de nutrientes, siendo uno de los primeros alimentos para el cual la FDA permitió el enriquecimiento con vitaminas y hierro. Mejorar la calidad nutricional de las pastas involucra principalmente aumentarles la cantidad de proteínas y de fibra dietética, y fortificarlas con vitaminas y minerales. Además, las pastas son reconocidas como un buen vehículo para incorporarles ingredientes beneficiosos para la salud (Marconi \& Carcea, 2001), transformándose así en alimentos funcionales.

Se denominan alimentos funcionales a aquellos alimentos cuyos componentes activos no solo proporcionan lo necesario para la nutrición básica, sino que además actúan en forma beneficiosa sobre determinadas funciones del organismo (ADA, 2004).

Tanto la harina de amaranto como la harina de soja pueden ser consideradas como ingredientes funcionales, debido a los elementos beneficiosos para la salud que pueden aportar a las formulaciones donde se las incorpore. 


\section{Propiedades funcionales inherentes a la estructura de las}

\section{pastas}

\section{Índice glucémico}

El índice glucémico (IG) fue desarrollado en un intento de clasificar sistemáticamente los carbohidratos de los diferentes alimentos, de acuerdo a los efectos integrados en el tiempo sobre la glucemia posprandial. Los alimentos con altos valores de IG son aquellos que se digieren y absorben más rápidamente, causando mayores fluctuaciones de la glucosa en la sangre por unidad de carbohidratos que los alimentos con valores de IG más bajos (BrandMiller et al., 2009).

El IG se ha definido metodológicamente como el área bajo la curva dada por el aumento de glucosa en sangre tras el consumo de un alimento, en relación con la curva producida por un alimento de referencia para una cantidad equivalente de carbohidratos de 25 o $50 \mathrm{~g}$ (Jenkins et al., 1981).

Las dietas bajas en índice glucémico han demostrado reducir la excreción urinaria del péptido $C$ en sujetos sanos (indicador indirecto de la hormona insulina que se produce en el organismo) (Jenkins et al., 2002), mejorar el control glucémico en pacientes diabéticos (Jenkins et al., 1988), y reducir los lípidos en suero en sujetos hiperlipidémicos (Jenkins et al., 1987). Por otra parte, el consumo de dietas bajas en índice glucémico se ha asociado con mayores concentraciones de HDL-colesterol (Ford \& Liu, 2001) y, en estudios de cohorte, con un menor riesgo de desarrollar diabetes y enfermedades cardiovasculares (Jenkins et al., 2002). Además, hay trabajos que demuestran asociaciones positivas entre el índice glucémico de la dieta y el riesgo de enfermedades de cáncer colorrectal y cáncer de endometrio (Gnagnarella et al., 2008). A pesar de existir ciertas incoherencias en los datos, suficientes resultados positivos sugieren que el índice glucémico en la dieta presenta una potencial importancia en el tratamiento y la prevención de las enfermedades crónicas (Jenkins et al., 2002).

Los alimentos ricos en carbohidratos difieren considerablemente en sus efectos sobre la glucosa en sangre y la liberación de insulina al ser ingeridos (Barkeling et al., 1995). Se han postulado varios mecanismos para explicar estas diferencias, tales como la textura o la estructura botánica de los alimentos, el tipo y la cantidad de fibra dietética y, para los alimentos en base a almidón, la estructura física, el grado de gelatinización y de retrogradación, así también como la composición química (relación amilosa /amilopectina) de la molécula de almidón (Barkeling et al., 1995). Además, se ha considerado la cantidad relativa 
de almidón rápidamente digerible, lentamente digerible y de almidón resistente (Englyst et al., 1999) y el grado de accesibilidad del almidón por la $\alpha$-amilasa (Bornet et al., 1989). Las interacciones individuales entre los componentes del alimento (almidón, proteínas, lípidos y fibra dietética) han sido también estudiadas a fin de comprender el comportamiento del almidón durante la degradación in vivo e in vitro (Tudoricâ et al., 2002).

La pasta es ingerida como un alimento sólido, con una textura densa y firme, debido al proceso de elaboración (extrusión o laminado), requiriendo un bajo grado de masticación antes de ser tragada, llegando al estómago en forma de partículas sólidas. Aquellas comidas conformadas por espaguetis, retardan el vaciamiento gástrico en comparación con comidas compuestas por arroz, papas o pan blanco. Esto ratifica que la estructura de la pasta permanece mayor tiempo en el estómago que la estructura del pan o de las papas (Fardet et al., 1998). Sin embargo, se ha demostrado que diferentes modelos de carbohidratos tienen la misma velocidad de vaciamiento gástrico a pesar de tener diferente respuesta glucémica (Bornet et al., 1990). De modo que, otros factores más allá de los relacionados con la interacción entre la pasta y el tracto gastrointestinal, son necesarios para explicar la lenta degradación del almidón. Factores intrínsecos al alimento o interacciones entre el alimento y las enzimas digestivas pueden estar también involucrados (Fardet et al., 1998).

Se ha demostrado que es la estructura compacta del alimento y no la naturaleza del trigo, lo que influye en la resistencia a la digestión. Además, el gran tamaño de la partícula de la pasta y la consecuente restricción a la susceptibilidad de la $\alpha$-amilasa sobre el almidón, son factores importantes y están íntimamente relacionados con el grado de compactación resultante del proceso de elaboración. En un trabajo realizado sobre cerdos, se encontró que una significante cantidad de pasta fue retirada del estómago en forma de partículas con tamaño mayor a 2 mm (Fardet et al., 1998). Por ejemplo, el índice glucémico de un espagueti molido se asemeja al del pan blanco, subrayando el importante papel que juega la estructura del alimento y la superficie del área en relación a la masa. La restricción en el hinchamiento del almidón durante la cocción de la pasta debido a la presencia de una red de proteínas también limita la susceptibilidad de la $\alpha$-amilasa sobre el almidón, contrariamente a lo que se observa sobre un almidón completamente gelatinizado (Fardet et al., 1998).

La red de proteínas constituye la columna vertebral de la estructura de la pasta, atrapando estrechamente los gránulos de almidón gelatinizados y parcialmente hinchados (Sung \& Stone, 2005; Kim et al., 2008). De acuerdo a Fardet et al. (1998), los mecanismos por los cuales la red de proteínas retarda la acción de la $\alpha$-amilasa son: 1 ) la densa estructura de la pasta resulta en una baja porosidad que limita el acceso a la enzima; 2) la tortuosidad de la matriz proteica; 3 ) 
la posible interacción de la $\alpha$-amilasa con la matriz proteica; 4) la estructura del almidón en la pasta.

\section{Almidón resistente}

Las pastas además de ser consumidas como platos calientes, pueden ser usadas como ingrediente para ensaladas o como base para otras preparaciones, en donde la pasta hervida es almacenada a temperaturas sub-ambientes para ser utilizada horas más tarde en la elaboración de alguna comida (Riva et al., 2000).

Durante el enfriamiento de la pasta cocida, se inicia una retrogradación del almidón que comienza desde la superficie y progresa hacia el interior, siendo este fenómeno más pronunciado en los espaguetis de trigo pan que en los de trigo durum (Heneen \& Brismar, 2003).

Durante la retrogradación del almidón, la amilosa forma un complejo térmicamente estable, resistente a las amilasas, el cual es considerado como almidón resistente tipo 3 (Haralampu, 2000). El almidón resistente (AR) se caracteriza por no ser asimilado en el intestino delgado, y al llegar al intestino grueso actuar como sustrato fermentable por la microflora intestinal (Rahman et al., 2007).

Los efectos fisiológicos del almidón resistente son semejantes a los de la fibra soluble. Si bien en el intestino delgado el AR puede ser lentamente absorbido, lo más importante es que provoca una mala absorción del almidón, disminuyendo la glucosa postprandial y la respuesta de insulina (Haralampu, 2000).

La interferencia con la absorción del almidón además implica beneficios a largo plazo en el control de la hiperlipidemia. En el colon, el AR incrementa el volumen fecal, disminuye el pH y la porción fermentada por la microflora del intestino genera una amplia variedad de ácidos grasos de cadena corta, principalmente acetato, propionato y butirato (Haralampu, 2000). Una particularidad del almidón resistente es que su fermentación genera altos niveles de ácido butírico en comparación con otros carbohidratos fermentables. El butirato es un importante sustrato para las células epiteliales del intestino y parece tener especial relevancia en el bienestar del epitelio del colon. La deficiencia de butirato luminal conduce a un estado de energía deficiente para el colonocito y, en consecuencia, una atrofia de la mucosa. Además el butirato es un potente inductor de diferenciación de las células tumorales pudiendo frenar la proliferación de varias líneas celulares de cáncer colorrectal (Brighenti et al., 1998). 


\section{Propiedades funcionales de la harina de amaranto}

El amaranto es una de las plantas más antiguas de América, originaria de México aunque luego fue trasladada a otros países. Sus hojas han sido utilizadas como hortalizas y sus semillas como cereal (Figari et al., 2001).

El amaranto es conocido con diferentes nombres locales de acuerdo a la región: "Sangoroche” y “Ataco" (Ecuador), “Achis", “Achita”, "Inca Jataco”, “Coimi” y "Kiwicha” (Perú), “Millmi" (Bolivia), "Trigo Inca" e "Icapachaqui" (Argentina) (Figari et al., 2001).

Las tres principales especies del género Amaranthus son hypochondriacus (A. hybridus L.), A. cruentus (Amaranthus chlorostachys Willd, A. paniculatus L.) y A. caudatus (Amaranthus edulis Spegazzini, Amaranthus mantegazzianus Passerini). Las dos primeras fueron cultivadas en Mesoamérica y la última en los Andes (Repo-Carrasco-V et al., 2006)

El amaranto es considerado como un cultivo andino de alto valor nutritivo por ser buena fuente de proteínas y de lípidos. Todas las especies de Amaranthus tienen un contenido proteico alto y su composición en aminoácidos esenciales es bien balanceada (Repo-CarrascoV et al., 2006)

El amaranto tiene un contenido mínimo de proteínas de $16 \%$, el cual en general es superior a aquellos encontrados en las variedades comerciales de los cereales comunes. Las proteínas del amaranto presentan características únicas debido a que su balance de aminoácidos está cercano al balance óptimo requerido para la nutrición humana. El contenido de lisina es especialmente alto en relación con los cereales comunes. La importancia del amaranto es que sus aminoácidos esenciales pueden complementar a los del maíz, arroz y trigo. A pesar que la proteína de amaranto presenta un bajo contenido del aminoácido leucina, no constituye una limitación debido a que este aminoácido está en exceso en la mayoría de los granos comunes (Plucknett et al., 1984). En estudios posteriores se reconoció a la treonina como el aminoácido limitante del amaranto (Berghofer \& Schoenlechner, 2002).

La relación de eficiencia proteica del grano cocido de amaranto (PER) está comprendida entre 1,5 a 2,0 (valor de referencia: 2,5 de la caseína) y la digestibilidad total es cercana al $90 \%$ (Plucknett et al., 1984). La proteína presenta un valor biológico de 75 (debido principalmente al alto contenido de lisina), resultando un valor cercano al de la proteína de leche (Berghofer \& Schoenlechner, 2002). Cuando la harina de amaranto se mezcla con la de otros granos, el balance de aminoácidos se vuelve cercano a 100, ya que los aminoácidos deficientes en uno son abundantes en el otro (Plucknett et al., 1984). 
El contenido de almidón en la semilla de amaranto está entre el 50 a $60 \%$ de su peso seco y presenta características muy diferentes a las del almidón de trigo, y en general contiene menos amilosa (5-7\%). Así, la capacidad del almidón de Amaranthus para hincharse cuando se mezcla con agua es mucho más baja que la del trigo. El tamaño de gránulos del almidón de amaranto es pequeño, 0,7-3 $\mu \mathrm{m}$. La temperatura de gelatinización es 62-68 ${ }^{\circ} \mathrm{C}$. (RepoCarrasco-V et al., 2006).

La cantidad de lípidos en el amaranto también es mayor que en los cereales, estando comprendida entre el 7 al 8\%. El aceite de amaranto está formado por $70 \%$ de ácidos oleico y linoleico, $20 \%$ de ácido esteárico y $1 \%$ de ácido linolénico (Plucknett et al., 1984). Dentro de la materia insaponificable, el escualeno es el principal componente (aproximadamente el $8 \%$ del aceite de la semilla). Este triterpeno de cadena abierta altamente insaturado, más allá de ser usado en la industria cosmética (productos para el cuidado de la piel) y como lubricante industrial resistente a la oxidación (Berghofer \& Schoenlechner, 2002), se le atribuye un efecto quimio-preventivo en el cáncer de colon (Rao et al., 1998). Además se ha demostrado que es efectivo para disminuir los niveles séricos de colesterol. También hay estudios que indican que el escualeno ejerce acción hipocolesterolémica cuando se lo administra en conjunto con tocotrienoles (He et al., 2002).

En un estudio realizado en pollos alimentados con amaranto, se encontró que el colesterol total y colesterol LDL disminuyeron un $10-30 \%$ y $7-70 \%$, respectivamente, mientras que el HDLcolesterol no fue afectado. La actividad de la enzima hepática $7 \alpha$-hidroxilasa (enzima responsable de la descomposición del colesterol en ácidos biliares) fue 10-18\% mayor que en las aves alimentadas con la dieta control, mientras que la actividad de la 3-hidroxi-3metilglutaril coenzima A reductasa (HMG-CoA) (enzima hepática que limita la velocidad de la biosíntesis del colesterol) se redujo alrededor del 9\% (Qureshi et al., 1996).

El escualeno es un inhibidor de la retroalimentación de la actividad de la HMG-CoA. En los tejidos esterogénicos, la síntesis de mevalonato es modulada principalmente a través de la retroalimentación de los esteroles, que se hace por medio de la regulación de la transcripción del ARNm de la HMG-CoA. La conversión de escualeno a colesterol, el principal producto final de la vía del mevalonato animal, también suprime la síntesis de mevalonato a nivel de la transcripción al actuar como inhibidor de la retroalimentación (Qureshi et al., 1996).

En un trabajo realizado en hámsteres, con una dieta hipercolesterolémica previa, alimentados con aceite de amaranto (5\%), se observó una reducción de los valores de 
colesterol total y LDL colesterol en un 15 y $22 \%$ respectivamente, en comparación con el grupo control (He et al., 2002).

Además se han postulado efectos beneficiosos del aceite de amaranto sobre la hipertensión arterial. Se sabe que en la hipertensión la membrana celular es defectuosa y, por tanto, el movimiento de los iones Na y $\mathrm{K}$ a través de ella también se ve afectado, favoreciendo así al aumento de la presión arterial. Se ha demostrado que el aceite de amaranto modula la fluidez de la membrana y puede estabilizar los canales iónicos de los eritrocitos. Sobre estas propiedades se basa la hipótesis de que el aceite de amaranto puede ser de gran beneficio para los pacientes con enfermedades cardiovasculares (Pogojeva et al., 2006).

El contenido de minerales en el grano de amaranto es aproximadamente el doble que en los cereales comunes $(3,0-3,3 \%$ respecto a 1,8 del trigo), encontrándose el $66 \%$ de los minerales en la fracción del salvado y del germen. Presenta un alto contenido de calcio, magnesio, hierro, potasio y zinc. La relación calcio/fósforo es muy buena, con un valor de 1:1,9-2,7, atendiendo a que las recomendaciones nutricionales rondan en 1:1,5 (Ca:P) (Berghofer \& Schoenlechner, 2002).

En general se puede considerar que el amaranto no significa una fuente importante de vitaminas, sin embargo el contenido de riboflavina (B2) y de ácido ascórbico es mayor que en los cereales comunes. Además el amaranto es una buena fuente de vitamina E (Berghofer \& Schoenlechner, 2002).

La cantidad de fibra dietética en el grano de amaranto es ligeramente inferior al grano de trigo. La fracción de fibra insoluble puede variar desde 19,5 hasta 49,3\% dependiendo de la variedad (Berghofer \& Schoenlechner, 2002).

\section{Propiedades funcionales de la harina de soja}

La soja o soya (Glycine max L. Merr) es una leguminosa que pertenece a la sub familia de las papilionáceas que se cultiva con dos propósitos, la obtención de aceite y de harinas proteicas. Los granos de soja contienen en promedio $40 \%$ de proteínas, $20 \%$ de lípidos, $35 \%$ de carbohidratos y $5 \%$ de cenizas; pudiendo variar según el genotipo y el medio ambiente (Puppo et al., 2006).

En cualquier caso, la soja tiene un contenido mucho más alto de proteínas que otros granos de leguminosas cuyo promedio es entre 20 y $30 \%$ y que los cereales cuyo contenido de proteínas está comprendido entre 8-15\%. El patrón de aminoácidos que presenta es uno de los 
más completos en comparación con otras fuentes vegetales de proteínas, la principal deficiencia es de aminoácidos sulfurados (metionina) (Endres, 2001a).

La ausencia de un balance ideal de aminoácidos esenciales de una materia prima en particular, no es necesariamente una limitante, considerando que nuestra dieta contiene una variedad de fuentes de proteínas, tales como los cereales, legumbres y proteínas animales; cada una de ellas con su patrón de aminoácidos característicos. Dado que las proteínas de soja contienen un nivel de lisina que excede los requerimientos del ser humano, puede ser usada para suplementar la deficiencia de lisina de algunos granos como el trigo y el maíz (Endres, 2001a).

La calidad de la proteína de soja, medida en término de PDCAAS (Protein Digestibility Corrected Amino Acid Score), el cual toma en consideración el contenido de aminoácidos esenciales, la digestibilidad, y la habilidad de suplementar aminoácidos esenciales para suplir las necesidades del ser humano, resultó 0,92 y 0,99 para el aislado y el concentrado de proteínas de soja, respectivamente (PSCAAS de la caseína y de la clara de huevo 1,0) (Endres, 2001a).

Estudios clínicos realizados tanto en animales como en humanos han demostrado que las proteínas de soja tienen una digestibilidad comparable con otras fuentes de proteínas de alta calidad tales como leche, carne, huevo y pescado. Los valores medidos de digestibilidad de la harina de soja estuvieron comprendidos entre $84 \%$ para niños hasta $96 \%$ para adultos (Endres, 2001a).

Existe amplia evidencia que las proteínas de soja tienen una influencia positiva sobre la salud. Recientes estudios han considerado la importancia de la dieta para explicar al menos en parte, las diferencias en la tasa de mortalidad debida a enfermedades cardiovasculares y diversos tipos de cáncer en varios países. Cierto número de estudios sugieren que la proteína animal, usualmente la caseína, es más colesterolémica y aterogénica que las proteínas vegetales, especialmente la de soja. La diferencia persiste aún con alto consumo de grasas saturadas (Endres, 2001b).

Trabajos previos mostraron que las ratas alimentadas con dietas basadas en soja y trigo tuvieron menor concentración de colesterol en suero que aquellas alimentadas con dieta de control. Otros ensayos demostraron que el colesterol total fue significativamente menor en las ratas alimentadas con cinco proteínas vegetales (alfalfa, haba, gluten, guisante y soja) que aquellas alimentadas con tres proteínas animales (caseína, lactoalbúmina y ovoalbúmina) (Friedman \& Brandon, 2001). 
Los datos en animales sobre los efectos hipocolesterolémico de proteínas de soja han sido confirmados por numerosos estudios en humanos. Un posible mecanismo del efecto reductor del colesterol de proteína de soja es su capacidad para modular los niveles del receptor de LDL en el hígado (Friedman \& Brandon, 2001).

En 1999 la FDA autorizó una alegación de salud (health claim) para la rotulación de alimentos que contengan proteína de soja acerca del rol de esta proteína en la reducción del riesgo de enfermedades coronarias (FDA Final Rule, 1999).

Hay que tener en cuenta que los porotos de soja crudos contienen inhibidor de tripsina (Bowman Birk y Kunitz, citocromo $\mathrm{C}$ y $\alpha$-conglicinina). Estos factores anti nutricionales deben inactivarse cuando los porotos son destinados para el consumo humano (Puppo et al., 2006), ya sea por tratamiento térmico o por fraccionamiento durante la elaboración del alimento (Friedman \& Brandon, 2001).

Los granos de soja contienen además $38 \%$ de hidratos de carbono, de los cuales $17 \%$ son solubles y el $21 \%$ restante son insolubles. La primera fracción está formada por azúcares de bajo peso molecular, como estaquiosa, rafinosa y sacarosa, y la segunda por hidratos de carbono de alto peso molecular, arabinanos, arabinoglucanos y polisacáridos acídicos, que constituyen la fibra dietética (Puppo et al., 2006). Considerando que los productos que contienen soja son una excelente fuente de fibra dietética y dado que ésta última parece ejercer un rol en el control del colesterol sanguíneo, tener un efecto preventivo en el cáncer de colon y mejorar la tolerancia a la glucosa; estudios con dietas conteniendo harina de soja, concentrado de soja y fibra de soja merecen una atención especial (Endres, 2001b).

Además el grano de soja contiene potasio $(1,5-1,9 \%)$, sodio $(0,4-0,6 \%)$, fósforo $(0,35-$ $0,70 \%)$, magnesio $(0,09-0,21 \%)$, calcio $(0,02-0,06 \%)$ y hierro $(0,004-0,016 \%)$ (Puppo et al., 2006).

La soja es una fuente de isoflavonas incluyendo genisteína y daidzeína. El contenido de isoflavonas varía entre las variedades de soja, sin embargo, una concentración promedio se encuentra entre 1 a $4 \mathrm{mg} / \mathrm{g}$. Las isoflavonas son una subclase de los flavonoides, cuya estructura básica característica es el núcleo flavona, el cual comprende dos anillos bencénicos (A y B) unidos a través de un anillo pirano heterocícliclo (C). Las principales isoflavonas presentes en la soja son genisteína (4'-5,7-trihidroxiisoflavona) y daidzeína (4',7dihidroxiisoflavona) y sus respectivos $\beta$-glicósidos, genistina y daidzina (los cuales presentan azúcares unidos a la posición 7 del anillo A). Generalmente en la soja hay algo más de genisteína que de daizeína. En la soja también se encuentran en menor cantidad una tercer 
isoflavona, la gliciteína (7,4'-dihidroxi-6-methoxiisoflavona) y su glicósido, glicitina. Además cada glicósido de isoflavona puede tener un grupo acetil o malonil unido al carbono 6 del anillo A, por lo que hay 12 isómeros deferentes de isoflavonas en la soja (Figura I.14) (Messina et al., 2001).
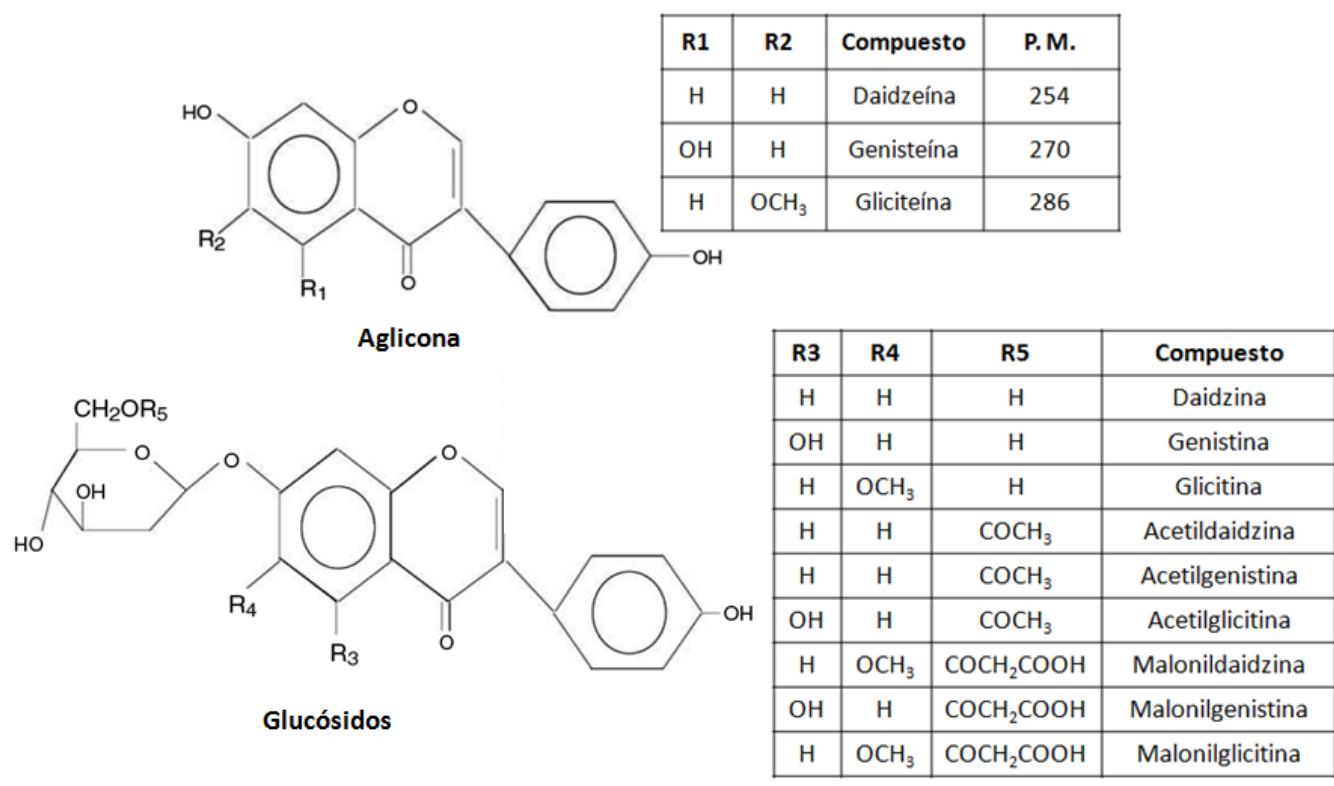

Figura I.14 - Estructura química de los 12 isómeros de isoflavonas (Messina et al., 2001).

Una vez ingeridos, los glucósidos de isoflavonas son metabolizados en el intestino por la $\beta$ glucosidasa de la microflora intestinal en las agliconas genisteína y daidzeína, respectivamente (Vincent \& Fitzpatrick, 2000). Estos compuestos son absorbidos como isoflavonas libres y también son metabolizados por la flora intestinal en otros metabolitos tales como el equol, el cual deriva de la daidzeína y al que se lo reconoce como el metabolito más potente dentro de las isoflavonas de la soja (Levis et al., 2010).

Las isoflavonas de soja han recibido especial atención desde que se descubrió que podían unirse a receptores de tipo estrogénicos, por los que se los ha dado en llamar fitoestrógenos. Además las isoflavonas han sido reconocidas como compuestos con propiedades preventivas y terapéuticas del cáncer y de la osteoporosis (Dillard \& German, 2000).

Estudios realizados en ratas ovariectomizadas, alimentadas durante 30 días con genisteína ( $30 \mu \mathrm{mol} / \mathrm{día})$, incrementaron el peso seco de las cenizas del fémur $(p<0,05)$ en $12 \%$ respecto del control (Messina et al., 2001).

En ratones alimentados con dietas con componentes de soja, se inhibió el crecimiento de cáncer experimental de próstata y se alteraron biomarcadores tumorales asociados con 
angiogénesis. Datos epidemiológicos sugieren que la soja podría disminuir el riesgo de cáncer de mama (Imhof et al., 2008) y próstata. Además se ha propuesto que la genisteína inhibe el crecimiento in vitro de la mayoría de las células cancerígenas dependientes e independientes de hormonas, incluyendo células cancerígenas de colon (Dillard \& German, 2000).

En estudios realizados en mujeres premenopáusicas sanas con una ingesta diaria de proteína vegetal texturizada con $45 \mathrm{mg}$ de isoflavonas, se verificó una modificación del ciclo menstrual prolongando su duración. La duración del ciclo menstrual, mostrado como dato epidemiológico, es uno de los factores de riesgo para el cáncer de mama, si bien las razones de esta asociación no son del todo claras. El ciclo promedio en países occidentales, en los cuales el riesgo de cáncer de mama es alto, es de 28-29 días, mientras que en mujeres japonesas es de 32 días donde el riesgo de cáncer de mama es cuatro a cinco veces menor. Además, estudios epidemiológicos mostraron que una dieta rica en isoflavonas durante 12 semanas, provocó una reducción del 40 al 55\% de los síntomas postmenopáusicos, respecto a la dieta control donde la reducción de los sofocos estuvo comprendida entre 20-35\% (Setchell \& Cassidy, 1999).

Si bien muchos son los beneficios sobre la salud que se le atribuye a la soja, en los últimos años se han planteado dudas sobre tales propiedades (Kok et al., 2005; Heneman et al., 2007; Wuttke et al., 2007; Liu et al., 2009). De acuerdo a Patisaul \& Jefferson (2010) el interrogante de si los fitoestrógenos son beneficiosos o perjudiciales para la salud humana sigue sin resolverse. La respuesta es probablemente compleja y puede depender de la edad, el estado de salud, e incluso la presencia o ausencia de una microflora intestinal específica en las personas evaluadas.

En la soja están presentes casi todas las vitaminas principales, excepto la vitamina C y D. Las vitaminas hidrosolubles tiamina, piridoxina y ácido fólico se encuentran en proporciones mayores. Los tocoferoles en la soja son de particular importancia no sólo como parte de la actividad de la vitamina $K$, sino también por sus propiedades antioxidantes.

Más allá de las propiedades nutricionales y funcionales, desde el punto de vista tecnológico, la funcionalidad de las harinas de soja se relaciona con la propiedad que tienen sus proteínas en relación a la capacidad de absorción de agua y de grasa, y de pegajosidad. Estas propiedades dependen del grado de desnaturalización que tengan estas proteínas y en menor medida, del tamaño de partícula. La funcionalidad es mayor en productos no tostados y se reduce en proporción al grado del tratamiento térmico. Las harinas de soja con más proteínas, más dispersables (alto índice de nitrógeno soluble o índice de dispersibilidad de 
proteína), son usadas en productos de panadería y otros en base a cereales, siendo agregadas directamente a la masa (Endres, 2001c). También las pastas, ya sean preparadas a partir de sémola de trigo duro o de harina de trigo pan, fortificadas con harina de soja, mejoran su valor nutricional. Aunque hay que tener en cuenta que todos los productos con proteínas de soja van a aumentar la absorción de agua de la pasta y van a afectar las condiciones de proceso (Endres, 2001c).

Al respecto, trabajos previos revelan que las proteínas de soja interfieren en forma directa e indirecta en la formación de la red de gluten. El efecto directo está relacionado con la interacción de las proteínas de trigo y soja, mientras que el indirecto se relaciona con la competencia entre las proteínas de soja y trigo por el agua necesaria para su hidratación (Ribotta et al., 2005a,b). Otros investigadores atribuyen los problemas asociados a la calidad a una dilución del gluten (Doxastackis et al., 2002).

\section{Objetivo general}

- Evaluar la aptitud de las pastas para actuar como alimentos funcionales, estudiando el efecto del agregado de diferentes ingredientes sobre su calidad tecnológica y nutricional.

\section{Objetivos específicos}

- Objetivo I: estudiar los parámetros que definen la calidad de las pastas.

- Objetivo II: evaluar el efecto del almidón, del gluten y del agua sobre la calidad de las pastas frescas elaboradas con harina de trigo pan.

- Objetivo III: evaluar el efecto de harinas con diferentes características sobre el color de pastas frescas laminadas.

- Objetivo IV: obtener pastas de calidad tecnológica y sensorial aceptables, elaboradas con harina de amaranto y harina de soja a fin de otorgarles propiedades funcionales y mejorar su calidad nutricional.

- Objetivo V: determinar los componentes con propiedades funcionales aportados por la harina de amaranto y la harina de soja y evaluar la calidad nutricional de las pastas obtenidas con ella. 


\section{MATERIALES Y MÉTODOS}




\section{Pastas comerciales}

\section{Muestras}

En un mercado de la provincia de Córdoba se obtuvieron 5 muestras de espaguetis secos, las que se identificaron como Com1, Com2, Com3, Com4 y Com5.

\section{Formulación}

De acuerdo a la rotulación del envase, Com1 estuvo preparada a partir de sémola de trigo candeal, mientras que el resto de las muestras estuvieron elaboradas a partir de harina de trigo fortificada con hierro, niacina, tiamina, ácido fólico, riboflavina, con semolín y colorante cúrcuma.

\section{Pastas frescas}

\section{Harinas}

Harina de trigo pan (Triticum aestivum L.) var. Buck Guapo (BUK), var. Baguette 10 (BAG), harina de Triticale (Triticosecale Wittmack) var. Tatú (TRI), las que se obtuvieron por molienda de sus granos previo acondicionamiento de $24 \mathrm{~h}$ a $16 \% \mathrm{p} / \mathrm{p}$ de humedad con AQC 109Laboratoy Mill-Agromatic AG (Alemania), y con una tasa de extracción comprendida entre el 30 a $40 \%$ p/p. Además se utilizó harina de trigo pan (MCA), mezcla de variedades (Campaña 2004, Molino Campodónico, Argentina). Como modificadores de la formulación se utilizaron almidón de trigo, grado alimenticio (Montreal, Canadá) y gluten Abeve (USA).

\section{Formulación}

Las pastas fueron preparadas a partir de $50 \mathrm{~g}$ de harina, $500 \mathrm{mg}$ de $\mathrm{NaCl}$, empleando dos cantidades de agua, 37,5 y $43,8 \mathrm{~mL} / 100 \mathrm{~g}$ de harina. A la preparación con menor contenido de agua, se le agregaron dos cantidades de almidón, 5 y $10 \mathrm{~g} / 100 \mathrm{~g}$ de harina y dos de gluten, 3 y $6 \mathrm{~g} / 100 \mathrm{~g}$ de harina. La sal fue incorporada en forma de salmuera, disolviéndola en la porción de agua a utilizar. 


\section{Preparación}

Sobre los ingredientes secos tamizados (harina, harina más almidón o harina más gluten), se agregó el agua con la sal e inmediatamente se amasó la pasta con una amasadora manual Philips 190 W HR 1495, máxima velocidad, durante $3 \mathrm{~min}$. Se tomó la masa con las manos, conformando un bollo al que se dejó descansar $10 \mathrm{~min}$. Para el laminado se utilizó una fabricadora de pastas Drago® (Argentina), de $14 \mathrm{~cm}$ de longitud de ancho de lámina, con apertura regulable de los rodillos del 1 al 7. Antes de comenzar el laminado, se estiró el bollo con un palote y se pasó por la laminadora en el punto № 7, se plegó por la mitad y se volvió a pasar por el punto №7, repitiendo esta operación un total de siete veces y pasando de igual modo solo una vez, por los puntos №6, №5, №4 y №3. Para finalizar el laminado se pasó una vez más por el punto №3, sin hacer ningún doblez previo. Los fideos se cortaron de $\approx 2 \mathrm{~mm}$ de ancho e inmediatamente se colocaron en bolsas plásticas, herméticamente cerradas hasta su uso

\section{Cocción}

Las pastas se cocinaron en una relación 1:10 pasta:agua destilada a ebullición, hasta alcanzar los tiempos óptimos de cocción (TOC) de cada muestra. Luego, se retiraron, enjuagando con $50 \mathrm{~mL}$ de agua destilada y dejando escurrir durante $30 \mathrm{~s}$.

\section{Pastas secas}

\section{Harinas}

Las harinas utilizadas fueron: harina de trigo pan (Triticum aestivum L.), (Molino Tiranti (Argentina, campaña 2007); harina de soja (Glycine max L.) desgrasada, micronizada (100 $\mu \mathrm{m}$ ), inactivada (Complementos Proteicos SA, Argentina) y harina integral de amaranto (A. mantegazzianus Pass.), obtenida a partir de la molienda de granos crudos enteros (Gran Diet, Argentina), con molino a martillo Fritsch Pulverisette 16 (Alemania), tamizada por malla \#30 (590 $\mu \mathrm{m}$ de apertura), tamizador Zony Test MR (Argentina).

\section{Formulación}

Las muestras fueron preparadas a partir de la sustitución de la harina de trigo pan, por harina de amaranto y harina de soja en un 15, 30, 40 y 50\% p/p, resultando A15, A30, A40, $A 50, S 15, S 30, S 40$ y S50, respectivamente. Además se preparó una muestra solo con harina de 
trigo, a la que se consideró como muestra control (Co) (Figura M.1-A). Tanto para cada nivel de sustitución, como para la muestra control, se elaboraron tres lotes diferentes. Para la elaboración de cada lote se utilizaron $50 \mathrm{~g}$ de la mezcla de las harinas con una cantidad de agua óptima, determinada experimentalmente por prueba y error, de acuerdo a la apariencia y propiedades para la manipulación y laminado que presentaba la masa, a la que se le agregaron $500 \mathrm{mg}$ de $\mathrm{NaCl}$.

\section{Preparación}

Sobre los ingredientes secos y tamizados (harina de trigo y mezcla de harina de trigo más harina de amaranto o harina de soja), se agregó el agua con la sal e inmediatamente se amasó con una amasadora manual Philips 190W HR 1495 (Argentina), a máxima velocidad durante 3 min (Figura M.1-B). Se tomó la masa con las manos, conformando un bollo (Figura M.1-C) al que se dejó descansar $13 \mathrm{~min}$. Para el laminado se utilizó una laminadora de pastas Pastalinda ${ }^{\circledR}$ (Argentina), de $20 \mathrm{~cm}$ de ancho de lámina, con apertura regulable de los rodillos del 1 al 9, de mayor a menor grado. Antes de comenzar el laminado, se estiró el bollo con un palote (Figura M.1-D), se pasó por la laminadora en el punto № 1 (Figura M.1-E), se plegó por la mitad (Figura M.1-F) y se volvió a pasar por el №1, repitiendo esta operación seis veces en el punto $\mathrm{N}^{\circ} 1$ y solo una vez en los puntos №2, №3, №4, №5, №6, №7 y №8 a fin de reducir el espesor de la lámina. Antes de finalizar el laminado se pasó una vez más por el punto №8 (Figura M.1-G), sin hacer ningún doblez previo. Los fideos se cortaron de $\approx 2 \mathrm{~mm}$ de ancho (Figura M.1-H) e inmediatamente se colgaron en un tendedero diseñado ad hoc, (Figura M.1I,J), para luego ser secados.

\section{Secado}

Las pastas fueron secadas hasta $10 \pm 1 \% \mathrm{p} / \mathrm{p}$ de humedad, por medio de dos ciclos; primero un presecado en una estufa con corriente de aire, Memmert Modell 600 D060602 (Alemania), a $30{ }^{\circ} \mathrm{C}$, durante $30 \mathrm{~min}$, con una humedad relativa ambiente, HR, entre 30 y $40 \%$ (Figura M.1-K), seguido de un ciclo de secado en una estufa sin corriente de aire Hessico, Otto Hess SA (Argentina), a $30^{\circ} \mathrm{C}$, durante $17 \mathrm{~h}$, con una HR de 65\% (Figura M.1-L). El control de la humedad de esta última estufa se ajustó por la carga de trabajo que, determinada por prueba y error, resultó $300 \mathrm{~g}$ por ciclo (6 lotes). Una vez secos, los fideos fueron conservados en bolsas plásticas, cerradas herméticamente hasta su uso. 


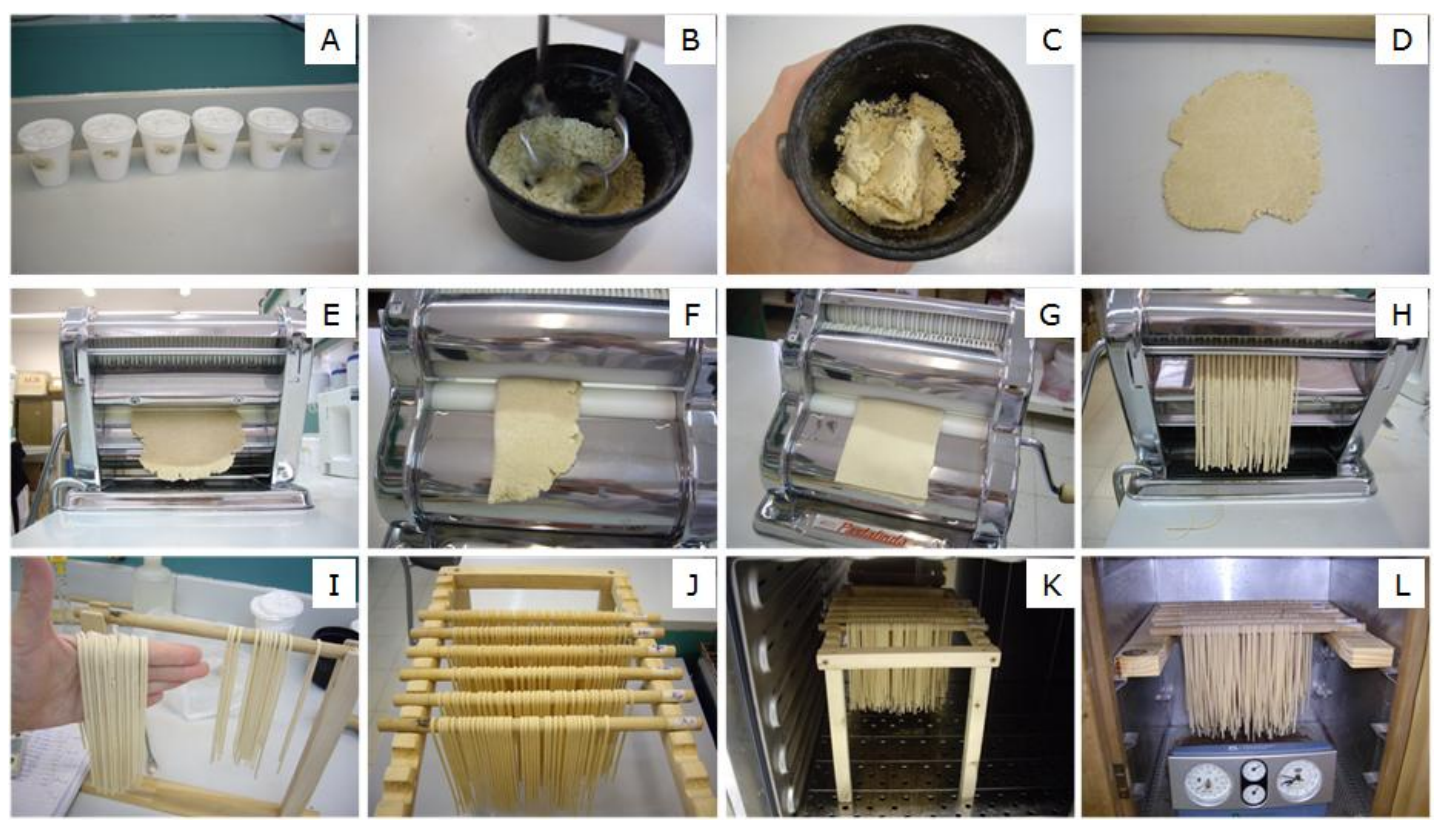

Figura M.1 - Elaboración de pastas secas: preparación de las mezclas de las harinas (A), amasado (B), conformación del bollo (C), primer estirado con el palote (D), primera pasada por la laminadora (E), doblez (F), última pasada por la laminadora (G), corte (H), colgado de cada lote (I), colocación en el secadero (J), ciclo de presecado (K), ciclo de secado (L).

\section{Cocción}

Para la cocción se utilizó agua destilada a ebullición, en una relación mínima de una parte de pasta en diez partes de agua. Las pastas se cocinaron hasta alcanzar los TOC de cada muestra, luego se retiraron, enjuagando con $50 \mathrm{~mL}$ de agua destilada y dejando escurrir en un colador inclinado hacia un lado durante 20 s y hacia el lado opuesto, otros $20 \mathrm{~s}$.

\section{Evaluación de las harinas}

\section{Proteínas}

El contenido de nitrógeno en las harinas se determinó de acuerdo a AACC 46-13 (AACC, 1995), realizando una mineralización de $100 \mathrm{mg}$ de harina con $\mathrm{H}_{2} \mathrm{SO}_{4}$ a $400{ }^{\circ} \mathrm{C}$; el amonio resultante se destiló por medio de un destilador Velp UDK 126 (Italia), recogiendo el $\mathrm{NH}_{3}$ en exceso de Ácido Bórico y valorando con $\mathrm{HCl}$. Los porcentajes de proteína total se calcularon como $\mathrm{N}$ x 5,7 ó 6,25 dependiendo de la muestra analizada. 


\section{Humedad}

El contenido de humedad se determinó de acuerdo a AACC 44-19 (AACC, 1995); 2 g de harina, secados en estufa a $130^{\circ} \mathrm{C}, 2,5 \mathrm{~h}$ a presión normal.

\section{Cenizas}

El contenido de cenizas se determinó de acuerdo a AACC 08-01 (AACC, 1995) por diferencia, calcinando $2 \mathrm{~g}$ de harina a $550{ }^{\circ} \mathrm{C}$, mufla Indef (Argentina), durante $8 \mathrm{~h}$.

\section{Fibra cruda}

Se determinó de acuerdo a AACC 32-10 (AACC, 1995), por medio de una digestión ácida $\left(\mathrm{H}_{2} \mathrm{SO}_{4} 1,25 \%\right)$ seguida de una digestión alcalina ( $\left.\mathrm{NaOH} 1,25 \%\right)$.

\section{Fibra dietética total}

Fue determinada de acuerdo AACC 32-05 (AACC, 1995), como el residuo obtenido luego de someter un gramo de muestra seca y desgrasada a sucesivas digestiones enzimáticas (primero con $\alpha$-amilasa termoestable, luego con proteasa y finalmente con amiloglucosidasa).

\section{Materia grasa}

Se determinó en base al método AACC 30-26 Crude Fat in Soy Flour (AACC, 1995), a través de una extracción continua por medio de un sistema tipo Soxhlet durante $8 \mathrm{~h}$, utilizando hexano como solvente de extracción.

\section{Caracterización de las proteínas}

\section{Preparación de los extractos}

A partir de las diferentes harinas y de las mezclas de las harinas con los modificadores, se realizó una extracción secuencial sobre la base de la afinidad de las diferentes fracciones proteicas por los distintos solventes de extracción. A partir de $\sim 660 \mathrm{mg}$ de muestra se realizaron tres extracciones de manera secuencial; la primera con $10 \mathrm{~mL}$ de $\mathrm{NaCl} 5 \% \mathrm{p} / \mathrm{v}$ durante $2 \mathrm{~h}$ para la extracción de albúminas y globulinas, la segunda con $10 \mathrm{ml}$ de Isopropanol $70 \% \mathrm{v} / \mathrm{v}$ durante $3 \mathrm{~h}$ para extraer gliadinas y por último con $10 \mathrm{~mL}$ de SDS 1,5\% p/v durante $8 \mathrm{~h}$ para extraer gluteninas. Las extracciones se realizaron usando un agitador oscilatorio horizontal (FBR, Decalab SRL, Argentina) a máxima velocidad, centrifugando (centrifuga EBA 12, Hettich, D-78532 Tuttlingen, Alemania) después de cada tiempo de extracción a 2600 x g, $25^{\circ} \mathrm{C}$, durante $20 \mathrm{~min}$. Los sobrenadantes resultantes de cada solvente de extracción se 
dividieron en dos porciones, una para determinar proteínas totales por Kjeldahl y la otra para el análisis por electroforesis (SDS-PAGE) (Figura M.2).

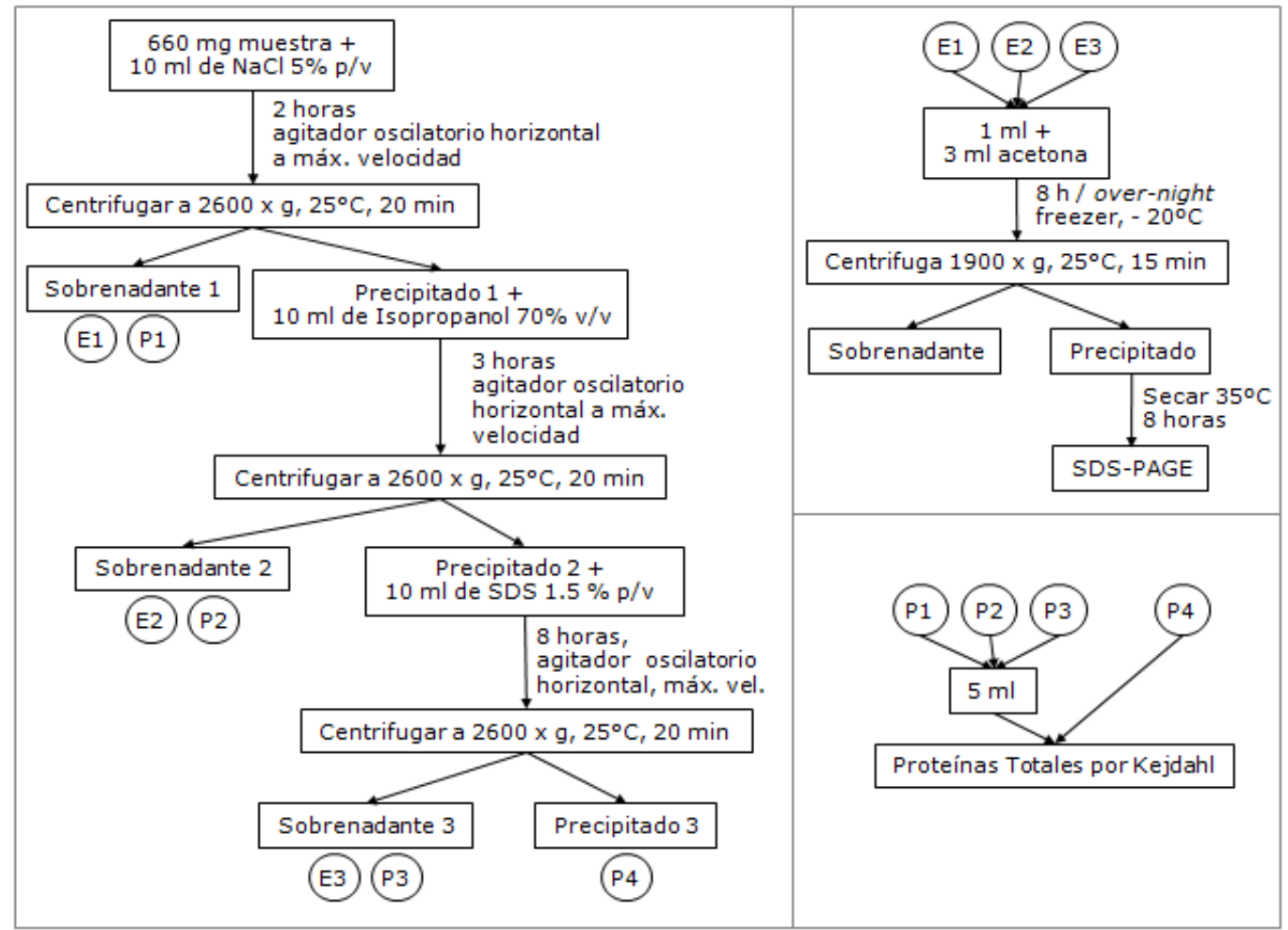

Figura M.2- Extracción secuencial de las proteínas de las harinas.

Los sobrenadantes destinados a electroforesis se precipitaron con acetona, relación 1:3, durante $8 \mathrm{~h}$ en freezer a $-20^{\circ} \mathrm{C}$. Luego, las muestras fueron centrifugadas (centrífuga Cavour VT 3216, Argentina) a $1900 \times \mathrm{g}, 25^{\circ} \mathrm{C}, 15 \mathrm{~min}$. Una vez eliminados los sobrenadantes, los precipitados se secaron a $35{ }^{\circ} \mathrm{C}$ durante 8 horas y se guardaron en freezer a -20 으 C hasta el momento de realizar el ensayo. Para la corrida electroforética, los precipitados se resuspendieron con $0,5 \mathrm{~mL}$ de buffer de muestra (Tabla M.1), se colocaron durante una hora en el agitador oscilatorio horizontal y finalmente se los sumergió en agua a ebullición 5 min. Una vez que alcanzaron temperatura ambiente, se sembraron en el gel de electroforesis, entre 10 y $15 \mu \mathrm{L}$ de cada muestra, previa agitación en el vórtex por algunos segundos. 
Tabla M.1 - Buffer de Muestra x 3

\begin{tabular}{cc}
\hline Componente & Cantidad para $100 \mathrm{~mL}$ \\
\hline Buffer de gel compactador & $37,5 \mathrm{~mL}$ \\
Glicerol & $30,0 \mathrm{~mL}$ \\
Solución de SDS 20\% p/v & $22,5 \mathrm{~mL}$ \\
B-mercapto-etanol & $9,0 \mathrm{~mL}$ \\
Azul de bromo fenol & $0,01 \mathrm{~g} / \mu \mathrm{L}$ \\
\hline
\end{tabular}

\section{Electroforesis en SDS-PAGE}

Las electroforesis se realizaron en placa $(70 \times 80 \mathrm{~mm})$ sobre geles de poliacrilamida con SDS (SDS-PAGE), de acuerdo al sistema de buffer discontinuo de Laemmli (1970). La poliacrilamida se forma por copolimerización de dos compuestos, la acrilamida y la bisacrilamida (N,N'-metilén-bis-acrilamida), en una reacción iniciada por la tetrametiletiléndiamina (TEMED) y el persulfato de amonio. El radical persulfato activa al TEMED, el cual a su vez activa al monómero de acrilamida para que polimerice. Las cadenas de poliacrilamida son entrecruzadas al azar por la bisacrilamida, formándose así una red de porosidad bastante uniforme, la que puede ser regulada variando las condiciones de la reacción y las concentraciones de los monómeros. En la técnica de SDS-PAGE, se mezclan las proteínas con el detergente aniónico SDS para formar complejos desnaturalizados, cargados negativamente. La cantidad de SDS unido a las proteínas es proporcional a su tamaño: el SDS se une en una proporción aproximada de 1,4 g SDS/g proteína. Los complejos proteína/SDS poseen una estructura elipsoide o de bastón, donde la cadena proteica es distendida y solubilizada por el detergente. Dado que la relación final carga/masa es constante para las distintas proteínas (se anula su carga intrínseca), estas se van a separar en el gel poroso, fundamentalmente en base a sus diferencias de peso molecular: a menor tamaño, mayor movilidad de la proteína, y viceversa. El poder de resolución de la técnica de SDS-PAGE se debe al uso de un sistema electroforético discontinuo, formado por dos geles de distinta porosidad y $\mathrm{pH}$, que primero compacta las muestras (en el gel superior o compactador, "stacking") y luego las separa (en el gel inferior o separador), (Figura M.3). En el gel separador, la movilidad es restringida por el tamaño del poro, el cual depende de la concentración de monómeros del gel. 


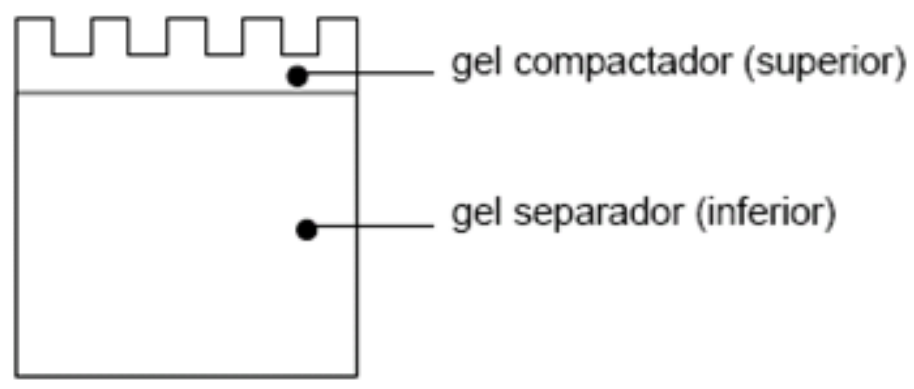

Figura M.3 - Partes de un gel de SDS-PAGE.

En este ensayo la concentración de acrilamida/bisacrilamida utilizada fue $4 \%$ y $12 \%$ p/v y los $\mathrm{pHs} 6,8$ y 8,8 para el gel compactador y separador respectivamente. Los componentes de cada gel se detallan en Tabla M.2.

Tabla M.2 - Composición de los geles de SDS-PAGE

\begin{tabular}{ccc}
\hline Componente & Gel Compactador, $\mathbf{4 \%} \mathbf{p} / \mathbf{v}$ & Gel Separador, $\mathbf{1 2 \%} \mathbf{p} / \mathbf{v}$ \\
\hline Agua Desionizada & $2,21 \mathrm{~mL}$ & $3,14 \mathrm{~mL}$ \\
Buffer Upper-Tris/HCl 1,5 M, pH 6,8 & $0,90 \mathrm{~mL}$ & $2,38 \mathrm{~mL}$ \\
Acrilamida 30\%/Bisacrilamida 0,8\% & $0,49 \mathrm{~mL}$ & $3,80 \mathrm{~mL}$ \\
PSA 4\% (Persulfato de amonio) & $45 \mu \mathrm{L}$ & $119 \mu \mathrm{L}$ \\
TEMED & $8 \mu \mathrm{L}$ & $12 \mu \mathrm{L}$ \\
Volumen Total & $3,65 \mathrm{~mL}$ & $9,6 \mathrm{~mL}$ \\
\hline
\end{tabular}

La cámara electroforética utilizada fue Mini Protean II Dual Slab Cell (Bio-Rad Laboratories, Estados Unidos). Las corridas se hicieron con voltaje constante (150 V), hasta que el marcador del frente alcanzó el final del gel (aproximadamente $90 \mathrm{~min}$ ).

Como marcadores de peso molecular se utilizó una mezcla constituida por Miosina (200,0 $\mathrm{kDa}), \beta$-galactosidasa $(116,25 \mathrm{kDa})$, Fosforilasa b $(97,4 \mathrm{kDa})$, Albúmina sérica $(66,2 \mathrm{kDa})$, Ovoalbúmina (45,0 kDa), Anhidrasa carbónica $(31,0 \mathrm{kDa})$, Inhibidor de tripsina (21,5 kDa), Lisozima (14,4 kDa) y Aprotina (6,5 kDa) (Bio-Rad laboratories, 161-0317, Estados Unidos).

Los geles fueron teñidos con Comassei Brillant Blue R 0,25\% usando como solvente metanol/agua/ácido acético (4:5:1 v/v) y luego desteñidos con el mismo solvente.

\section{Índice de sedimentación en SDS (IS-SDS)}

El índice de sedimentación en SDS (Sodium Dodecil Sulfate) se determinó de acuerdo a AACC 56-70, modificado según Dick \& Quick (1983). 


\section{Capacidad de retención de agua (WRC)}

La capacidad de retención de agua se realizó de acuerdo a AACC 56-10 (AACC, 1995), modificada según Park \& Baik (2002), utilizando agua destilada en lugar de la solución de bicarbonato de sodio.

\section{Propiedades de pasting (RVA)}

\section{Principio del método}

El Viscoanalizador (RVA, Rapid Visco Analyzer) es un equipo que cuantifica la viscosidad, es decir determina la resistencia al flujo de una pasta con base de almidón cuando es sometida a una tensión de desplazamiento constante, incorporando a su vez condiciones de tiempo y temperaturas específicas de acuerdo a la muestra. Este instrumento sustituye al amilógrafo de Brabender, el cual es un método que requiere mucho tiempo, una gran cantidad de muestra y una preparación complicada. El ensayo de RVA consiste en someter la muestra a un ciclo clásico de la cocción (precalentamiento - calentamiento - reposo) donde la viscosidad registra un comportamiento que depende en gran medida del origen y las propiedades del almidón (Ávila 2002).

Los almidones nativos se encuentran como agregados microscópicos llamados gránulos, los que difieren en tamaño y forma de acuerdo al genotipo. Los gránulos pueden ser descriptos como una serie de moléculas de capas concéntricas que definen regiones amorfas y cristalinas. Las moléculas están constituidas por unidades de glucosa encontrándose principalmente dos polímeros, la amilosa que está formada por cadenas lineales y la amilopectina que está integrada esencialmente por cadenas ramificadas. Los cambios de viscosidad producidos por efecto del calentamiento y enfriamiento de una suspensión o dispersión de almidón en agua, generalmente proveen una curva característica (curva de pasting). Los gránulos de almidón son insolubles en agua a temperaturas inferiores a $50{ }^{\circ} \mathrm{C}$; cuando se incrementa por encima de esta temperatura, los gránulos comienzan a hidratarse aumentando su tamaño original, luego sufren un fenómeno irreversible conocido como gelatinización, el cual se caracteriza por la pérdida de su cristalinidad (Ávila, 2002).

Al inicio de la corrida del RVA (Figura M.4) se observa, a bajas temperaturas, una menor viscosidad; al incrementar la temperatura cerca del rango de la gelatinización, los gránulos comienzan a apretarse unos contra otros formando una pasta lo que produce un incremento en la viscosidad, este instante se conoce como "Temperatura de la Pasta o Temperatura Media de Gelatinización", la que puede ser definida como la temperatura mínima requerida para 
cocinar la muestra. Luego los gránulos siguen hinchándose y ocurre un aumento súbito en la viscosidad hasta llegar a un intervalo máximo de temperatura donde los gránulos alcanzan su mayor nivel de absorción de agua denominado "Viscosidad Pico". Posteriormente los gránulos se rompen por efecto de la agitación y los polímetros lixivian provocando una disminución en la viscosidad hasta llegar a un punto llamado "Viscosidad Media". La diferencia entre la viscosidad pico y la viscosidad media se conoce como "Breakdown", e indica la estabilidad del gránulo frente a la cocción.

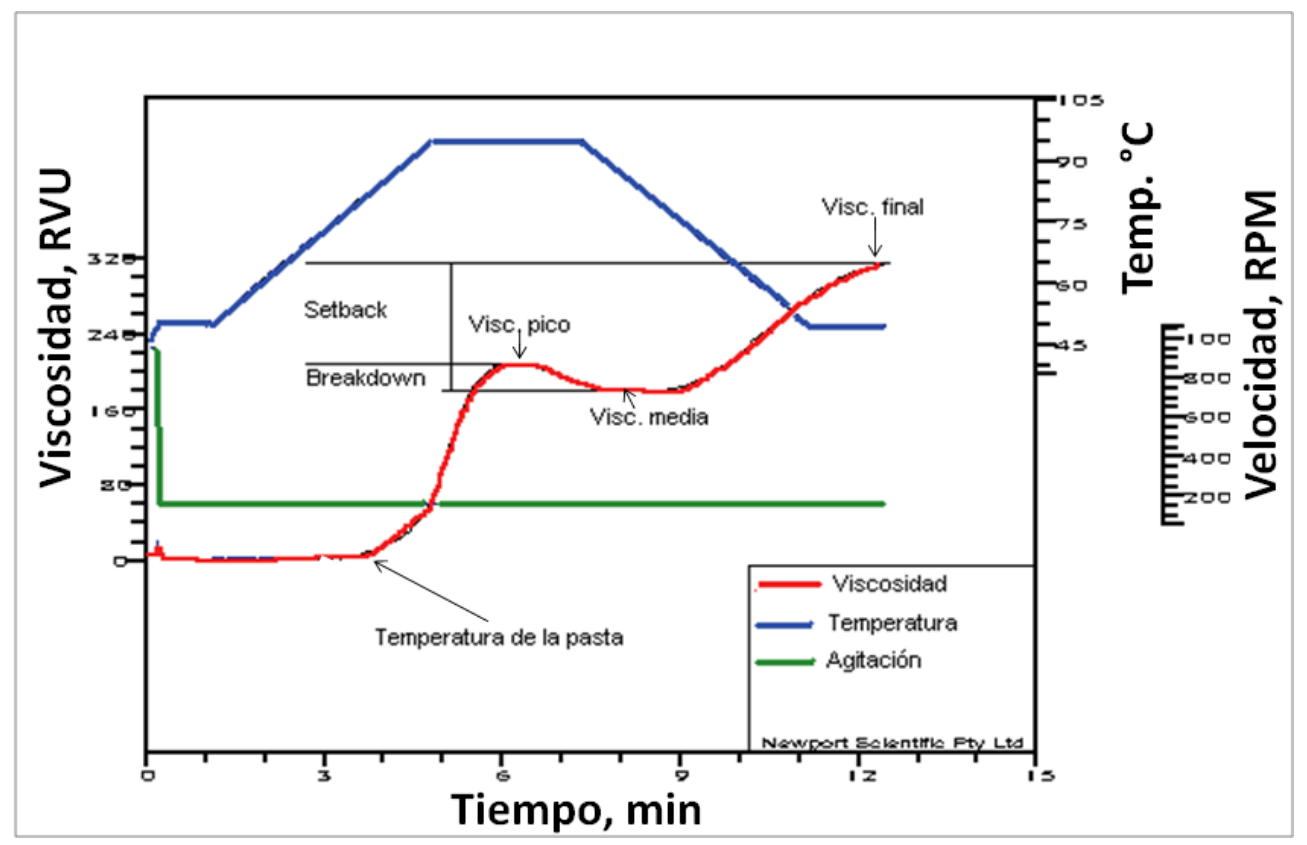

Figura M.4 - Registro de una corrida del RVA y de sus principales indicadores (Ávila 2002).

Finalmente, en el período de disminución de la temperatura, ocurre la retrogradación, que implica el reordenamiento de las moléculas de almidón a pequeños agregados cristalinos insolubles, este fenómeno es el precursor de la formación del gel y la amilosa es la principal responsable. Allí se describe un nuevo incremento de la viscosidad hasta llegar al punto final de la prueba. El Setback es aquella región definida por la diferencia entre la Viscosidad Pico y la Viscosidad Final (Ávila, 2002).

\section{Realización del ensayo}

Las propiedades de pasting de la harina de trigo, de la harina de amaranto, de la harina de soja y de las mezclas de ellas, en las proporciones utilizadas para elaborar las pastas, fueron determinadas por medio de un Rapid Visco Analyser (RVA, Newport Scientific, Narrabeen, Australia). Una muestra de $3 \mathrm{~g}$ de harina se colocó en una cápsula, a la que se le agregó $25 \mathrm{~mL}$ 
de agua y se colocó en la torre del equipo previa agitación de la suspensión. Las propiedades de pasting fueron determinadas de acuerdo al método estándar Newport Scientific, para lo cual se realizó un ciclo de calentamiento desde $50{ }^{\circ} \mathrm{C}$ a $95{ }^{\circ} \mathrm{C}$ en $282 \mathrm{~s}$ y mantenido a $95{ }^{\circ} \mathrm{C}$ durante $150 \mathrm{~s}$ y luego enfriando hasta $50^{\circ} \mathrm{C}$. Cada ciclo fue iniciado con un período de $10 \mathrm{~s}$ de mezclado a $960 \mathrm{rpm}$ de velocidad de paleta, mientras que para el resto del ensayo se utilizó una velocidad de paleta de $160 \mathrm{rpm}$. La temperatura media de gelatinización (TMG), viscosidad de pico (PV), viscosidad fina (FV), breakdown (BD), y setback (SB) fueron obtenidos de la curva de pasting.

\section{Determinación de amilosa en la harina}

\section{Principio del ensayo}

La determinación de amilosa se realizó utilizando el kit de ensayo Amylose/amylopectin KAmyl 04/06 (Megazyme International Ireland Ltd., Bray, Ireland). El almidón de la muestra es completamente dispersado en dimetil-sulfóxido (DMS), mientras que los lípidos son removidos por precipitación del almidón en etanol con posterior recuperación del almidón precipitado. Después de la disolución del precipitado en una solución de acetato de sodio 100 mM, pH 4,5, la amilopectina es específicamente precipitada por la adición de Concavalina A y removida por centrifugación. La amilosa que permanece en el sobrenadante es enzimáticamente hidrolizada a D-glucosa la cual es analizada por medio del reactivo glucosa/oxidasa/peroxidasa (GOP) (el principio de reacción se detalla en determinación de almidón resistente). En otra alícuota de solución de acetato de sodio $(100 \mathrm{mM}, \mathrm{pH} 4,5)$, el almidón total es hidrolizado también a Dglucosa y medido colorimétricamente con GOP. La concentración de amilosa en la muestra de almidón se calcula como la relación entre la absorbancia a $510 \mathrm{~nm}$ medida en la muestra proveniente del sobrenadante de Concavalina A respecto de aquella medida en la muestra de almidón total.

\section{Realización del Ensayo}

A una muestra de harina conteniendo entre 20 a $25 \mathrm{mg}$ de almidón, pesada al 0,1 mg en tubo de vidrio con tapa a rosca, se le agregó $1 \mathrm{~mL}$ de ácido dinitro-salicílco (DNS) (Sigma D0550) y después de mezclar en vortex (Fbr ${ }^{\circledR}$ Decalab, Argentina) a baja velocidad, el tubo se sumergió en un baño de agua en ebullición (Vicking Dufnoff 5002, Argentina) hasta dispersar completamente la muestra. Luego se la agitó nuevamente en el vortex, pero esta vez vigorosamente y se la colocó en el baño de agua a ebullición $15 \mathrm{~min}$, con agitaciones intermitentes en el vortex. Luego de permanecer la muestra a temperatura ambiente durante 
5 min se le agregó $2 \mathrm{~mL}$ de etanol 95\% v/v (Porta Cod.22071000) y previa agitación en el vortex, se le adicionaron otros $4 \mathrm{~mL}$ de etanol y se mezcló por inversión hasta la aparición del precipitado de almidón, dejando reposar la muestra durante $15 \mathrm{~min}$. La muestra fue centrifugada (centrífuga Cavour VT 3216, Argentina) a 2000 x g durante 5 min a $25^{\circ} \mathrm{C}$ y luego de descartar el sobrenadante, se dejó escurrir el tubo sobre papel tisú durante 10 min para eliminar el resto del etanol. Sobre el sedimento así obtenido, se agregaron $2 \mathrm{~mL}$ de DMS, se mezcló por medio de un vortex y se colocó en un baño de agua en ebullición durante 15 min, mezclando ocasionalmente. Inmediatamente después de retirar la muestra del baño de agua, se colocó $4 \mathrm{~mL}$ del buffer de Concavalina A (600 mM, en buffer acetato de sodio pH 6,4 + $\mathrm{CaCl}_{2} \cdot 2 \mathrm{H}_{2} \mathrm{O}$ y $\mathrm{MgCl}_{2} \cdot 6 \mathrm{H}_{2} \mathrm{O}$ ), y previa agitación se transfirió cuantitativamente el contenido del tubo a un matraz de $25 \mathrm{~mL}$, completando el volumen con el mismo buffer (Solución A). Para la determinación de amilosa, de esta última solución, se transfirió $1 \mathrm{~mL}$ a un tubo ependorf, al que se le agregó $0,5 \mathrm{~mL}$ de solución de Concavalina A (provista por el kit), agitándolo suavemente por inversión. Después de reposar $1 \mathrm{~h}$ a temperatura ambiente, se centrifugó a $14.000 \times$ g durante $10 \mathrm{~min}$ a $25^{\circ} \mathrm{C}$. En un tubo de centrífuga se tomó $1 \mathrm{~mL}$ del sobrenadante más $3 \mathrm{~mL}$ de buffer acetato de sodio $100 \mathrm{mM} \mathrm{pH} \mathrm{4,5,} \mathrm{y} \mathrm{se} \mathrm{colocó} \mathrm{el} \mathrm{tubo} \mathrm{en} \mathrm{un} \mathrm{baño} \mathrm{de} \mathrm{agua}$ en ebullición $5 \mathrm{~min}$, para desnaturalizar la Concavalina A. Luego se pasó el tubo a un baño de agua a $40{ }^{\circ} \mathrm{C}, 5 \mathrm{~min}$, se agregó $0,1 \mathrm{~mL}$ de la mezcla de enzimas amiloglucosidasa/ $\alpha$-amilasa (provista por el kit), se incubó a $40{ }^{\circ} \mathrm{C}, 30 \mathrm{~min}$ y se centrifugó a 2000 x g, $5 \mathrm{~min}$ a $25^{\circ} \mathrm{C}$. Sobre una alícuota de $1 \mathrm{~mL}$ del sobrenadante se agregó $4 \mathrm{~mL}$ del reactivo glucosa oxidasa-peroxidasa (GOP), se incubó a $40^{\circ} \mathrm{C}, 20 \mathrm{~min}$, y se midió la absorbancia a $510 \mathrm{~nm}$ contra blanco de reactivo (buffer acetato de sodio 100 mM, pH 4,5). Para la determinación de almidón, se mezclaron 0,5 $\mathrm{mL}$ de la solución A con $4 \mathrm{~mL}$ de buffer acetato de sodio $100 \mathrm{mM}, \mathrm{pH}$ 4,5. Luego se agregó 0,1 $\mathrm{mL}$ de la mezcla de enzimas amiloglucosidasa/ $\alpha$-amilasa y se incubó a $40{ }^{\circ} \mathrm{C}, 10 \mathrm{~min}$. Por duplicado, se transfirió sobre un tubo de vidrio $1 \mathrm{~mL}$, al que se le agregó $4 \mathrm{~mL}$ de GOP y luego de incubar a $40{ }^{\circ} \mathrm{C}, 20 \mathrm{~min}$, se midió la absorbancia a $510 \mathrm{~nm}$. La concentración de amilosa se calculó como: $\frac{\text { Absorbancia sobrenadante Concavalina A }}{\text { Absorbancia alícuota de Almdón Total }} \times \frac{6,15}{9,2} \times \frac{100}{1}$;

donde 6,15 y 9,2 son los factores de dilución de las alícuotas de Concavalina $A$ y del almidón total respectivamente. 


\section{Evaluación instrumental de las pastas}

\section{Humedad de los fideos secos}

Se determinó de acuerdo a AOAC 926.07 B (AOAC, 1998); 2 -3 g de fideos secos, se colocaron en una cápsula de petri previamente secada y tarada, a $100{ }^{\circ} \mathrm{C}$ (presión normal), durante $24 \mathrm{~h}$.

\section{Tiempo óptimo de cocción (TOC)}

El tiempo óptimo de cocción se determinó de acuerdo a AACC 16-50 Cooking Time (AACC, 1995). La muestra se colocó en agua destilada a ebullición, a partir de la cual se fueron tomando sucesivas porciones, cada $1 \mathrm{~min}$, a las que se les observaba la desaparición del centro blanco que presenta inicialmente al realizarle una ligera presión entre dos portaobjetos.

\section{Residuo de cocción}

El residuo de cocción se determinó de acuerdo a AACC 16-50 Cooking Loss (AACC, 1995), sobre $4 \mathrm{~g}$ de muestra colocados en $150 \mathrm{~mL}$ de agua destilada a ebullición, hasta su TOC. El agua de cocción se evaporó a $100{ }^{\circ} \mathrm{C}$ hasta peso constante, expresando los sólidos como \% p/p de muestra.

\section{Absorción de agua}

La absorción de agua fue determinada de acuerdo a Tudoricâ et al. (2002). Cinco gramos de muestra, cortada en segmentos de $5 \mathrm{~cm}$ de longitud, se cocinaron hasta su TOC en $200 \mathrm{~mL}$ de agua destilada a ebullición, se enjuagaron con $50 \mathrm{~mL}$ de agua destilada, se escurrieron durante $20 \mathrm{~s}$ de un lado y otros $20 \mathrm{~s}$ del lado opuesto y se colocaron en un envase de cierre hermético previamente tarado hasta alcanzar temperatura ambiente. Se tomó entonces el peso de la pasta escurrida y se calculó la absorción de agua como [(Peso de la muestra cocidapeso de muestra cruda) / (peso de muestra cruda)] x 100.

\section{Índice de hinchamiento (Swelling Index)}

El índice de hinchamiento fue determinado de acuerdo a Tudoricâ et al. (2002), de manera semejante a la absorción de agua pero calculado como: [(Peso de la pasta cocida-peso de muestra cocida secada) / (peso de muestra cocida secada)]. 


\section{Contenido de amilosa en el agua de cocción}

El contenido de amilosa se determinó de acuerdo a Funami et al. (2005). El agua de cocción resultante del ensayo de absorción de agua se llevó a un volumen final de $300 \mathrm{~mL}$, del cual se tomó una alícuota, a la que se mezcló con igual volumen de $\mathrm{NaOH} 0,33 \mathrm{M}$ y se colocó en baño de agua a ebullición durante 20 min para completar la gelatinización. A partir de la esta suspensión, se tomó una nueva alícuota de $50 \mu \mathrm{l}$, a la que se le agregó iguales volúmenes de agua destilada e $\mathrm{NaOH} 0,33 \mathrm{M}$, más $1 \mathrm{~mL}$ de TCA $1 \%$ y $50 \mu \mathrm{l}$ de Lugol $\left(\mathrm{I}_{2}, 0,2 \%+\mathrm{KI} 2 \%\right)$. Luego de 20 min se midió espectrofotométricamente la absorbancia de la solución coloreada, a $620 \mathrm{~nm}$. La cuantificación de amilosa se realizó por medio de un análisis de regresión lineal empleando una serie de soluciones de amilosa de referencia (Sigma, Corn A-7043) de 0,2; 0,5; 1 y $2 \mathrm{mg} / \mathrm{mL}$.

\section{Determinación de color de las pastas}

\section{Condiciones generales del ensayo}

El color de los fideos se determinó de acuerdo a AACC 14-22 (AACC, 1995), con un espectrofotómetro de reflectancia Minolta 508d de $8 \mathrm{~mm}$ de apertura (Ramsey, NJ), ángulo del observador 10, iluminante D65, componente especular incluido, utilizando la escala CIE-Lab ( $L^{*}$ : luminosidad, $a^{*}$ : rojo-verde y $b^{*}$ : amarillo - azul).

\section{Condiciones de medición de las pastas comerciales}

La determinación de color se hizo sobre los espaguetis secos y cocidos, sobre una monocapa de fideos ordenados de manera paralela y adyacente, sobre un fondo negro.

\section{Condiciones de medición de las pastas frescas}

La determinación de color de las pastas frescas se hizo sobre la lámina de masa, reducida a su menor espesor, justo antes de ser cortada en fideos.

\section{Condiciones de medición de las pastas cocidas elaboradas con harina de amaranto y de soja}

El color de las pastas elaboradas con harina de amaranto y de soja se midió sobre 4 segmentos de fideos cocidos, colocados en paralelo, cubiertos con un vidrio de baja reflectancia. Las mediciones se realizaron en tres puntos diferentes (ubicando el espectrofotómetro en tres zonas diferentes de la superficie de los fideos a medir), repitiendo este procedimiento tres veces por lote, por nivel de sustitución (27 mediciones por nivel de sustitución). 


\section{Textura de las pastas}

La textura es la respuesta primaria del sentido del tacto a los estímulos físicos provocados por el contacto entre una parte del cuerpo y un alimento. El sentido del tacto es el método principal para evaluar la textura, pero la kinestesia (sensación de movimiento y posición), la vista (grado de depresión, velocidad de flujo) y el sonido (asociado con texturas suaves, crocantes y crujientes) también son utilizadas para evaluar la textura (Bourne, 2002).

El término "textura" es algo engañoso ya que la mayoría de los alimentos, incluyendo la pasta, exhiben más de un parámetro de textura. Por lo tanto, es preferible utilizar el término "propiedades de textura" ya que este término incluye más de único parámetro (Marchylo et al., 2004).

Las propiedades de textura de un alimento son ese grupo de características físicas que: 1) surgen de los elementos estructurales de los alimentos, 2) que se perciben sobre todo por la sensación del tacto, 3) que se relacionan con la deformación, la desintegración y el flujo del alimento provocado por la aplicación de una fuerza y 4) que son medidas objetivamente por medio de funciones de masa, tiempo y distancia (Bourne, 2002).

La textura de la pasta cocida es el principal criterio para evaluar la calidad global de la pasta, y desempeña un papel dominante en la aceptación del consumidor. Las principales propiedades de textura en la pasta cocida incluyen firmeza, elasticidad, integridad de la superficie y ausencia de una superficie pegajosa (Marchylo et al., 2004).

Si la textura de un alimento está de acuerdo con la manera en que la gente ha aprendido que sea y es psicológica y fisiológicamente aceptable, entonces apenas se notará. Sin embargo, si la textura no es lo que se espera que sea, se convierte en un punto central para la crítica y el rechazo de ese alimento (Bourne, 2002).

La preferencia de los consumidores en la textura de las pastas varía alrededor del mundo; sin embargo lo que primero viene a la mente cuando se habla de pastas es la tradición italiana de una textura "al dente", caracterizada por un alto grado de firmeza y elasticidad (Marchylo et al., 2004).

Szczesniak (1963) clasificó las características texturales de los alimentos en propiedades mecánicas y geométricas por un lado y por otro, en aquellas relacionadas con el contenido de grasa y la humedad del alimento. Las características mecánicas son los parámetros relacionados con la reacción de los alimentos ante la aplicación de una fuerza. Se incluyen cinco parámetros principales (dureza, cohesividad, viscosidad, elasticidad y pegajosidad) y tres parámetros secundarios (fracturabilidad, masticabilidad y gomosidad), que son compuestos de 
los parámetros primarios. Las características geométricas están relacionadas con la disposición geométrica de la matriz del alimento y se dividen en dos clases: las relacionadas con el tamaño y la conformación de la partícula y las referidas con la forma y la orientación de la partícula (Marchylo et al., 2004).

Este sistema de clasificación fue desarrollado con el fin de servir de base para la medición sensorial e instrumental de la textura de los alimentos; constituyendo el fundamento del análisis del perfil de textura (TPA), el cual intenta medir las propiedades de textura de un alimento de una manera integral (Marchylo et al., 2004).

De acuerdo al sistema de clasificación propuesto por Szczesniak (1963), la textura de la pasta cocida puede ser definida por los parámetros mecánicos que figuran en la Tabla M.3.

La medición de las propiedades de textura de la pasta cocida debe ser cuidadosamente estandarizada con el fin de proporcionar resultados significativos y reproducibles. Los factores más importantes a considerar son: el tiempo de cocción, la relación pasta agua, la dureza y el $\mathrm{pH}$ del agua de la cocción y el tiempo transcurrido desde que se retira la pasta del agua de cocción y la realización del ensayo (Marchylo et al., 2004). Se ha demostrado que éste último afecta a la firmeza y a pegajosidad de la pasta, mientras que la dureza del agua afecta la pegajosidad de la superficie (Dexter et al., 1983; Malcolmson \& Matsuo, 1993).

Tabla M.3 - Propiedades mecánicas de las pastas cocidas (Adaptadas por Szczesniak, 1963; Marchylo et al., 2004).

Dureza/Firmeza
(Hardness/firmness) Fuerza necesaria para alcanzar una dada deformación.

Cohesividad

(Cohesiveness)

Elasticidad/Elasticidad instantánea (Elasticity/springiness)

Adhesividad/pegajosidad (Adhesiveness/Stickiness)

Medida en que un material puede deformarse antes de su ruptura.

Grado en que un material deformado vuelve a su estado no deformado luego de que la fuerza deformante es removida.

Trabajo necesario para superar las fuerzas de atracción entre la superficie del alimento y la superficie de otro material que haya entrado en contacto con el alimento.

Masticabilidad (Chewiness)

Energía requerida para reducir el alimento a un estado listo para ser tragado. Es producto de la dureza, de la cohesividad y de la pegajosidad.

\section{Textura de las pastas secas}

La textura de las pastas secas fue medida en términos de fracturabilidad, empleando la sonda HDP/3PB (Figura M.5), modo de ensayo: medida de fuerza de compresión, vuelve al 
inicio; velocidad pre-ensayo: $2,0 \mathrm{~mm} / \mathrm{s}$, velocidad de ensayo: $3,0 \mathrm{~mm} / \mathrm{s}$, velocidad post-ensayo: 10,0 mm/s, distancia de deformación: 5,0 mm, trigger: $15 \mathrm{~g}$.

Las mediciones se realizaron sobre un segmento de fideo seco apoyado sobre los dos brazos inferiores de la sonda, realizando 6 repeticiones por lote, por nivel de sustitución (18 mediciones por nivel de sustitución).

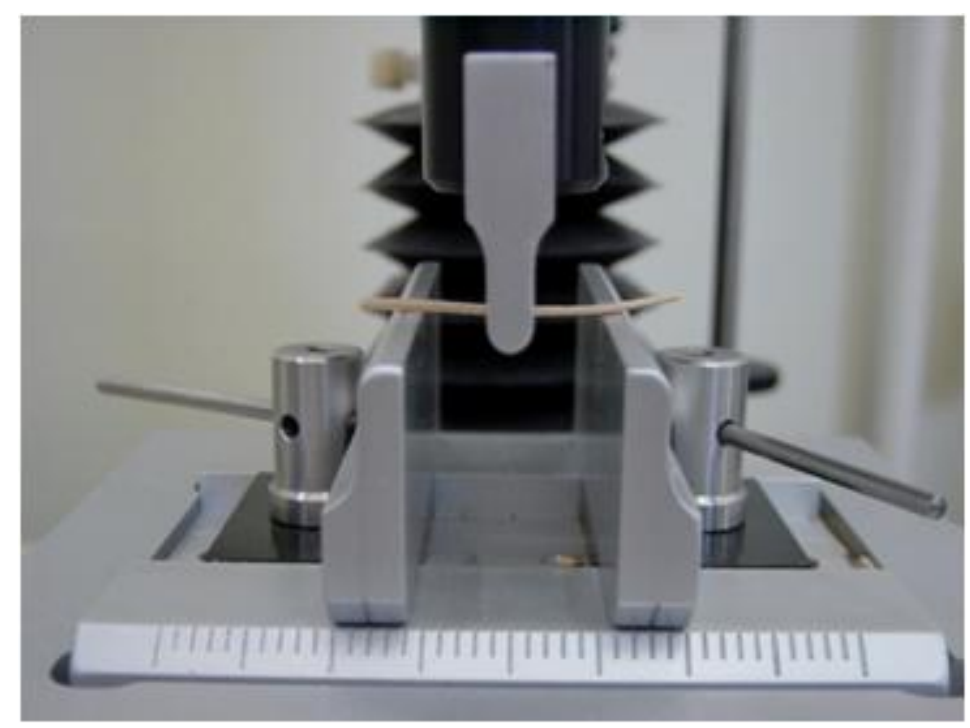

Figura M.5 - Sonda HDP/3PB Three Point Bend Rig, usada para medir fracturabilidad de las pastas secas elaboradas con harina de amaranto y con harina de soja.

\section{Textura de las pastas cocidas}

\section{Condiciones generales del ensayo}

El análisis instrumental de textura se realizó en base a Approved Methods 16-50 Pasta Cooking Quality - Firmness (AACC, 1995), utilizando para ello un texturómetro, TA-XT2i Texture Analyzer (Stable Micro Systems, UK), equipado con una celda de carga de $25 \mathrm{~kg}$ y software Texture Expert 1.22, evaluando los siguientes parámetros: firmeza, pegajosidad, cohesividad, elasticidad, masticabilidad (chewiness) y resiliencia. Cinco gramos de fideos cortados en segmentos de $5 \mathrm{~cm}$ longitud, cocinados hasta su TOC en $200 \mathrm{~mL}$ de agua destilada en ebullición, se enjuagaron con $50 \mathrm{~mL}$ de agua destilada a temperatura ambiente y se colocaron en un vaso de precipitado con $100 \mathrm{~mL}$ de agua destilada dentro de un baño de hielo hasta el momento de su medición. Al momento del análisis, los segmentos de fideos cocidos se colocaron sobre la base del texturómetro de manera paralela, adyacentes entre sí y perpendicular a la sonda, previo secado del agua de la superficie por medio de un papel absorbente. 


\section{Condiciones particulares para la evaluación de textura de las pastas comerciales}

Para la medición de firmeza se utilizó una sonda Blade HDP/BS, modo de ensayo: medida de fuerza de compresión, vuelve al inicio; velocidad pre-ensayo: 0,50 mm/s, velocidad de ensayo: 0,17 mm/s, velocidad post-ensayo: $10,0 \mathrm{~mm} / \mathrm{s}$, distancia $70 \%$ deformación, trigger: 20 g; sobre cinco segmentos de fideos en dos posiciones diferentes de la superficie expuesta. La muestra fue preparada por duplicado y a partir de cada preparación se realizaron 5 ensayos, alcanzando un total de 20 repeticiones. La determinación de firmeza se hizo, además de al TOC, a tiempos de cocción del 50 y 100\% mayor al TOC.

La determinación de firmeza, masticabilidad (chewiness) y elasticidad se realizó de acuerdo a Tang et al.(1999), empleando una sonda HDP/PFS Pasta Firmness/Stckiness; modo de ensayo: medida de fuerza de compresión, repite $\mathrm{n}$ veces; velocidad pre-ensayo: 2,00 mm/s, velocidad de ensayo: $2,00 \mathrm{~mm} / \mathrm{s}$, velocidad post-ensayo: $2,00 \mathrm{~mm} / \mathrm{s}$, distancia $70 \%$ deformación, contador 2, trigger: $40 \mathrm{~g}$, colocando cinco segmentos de fideos sobre la base del texturómetro, de manera paralela al lado mayor de la sonda. Mientras que para la medición de pegajosidad se utilizó una sonda HDP/PFS Pasta Firmness/Stckiness, modo de ensayo: test de Adhesividad, velocidad pre-ensayo: $1,00 \mathrm{~mm} / \mathrm{s}$, velocidad de ensayo: $0,5 \mathrm{~mm} / \mathrm{s}$, velocidad post-ensayo: 10,00 mm/s, distancia $90 \%$ deformación, fuerza: $5000 \mathrm{~g}$, tiempo $2 \mathrm{~s}$, trigger: $40 \mathrm{~g}$. Todas las muestras fueron preparadas por duplicado, realizando 5 ensayos sobre cada preparación, alcanzando un total de 10 repeticiones.

\section{Condiciones particulares para la evaluación de textura de las pastas frescas}

Para la determinación de firmeza, masticabilidad y pegajosidad se empleó una sonda Blade HDP/BS, modo de ensayo: medida de fuerza de compresión, ciclos 2; velocidad pre-ensayo: 0,50 mm/s, velocidad de ensayo: $0,1 \mathrm{~mm} / \mathrm{s}$, velocidad post-ensayo: $1,0 \mathrm{~mm} / \mathrm{s}$, distancia $70 \%$ deformación, trigger: 0,2 N. La muestra fue preparada por duplicado y a partir de cada preparación se realizaron 5 ensayos, con lo cual se alcanzó un total de 10 repeticiones.

Condiciones particulares para la evaluación de textura de las pastas elaboradas con harina de amaranto y con harina de soja

\section{Ensayo 1}

Los parámetros de firmeza, pegajosidad, cohesividad, elasticidad, masticabilidad (chewiness) y resiliencia fueron calculados a partir de un análisis del perfil de textura obtenido 
a partir de dos ciclos de 70\% de deformación, empleando la sonda HDP/BS del lado romo de la guillotina; modo de ensayo: medida de fuerza de compresión, repite $\mathrm{n}$ veces; velocidad preensayo: $1,00 \mathrm{~mm} / \mathrm{s}$, velocidad de ensayo: $0,50 \mathrm{~mm} / \mathrm{s}$, velocidad post-ensayo: $2,00 \mathrm{~mm} / \mathrm{s}$, trigger: $20 \mathrm{~g}$, sobre un segmento de fideo cocido hasta su TOC; realizando 12 mediciones para cada uno de los tres lotes, para cada nivel de sustitución.

\section{Ensayo 2}

Los parámetros de firmeza, pegajosidad, cohesividad, elasticidad, masticabilidad (chewiness) y resiliencia fueron calculados a partir de un análisis del perfil de textura obtenido a partir de dos ciclos de $70 \%$ de deformación, empleando la sonda HDP/PFS Pasta Firmness /Stickiness Rig (Figura M.6); modo de ensayo: medida de fuerza de compresión, repite 2 veces; distancia: $70 \%$; velocidad pre-ensayo: $1,0 \mathrm{~mm} / \mathrm{s}$, velocidad de ensayo: $0,50 \mathrm{~mm} / \mathrm{s}$, velocidad post-ensayo: 2,0 mm/s, trigger: $20 \mathrm{~g}$; sobre 3 segmentos de fideos cocidos hasta su TOC, realizando 5 mediciones para cada uno de los tres lotes elaborados, para cada nivel de sustitución (15 mediciones por nivel de sustitución).

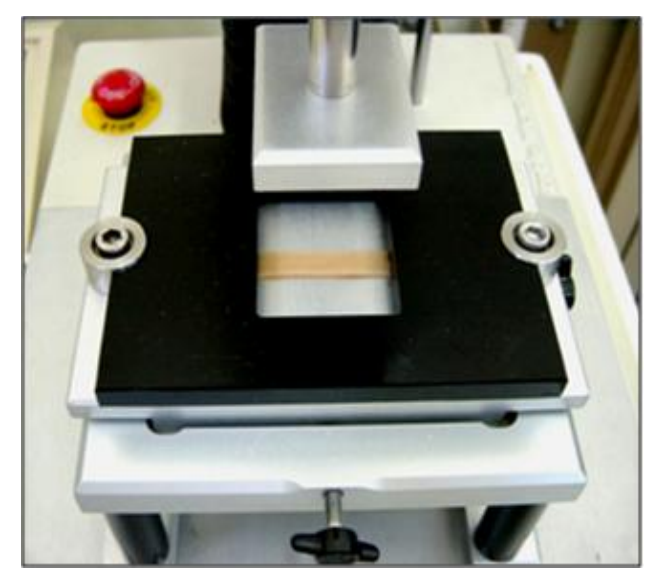

Figura M.6 - Sonda HDP/PFS Pasta Firmness Stickiness Rig, usada para la determinación de textura de las pastas cocidas.

\section{Reología de las pastas cocidas}

\section{Principio}

La Reología es la ciencia del flujo que estudia la deformación de un cuerpo sometido a esfuerzos externos. Es la parte de la mecánica que estudia la elasticidad, la plasticidad y la viscosidad de la materia. La reología es la ciencia del flujo y la deformación (Ramírez Navas, 2006). 
Las propiedades reológicas de un alimento pueden expresarse en términos de funciones viscosas, elásticas y viscoelásticas, que relacionan el esfuerzo con la deformación. El esfuerzo, definido como una fuerza sobre unidad de área y expresado generalmente en $\mathrm{Pa}\left(\mathrm{N} / \mathrm{m}^{2}\right)$, puede producirse por tensión, compresión o corte, mientras que la deformación, medida adimensional, es la proporción de cambio de longitud de deformación con la longitud original del material cuando se aplica un esfuerzo. La derivada de la deformación con respecto al tiempo da la velocidad de deformación, la cual se expresa en $\mathrm{s}^{-1}$. Las funciones de viscosidad se utilizan generalmente para relacionar el esfuerzo con la velocidad de corte, mientras que las funciones de elasticidad relacionan el esfuerzo con la deformación de materiales sólidos (Rodríguez Sandoval et al., 2005).

Las masas elaboradas a partir de harina de trigo son materiales viscoelásticos y sus propiedades reológicas dependen de su composición y de las condiciones de proceso utilizadas en su elaboración (Rodríguez Sandoval et al., 2005). El comportamiento reológico de las masas se puede conocer a través de dos tipos de técnicas de medición; las de tipo fundamental y las de tipo empírico. Los métodos empíricos, como el farinógrafo, mixógrafo, extensógrafo, ofrecen información útil y práctica para la industria de la panadería y molinería; sin embargo no dan suficiente información para interpretar el comportamiento fundamental de la reología de la masa de trigo porque utilizan medidas arbitrarias propias de cada equipo (Rodríguez Sandoval et al., 2005).

Si un material sólido responde a una carga aplicada deformándose levemente y recuperando su forma original cuando se remueve la carga, se dice que presenta un comportamiento elástico. Los materiales elásticos ideales se comportan de acuerdo a la ley de Hooke, la cual describe la proporcionalidad directa entre el esfuerzo normal y la deformación, de acuerdo a la Ecuación 1:

$$
\sigma=\mathrm{E} . \varepsilon \quad(\mathrm{Ec} .1),
$$

donde $\sigma$ : esfuerzo de deformación (Pa), E: módulo de deformación (Pa.s) y $\varepsilon$ : velocidad de deformación ( $\mathrm{s}^{-1}$ ) (Rodríguez Sandoval et al., 2005).

Si un fluido se deforma cuando se le aplica una carga y no recupera su forma original cuando la carga se remueve, se dice que presenta un comportamiento viscoso. El flujo de un sistema viscoso simple se describe con la ley de Newton de acuerdo a la Ecuación 2:

$$
\sigma=\eta \dot{\gamma} \quad(\text { Ec. } 2),
$$

donde $\eta$ : viscosidad aparente (Pa.s) y $\dot{y}$ : velocidad de corte $\left(\mathrm{s}^{-1}\right)$ (Rodríguez Sandoval et al., 2005). 
Numerosos alimentos, entre ellos las masas, se denominan viscoelásticos por su carácter combinado de viscosidad y elasticidad. Las funciones de los materiales viscoelásticos se pueden determinar utilizando experimentos que involucran la aplicación de deformaciones en estado no estacionario. Las medidas de corte en estado no estacionario suministran resultados dinámicos que se utilizan para evaluar la viscoelasticidad de los materiales (Rodríguez Sandoval et al., 2005).

Generalmente las técnicas dinámicas se han dividido en dos categorías: transientes y oscilatorias. Los métodos transientes incluyen pruebas de fluencia y esfuerzo de relajación. En una prueba de fluencia, el material se somete instantáneamente a un esfuerzo constante y la correspondiente deformación se mide como una función del tiempo. En una prueba de esfuerzo de relajación, la muestra se somete instantáneamente a una deformación constante y se registra el cambio de esfuerzo en función del tiempo. Los experimentos dinámicos, al efectuarse en estado no estacionario, generan datos que reflejan el comportamiento viscoelástico de un material (Rodríguez Sandoval et al., 2005).

Las pruebas dinámicas oscilatorias se realizan aplicando una pequeña deformación (o esfuerzo) sinusoidal, midiendo el esfuerzo (o deformación) resultante. Las pruebas oscilatorias pueden conducirse en tensión, compresión o corte. Para la evaluación del comportamiento viscoelástico de un alimento el más utilizado es el modo de deformación de corte. La deformación de corte puede generarse empleando configuración de platos paralelos, cono y plato o cilindros concéntricos (Rodríguez Sandoval et al., 2005).

Los ensayos con pequeñas amplitudes se utilizan en las pruebas dinámicas viscoelásticas. Las deformaciones utilizadas en las pruebas oscilatorias frecuentemente están en el orden del 1 al 3\%, para asegurar que la respuesta del material esté en el rango lineal, es decir en el intervalo en el cual el esfuerzo es linealmente proporcional a la deformación aplicada (Rodríguez Sandoval et al., 2005).

Si se supone que la muestra se localiza en un reómetro de platos con velocidad controlada y se somete a una pequeña amplitud oscilatoria, la deformación del material es función del tiempo, Ecuación 3:

$$
\gamma=\gamma_{0} \cdot \operatorname{sen}(\omega . t) \quad(\text { Ec. } 3),
$$

en donde $\gamma$ : deformación del material (adimensional), $\gamma_{0}$ : amplitud de la deformación (adimensional), $\omega$ : frecuencia angular dinámica $\left(\mathrm{rad} \mathrm{s}^{-1}\right)$ y $\mathrm{t}$ : tiempo de prueba (s) . 
La deformación aplicada genera dos componentes de esfuerzo en el material: un componente elástico en línea con la deformación, y un componente viscoso $90^{\circ}$ fuera de fase. Al derivar la (Ec. 3) con respecto al tiempo, se obtiene la velocidad de corte periódica (Ecuación 4), utilizada para evaluar el componente viscoso del material,

$$
\bar{\gamma}=\frac{d \gamma}{d t}=\gamma_{o} \cdot \omega \cdot \cos (\omega . t)
$$

donde $\bar{\gamma}$ : velocidad de corte periódica $\left(s^{-1}\right)$ y $d \gamma / d t$ :velocidad de deformación.

El esfuerzo producido por la aplicación de una fuerza sinusoidal a un material viscoelástico dentro de la región lineal se puede presentar como muestra la Ecuación 5:

$$
\sigma(t)=\gamma_{o} . G^{\prime}(\omega) \cdot \operatorname{sen}(\omega . t)+\gamma_{o} \cdot G^{\prime \prime}(\omega) \cdot \cos (\omega . t) \quad(\text { Ec. 5), }
$$

donde $\mathrm{G}^{\prime}$ : módulo de corte elástico o de almacenamiento ( $\mathrm{Pa}$ ) y $\mathrm{G}^{\prime \prime}$ : módulo de corte viscoso o de pérdida ( $\mathrm{Pa}$ ). G' es una medida de la energía almacenada y liberada por cada ciclo, y relaciona los eventos moleculares de naturaleza elástica. $G^{\prime \prime}$ es una medida de la energía disipada como calor y relaciona los eventos moleculares de naturaleza viscosa (Rodríguez Sandoval et al., 2005).

Otra propiedad viscoelástica comúnmente usada es la tangente del ángulo de fase o tangente de pérdida (Ecuación 6), la cual describe los efectos de los componentes viscosos y elásticos en el comportamiento viscoelástico, y también es función de la frecuencia angular;

$$
\tan (\delta)=\frac{G \prime \prime}{G^{\prime \prime}} \quad(\text { Ec. 6) }
$$

donde $\delta$ : ángulo de fase relativo a la deformación (rad).

\section{Realización del ensayo}

La viscosidad dinámica de las pastas cocidas fue medida usando un reómetro (Anton Paar, Physica MCR 301, Austria), geometría plato/plato, entre 0,5 y $10 \mathrm{~Hz}$, dentro de un rango de viscoelasticidad lineal (0,1\% de deformación). La determinación fue realizada sobre un fideo cocido tipo cinta de $28 \mathrm{~mm}$ de ancho, laminado especialmente para este ensayo, el cual fue colocado sobre la base del reómetro (Figura M.7-A); una vez alcanzado el gap de 1,5 mm, se cortó la pasta copiando la forma del plato de $25 \mathrm{~mm}$ de diámetro (Figura M.7-B) y sobre la superficie expuesta de la muestra se aplicó aceite mineral para evitar la deshidratación durante el ensayo (Figura M.7-C). Por medio del software Rheoplus/32 V3.10 se calcularon los datos de $G^{\prime}, G^{\prime \prime}, \tan \delta$ y viscosidad $\mu$. Los ensayos fueron realizados por triplicado para cada una de las muestras de los tres lotes laminados. 

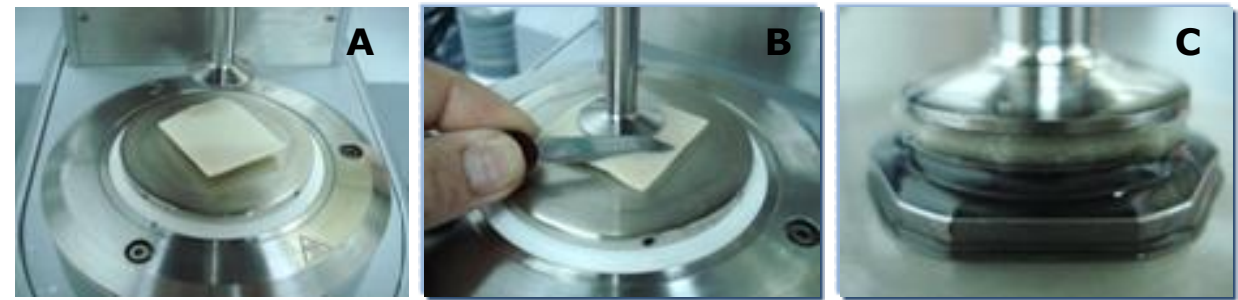

Figura M.7 - Medición de las propiedades reológicas de las pastas cocidas.

\section{Microscopía electrónica de barrido (SEM) de las pastas secas y cocidas}

\section{Principio}

El interés del hombre de poder visualizar cosas muy pequeñas lo llevó a desarrollar sistemas que le permitieran hacerlo. Es así como, hace aproximadamente 300 años con la invención del microscopio de luz, surgió la microscopía, la cual podemos definir como la ciencia de ver aquellos objetos que por tener dimensiones tan pequeñas, son imperceptibles a simple vista. Un microscopio es, básicamente, un sistema óptico que transforma un objeto en una imagen, la cual amplifica detalles característicos del objeto. El desarrollo del microscopio electrónico en la primera mitad de este siglo, provocó un cambio fundamental en la microscopía (Sorrivas \& Yánez, 2006).

Básicamente, los microscopios de luz y electrónico son esencialmente, idénticos. Tanto uno como otro nos permiten amplificar aquellos objetos que son indistinguibles al ojo humano. La diferencia fundamental entre los dos es la fuente de iluminación. Mientras que un microscopio de luz utiliza un haz de luz en el rango de las longitudes de onda del visible (2000 $\AA$ - $7500 \AA$ A), el microscopio electrónico emplea un haz de electrones de muy corta longitud de onda $(0,037 \AA-0,086 \AA$ ) que permite obtener una mayor resolución. Mientras que con el microscopio de luz se resuelven detalles del orden del micrón, con el microscopio electrónico se alcanza a resolver en el orden de los angstrom (Sorrivas \& Yánez, 2006).

En el microscopio electrónico, un haz de electrones incide sobre una muestra y de la interacción de estos electrones con los átomos de la misma, surgen señales que son captadas por algún detector o bien, proyectadas directamente sobre una pantalla.

Dentro de la familia de microscopios electrónicos, se encuentran el microscopio electrónico de transmisión (TEM) y el microscopio electrónico de barrido (SEM). Cada uno de ellos, permite el estudio de diferentes características de una muestra. EI SEM provee información sobre morfología y características de la superficie externa, mientras que con el TEM podemos observar la estructura interna y detalles ultraestructurales. 
El microscopio electrónico de barrido (SEM) consta básicamente de un cañón de electrones donde se genera el haz de electrones, lentes condensadoras, objetivo y sistema de vacío. En el SEM, el haz electrónico, atraviesa la columna y llega a la muestra. Un generador de barrido es el responsable de producir el movimiento del haz, de manera que barra la muestra punto a punto. De la interacción entre los electrones incidentes con los átomos que componen la muestra se generan señales, las cuales pueden ser captadas con detectores adecuados para cada una de ellas (Sorrivas \& Yánez, 2006).

\section{Realización del ensayo}

La microestructura de las pastas fue evaluada por medio de un microscopio electrónico de barrido (Jeol $35 \mathrm{CF}$, Japón), con un voltaje de aceleración de 6kV. Para la toma de las microfotografías, pequeñas porciones de las pastas, tanto crudas como cocidas hasta su TOC, fueron fijadas con glutaraldehído (1:30) durante $2 \mathrm{~h}$ y luego deshidratadas por inmersión en soluciones de acetona de concentraciones crecientes $(25,50,75,80$ y $100 \%)$ durante $20 \mathrm{~min}$, repitiendo el procedimiento en la solución de $100 \%$ de acetona un total de tres veces, a modo de asegurar una completa deshidratación. Luego las muestras fueron secadas por punto crítico, removiendo la acetona con $\mathrm{CO}_{2}$, con el cuidado de no generar tensiones superficiales que pudieran distorsionar la muestra. Las pastas así deshidratadas, fueron recubiertas con partículas de oro durante $4 \mathrm{~min}$. Las microfotografías fueron tomadas usando una magnificación de 128x, 500x, 1500x y 3000x, sobre cuatro zonas diferentes de la pasta, según se muestra en la Figura M.8.

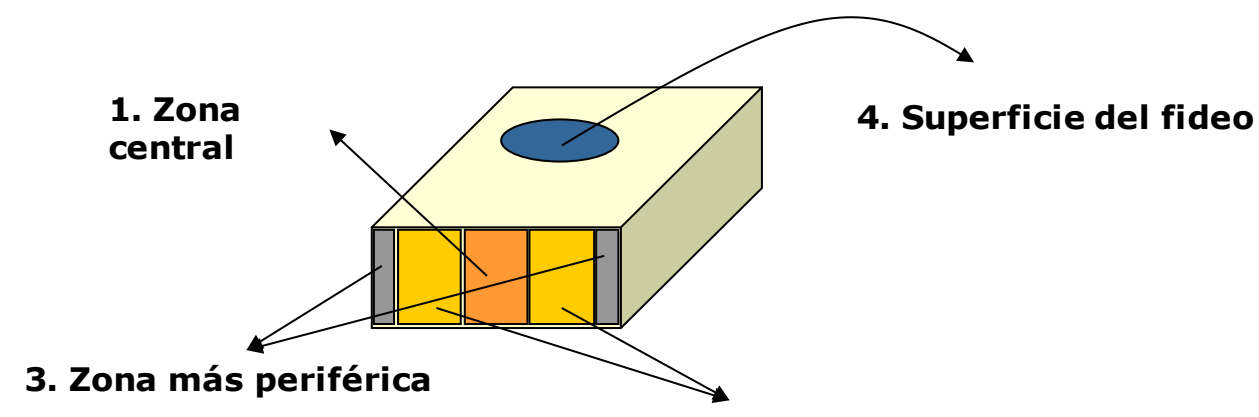

2. Zona de los extremos

Figura M.8 - Zona de la superficie y del corte transversal de un fideo que fueron definidas para la toma de imágines con SEM. 


\section{Determinación de isoflavonas por HPLC en las harinas y en las pastas cocidas}

La determinación de Isoflavonas se realizó sobre 50-60 mg de pastas cocidas, secas y molidas, una extracción hidro-alcohólica (etanol absoluto: agua, 60:40), durante 2 h, seguido de dos etapas de centrifugación de $10 \mathrm{~min}$ a 15,000 x g a $25^{\circ} \mathrm{C}$. El sobrenadante resultante se analizó por HPLC, empleando para ello una columna C8 Sephasil Peptide, $12 \mu$, ST 4,6/250, Pharmacia Biotech ${ }^{\circledR}$ y un gradiente no lineal generado con una fase móvil A: agua milli $Q$ con ácido acético $0,1 \%$ v/v y fase móvil $B$ : agua con ácido acético 0,1\% v/v: acetonitrilo, 50:50. Las isoflavonas determinadas fueron daidzina, malonil-daidzina, daidzeína, genistina, malonilgenistina, acetil genistina y genisteína.

\section{Determinación de escualeno por HPLC en las harinas y en las pastas cocidas}

\section{Preparación de las muestras}

Aproximadamente $10 \mathrm{~g}$ de pastas secas fueron cocinadas hasta su TOC, luego se congelaron por medio de aire líquido (punto de fusión: $-216,2^{\circ} \mathrm{C}$, punto de ebullición: $194,35^{\circ} \mathrm{C}$ ) y finalmente se liofilizaron (L-T8 Rificor, Argentina) durante $36 \mathrm{~h}$.

\section{Extracción de la fracción lipídica}

A $5 \pm 1$ g de pasta liofilizada y molida, se los colocó en un cartucho de papel de filtro, según AACC Method 30-26 (AACC, 1995) para ser sometidos a la extracción de la fracción lipídica por medio de un sistema tipo Soxhlet, con $170 \mathrm{~mL}$ de hexano (pro análisis, ACS, Sintorgan SIN088003-01, Argentina) durante $5 \mathrm{~h}$. Una vez eliminado el solvente por medio de un evaporador rotatorio a presión reducida (R110 Büchi, Suiza), la materia grasa fue recuperada del balón de extracción, con tres porciones sucesivas de 3,2 y $1 \mathrm{~mL}$ de hexano y colocada en un tubo de ensayo (Figura M.9-A).

\section{Extracción en fase sólida (SPE)}

La materia grasa recuperada fue sometida a una extracción en fase sólida por medio de un cartucho de sílica (SPE Si $1000 \mathrm{mg} / 6 \mathrm{~mL}$, Teknokroma Finisterre, España), utilizando una bomba tipo Venturi y un kitasato para realizar el vacío. El cartucho fue activado con $6 \mathrm{~mL}$ de hexano (Figura M.9-B), luego se colocó la muestra (Figura M.9-C), lavando el tubo de ensayo con tres porciones sucesivas de $1 \mathrm{~mL}$ de hexano y finalmente se lavó el cartucho con $6 \mathrm{~mL}$ de hexano 
(Figura M.9-D). El extracto fue trasvasado cuantitativamente a un balón de $50 \mathrm{~mL}$, para evaporar el solvente a presión reducida (Figura M.9-E), para lo cual se lavo el kitasato con tres porciones sucesivas de 2, 2, y $1 \mathrm{~mL}$ de hexano respectivamente. El residuo resultante fue recuperado con la mezcla de solventes utilizada como fase móvil, llevando a un volumen final de $10 \mathrm{~mL}$. Antes de ser inyectados en el HPLC el extracto fue filtrado con una membrana de nylon de 0,45 $\mu \mathrm{m}$ (Y04047WPH Microclar, Argentina), (Figura M.9-F y G).

\section{Determinación por HPLC}

Para la determinación del escualeno se utilizó un HPLC compuesto por una bomba LC20AT, una unidad controladora SCL-10A VP, un horno CTO-10 AS VP, un detector PDA SPDM20A Shimadzu ${ }^{\circledR}$ (Japón); siendo todas las unidades operadas a través del software LC solution V. 1.22 SP1, Shimadzu ${ }^{\circledR}$ (Japón), con el cual se realizaron las corridas cromatográficas, y se integraron los cromatogramas obtenidos. La columna utilizada fue del tipo C18, Microsorb-MV100, tamaño de partícula de $5 \mu$, de $150 \mathrm{~mm}$ de largo y 4,6 mm de diámetro, Varian $^{\circledR}$ (Estados Unidos), mantenida a $26{ }^{\circ} \mathrm{C}$. El solvente de elución fue acetonitrilo:2propanol:hexano, 72:17:11 (Acetonitrilo: ACS Gold para HPLC, 421375, Carlo Erba, Italia; 2propanol: grado HPLC, SIN-026008-01 Sintorgan, Argentina; hexano: pro análisis ACS, SIN088003-01 Sintorgan, Argentina), a una velocidad de flujo de $1 \mathrm{~mL} / \mathrm{min}$ y el volumen de inyección fue $20 \mu \mathrm{L}$. La detección del compuesto fue realizada a $205 \mathrm{~nm}$.

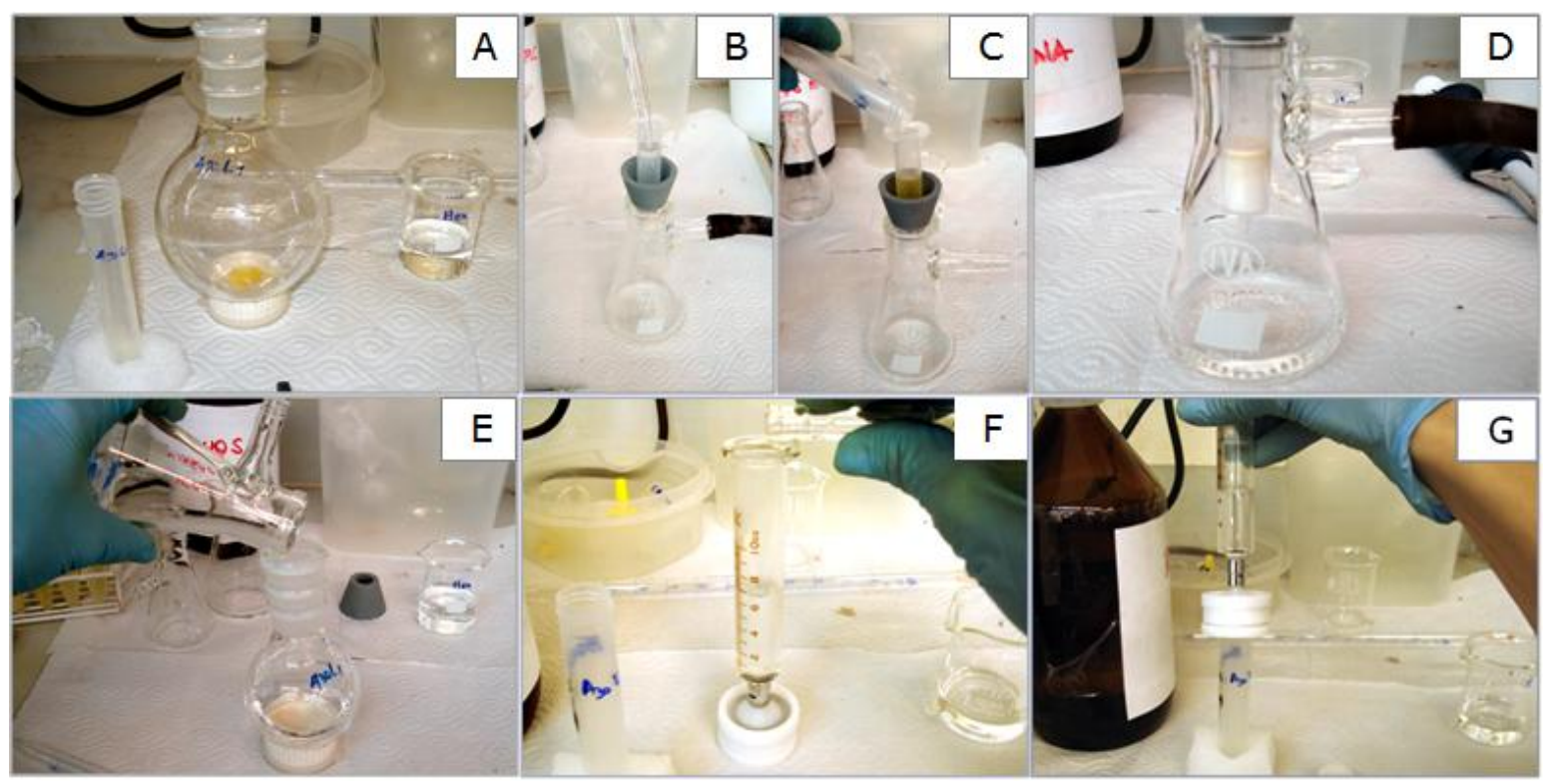

Figura M.9- Preparación de la muestra para la determinación de Escualeno. 


\section{Identificación y cuantificación}

Para la identificación y cuantificación se utilizó un estándar de escualeno (S3626 SigmaAldrich, Estados Unidos). La identificación se hizo por comparación de espectros y evaluación de la pureza del pico, mientras que para la cuantificación se prepararon soluciones de 15,56; 31,12; 46,68; 77,$8 ; 155,6 \mu \mathrm{g} / \mathrm{mL}$ de escualeno, con las que, a partir un análisis de regresión lineal, se determinó la concentración de escualeno en las muestras analizadas. Las corridas cromatográficas se realizaron por duplicado, para cada una de las muestras de los tres lotes laminados.

\section{Almidón resistente, soluble y total}

La determinación de almidón resistente se realizó de acuerdo a AOAC 2002.02, AACC 3240, utilizando el kit de ensayo K-RStar, (Megazyme International Ireland Ltd., Bray, Ireland).

\section{Principio del método}

La muestra se incuba con la enzima pancreática, $\alpha$-amilasa y amiloglucosidasa, durante 16 h a $37^{\circ} \mathrm{C}$, para que el almidón no resistente se solubilice y se hidrolice a D-glucosa. La reacción se detiene con etanol $50 \%$ y el AR se recupera como un precipitado, luego de centrifugar la muestra, el precipitado se disuelve con $\mathrm{KOH} 2 \mathrm{M}$. Finalmente este almidón es cuantitativamente hidrolizado a glucosa por medio de la enzima amiloglucosidasa. Tanto la Dglucosa proveniente del almidón soluble como la del almidón resistente se cuantifican por medio de una reacción de color con el reactivo glucosa oxidasa/peroxidasa que se mide espectrofotométricamente.

\section{Preparación de las muestras}

Las pastas secas cocidas hasta SU TOC, se congelaron por medio de aire líquido (punto de fusión: $-216,2^{\circ} \mathrm{C}$, punto de ebullición:- $194,35^{\circ} \mathrm{C}$ ) para ser luego liofilizadas (L-T8 Rificor, Argentina) durante 48 h. El grado de deshidratación alcanzado en las muestras fue corroborado por la determinación de humedad de acuerdo al método AACC 44-19 (AACC, 1995). Finalmente las muestras liofilizadas fueron molidas hasta pasar por un tamiz con una malla de apertura $\leq 1000 \mu \mathrm{m}$. 


\section{Realización del ensayo}

Por razones de disponibilidad de reactivos, todas las cantidades del kit utilizado fueron reducidas a la mitad. Se pesaron en tubos plásticos con tapa hermética de $10 \mathrm{~mL}$ de capacidad, al los que se le registró el peso vacío (P1); $50 \pm 2$ mg de muestra preparada como se detalló anteriormente cuidando que esta quedara en el fondo del tubo. Luego se agregó $4,0 \mathrm{~mL}$ de una solución de $\alpha$-amilasa pancreática $(10 \mathrm{mg} / \mathrm{mL}$ ), (Pancreatin $10 \mathrm{~g}$, 3 Ceralpha units $/ \mathrm{mg}$ ) y de amiloglucosidasa $(3 \mathrm{U} / \mathrm{mL}$ ), ambas provistas por el kit K-RStar, Megazyme International (Ireland Ltd., Bray, Ireland), se tapó el tubo, se mezcló el contenido por agitación en vortex (Fbr ${ }^{\circledR}$ Decalab, Argentina) y se lo colocó horizontalmente en un baño de agua con agitación (Vicking Dufnoff 5002, Argentina), alineado con la dirección del movimiento (Figura M.10-A). Las muestras fueron incubadas durante exactamente $16 \mathrm{~h}$, a $37{ }^{\circ} \mathrm{C}$, con un movimiento continuo de 200 golpes/min (100 golpes hacia adelante y 100 golpes hacia atrás). Una vez alcanzado el tiempo de incubación, se retiraron los tubos, se les agregó 2,0 $\mathrm{mL}$ de etanol absoluto (Cicarelli, cód. 752110), se los agitó muy vigorosamente con un vortex y se los centrifugó (centrífuga Cavour VT 3216, Argentina) a 1500 x g durante 10 min a $25{ }^{\circ} \mathrm{C}$. Cuidadosamente se recuperaron los sobrenadantes en matraces de $100 \mathrm{~mL}$ (Figura M.10-B). A los precipitados resultantes se les agregó en $1 \mathrm{~mL}$ de etanol 50\% v/v mediante una vigorosa agitación con vortex y antes de volver a centrifugar a 1500 x g, $10 \mathrm{~min}$ a $25^{\circ} \mathrm{C}$. Se les adicionó 3 $\mathrm{mL}$ más de etanol $50 \% \mathrm{v} / \mathrm{v}$. Nuevamente se recuperaron los sobrenadantes en lo matraces de $100 \mathrm{~mL}$. Para resuspender y disolver los precipitados obtenidos en el último paso de centrifugación, a cada tubo se le añadió una barrita magnética ( $5 \times 10 \mathrm{~mm}$ ) más $1 \mathrm{~mL}$ de $\mathrm{KOH}$ $2 \mathrm{M}$, y se los agitó durante $20 \mathrm{~min}$ en un baño de agua con hielo sobre un agitador magnético (Figura M.10-C). A cada tubo se le agregó entonces $4 \mathrm{~mL}$ de buffer acetato de sodio 1,2 M (pH 3,8 ), se los agitó, e inmediatamente se les añadió $50 \mu \mathrm{L}$ de solución de amiloglucosidasa (3300 $\mathrm{U} / \mathrm{mL}$ ), provista por el kit K-RStar Megazyme, previa agitación se incubaron en el baño de agua a $50{ }^{\circ} \mathrm{C}, 30 \mathrm{~min}$, retirando las muestras cada $5 \mathrm{~min}$ y agitándolas con el vortex. Una vez alcanzado el tiempo de incubación, los tubos fueron centrifugados en las condiciones antes mencionadas y una vez que alcanzaron temperatura ambiente fueron pesados (P2) para estimar su volumen final (P2-P1), considerando despreciable el aporte de volumen por la muestra. A partir de cada tubo, por duplicado, se tomó una alícuota de $100 \mu \mathrm{L}$ del sobrenadante y se la colocó en un tubo de ensayo pequeño $(\varnothing 16 \mathrm{~mm}$, alto $150 \mathrm{~mm}$ ), en donde se le agregó además $3 \mathrm{~mL}$ del reactivo de glucosa oxidasa (GOP, provisto por el kit K-RStar, Megazyme) y se incubaron a $50{ }^{\circ} \mathrm{C}$ durante $20 \mathrm{~min}$. Después que los tubos alcanzaron temperatura ambiente, se midió la absorbancia de la solución a $510 \mathrm{~nm}$ (Espectrofotómetro 
Spectrum SP 2000 Vis, China) contra blanco de reactivo (buffer acetato de sodio $100 \mathrm{mM} \mathrm{(pH}$ 4,5) (Figura M.10-D). La cuantificación se realizó por comparación con la absorbancia resultante de una solución estándar de glucosa $(1 \mathrm{mg} / \mathrm{mL}$ ) (D-Glucose standard solution, provisto por el kit K-RStar, Megazyme), a la que, por cuadriplicado, se le realizó la misma reacción de color que para las muestras.

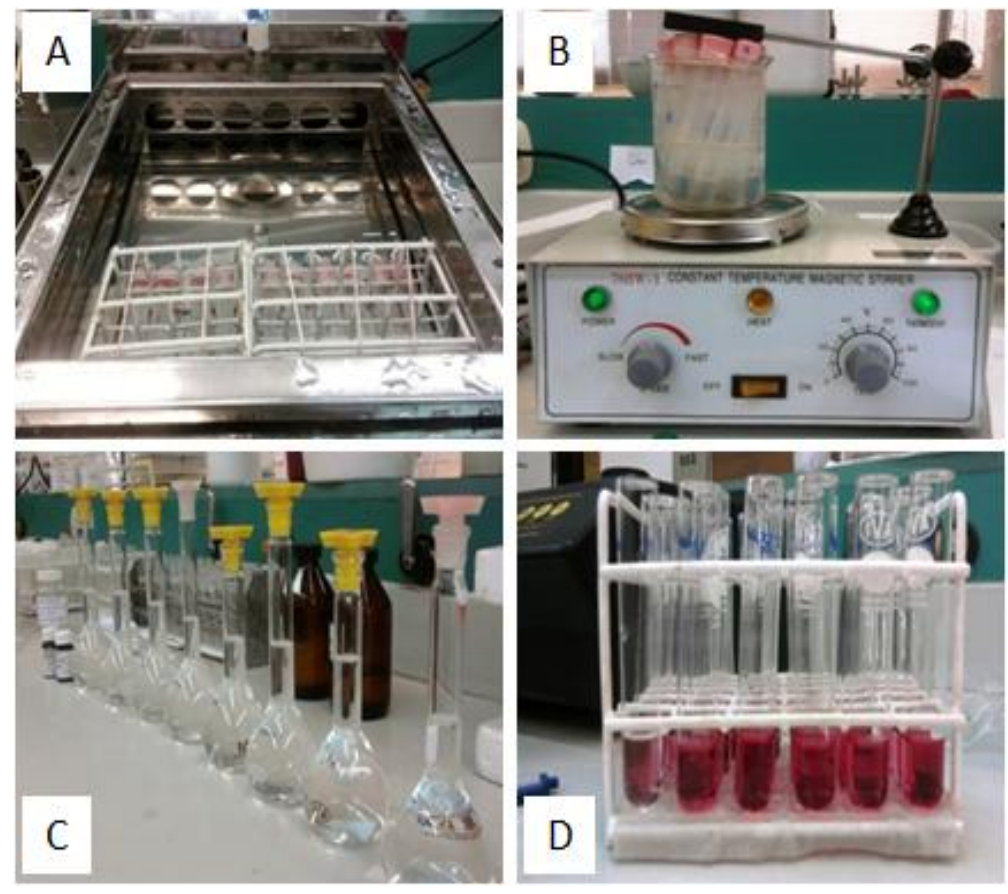

Figura M.10 - Determinación de almidón resistente.

Para la cuantificación del almidón soluble, una vez completado el volumen del matraz a $100 \mathrm{~mL}$ con buffer acetato de sodio $100 \mathrm{mM}$ (pH 4,5); por duplicado, se tomaron alícuotas de $100 \mu \mathrm{L}$, a las que se les agregó $3 \mathrm{~mL}$ del reactivo GOP para realizar la misma reacción de color que se describió anteriormente. El contenido de almidón total se obtuvo como la suma del contenido del almidón resistente más el de almidón soluble.

La determinación de D-glucosa se basa en que ésta se oxida por acción de la enzima glucosa oxidasa para dar ácido glucónico y peróxido de hidrógeno y luego el peróxido de hidrógeno reacciona en presencia de peroxidasa con el ácido 4-hidroxibenzoico y con la 4aminoantipiridina para dar lugar a un tinte de quinonimina rojo (Figura M.11). La intensidad del color formado es proporcional a la concentración de glucosa y se puede medir fotométricamente entre 460 y 560 nm (Thermo Fisher Scientific Inc., 2009). 


\section{Glucosa oxidasa}

1. Glucosa + $\mathrm{O} 2+\mathrm{H} 2 \mathrm{O}---------\longrightarrow$ Ácido glucónico + $\mathrm{H} 2 \mathrm{O} 2$

Peroxidasa

2. $\mathrm{H} 2 \mathrm{O} 2+\mathrm{HBA}+4-\mathrm{AAP}-------\longrightarrow$ Tinte de quinonimina + $\mathrm{H} 2 \mathrm{O}$

Figura M.11 - Reacción de color para la determinación de Glucosa.

\section{Digestibilidad del almidón}

\section{Realización del ensayo}

La digestión in vitro de almidón se realizó de acuerdo a la técnica de Brennan et al. (2004) con algunas modificaciones, mientras que los cálculos se realizaron de acuerdo a lo descripto por Goñi et al. (1997).

\section{Preparación de la muestra}

En un tubo tipo Falcon de $50 \mathrm{~mL}$ previamente tarado, se pesó 1,7 g (al 0,1 mg) de fideos secos (peso de fideos secos, P1) los que se cocinaron hasta su TOC y luego de ser enjuagados con $25 \mathrm{~mL}$ de agua destilada y escurridos por $20 \mathrm{~s}$, se volvieron a colocar en el mismo tubo Falcon para volver a registrarles el peso, una vez que éstos alcanzaran temperatura ambiente (peso de fideo cocido, P2). Una muestra de pan blanco (Figura M.12-A), preparada con la misma harina de trigo empleada en las pastas, fue analizada en paralelo para ser tomada como alimento de referencia. Para evitar que el almidón retrograde e interfiera en el proceso de hidrólisis, el tiempo desde que los panes fueron retirados del horno y la realización del ensayo no superó los $60 \mathrm{~min}$.

Para simular la masticación, la muestra se disgregó con el émbolo de un homogeneizador manual para tejidos (Cole Parmer, Glass Vessel; 50 mL, EW-44468-18, USA) dentro del mismo tubo Falcon (Figura M.12-B), durante $1 \mathrm{~min}$, previo el agregado de $5 \mathrm{~mL}$ de buffer fosfato $\mathrm{pH}$ 6,9. Antes de retirar el émbolo del homogeneizador, se lo lavó con $15 \mathrm{~mL}$ adicionales de buffer fosfato $\mathrm{pH}$ 6,9 (Figura M.12-C), y se llevó la muestra a pH 1,5 con HCl 8M (Figura M.12-D). Luego se agregó $5 \mathrm{~mL}$ de solución de pepsina $115 \mathrm{U} / \mathrm{mL}$ (Figura M.12-E), (pepsina de mucosa gástrica porcina, Sigma Aldrich P7000, 077K0661, 424 units/mg solid, disuelta en buffer de Na y $\mathrm{K} \mathrm{pH} \mathrm{1,5)} \mathrm{y} \mathrm{se} \mathrm{colocaron} \mathrm{las} \mathrm{muestras} \mathrm{en} \mathrm{un} \mathrm{baño} \mathrm{con} \mathrm{agitación} \mathrm{(Vikinf} \mathrm{Dufnoff} \mathrm{5002,}$ Argentina) a $37{ }^{\circ} \mathrm{C}$ (Figura M.12-F). Después de $30 \mathrm{~min}$ de incubación, se llevó el pH de las muestras a pH 6,9 (Figura M.12-G), con $\mathrm{NaOH} 4 \mathrm{M}$ y $\mathrm{NaOH} 10 \% \mathrm{p} / \mathrm{v}$ completando a $50 \mathrm{~mL}$ con 
buffer fosfato $\mathrm{pH}$ 6,9. El contenido de tubo se homogeneizó por medio de un vortex (Fbr ${ }^{\circledR}$ Decalab, Argentina) e inmediatamente se tomaron por duplicado alícuotas de $1 \mathrm{~mL}$, las que fueron colocadas en tubos ependorf. Estas primeras alícuotas fueron consideradas como blanco de muestra (tiempo $0 \mathrm{~min}$ ). Al tubo de muestra, con un volumen remanente de $48 \mathrm{~mL}$, se le agregó $1 \mathrm{~mL}$ de $\alpha$-amilasa $110 \mathrm{U} / \mathrm{mL}$ ( $\alpha$-amylase type VI B: from porcine pancreas A3176 $500 \mathrm{KU}$, Sigma 058K1053, 27 units/mg solid, disuelta en buffer fosfato pH 6,9) y se lo colocó en baño de agua con agitación a $37{ }^{\circ} \mathrm{C}$ durante $3 \mathrm{~h}$ (Figura M.12-H), tomando cada 30 min por duplicado, alícuotas de 0,50 mL, las que también fueron colocadas en sendos tubos ependorf.

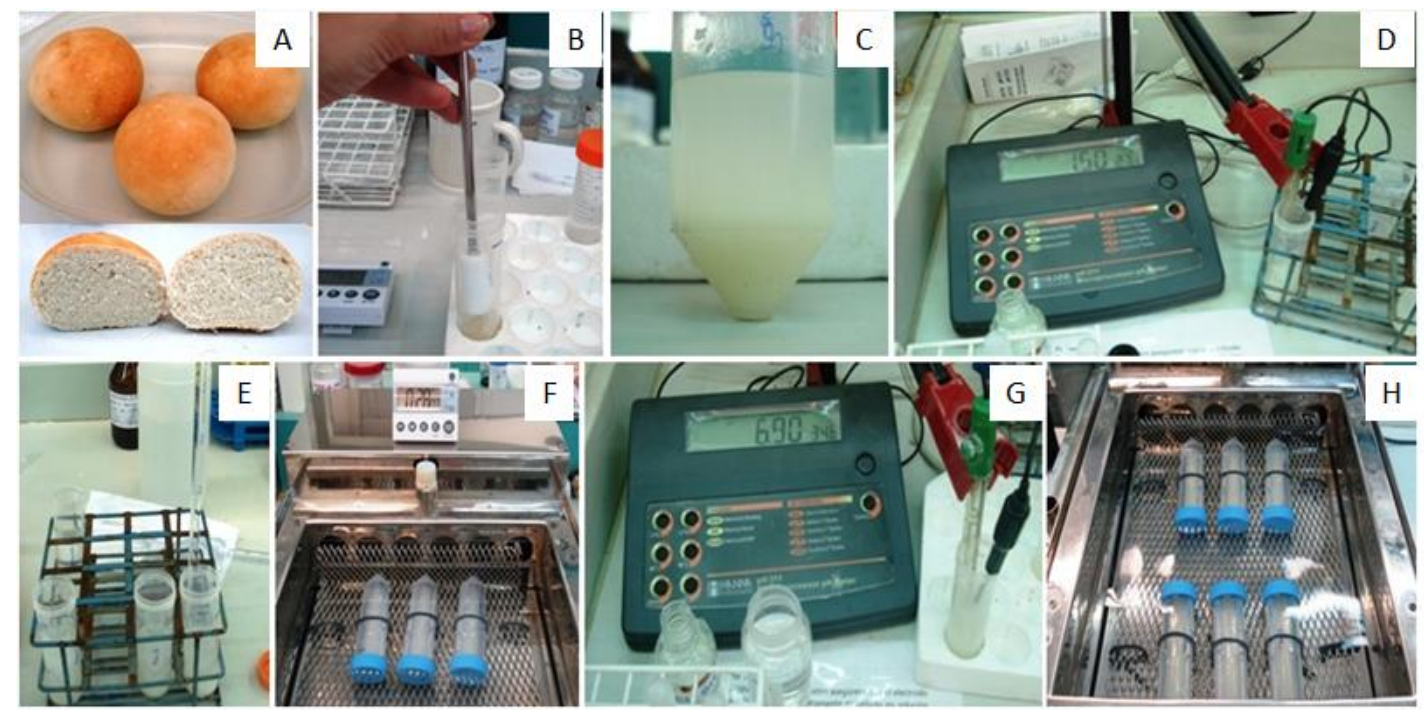

Figura M.12 - Digestibilidad in vitro de almidón en las pastas cocidas.

Una vez obtenidas las dos alícuotas, la muestra fue colocada rápidamente en el baño a 37 ${ }^{\circ} \mathrm{C}$ para continuar con la digestión. A medida que se fueron tomando las alícuotas a los distintos tiempos $(0,30,60,90,120,150$ y $180 \mathrm{~min})$, éstas fueron sumergidas inmediatamente en un baño de agua en ebullición durante $5 \mathrm{~min}$ a fin de detener la reacción enzimática y luego fueron colocadas en un freezer a $-20^{\circ} \mathrm{C}$, donde fueron conservadas para la medición posterior de maltosa.

Para la determinación de maltosa, una vez que las alícuotas alcanzaron temperatura ambiente, se las homogeneizó por medio del vortex y se las centrifugó a 5000 x g durante 10 min a $25{ }^{\circ} \mathrm{C}$. En un tubo de vidrio de medio ensayo, se colocó $0,1 \mathrm{~mL}$ del sobrenadante (excepto para el tiempo cero que se usó $0,5 \mathrm{~mL}$ ), se completó el completó el volumen hasta $0,5 \mathrm{~mL}$ con buffer fosfato $\mathrm{pH} 6,9$, se agregó $0,5 \mathrm{~mL}$ de reactivo de ácido dinitro-salicílico DNS (Sigma D0550) y se llevó a baño de agua en ebullición 5 min, previa homogenización con el vortex. Luego de retirar las muestras del baño, se les agregó $5 \mathrm{~mL}$ de agua destilada y una vez 
que los tubos alcanzaron temperatura ambiente, se les midió la absorbancia a $540 \mathrm{~nm}$ (Espectrofotómetro Spectrum SP 2000, China). Además se realizó un curva de maltosa (D-(+)Maltose Monohydrate $63418, \geq 99,0 \%$, Sigma 63418 ), tomando 0,$1 ; 0,2 ; 0,3 ; 0,4$ y $0,5 \mathrm{~mL}$ de una solución de maltosa de 4,308 $\mathrm{mg} / \mathrm{mL}$. La maltosa así medida fue convertida a almidón multiplicando por 0,9. La cantidad de almidón hidrolizado fue expresado como porcentaje del almidón total a los diferentes tiempos.

\section{Digestibilidad de proteínas}

La digestibilidad de las proteínas se realizó de acuerdo al método de Hamaker et al. (1987) modificado, sobre una muestra preparada de manera semejante a lo realizado en la digestibilidad de almidón. En un tubo tipo Falcon de $50 \mathrm{~mL}$, previamente tarado, se pesaron $200 \mathrm{mg}$ (al 0,1 mg) de fideos secos cortados en segmentos de 1,5 cm (peso de fideos secos, $\mathrm{P} 1)$, los que se cocinaron hasta su TOC y luego de ser enjuagados con $25 \mathrm{~mL}$ de agua destilada y escurridos por $20 \mathrm{~s}$, se volvieron a colocar en el mismo tubo Falcon para volver a registrarles el peso, una vez que éstos alcanzaron temperatura ambiente (peso de fideo cocido, P2).

Para simular la masticación, la muestra se disgregó con el émbolo de un homogeneizador manual para tejidos (Cole Parmer, Glass Vessel; 50 mL, EW-44468-18, USA) dentro del mismo tubo Falcon durante $1 \mathrm{~min}$, previo el agregado de $2 \mathrm{~mL}$ de agua destilada (Figura M.13-A). Antes de retirar el émbolo del homogeneizador, se lo lavó con $25 \mathrm{~mL}$ buffer fosfato $0,1 \mathrm{M}, \mathrm{pH}$ 2,0 (preparado a partir de una solución de ácido orto fosfórico 0,1M, Cicarelli Cod. 105110, llevada a pH con $\mathrm{NaOH} 4 \mathrm{M}$ ), completando hasta un volumen de $30 \mathrm{~mL}$ con el mismo buffer.

Para la digestión se agregaron $9 \mathrm{~mL}$ de una solución conteniendo $52,5 \mathrm{mg}$ de pepsina (Sigma P-7000, 975 units/mg protein, ${ }^{1 \%}{ }_{280}$ ) en bufer fosfato $\mathrm{pH} 2,0$. La mezcla fue incubada exactamente durante $2 \mathrm{~h}$ en un baño a $37^{\circ} \mathrm{C}$, con una agitación horizontal de 200 golpes por min (Vikinf Dufnoff 5002, Argentina) (Figura M.13-B). Inmediatamente alcanzado el tiempo de incubación, la digestión fue detenida por el agregado de $2 \mathrm{~mL}$ de $\mathrm{NaOH} 2 \mathrm{M}$ (Cicarelli, Cod. 893214). Del digesto obtenido se tomó una alícuota de $1 \mathrm{~mL}$, la que fue centrifugada a 14.000 x g durante $10 \mathrm{~min}$ a $25^{\circ} \mathrm{C}$. La determinación de nitrógeno se realizó sobre una fracción de ensayo de $200 \mu \mathrm{L}$ del sobrenadante, a través del método de Lowry (Waterborg, 2009), midiendo los valores de absorbancia resultantes de la reacción colorimétrica a $550 \mathrm{~nm}$ (Espectrofotómetro Spectrum SP 2000, China). Para la cuantificación se utilizó una solución madre de albúmina sérica bovina (Sigma $85040 \mathrm{C}$ ) de $2,08 \mathrm{mg} / \mathrm{mL}$, con la cual se prepararon por dilución, soluciones de 104, 208, 520, 1040 y $2080 \mu \mathrm{g} / \mathrm{mL}$ (Figura M.13-C) y por medio de 
un análisis de regresión lineal se determinó la concentración de las proteínas digeridas de las muestras (Figura M.13-D).

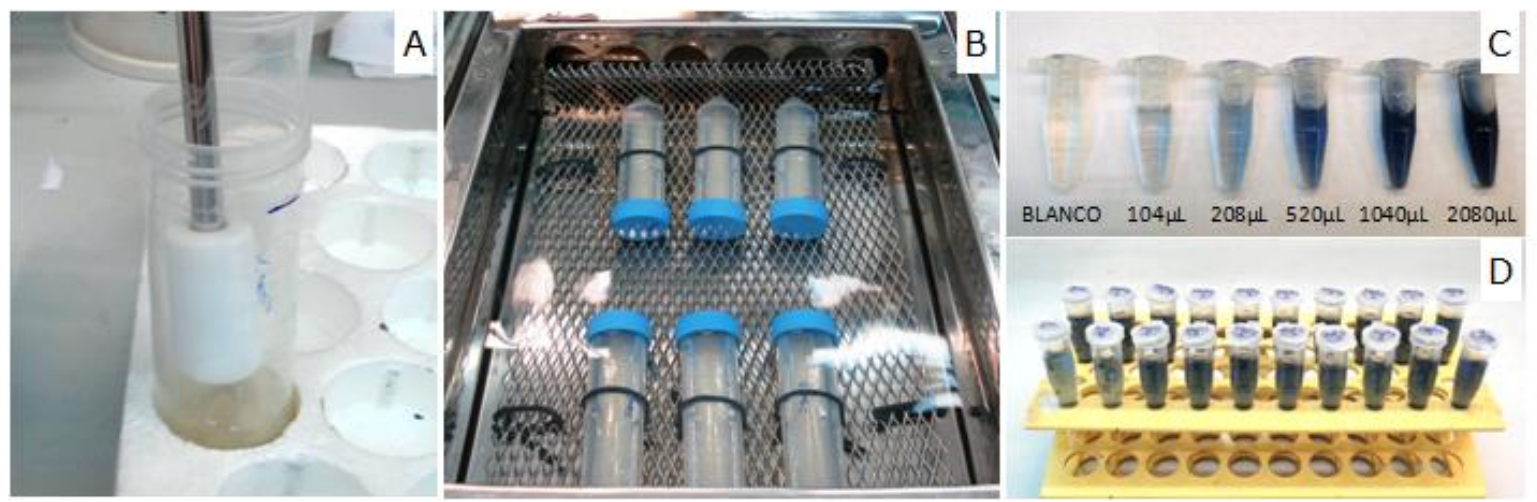

Figura M.13 - Digestibilidad in vitro de las proteínas en las pastas cocidas.

\section{Evaluación sensorial de las pastas}

\section{Condiciones generales del ensayo}

La evaluación sensorial se realizó en base a los trabajos de Kovacs et al. (1997) y de Tang et al. (1999), con ligeras modificaciones. En todas las ocasiones las pastas fueron cocinadas en agua destilada hasta sus TOC y presentadas a cada evaluador en envases térmicos con tapa, identificados con números aleatorios de tres dígitos, junto con un vaso de agua, una servilleta, una lapicera y la hoja de evaluación en donde estaba la definición y la forma de evaluar de cada una de las propiedades analizadas.

\section{Condiciones para la evaluación sensorial de las pastas comerciales}

Para la evaluación sensorial de las patas comerciales se utilizó el sentido de la vista, el del tacto y el del gusto. Por observación visual se valoró el color amarillo, el brillo y el aspecto superficial; la pegajosidad de la superficie y la elasticidad fue evaluadas por medio de las manos y por medio de la boca se determinó la firmeza y la masticabilidad (chewiness) (Tabla M.4), utilizando una escala discontinua de 7 puntos, donde uno de los extremos estaba indicado como "Muy Bajo" y el extremo opuesto indicado como "Muy Alto" (Figura M.14). Participaron 13 panelistas, 7 mujeres y 6 hombres, los que se dispusieron en dos turnos de 6 y 7 personas cada uno, alrededor de una mesa, con luz de día. 
Tabla M.4 - Definición de los Atributos Sensoriales

\begin{tabular}{|c|c|}
\hline Color amarillo & Intensidad de color amarillo que presenta la superficie del espagueti \\
\hline Brillo & Grado en que la luz se refleja en la superficie del espagueti \\
\hline $\begin{array}{l}\text { Aspecto } \\
\text { sunerficial }\end{array}$ & Cantidad de manchitas en la superficie del espagueti \\
\hline Firmeza & $\begin{array}{l}\text { Fuerza requerida para cortar el espagueti usando los dientes incisivos } \\
\text { delanteros }\end{array}$ \\
\hline $\begin{array}{l}\text { Masticabilidad } \\
\text { (chewiness) }\end{array}$ & $\begin{array}{l}\text { Tiempo requerido para masticar el espagueti hasta lograr una consistencia } \\
\text { apropiada para ser tragado (pueden contarse las veces que es necesario } \\
\text { masticarlo con los molares) }\end{array}$ \\
\hline $\begin{array}{l}\text { Pegajosidad de la } \\
\text { superficie }\end{array}$ & Grado de adherencia que presentan dos espaguetis al momento de separarlos \\
\hline Elasticidad & $\begin{array}{l}\text { Grado en que un espagueti retorna a su longitud original luego de ser estirado } \\
\text { (resistencia a la ruptura cuando el espagueti es estirado) }\end{array}$ \\
\hline
\end{tabular}

\begin{tabular}{|c|c|c|c|c|c|c|}
\hline \multicolumn{7}{|c|}{ Firmeza (fuerza requerida para cortar el espagueti usando los dientes delanteros) } \\
\hline \multirow{2}{*}{$\begin{array}{c}\text { No Muestra } \\
654\end{array}$} & \multicolumn{6}{|c|}{ Puntuación } \\
\hline & $\begin{array}{c}\text { Muy Bajo } \\
\square\end{array}$ & $\square$ & $\square$ & $\square$ & ㅁ & $\square \stackrel{\text { Muy Alto }}{\square}$ \\
\hline 988 & $\begin{array}{c}\text { Muy Bajo } \\
\square\end{array}$ & $\square$ & $\square$ & $\square$ & $\square$ & $\square \stackrel{\text { Muy Alto }}{\square}$ \\
\hline 777 & $\begin{array}{c}\text { Muy Bajo } \\
\square\end{array}$ & 口 & $\square$ & $\square$ & $\square$ & $\square \stackrel{\text { Muy Alto }}{\square}$ \\
\hline 826 & $\begin{array}{c}\text { Muy Bajo } \\
\square\end{array}$ & 口 & ㅁ & $\square$ & $\square$ & $\square \stackrel{\text { Muy Alto }}{\square}$ \\
\hline 299 & $\begin{array}{c}\text { Muy Bajo } \\
\square\end{array}$ & 口 & 口 & $\square$ & 口 & $\square \stackrel{\text { Muy Alto }}{\square}$ \\
\hline
\end{tabular}

Figura M.14 - Escala utilizada para la evaluación de las propiedades sensoriales de las pastas comerciales, ej. Firmeza.

\section{Condiciones para la evaluación sensorial de las pastas frescas}

En el ensayo de las pastas frescas se evaluó el color amarillo (por observación visual) y la firmeza, la pegajosidad y la masticabilidad (con la boca), utilizando una escala discontinua de 9 puntos (Figura M.15). Además, a cada evaluador se le pidió que ordenara las muestras de acuerdo a su preferencia ubicando la muestra control arbitrariamente en la mitad de la escala (Figura M.16).

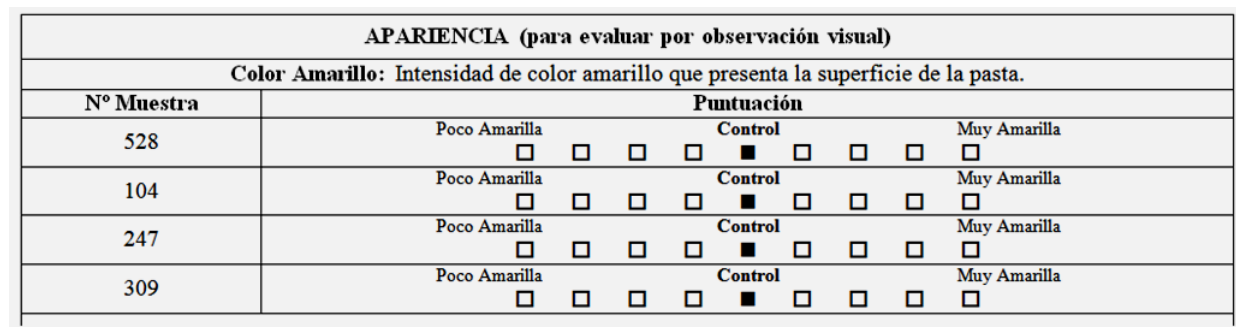

Figura M.15 - Escala utilizada para la evaluación sensorial de las pastas frescas; ej. Color Amarillo. 


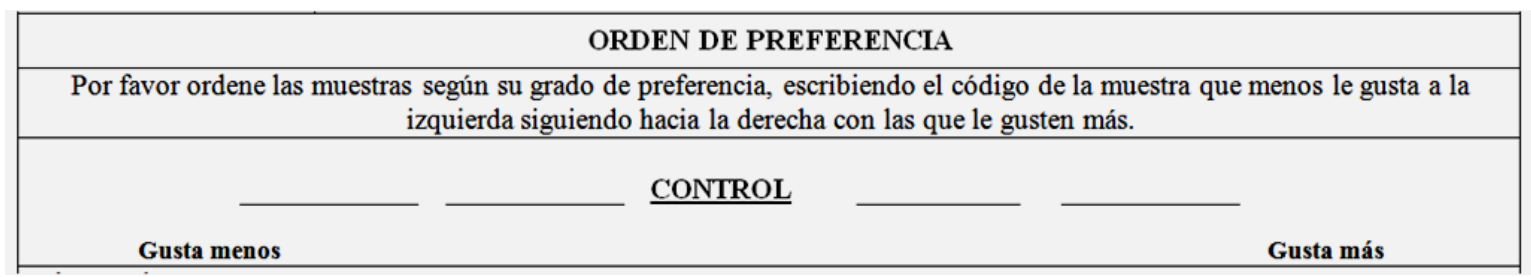

Figura M.16 - Escala para la evaluación de preferencia utilizada para las pastas frescas.

\section{Condiciones para la evaluación sensorial de las pastas elaboradas con}

\section{harina de amaranto y de soja}

Para las pastas elaboradas con harina de amaranto y harina de soja se planteó una evaluación sensorial discriminativa múltiple, en la cual por medio de la boca y de las manos, se cuantificaron la diferencia que presentaron las distintas muestras en firmeza, pegajosidad, masticabilidad y elasticidad (Tabla M.5), respecto de una muestra considerada como Control, situada arbitrariamente en el centro de una escala continua de 15 puntos. De la muestra Control hacia la izquierda, se ubicaron los valores negativos, mientras que hacia la derecha se encontraban los valores positivos; considerando $-7 y+7$ como el menor y mayor valor de la escala respectivamente (Figura M.17). El panel sensorial estuvo formado por 8 panelistas (personal académico semi-entrenado) (7 mujeres y 1 varón, entre 25 y 48 años), a los que se les pidió que se colocaran un par de anteojos de color rojo (Figura M.18) a fin de enmascarar las diferencias de color entre las muestras y evitar así posibles subjetividades.

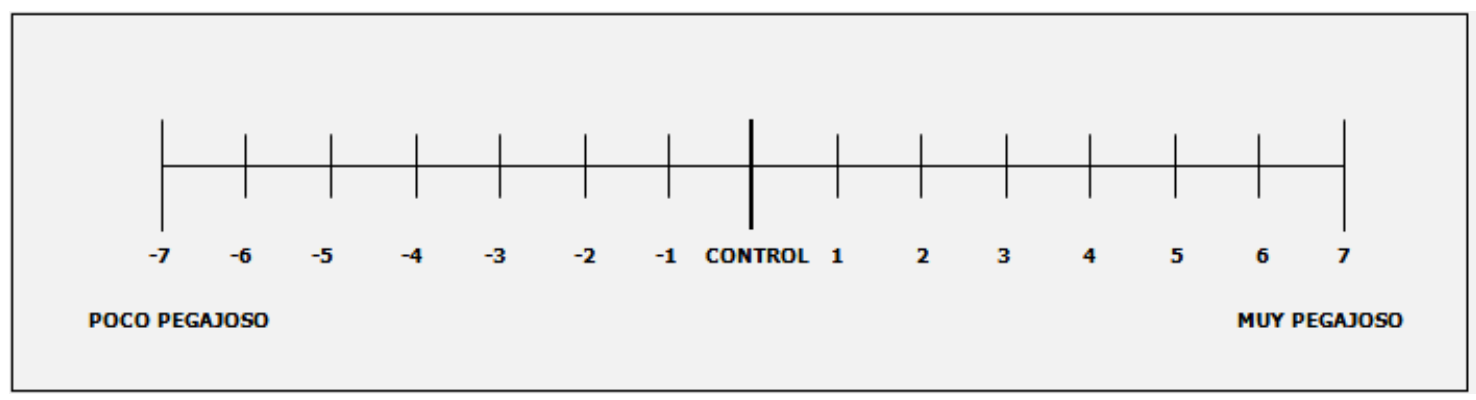

Figura M.17 - Escala continua de 15 puntos utilizada para la evaluación de las pastas elaboradas con harina de amaranto y de soja; ej. Pegajosidad. 

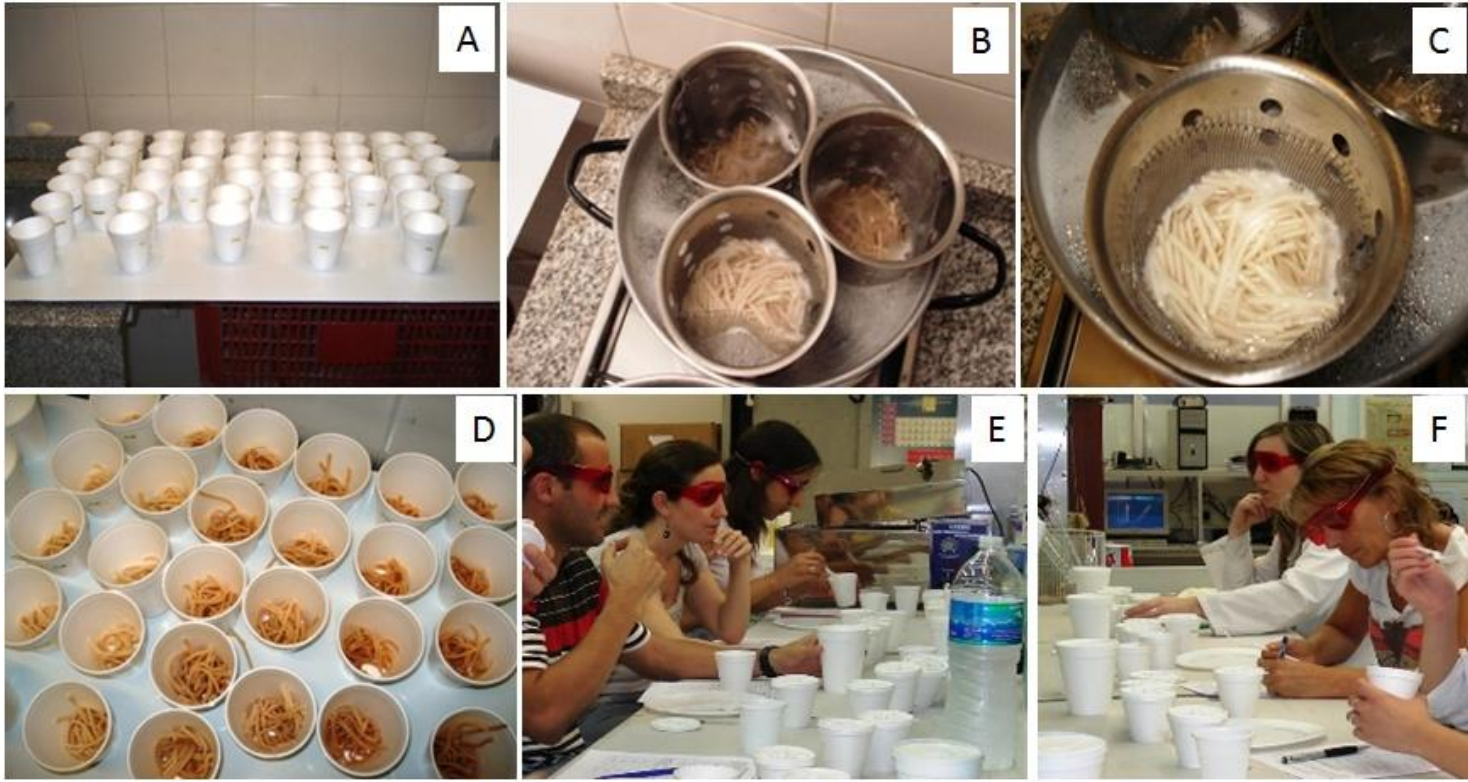

Figura M.18 - Preparación de las muestras (A-D) y evaluación por los panelistas (E-F) de las pastas cocidas elaboras con harina de amaranto y harina de soja.

Tabla M.5 - Definición de las propiedades sensoriales y técnica para su evaluación

\begin{tabular}{|c|c|c|}
\hline Firmeza & Definición: & $\begin{array}{l}\text { Fuerza requerida para comprimir la pasta entre los molares } \\
\text { cuando se la muerde uniformemente por primera vez. } \\
\text { Tomar de a un fideo, ubicarlo entre los molares, morderlo } \\
\text { uniformemente, evaluando la fuerza requerida para comprimirlo. }\end{array}$ \\
\hline \multirow{2}{*}{ Pegajosidad* } & Definición: & $\begin{array}{l}\text { Cantidad de producto adherido sobre o entre los dientes después } \\
\text { de la masticación } \\
\text { 1) Enjuagarse la boca con agua; 2) tomar un fideo, pegarlo contra } \\
\text { el paladar y evaluar la fuerza necesaria para removerlo con la } \\
\text { lengua. }\end{array}$ \\
\hline & Técnica 2: & $\begin{array}{l}\text { 1) Enjuagarse la boca con agua; } 2 \text { ) Introducir de a un fideo en la } \\
\text { boca y masticarlo normalmente. Evaluar la pegajosidad de la pasta } \\
\text { en base a la cantidad de producto que se adhiere entre o sobre los } \\
\text { dientes después de masticarlo cinco veces. }\end{array}$ \\
\hline \multirow{2}{*}{ Masticabilidad } & Definición: & $\begin{array}{l}\text { Número de veces requeridas para masticar la pasta, a velocidad } \\
\text { constante, hasta reducirla a una consistencia adecuada para ser } \\
\text { tragada. }\end{array}$ \\
\hline & Técnica: & $\begin{array}{l}\text { Tomar de a un fideo, ubicarlo en la boca y masticarlo a velocidad } \\
\text { constante, contando las veces requeridas para reducirlo hasta al } \\
\text { estado de ser tragado. }\end{array}$ \\
\hline \multirow[t]{2}{*}{ Elasticidad } & Definición: & $\begin{array}{l}\text { Grado en que el fideo vuelve a su forma original luego de ser } \\
\text { sometido a un esfuerzo. Resistencia a la ruptura cuando el fideo } \\
\text { es estirado. }\end{array}$ \\
\hline & Técnica: & $\begin{array}{l}\text { Tomar de a un fideo por los extremos y estirarlo. Evaluar el grado } \\
\text { en que la pasta vuelve a su largo original. }\end{array}$ \\
\hline
\end{tabular}

* La técnica 1 fue usada en la evaluación sensorial de pastas sustituidas con harina de soja y la técnica 2 fue usada en la evaluación sensorial de las pastas sustituidas con harina de amaranto. 
Además se le pidió a cada evaluador que ordenara las muestras de acuerdo a su preferencia, utilizando para ello una escala hedónica de 9 puntos según la Norma IRAM 20014: 1996 (ISO 4121, 1987) de mayor a menor preferencia desde el 9 al 1 respectivamente (Tabla M.6).

\section{Tabla M.6 - Evaluación de acuerdo al Orden de Preferencia}

Por favor califique a cada muestra de acuerdo a su preferencia. Puede tener Técnica: en cuenta el sabor, aroma, aspecto superficial o cualquier otra característica que usted considere que debe presentar un fideo agradable a su gusto. Puede tomar la cantidad de muestra que desee.

9 = Extremadamente agradable; $8=$ Muy agradable; $7=$ Agradable; $6=$ Escala: $\quad$ Ligeramente agradable; $5=\mathrm{Ni}$ agradable ni desagradable; $4=$ Ligeramente desagradable; 3 = Desagradable; 2 = Muy desagradable; $1=$ Extremadamente desagradable

\section{Análisis estadístico}

El análisis estadístico se realizó mediante el software InfoStat v. 1.0. (Facultad de Ciencias Agropecuarias, Universidad Nacional de Córdoba, Argentina). Las herramientas estadísticas empleadas fueron ANOVA, correlación de Pearson y Análisis de Componentes Principales, test de comparaciones múltiples de LSD Fisher, test de comparaciones múltiples de de DGC y análisis de varianza no paramétrico de Friedman, todos a un nivel de significancia del $5 \%\left({ }^{*}\right)$ y $1 \%(* *)$. 


\section{RESULTADOS Y} DISCUSIÓN 


\section{PRIMERA SECCIÓN}

\section{Estudio de los parámetros que definen la calidad de las pastas}


Con el propósito de estudiar los parámetros que definen la calidad de las pastas, se realizaron diferentes ensayos instrumentales y sensoriales en muestras de pastas secas comerciales, a fin de evaluar la aptitud de estos métodos como indicadores de la calidad de las pastas. Además se estudió la posible asociación entre las mediciones sensoriales e instrumentales en las muestras ensayadas.

\section{Composición de las muestras}

Los valores de humedad, proteínas y cenizas de las pastas secas comerciales se muestran en la Tabla 1.1. Las muestras presentaron en general valores similares de humedad, entre 10,5 y $11 \%$ p/p, a excepción de la muestra Com3, que mostró un valor de 12,5\% p/p.

La importancia de la humedad en las pastas secas comerciales está directamente relacionada con la estabilidad del producto en góndola, especialmente en términos de su inocuidad. Si bien el Código Alimentario Argentino (Art.720, CAA, 2009/10a) establece un máximo de $14 \%$ de humedad, ese valor no asegura la inocuidad microbiológica del producto, de modo que en la industria de las pastas se trabaja con valores inferiores a 12 a $12,5 \%$.

Tabla 1.1 - Humedad, proteínas y cenizas de las pastas

\begin{tabular}{cccc}
\hline Tipo Muestra & $\begin{array}{c}\text { Humedad } \\
\% \mathbf{p} / \mathbf{p}\end{array}$ & $\begin{array}{c}\text { Proteínas } \\
\% \mathbf{p} / \mathbf{p}, \mathbf{b s}\end{array}$ & $\begin{array}{c}\text { Cenizas } \\
\% \mathbf{p} / \mathbf{p}, \mathbf{b s}\end{array}$ \\
\hline Com1 & $10,7 \pm 0,0 \mathrm{~b}$ & $12,4 \pm 0,1 \mathrm{~b}$ & $1,10 \pm 0,02 \mathrm{e}$ \\
Com2 & $11,0 \pm 0,1 \mathrm{c}$ & $11,3 \pm 0,3 \mathrm{a}$ & $0,61 \pm 0,00 \mathrm{a}$ \\
Com3 & $12,5 \pm 0,0 \mathrm{~d}$ & $12,5 \pm 0,4 \mathrm{~b}$ & $0,67 \pm 0,01 \mathrm{~b}$ \\
Com4 & $10,5 \pm 0,0 \mathrm{a}$ & $12,1 \pm 0,1 \mathrm{~b}$ & $0,73 \pm 0,00 \mathrm{c}$ \\
Com5 & $10,8 \pm 0,1 \mathrm{~b}$ & $12,3 \pm 0,0 \mathrm{~b}$ & $0,79 \pm 0,02 \mathrm{~d}$ \\
\hline \multicolumn{4}{c}{ Valores seguidos de la misma letra dentro de una columna no presentan } \\
\multicolumn{4}{c}{ diferencias significativas ( $\mathrm{p}<=0,05)}$.
\end{tabular}

El contenido de proteínas estuvo comprendido entre $11,3 \%$ y $12,5 \%$; solamente Com2 fue significativamente diferente del resto de las muestras, mostrando el menor valor de proteínas de $11,3 \%$. Si bien el contenido de proteínas no determina por sí mismo la calidad final de las pastas cocidas, es un importante parámetro en la conformación de su estructura. Cuando el desarrollo de la masa es el adecuado, las proteínas constituyen una especie de pilar fundamental en la estructura de las pastas. Esta red de proteínas, la cual contiene los gránulos de almidón inmersos en ella de manera más o menos comprometida, es la que soporta el laminado o extrusado de las pastas y el corte, ya sea por rodillos o por discos puestos en la 
cabeza del extrusor. Además, esta red será la responsable en gran medida del comportamiento de las pastas durante el secado y la cocción. Desde luego, no solo la cantidad si no la calidad de las proteínas, junto con la calidad del almidón constituyente de la materia prima, serán determinantes en la calidad resultante del producto final.

El contenido de cenizas, dentro de las muestras elaboradas a partir de harina de trigo pan, presentó un amplio rango de valores, desde 0,61 hasta 0,79\% para Com2 y Com5 respectivamente. La muestra Com1, cuya materia prima era sémola de trigo candeal, presentó el mayor valor de cenizas, $1,10 \%$. Este elevado valor se debe en parte a que el contenido de cenizas del endosperma del trigo durum es más alto que el de los granos de trigo pan. Además, mientras que el Código Alimentario Argentino establece un valor máximo de cenizas para la harina proveniente del triticum aestivum, no lo hace para la sémola de trigo candeal. De modo que su valor queda sujeto a las especificaciones exigidas por la industria de las pastas a los molinos productores de sémola, acordando un contenido de cenizas máximo tolerable de 0,86\% (Calvelo, 2008).

\section{Propiedades de cocción de las pastas}

La Tabla 1.2 muestra los tiempos óptimos de cocción (TOC) de las muestras, los valores de residuo de cocción, de absorción de agua y el contenido de amilosa en el agua de cocción.

Tabla 1.2 - TOC, residuo de cocción, absorción de agua y amilosa en el agua de cocción

\begin{tabular}{ccccc}
\hline Tipo Muestra & $\begin{array}{c}\text { TOC } \\
\text { min }\end{array}$ & $\begin{array}{c}\text { Residuo de } \\
\text { Cocción, } \% \mathbf{p} / \mathbf{p}^{\mathbf{1}}\end{array}$ & $\begin{array}{c}\text { Absorción Agua } \\
\mathbf{\%} \mathbf{p} / \mathbf{p}^{1}\end{array}$ & $\begin{array}{c}\text { Amilosa } \\
\mathbf{\%} \mathbf{p} / \mathbf{p}^{\mathbf{1}}\end{array}$ \\
\hline Com1 & 10,5 & $5,3 \pm 0,0 \mathrm{~b}$ & $266 \pm 1 \mathrm{c}$ & $2,0 \pm 0,2 \mathrm{a}$ \\
Com2 & 8,5 & $4,4 \pm 0,0 \mathrm{a}$ & $256 \pm 1 \mathrm{ab}$ & $2,2 \pm 0,2 \mathrm{a}$ \\
Com3 & 9,5 & $4,5 \pm 0,0 \mathrm{ab}$ & $254 \pm 3 \mathrm{a}$ & $2,5 \pm 0,2 \mathrm{~b}$ \\
Com4 & 7,5 & $6,4 \pm 0,7 \mathrm{c}$ & $259 \pm 0 \mathrm{~b}$ & $4,7 \pm 0,1 \mathrm{~d}$ \\
Com5 & 7,5 & $6,3 \pm 0,3 \mathrm{c}$ & $267 \pm 0 \mathrm{c}$ & $3,7 \pm 0,1 \mathrm{c}$ \\
\hline
\end{tabular}

TOC: Tiempo óptimo de cocción. ${ }^{1}$ Cantidad en $\mathrm{g} / 100 \mathrm{~g}$ de pasta seca. Valores seguidos de la misma letra dentro de una columna no presentan diferencias significativas $(p<=0,05)$.

\section{Tiempo óptimo de cocción (TOC)}

El tiempo óptimo de cocción fue determinado a partir de, al menos, dos ensayos independientes tomando una muestra cada $30 \mathrm{~s}$. A partir de los diferentes resultados obtenidos, en lugar de trabajar con la media aritmética, se le atribuyó a cada muestra un TOC 
comprendido en la fracción de los 0,5 min, para evitar el uso de pequeñas fracciones de tiempo difíciles de llevar a la práctica.

Los valores de TOC estuvieron comprendidos entre $7,5 \mathrm{~min}$ y $10,5 \mathrm{~min}$. Las muestras elaboradas a partir de trigo pan mostraron TOC más cortos que la muestra preparadas con sémola de trigo candeal (Com1).

\section{Residuo de cocción}

Las diferentes muestras presentaron valores de residuo de cocción comprendidos entre 4,4 a 6,4 g residuo/100 g pasta seca; encontrándose diferencias significativas entre las muestras Com1, Com2 y Com3. Este parámetro es usado comúnmente como indicador de la calidad de la pasta cocida, tanto por los consumidores como por las industrias (Tudorică et al., 2002). En los espaguetis preparados con sémola de trigo candeal, si se pretende un producto final de buena calidad, los valores de pérdida por cocción deben ser próximos a un $7 \%$ y no deben superar el 8\% (Dick \& Youngs, 1988), pero desde luego, tanto las materias primas usadas, como el proceso de elaboración y el método de secado al que fueron sometidas las pastas pueden afectar cuantitativamente este parámetro. De modo que para las muestras evaluadas, todos los residuos de cocción se podrían considerar aceptables.

\section{Absorción de agua}

Los valores de absorción de agua medidos estuvieron comprendidos entre 254 y 266 g/100 g de pasta seca, mostrando diferencias significativas entre todas las muestras, excepto entre Com1 y Com5, quienes presentaron los valores más altos. En general, un valor adecuado de absorción de agua de un espagueti debe ser tres veces mayor al de su peso seco (Dick \& Youngs, 1988), con lo cual la absorción de agua que presentaron las muestras estudiadas fue apropiada.

\section{Contenido de amilosa en el agua de cocción}

Los valores de amilosa en el agua de cocción fueron estimados a partir de un análisis de correlación lineal $(y=7,508 x+0,092)$ (Figura 1.1), con un coeficiente de regresión $\left(r^{2}=0,998\right)$ y un valor de estadístico $\mathrm{F}(\mathrm{Fexp}=0,828)$. El contenido de amilosa en el agua de cocción estuvo comprendido entre 2,0 y 4,7\%. Com 1 mostró el valor más bajo, 2,0\%p/p, mientras que Com4 y Com5 mostraron los valores más altos, siendo iguales a 4,7 y $3,7 \%$, respectivamente. 


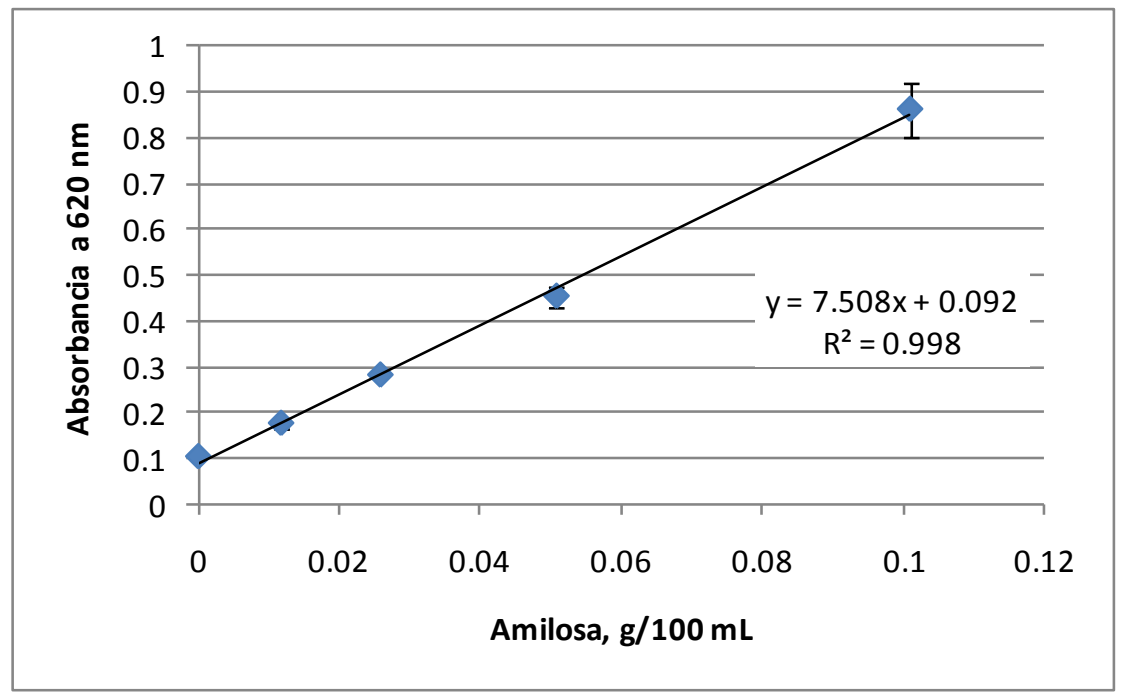

Figura 1.1 - Análisis de regresión lineal del contenido de amilosa en el agua de cocción.

Se observó una correlación positiva (Pearson, $r=0,81 ; p<0,001$ ), entre los valores de pérdida por cocción y el contenido de amilosa en el agua de cocción; resultados coincidentes con los obtenidos por Fortini (1988), quien sugirió que el principal constituyente del residuo de cocción es la amilosa.

De hecho, se puede estimar que las muestras Com4 y Com5 estaban formadas por una estructura más débil que el resto de las muestras, lo que seguramente favoreció un excesivo hinchamiento y gelatinización del almidón, lixiviando la amilosa hacia el agua de cocción y consecuentemente dejando a la amilopectina concentrada sobre la superficie de la pasta.

\section{Color de la pasta cruda y cocida}

El color de la pasta cruda es un importante factor de calidad para los consumidores. En los productos elaborados a partir de sémola de trigo candeal, los mayores valores de $L^{*}$ y $b^{*}$ son considerados como los atributos de color más importantes.

Los valores medidos del color de las pastas crudas y cocidas, en términos de $L^{*}, a^{*}$ y b* se muestran en la Tabla 1.3. Además, se calculó de acuerdo a la ecuación $L^{*}+\left(b^{*} \times 2\right) / 20$ (Hareland et al., 1995) una puntuación general del color de las pastas en una escala de 1 a 10, siendo 10 la mejor calificación. Dentro de las muestras crudas, Com3 obtuvo la puntuación más baja, 4,1, mientras que Com2 y Com5 fueron las mejor calificadas, 5,9; mientras que para las muestras cocidas, Com1 y Com2 fueron las que presentaron mejor color. 
Tabla 1.3 - Color de las pastas crudas y cocidas

\begin{tabular}{cccccc}
\hline Tratamiento & Muestra & $\mathbf{L}^{*}$ & $\mathbf{b}^{*}$ & $\mathrm{a}^{*}$ & Grado de Color $^{3}$ \\
\hline Pasta Cruda $^{1}$ & Com1 & $49,1 \pm 2,0 \mathrm{ab}$ & $32,0 \pm 1,0 \mathrm{~b}$ & $3,6 \pm 0,2 \mathrm{e}$ & 5,7 \\
& Com2 & $51,0 \pm 1,4 \mathrm{~d}$ & $33,9 \pm 0,8 \mathrm{c}$ & $-1,9 \pm 0,2 \mathrm{a}$ & 5,9 \\
& Com3 & $48,2 \pm 1,4 \mathrm{a}$ & $17,3 \pm 0,6 \mathrm{a}$ & $0,4 \pm 0,1 \mathrm{c}$ & 4,1 \\
& Com4 & $49,8 \pm 1,3 \mathrm{bc}$ & $31,6 \pm 0,6 \mathrm{~b}$ & $1,2 \pm 0,2 \mathrm{~d}$ & 5,7 \\
& Com5 & $50,7 \pm 1,4 \mathrm{~cd}$ & $33,6 \pm 0,8 \mathrm{c}$ & $-0,2 \pm 0,2 \mathrm{~b}$ & 5,9 \\
Pasta Cocida $^{2}$ & Com1 & $56,9 \pm 1,4 \mathrm{c}$ & $12,8 \pm 1,1 \mathrm{c}$ & $-1,8 \pm 0,2 \mathrm{~d}$ & 4,1 \\
& Com2 & $52,5 \pm 1,7 \mathrm{a}$ & $15,5 \pm 1,5 \mathrm{~d}$ & $-5,6 \pm 0,2 \mathrm{a}$ & 4,2 \\
& Com3 & $56,5 \pm 2,0 \mathrm{c}$ & $3,1 \pm 1,3 \mathrm{a}$ & $-1,9 \pm 0,1 \mathrm{~d}$ & 3,1 \\
& Com4 & $54,3 \pm 1,8 \mathrm{~b}$ & $10,0 \pm 1,6 \mathrm{~b}$ & $-4,0 \pm 0,1 \mathrm{c}$ & 3,7 \\
& Com5 & $55,9 \pm 1,0 \mathrm{bc}$ & $12,5 \pm 1,5 \mathrm{c}$ & $-4,4 \pm 0,1 \mathrm{~b}$ & 4,0 \\
\hline
\end{tabular}

Valores seguidos de la misma letra dentro de una columna no presentan diferencias significativas ( $p<=$ $0,05) .{ }^{1}$ Promedio resultante de 14 mediciones. ${ }^{2}$ Promedio resultante de 8 mediciones. ${ }^{3}$ Grado de Color: $\left(L^{*}+\left(b^{*} \times 2\right)\right) / 20$, escala: $1-10$, siendo 10 la calificación más favorable. (Hareland et al., 1995). Reflectancia del fondo negro, promedio de 10 mediciones: $L^{*}: 25,15 \pm 0,07 ; a^{*}: 0,20 \pm 0,01$ y $b^{*}:-0,30 \pm 0,04$.

El color de los espaguetis crudos y cocidos fue analizado a través del análisis del componente principal (PCA) (Figura 1.2).

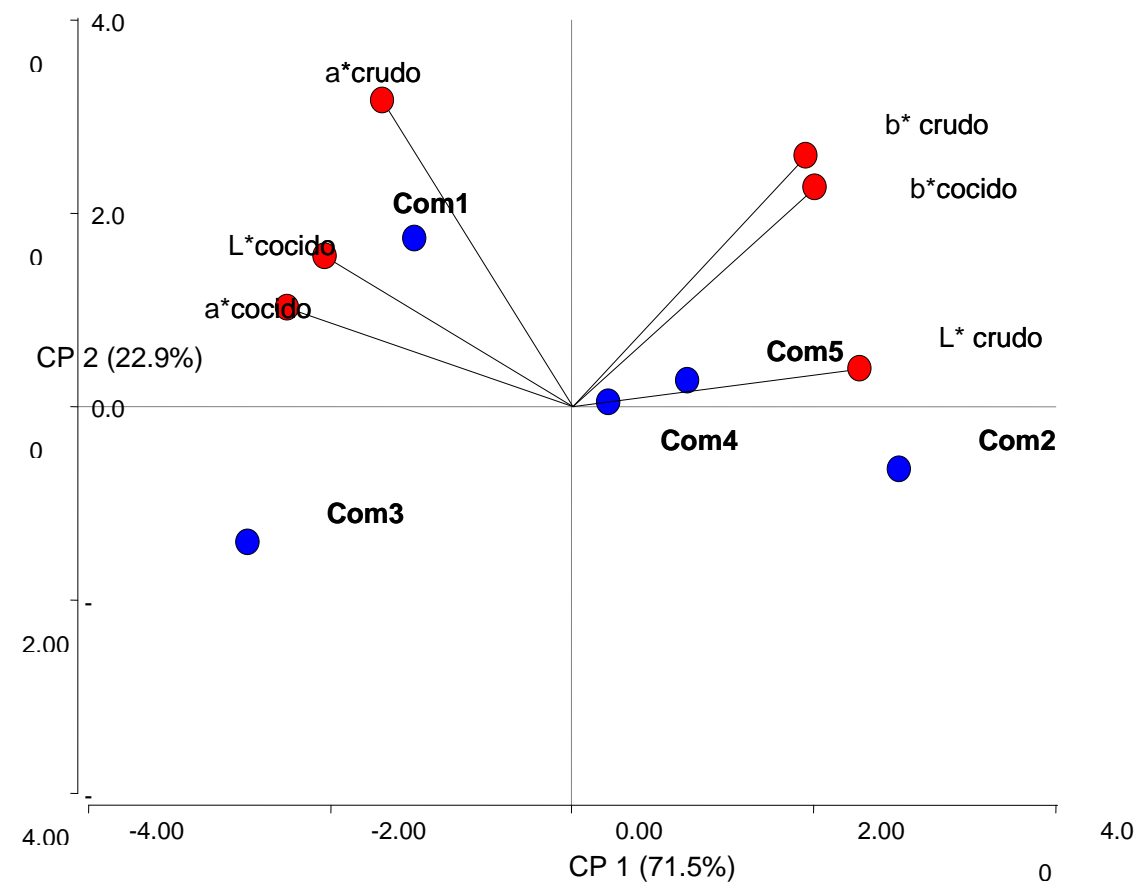

Figura 1.2 - Análisis de PCA de la evaluación del color de pastas crudas y cocidas.

Con el promedio estandarizado de las réplicas de cada medición se realizó la matriz de correlación. Las primeras dos dimensiones calculadas pudieron explicar el $94 \%$ de la varianza 
total. La primera dimensión separó claramente las muestras con altos valores de b* de los espaguetis crudos y cocidos, y con altos valores de $L^{*}$ de los espaguetis crudos. De esta manera, las muestras Com2, Com4 y Com5 se asociaron principalmente a la variable b* (de crudos y cocidos), mientras Com 1 y Com3 se asociaron a las variables a* (de crudos y cocidos) y a variable $L^{*}$ (sólo de los espaguetis cocidos).

\section{Evaluación sensorial}

Dentro de los atributos sensoriales, el color amarillo, el brillo, la firmeza, la masticabilidad y la elasticidad se consideraron como atributos positivos, es decir, cuantos más altos sean los valores obtenidos, mejor será la calidad de las pastas. Por el contrario, el aspecto superficial (para el cual en realidad se tenían en cuenta los defectos de la superficie) y la pegajosidad se consideraron como atributos negativos, es decir, cuantos más pequeños sean los valores obtenidos, mejor será la calidad de las pastas evaluadas.

La Tabla 1.4 muestra la media obtenida para cada atributo evaluado por los 13 panelistas en dos sesiones independientes. A excepción de la pegajosidad de la superficie, todos los parámetros mostraron diferencias significativas entre las muestras. Para el atributo firmeza, Com1 y Com3 fueron las pastas mejores calificadas, mientras que Com4 y Com5, obtuvieron las peores calificaciones. En el caso del color amarillo, las calificaciones variaron entre 4,5 para Com2, seguido de Com5, mientras que Com3 obtuvo la peor calificación de 1,4. Para el atributo brillo los resultados obtenidos variaron entre 4,5 para Com5, 4,2 para Com2 a 2,9 para Com4, siendo ésta última la muestra peor calificada. En el caso de masticabilidad, los valores estuvieron comprendidos entre 5,1 para Com1 a 3,0 para Com5.

Tabla 1.4 - Evaluación sensorial de espaguetis cocidos

\begin{tabular}{ccccccc}
\hline Muestra & Firmeza & $\begin{array}{c}\text { Color } \\
\text { amarillo }\end{array}$ & Brillo & $\begin{array}{c}\text { Masticabilidad } \\
\text { (chewiness) }\end{array}$ & $\begin{array}{c}\text { Pegajosidad de } \\
\text { la superficie }\end{array}$ & $\begin{array}{c}\text { Aspecto } \\
\text { superficial }\end{array}$ \\
\hline Com1 & $4,9 \pm 1,5 \mathrm{~b}$ & $3,8 \pm 1,4 \mathrm{bc}$ & $3,5 \pm 1,5 \mathrm{ab}$ & $5,1 \pm 1,4 \mathrm{c}$ & $3,5 \pm 2,2 \mathrm{a}$ & $3,2 \pm 1,2 \mathrm{~b}$ \\
Com2 & $3,3 \pm 1,4 \mathrm{a}$ & $4,5 \pm 1,6 \mathrm{c}$ & $4,2 \pm 1,3 \mathrm{bc}$ & $4,2 \pm 1,4 \mathrm{bc}$ & $4,4 \pm 1,6 \mathrm{a}$ & $2,5 \pm 1,4 \mathrm{ab}$ \\
Com3 & $4,9 \pm 1,0 \mathrm{~b}$ & $1,4 \pm 0,5 \mathrm{a}$ & $3,5 \pm 1,1 \mathrm{abc}$ & $5,0 \pm 1,2 \mathrm{c}$ & $3,6 \pm 1,6 \mathrm{a}$ & $5,1 \pm 1,0 \mathrm{c}$ \\
Com4 & $2,6 \pm 1,1 \mathrm{a}$ & $3,0 \pm 1,0 \mathrm{~b}$ & $2,9 \pm 1,3 \mathrm{a}$ & $3,5 \pm 1,6 \mathrm{ab}$ & $3,8 \pm 1,5 \mathrm{a}$ & $2,0 \pm 0,7 \mathrm{a}$ \\
Com5 & $2,5 \pm 1,5 \mathrm{a}$ & $4,0 \pm 1,2 \mathrm{c}$ & $4,5 \pm 1,1 \mathrm{c}$ & $3,0 \pm 1,6 \mathrm{a}$ & $4,5 \pm 1,7 \mathrm{a}$ & $2,5 \pm 1,1 \mathrm{ab}$ \\
\hline
\end{tabular}

Valores seguidos de la misma letra dentro de una columna no presentan diferencias significativas $(p<=0,05)$. 
Dentro de los atributos negativos, si bien no se encontraron diferencias significativas para pegajosidad de la superficie, Com 2 y Com5 fueron las peor calificadas, mientras que Com3 fue la muestra que presentó el peor aspecto superficial.

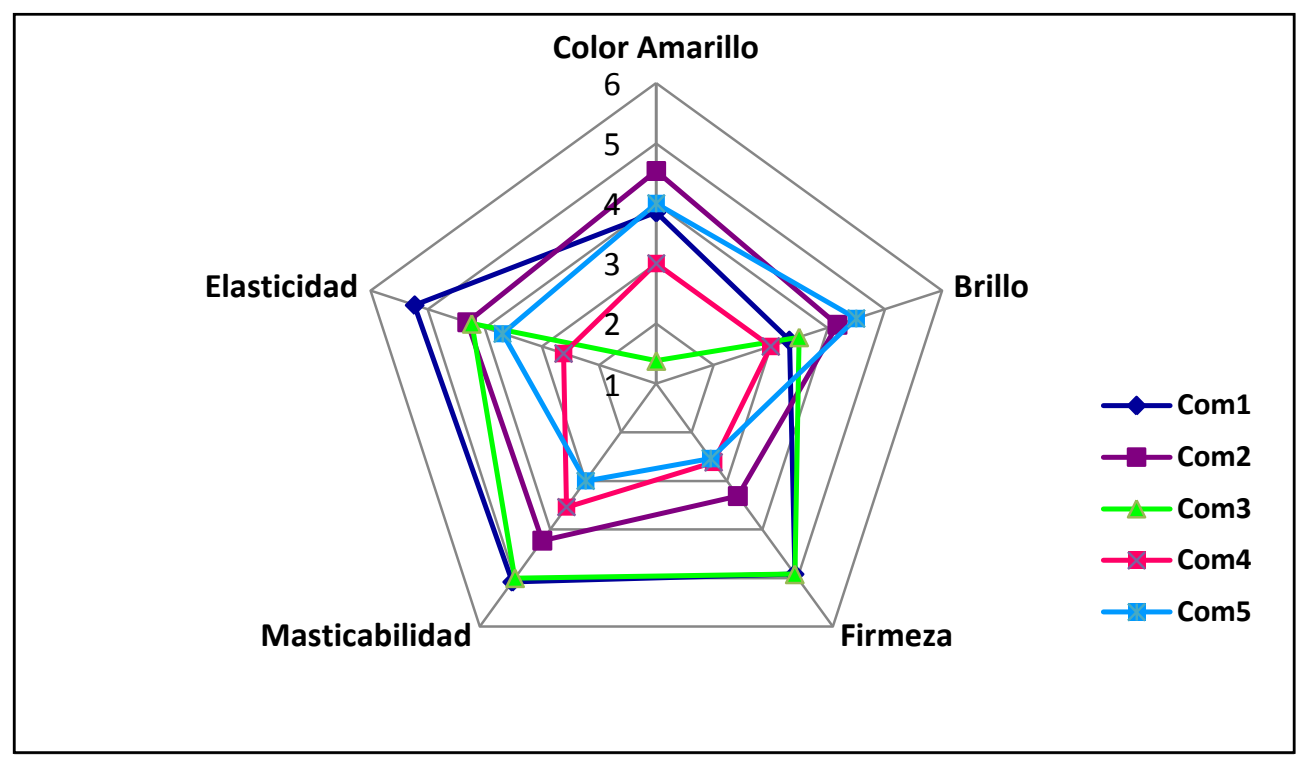

Figura 1.3 - Representación de los atributos sensoriales, considerados como positivos, de las pastas cocidas.

Aquellos atributos considerados "positivos" se muestran en la Figura 1.3, representado a cada uno de ellos un eje del gráfico. Considerando que áreas más grandes indican pastas de mejor calidad, Com1 y Com2 fueron las mejores calificadas, mientras que Com4, al tener el área más pequeña se podría considerar como la de peor calidad de acuerdo a la evaluación sensorial.

El PCA realizado a partir de la evaluación sensorial, habiendo sometidos los datos estandarizados a un análisis de matriz de correlación (Figura 1.4), mostró que las dos primeras dimensiones pueden explicar el $86 \%$ de la varianza total. La primera dimensión separó las muestras en dos grupos, el primero con los valores más altos de firmeza, masticabilidad (chewiness) y aspecto superficial, donde se encontraban Com1 y Com3 y un segundo grupo incluyendo a Com2, Com4 y Com5, con altos valores de pegajosidad, brillo y color amarillo. 


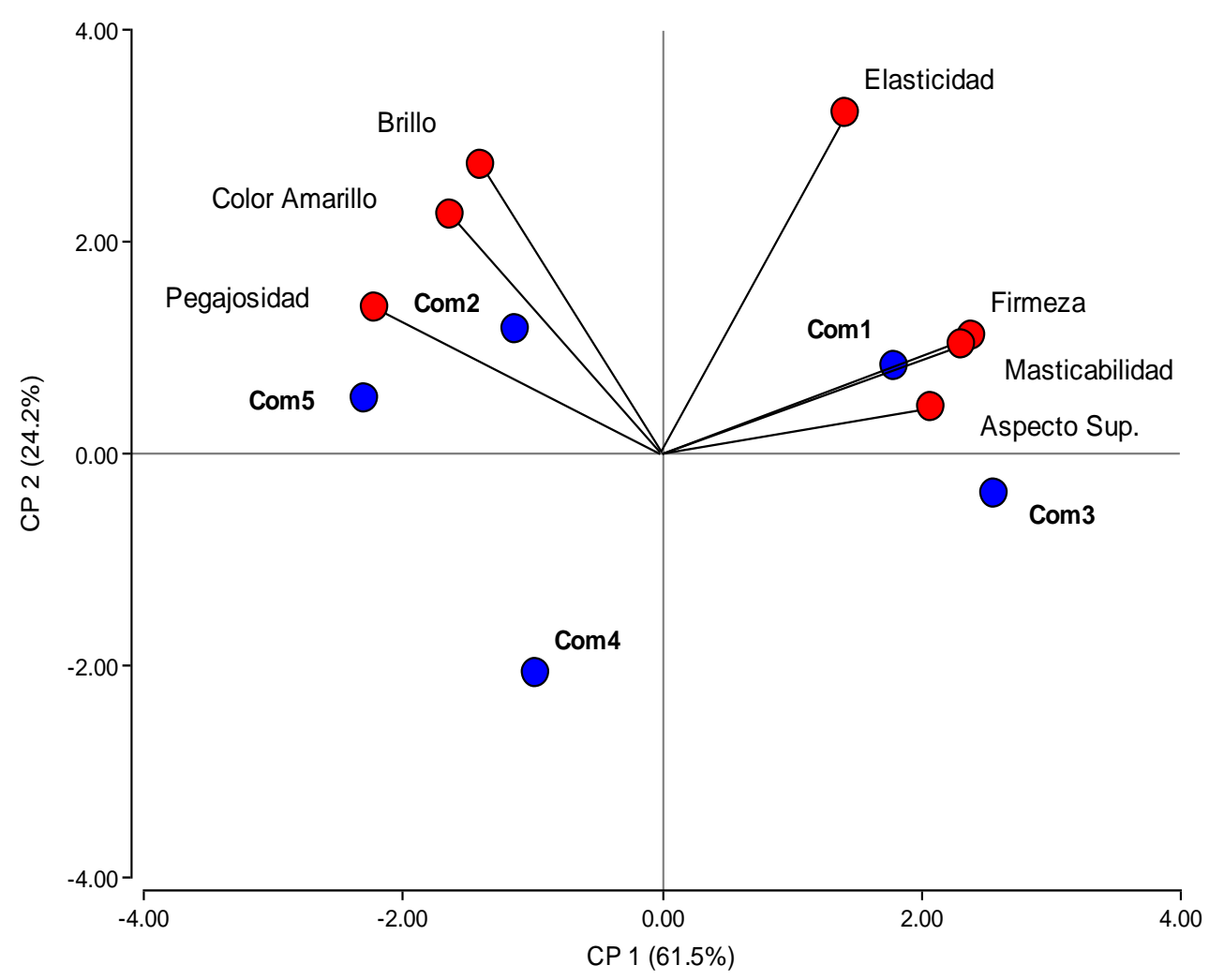

Figura 1.4 - Análisis de PCA de los atributos sensoriales evaluados en las pastas cocidas.

\section{Análisis instrumental de textura}

\section{Firmeza}

La Figura 1.5 muestra el perfil de fuerza en función del tiempo, a partir del cual se estimó la firmeza como el pico de fuerza máxima de la curva, mientras que el área bajo la curva fue tomada como el trabajo necesario para deformar los espaguetis hasta el $70 \%$ de su altura inicial. Todos los valores fueron normalizados por el área de contacto entre la sonda y la muestra. 


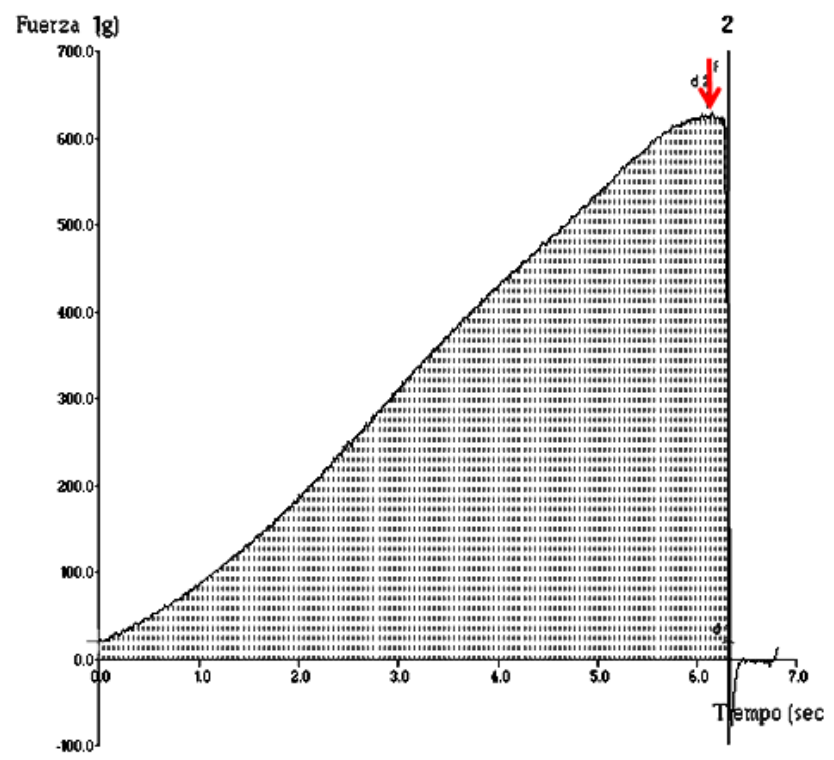

Figura 1.5 - Perfil de fuerza en función del tiempo utilizado para la determinación de Firmeza.

La Figura 1.6 compara los valores de firmeza obtenidos para los espaguetis cocidos a su TOC y a tiempos de $50 \%$ y $100 \%$ mayores a sus TOC. Los valores de firmeza a los correspondientes TOC estuvieron comprendidos entre 13,6 N para Com1 a 6,1 N para Com4 y Com5. Los valores de firmeza a tiempos 50 y $100 \%$ más prolongados que los TOC mostraron igual tendencia; valores más altos para Com1 y valores más bajos para Com4 y Com5.

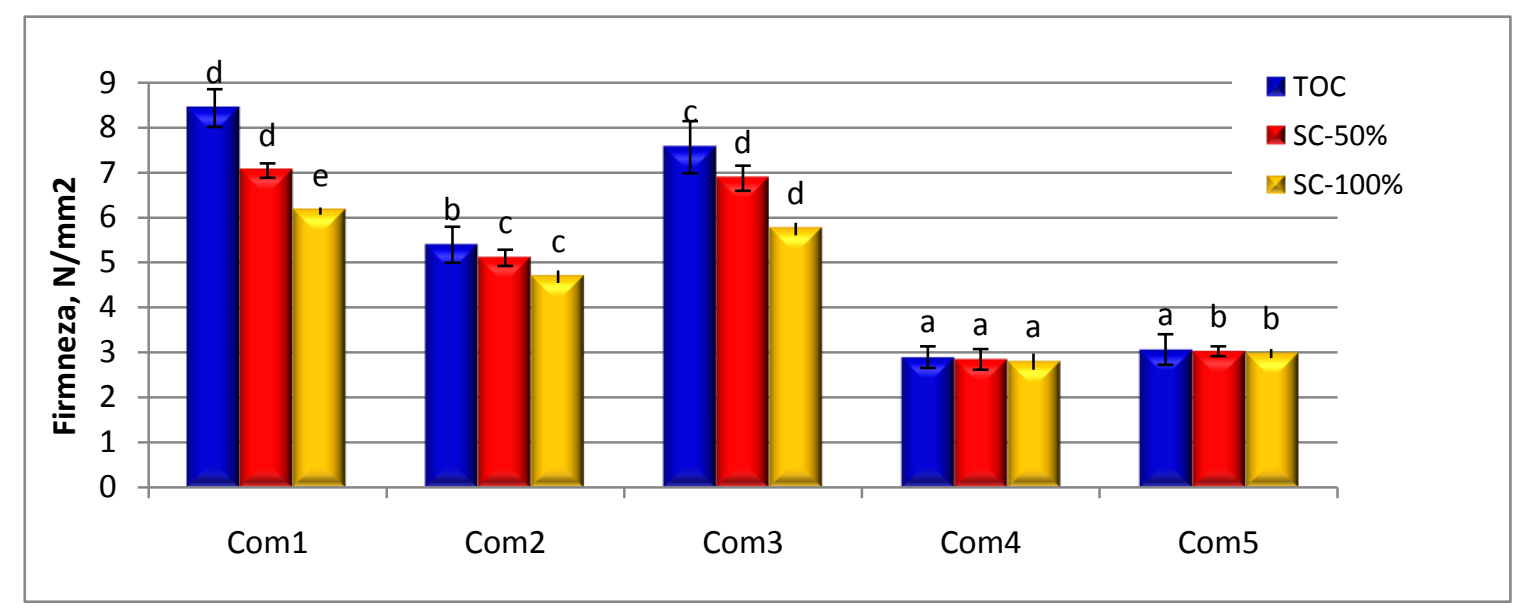

Figura 1.6 - Firmeza de las pastas cocidas a sus tiempos óptimos de cocción (TOC) y con una sobrecocción del 50 y del 100\% (SC-50\%, SC-100\%). Valores seguidos de la misma letra dentro del mismo tiempo de cocción no presentan diferencias significativas $(p \leq 0,05)$.

Sólo las muestras Com1, Com2 y Com3 mostraron diferencias significativas entre los tiempos de cocción, no así las muestras Com4 y Com5, pudiendo interpretarse como que estas dos últimas muestras tendrían una mejor resistencia a la sobre-cocción. Pero en realidad, 
Com4 y Com5 mostraron valores muy bajos de firmeza ya a sus TOC, de modo que la sobrecocción del 50 y $100 \%$, probablemente no pudo afectar más la firmeza de estas muestras.

La muestra elaborada con sémola de trigo candeal mantuvo una mejor textura después de la sobre-cocción que las muestras elaboradas con trigo pan, resultado coincidente con los mayores valores de firmeza de Com1. En general, cuando las pastas se elaboran por extrusión la sémola de trigo candeal genera pastas con mejor textura que la harina de trigo pan (Dexter et al., 1983). De hecho el proceso de extrusión no es apto para cuando la materia prima con la que se va a elaborar la pasta es de mala calidad, como pueden ser las harinas débiles (Abecassis et al., 1994).

\section{Cohesividad, elasticidad, masticabilidad (chewiness) y resiliencia}

A partir del perfil de textura que se muestra en la Figura 1.7, se estimó la cohesividad como el cociente entre el área comprendida entre los anclajes 5 y 6 y el área comprendida entre los anclajes 1 y 3 , y la elasticidad como el cociente entre la distancia desde el anclaje 5 al 7 y la distancia desde el anclaje 1 al 2. Además, se calculó la masticabilidad (chewiness) como el producto entre la cohesividad y la elasticidad y la resiliencia como el cociente entre el área comprendida entre el anclaje 2 y 3 y el área comprendida entre los anclajes 1 y 2.

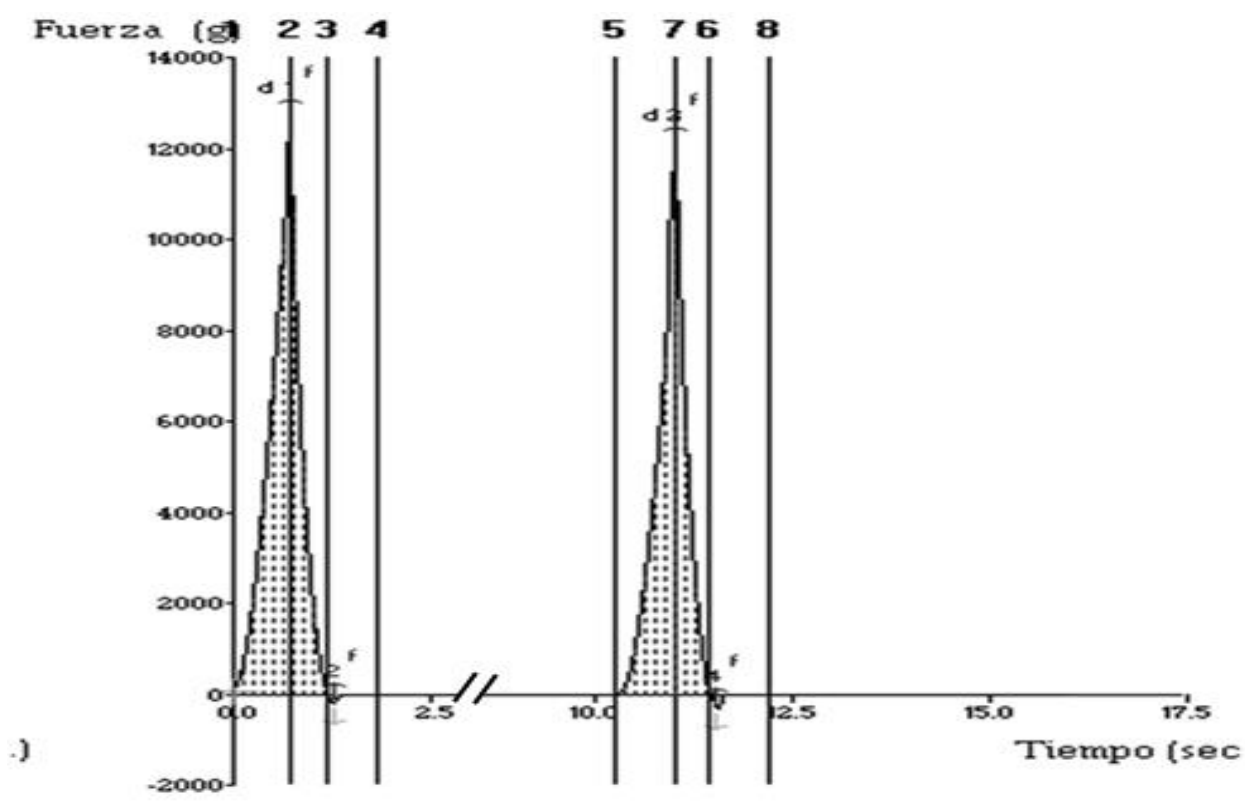

Figura 1.7 - Perfil de textura usado para el cálculo de cohesividad, elasticidad, masticabilidad (chewiness) y resiliencia. 
En la Tabla 1.5 se muestran los valores de elasticidad, cohesividad, masticabilidad y resiliencia para los espaguetis cocidos. Las muestras Com4 y Com5 presentaron los mayores valores de elasticidad y cohesividad; mientras que para masticabilidad (chewiness) los valores calculados estuvieron comprendidos entre 9,5 y $11,4 \mathrm{~N}$, correspondiendo el menor valor a las muestras Com2 y Com4 y el mayor valor a la muestra Com3. Respecto a la resiliencia, la muestra Com1 presentó el mayor valor, siendo éste 0,073.

Tabla 1.5 - Elasticidad, cohesividad, masticabilidad (chewiness) y resiliencia

\begin{tabular}{ccccc}
\hline Muestra & Elasticidad & Cohesividad & $\begin{array}{c}\text { Masticabilidad } \\
\text { (chewiness)(N) }\end{array}$ & Resiliencia \\
\hline Com1 & $0,123 \pm 0,001 \mathrm{c}$ & $0,107 \pm 0,002 \mathrm{~b}$ & $10,8 \pm 0,5 \mathrm{c}$ & $0,073 \pm 0,002 \mathrm{~d}$ \\
Com2 & $0,122 \pm 0,001 \mathrm{~b}$ & $0,106 \pm 0,003 \mathrm{~b}$ & $9,5 \pm 0,3 \mathrm{a}$ & $0,068 \pm 0,002 \mathrm{c}$ \\
Com3 & $0,105 \pm 0,000 \mathrm{a}$ & $0,092 \pm 0,005 \mathrm{a}$ & $11,4 \pm 0,5 \mathrm{~d}$ & $0,060 \pm 0,002 \mathrm{a}$ \\
Com4 & $0,167 \pm 0,002 \mathrm{e}$ & $0,132 \pm 0,005 \mathrm{c}$ & $9,5 \pm 0,6 \mathrm{a}$ & $0,064 \pm 0,004 \mathrm{~b}$ \\
Com5 & $0,159 \pm 0,002 \mathrm{~d}$ & $0,128 \pm 0,004 \mathrm{c}$ & $10,0 \pm 0,7 \mathrm{~b}$ & $0,068 \pm 0,005 \mathrm{c}$ \\
\hline \multicolumn{5}{c}{ Valores seguidos de la misma letra dentro de una columna no presentan diferencias } \\
\multicolumn{5}{c}{ significativas ( $\mathrm{p} \leq 0,05)}$.
\end{tabular}

\section{Pegajosidad}

La pegajosidad de los espaguetis cocidos fue estimada a partir del pico de fuerza máxima del perfil de textura que se muestra en la Figura 1.8.

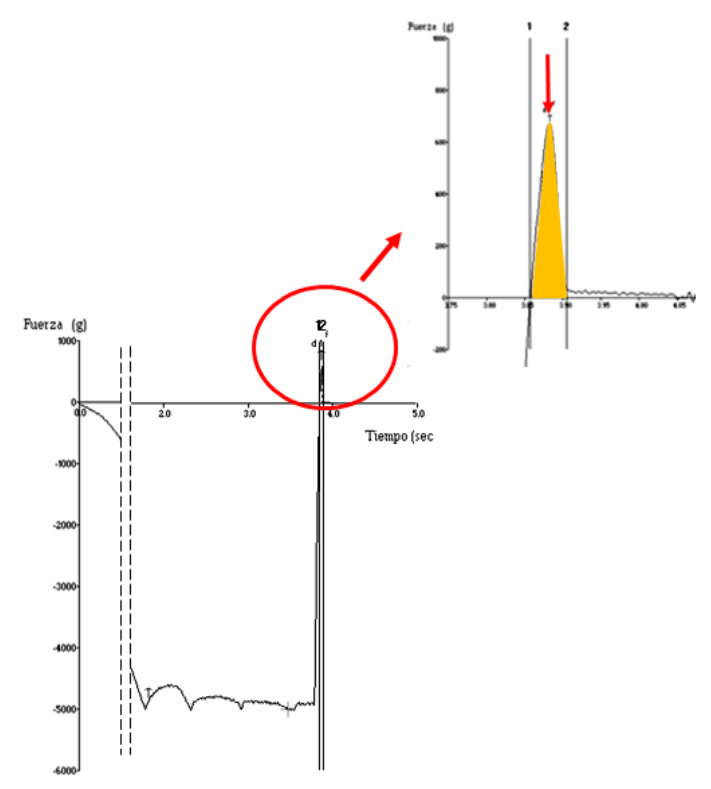

Figura 1.8 - Perfil de textura utilizado para estimar pegajosidad y trabajo de adhesión de las pastas cocidas 
Además, el área bajo la curva fue considerada como el trabajo de adhesión necesario para despegar la sonda de la muestra después de haberle aplicado una determinada fuerza, por un cierto tiempo.

Las muestras Com4 y Com5 mostraron los valores más altos tanto para la pegajosidad como para el trabajo de adhesión (Tabla 1.6), siendo éstos 2,11 y $2,01 \mathrm{~N} / \mathrm{cm}^{2}$ respectivamente, mientras que Com 1 y Com 3 mostraron los valores más bajos, 0,29 y 0,38 N/cm².

A partir del análisis de correlación de Pearson realizado sobre las variables de textura medidas, se encontró que la firmeza presentó una correlación negativa con la elasticidad ( $r=-$ $0,89 ; p \leq 0,05)$ y con la pegajosidad $(r=-0,98 ; p<0,001)$. Es decir que de acuerdo a la evaluación instrumental de textura, las pastas más firmes son aquellas menos elásticas y menos pegajosas. Además la cohesividad mostró una excelente correlación positiva con la elasticidad $(r=1,00 ; p<0,001)$ y con la pegajosidad $(r=0,93, p<0,05)$. Asimismo, la elasticidad también mostró correlación positiva con la pegajosidad $(r=0,95, p<0,05)$.

Por otro lado, se encontró que la pegajosidad de las muestras presentó una correlación con el contenido de amilosa cuantificado en el agua de cocción ( $r=0,93 ; p=0,02)$, resultados coincidentes con los informados por Grant et al., (1993).

\begin{tabular}{|c|c|c|}
\hline Muestra & $\begin{array}{l}\text { Pegajosidad } \\
\left(\mathrm{N} / \mathrm{cm}^{2}\right)\end{array}$ & $\begin{array}{l}\text { Trabajo de adhesión } \\
\left(\mathrm{N} \mathrm{s} / \mathrm{cm}^{2}\right)\end{array}$ \\
\hline Com1 & $0,29 \pm 0,02 a$ & $0,005 \pm 0,001 \mathrm{a}$ \\
\hline Com2 & $0,86 \pm 0,05 b$ & $0,025 \pm 0,004 b$ \\
\hline Com3 & $0,38 \pm 0,06 a$ & $0,008 \pm 0,005 a$ \\
\hline Com4 & $2,11 \pm 0,15 c$ & $0,099 \pm 0,020 c$ \\
\hline Com5 & $2,01 \pm 0,22 c$ & $0,094 \pm 0,020 c$ \\
\hline
\end{tabular}

El análisis de componentes principales de los valores de textura de las pastas cocidas (datos previamente estandarizados), también pudo ser representado en dos dimensiones, correspondiendo éstas al 80\% de la varianza total (Figura 1.9). La primera dimensión separó muestras con altos valores de firmeza y masticabilidad correspondientes a Com1 y Com3; mientras que la cohesividad, elasticidad, pegajosidad y trabajo de adhesión fueron relacionados con las muestras Com2, Com4 y Com5. 
De acuerdo al análisis de PCA, el mapa derivado de la evaluación sensorial fue similar al derivado de las mediciones instrumentales de textura.

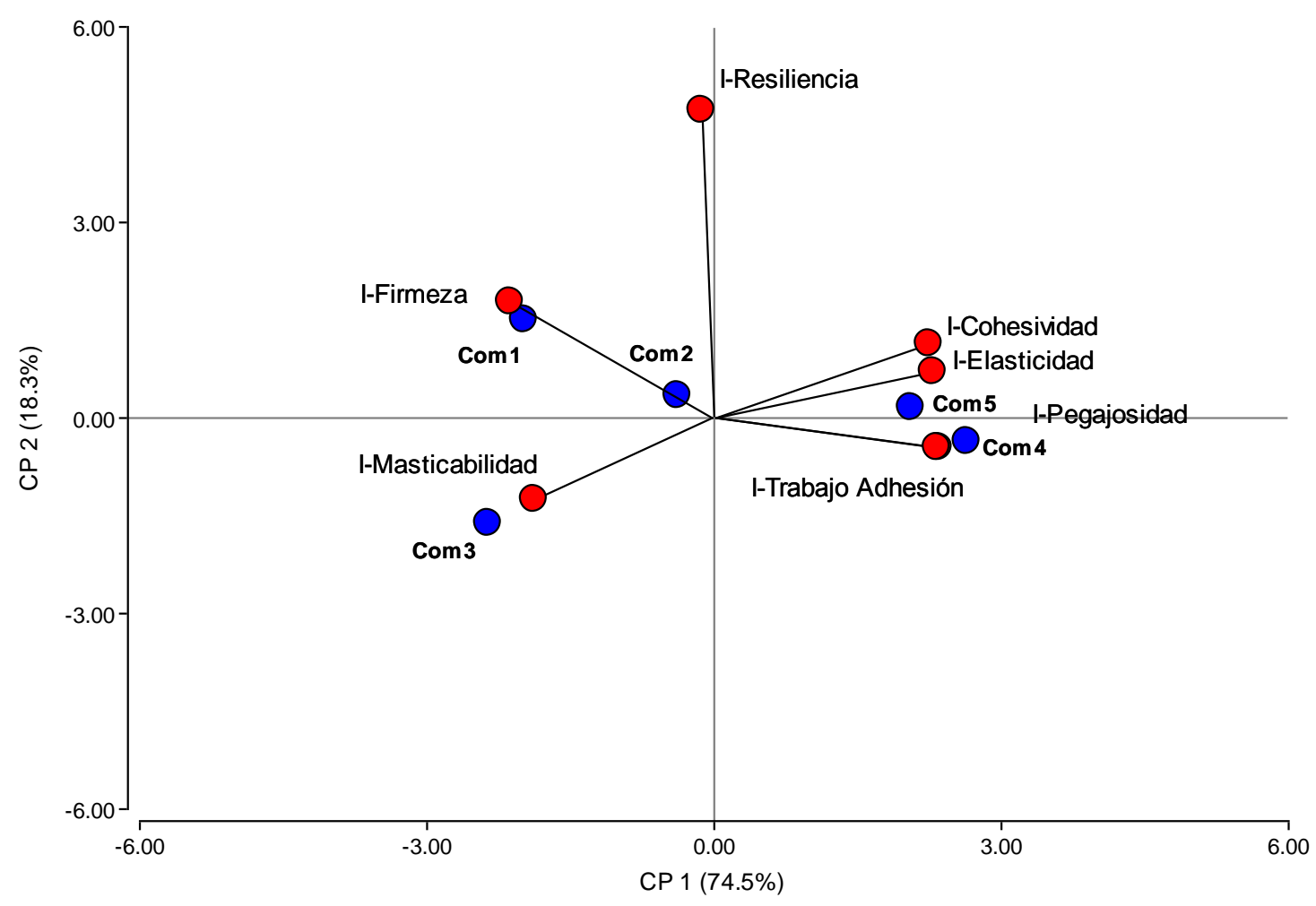

Figura 1.9 - PCA de la evaluación de la textura de las pastas cocidas.

\section{Correlación entre la evaluación sensorial y el análisis instrumental de textura}

Es de suma importancia encontrar una posible correlación entre la evaluación sensorial y la medición instrumental ya que así se podría identificar si un método instrumental es capaz de predecir la característica sensorial correspondiente (Tang et al., 1999).

En este trabajo se encontró una excelente correlación entre el color amarillo de la evaluación sensorial con su respectiva medición instrumental, valor $b^{*}$ (Pearson, $r$ : 0,99; $p<0,001)$. De igual modo se encontró una correlación entre la firmeza proveniente de la medición instrumental y la firmeza y la masticabilidad provenientes de la evaluación sensorial ( $r$ : 0,98, p<0,001 y $r=0,97, p<0,05$, respectivamente). Si bien entre la masticabilidad instrumental y sensorial no se encontró correlación, si la hubo entre la cohesividad instrumental y la masticabilidad evaluada sensorialmente $(r=-0,87 ; p \leq 0,05)$. 
Contrariamente a lo esperado, la pegajosidad medida instrumentalmente no presentó correlación con la pegajosidad evaluada sensorialmente, aunque sí lo hizo y de manera negativa con la firmeza y la masticabilidad provenientes de la evaluación sensorial $(r=-0,94$; $p<0,05$ y $r=-0,96 ; p<0,05$, respectivamente). Probablemente la dificultad que presentó la pegajosidad tanto para ser medida por medio de un instrumento como por un panel de evaluadores, especialmente en términos de sensibilidad, sea el problema que explique esta discrepancia entre la medición objetiva y subjetiva de esta propiedad.

Para analizar la habilidad de las mediciones instrumentales y sensoriales de predecir la calidad de las pastas cocidas, se llevó a cabo un PCA a partir de todos los atributos evaluados (Figura 1.10). Las primeras dos dimensiones pudieron explicar el $88 \%$ del total de la varianza. La primera dimensión separó muestras con altos valores de firmeza y masticabilidad, provenientes tanto de la medición instrumental como de la sensorial, de aquellas muestras con altos valores de pegajosidad y color amarillo. La segunda dimensión indicó la variabilidad dada por el color amarillo y el valor b* y la elasticidad proveniente tanto de la evaluación sensorial como de la instrumental.

A partir de los ángulos de los vectores, es posible interpretar la fuerte correlación positiva entre firmeza y masticabilidad y entre el color amarillo y los valores $b^{*}$ de las mediciones sensoriales e instrumentales respectivamente, coincidente con lo observado a través de los análisis de correlación de Pearson. Además el largo de los vectores sugiere una contribución similar de cada variable en la representación del PCA.

Cuando se comparó el PCA obtenido para el color de las pastas, junto con el de la evaluación sensorial y el de la medición instrumental de textura de las cinco muestras analizadas, los tres coincidieron en dividir las muestras en los mismos dos grupos; Com2, Com4 y Com5 por un lado y Com1 y Com3 por el otro. 


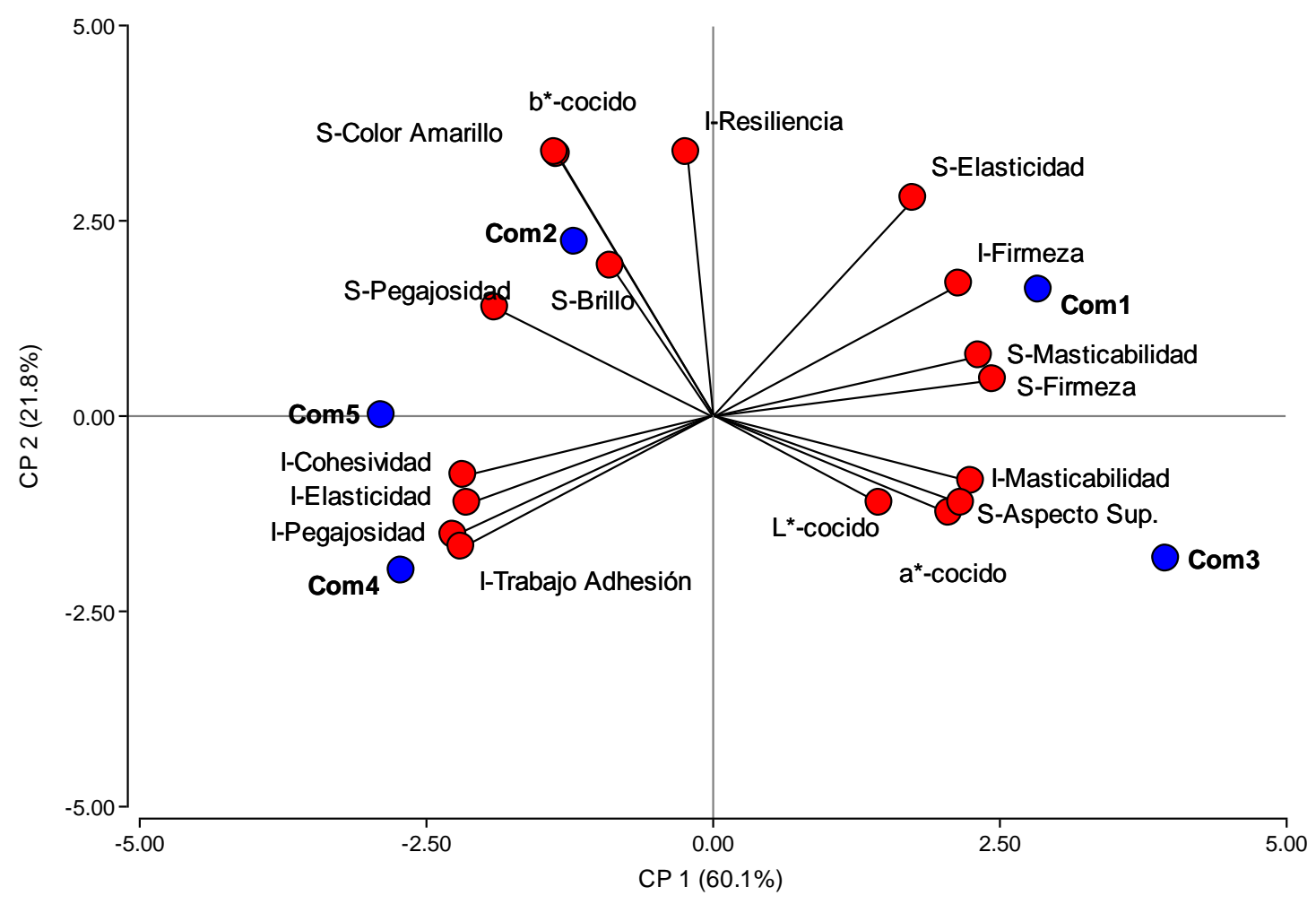

Figura 1.10 - PCA de las variables instrumentales y sensoriales de las pastas cocidas (Datos estandarizados).

\section{Conclusión}

La muestra Com1 fue la que resultó ser la de mejor calidad por presentar un bajo residuo de cocción, el menor contenido de amilosa en el agua de cocción, la mayor firmeza y la menor pegajosidad entre todas las muestras evaluadas.

El análisis químico, el comportamiento de las pastas durante la cocción, las mediciones instrumentales de textura y la evaluación sensorial de las muestras, mostraron buena sensibilidad para ser utilizados como parámetros de calidad de las pastas. Entre las mediciones instrumentales y sensoriales se encontró una significativa correlación para la mayoría de las variables según se observó a través de los coeficientes de Pearson y el análisis de componentes principales. Justamente a partir de esas correlaciones encontradas, es que se sugiere que la medición instrumental de firmeza y el color amarillo de las pastas, pueden ser postuladas como métodos indicadores de la calidad final de las pastas. 


\section{SEGUNDA SECCIÓN}

\section{Evaluación del efecto del almidón y del gluten sobre la calidad de las pastas laminadas elaboradas con harina de} trigo pan 
Para estudiar cómo influyen los principales componentes de la harina en la calidad de las pastas, la harina de trigo fue sustituida con diferentes niveles de almidón y de gluten.

\section{Composición química de la harina de trigo, del almidón y del gluten}

\section{Contenido de proteínas, de cenizas y de fibra cruda}

Se utilizó harina comercial de trigo pan (MCA). Además, como modificadores de la formulación se utilizaron almidón de trigo y gluten.

Los valores obtenidos de proteínas, cenizas y fibra cruda para la harina de trigo (MCA) fueron $11,2 \%, 0,57 \%, 0,21 \% \mathrm{p} / \mathrm{p}$ en base seca, respectivamente. Además el contenido de proteínas medido en el gluten y el almidón fue 74,1 y $0,2 \%$ y el de cenizas 0,86 y $0,13 \%, p / p$, base seca.

\section{Determinación de I-SDS y WRC en las harinas sustituidas con almidón y con gluten}

La harina de trigo utilizada para elaborar las pastas fue sustituida con dos cantidades de almidón, 5 y $10 \mathrm{~g} / 100 \mathrm{~g}$ de harina (A5, A10), y dos de gluten, 3 y $6 \mathrm{~g} / 100 \mathrm{~g}$ de harina $(\mathrm{G} 3, \mathrm{G} 6)$. Los valores de I-SDS y WRC de las mezclas de harinas más almidón y de la harina más gluten se muestran en la Tabla 2.1.

El efecto de la sustitución de la harina con gluten provocó, como era esperado, un aumento en los volúmenes de I-SDS. De manera contraria, cuando la harina fue sustituida con diferentes cantidades de almidón, los valores de I-SDS disminuyeron al compararlos con los valores medidos en la harina sin sustituir, debido al efecto diluyente del almidón sobre las proteínas presentes en la harina.

En el caso de la WRC, como es un parámetro que no solo depende de la cantidad de proteínas sino que además se relaciona con los pentosanos, las glicoproteínas, los complejos proteína-polisacáridos y el almidón dañado, no se observó una tendencia determinada ante el agregado de gluten o de almidón. 
Tabla 2.1 - I-SDS y WRC de las mezclas formadas por la sustitución de la harina MCA con diferentes cantidades de almidón y de gluten.

\begin{tabular}{ccc}
\hline Muestra & I-SDS, $\mathbf{~} L$ & WRC, $\mathbf{g} / \mathbf{1 0 0 g}$ \\
\hline Control $^{1}$ & $9,8 \pm 0,4 \mathrm{~b}$ & $60 \pm 1 \mathrm{a}$ \\
A5 & $9,4 \pm 0,2 \mathrm{~b}$ & $68 \pm 1 \mathrm{bc}$ \\
A10 & $7,6 \pm 0,3 \mathrm{a}$ & $68 \pm 1 \mathrm{~b}$ \\
G3 & $15,1 \pm 0,4 \mathrm{c}$ & $70 \pm 1 \mathrm{c}$ \\
G6 & $16,1 \pm 0,2 \mathrm{~d}$ & $69 \pm 1 \mathrm{bc}$ \\
\hline
\end{tabular}

Valores seguidos de la misma letra dentro de una columna no presentan diferencias significativas $(p<=0,05)$. ${ }^{1}$ Muestra Control: elaborada solo con harina de trigo sin el agregado de ningún modificador.

\section{Características de las pastas frescas}

\section{Comportamiento durante la cocción}

El tiempo óptimo de cocción (TOC), el residuo de cocción y la absorción de agua de las pastas, elaboradas con harina de trigo pan sustituida con diferentes cantidades de almidón y de gluten, se muestran en la Tabla 2.2 .

Tabla 2.2 - TOC, Residuo de cocción y absorción de agua de las pastas

\begin{tabular}{cccc}
\hline Muestra & TOC, $\min$ & $\begin{array}{c}\text { Residuo de Cocción } \\
\% \mathbf{p} / \mathbf{p}\end{array}$ & $\begin{array}{c}\text { Absorción de Agua } \\
\% \mathbf{p} / \mathbf{p}\end{array}$ \\
\hline Control $^{1}$ & 12 & $6,5 \pm 0,2 \mathrm{~b}$ & $149 \pm 4 \mathrm{~b}$ \\
A5 & 12 & $6,7 \pm 0,0 \mathrm{bc}$ & $150 \pm 1 \mathrm{~b}$ \\
A10 & 12 & $6,8 \pm 0,1 \mathrm{c}$ & $152 \pm 1 \mathrm{~b}$ \\
G3 & 14 & $6,0 \pm 0,0 \mathrm{a}$ & $145 \pm 0 \mathrm{ab}$ \\
G6 & 14 & $5,9 \pm 0,1 \mathrm{a}$ & $139 \pm 6 \mathrm{a}$ \\
\hline \multicolumn{2}{l}{ Valores seguidos de la misma letra dentro de una columna no presentan } \\
diferencias significativas (p<=0,05). ${ }^{1}$ Muestra Control: elaborada solo \\
con harina de trigo sin el agregado de ningún modificador. A: almidón,
\end{tabular}
G: gluten.

EI TOC para la muestra control (elaborada solo con harina MCA) y para las muestras con almidón, A5 y A10, resultó ser 12 min, mientras que para las muestras sustituidas con gluten, G3 y G6, el TOC medido fue de 14 min. Estos resultados son coincidentes con los informados por Park \& Baik (2004), quienes determinaron que cuanto mayor es el contenido de proteínas, los TOC son más prolongados.

En la Figura 2.1 se compara la estructura de la pasta, sustituida con $10 \%$ p/p de almidón (A) con la que contiene $6 \% \mathrm{p} / \mathrm{p}$ de gluten (B) después de haber sido sometidas a 3 minutos de 
cocción. Se puede observar el mayor grado de gelatinización del almidón (zona traslúcida) en la pasta sustituida con almidón respecto a la sustituida con gluten, indicando que la estructura de la primera muestra resultó más débil que la de la segunda, permitiendo una mayor difusión del agua de cocción al interior de la pasta.
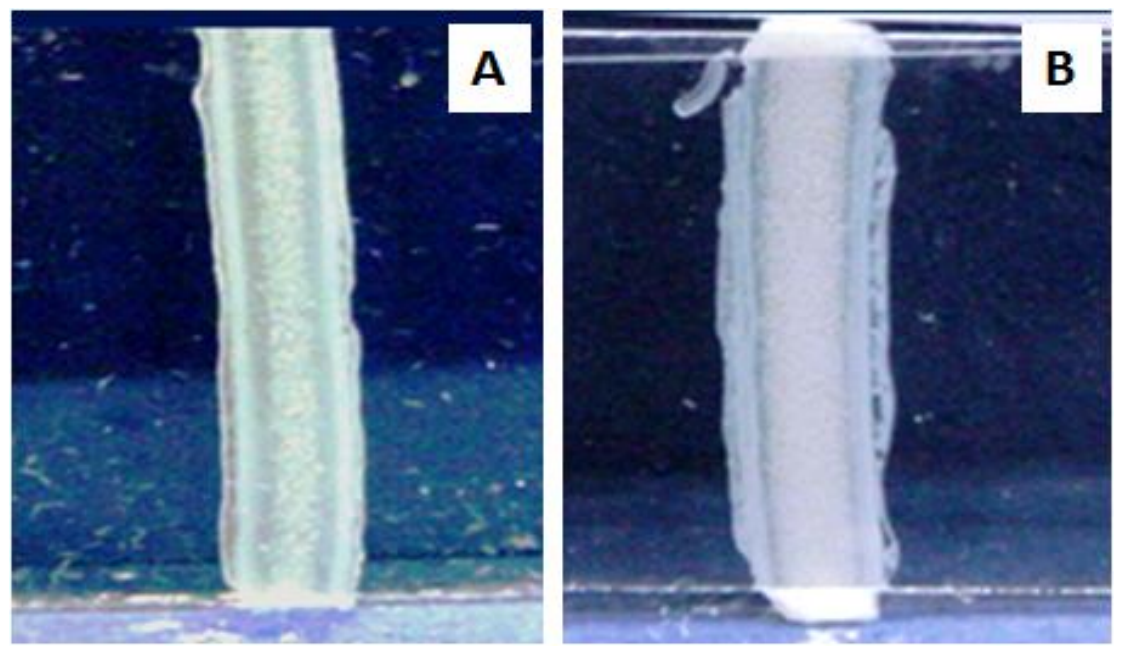

Figura 2.1 - Estructura de pastas laminadas elaboradas con harina de trigo pan, siendo esta última sustituida con $10 \% \mathrm{p} / \mathrm{p}$ de almidón $(A)$ y con $6 \% \mathrm{p} / \mathrm{p}$ de gluten $(B)$, después de haber sido sometida a 3 minutos de cocción.

Las muestras sustituidas con gluten, mostraron menores valores de residuo de cocción y menores valores de absorción de agua que la muestra control, aun habiendo sido sometidas un tiempo de cocción 2 minutos más prolongado. Para las pastas sustituidas con almidón se obtuvieron mayores valores de residuos de cocción, mientras que para la absorción de agua, si bien presentó una tendencia a aumentar con la creciente sustitución de almidón, no se encontraron diferencias significativas con la muestra control.

A pesar que la absorción de agua depende fuertemente del tiempo de cocción (Zweifel et al., 2003), el mayor contenido de proteínas en las muestras sustituidas con gluten tuvo un mayor efecto sobre el comportamiento de las pastas durante la cocción, al ayudar a constituir una estructura más firme capaz de limitar la difusión del agua al interior de la pasta (Zweifel et al., 2003), aumentando los tiempos de cocción y disminuyendo así la lixiviación de sólidos al agua de cocción (De Noni \& Pagani, 2010). 


\section{Color de las pastas}

La adición de almidón y de gluten también influyó sobre el color de las pastas frescas. Mientras que el agregado de gluten disminuyó la luminosidad y aumentó los valores $\mathrm{a}^{*}$ y b* respecto de la muestra control, el agregado de almidón produjo el efecto contrario (Figura 2.2).

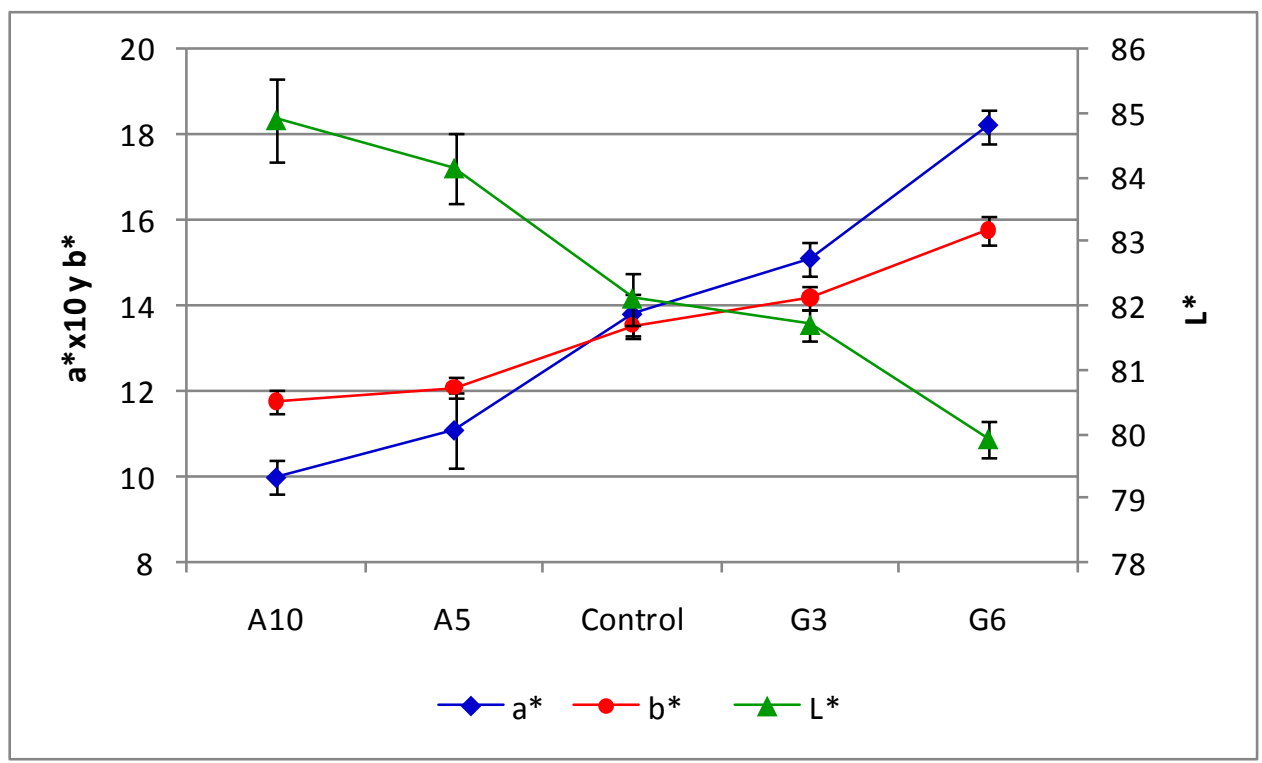

Figura 2.2 - Color de las pastas frescas en términos de $L^{*}, a^{*}$ y $b^{*}$ elaboradas con harina sustituida con almidón y con gluten. (El componente a* fue multiplicado por 10 para ser mostrado en la misma escala que $\left.b^{*}\right)$.

Además se correlacionó el color medido con el contenido de proteínas de las pastas sustituidas con almidon ( $A 5=10,2 ; A 10=9,7 \% p / p)$, y con gluten $(G 3=12,8 ; G 6=14,7 \% p / p)$. En este sentido se observó una correlación negativa entre las proteínas y el componente $L^{*}$ ( $r$ : $\left.-0,98^{* *}\right)$ y positva con $\mathrm{a}^{*}\left(\mathrm{r}: 0,98^{* *}\right)$ y con $\mathrm{b}^{*}\left(\mathrm{r}: 1,0^{* *}\right)$. Las proteínas presentes en la pasta favorecieron la formación de una estructura compacta, debido a una mayor adherencia entre el gluten y el almidón, resultando en una masa de apariencia traslúcida (Oh et al., 1985); por lo tanto a mayor contenido de proteínas, menor capacidad de reflejar la luz y menores valores $L^{*}$.

\section{Medición instrumental de la textura de las pastas}

Los parámetros de firmeza, masticabilidad y pegajosidad medidos en las pastas frescas laminadas se muestran en la Tabla 2.3. 
Mientras que la sustitución con gluten resultó en pastas de mayor firmeza y masticabilidad, la pegajosidad, no mostró diferencias significativas con la muestra control, ni con las muestras sustituidas con almidón.

Tabla 2.3 - Medición instrumental de textura de las pastas frescas

\begin{tabular}{cccc}
\hline Muestra & Firmeza (N) & Masticabilidad(N) & Pegajosidad (N s) \\
\hline Control $^{1}$ & $3,25 \mathrm{a}$ & $1,92 \mathrm{ab}$ & $-0,15 \mathrm{~b}$ \\
A5 & $3,50 \mathrm{~b}$ & $2,14 \mathrm{bc}$ & $-0,18 \mathrm{a}$ \\
A10 & $3,57 \mathrm{~b}$ & $1,84 \mathrm{a}$ & $-0,19 \mathrm{a}$ \\
G3 & $3,90 \mathrm{c}$ & $2,18 \mathrm{c}$ & $-0,17 \mathrm{ab}$ \\
G6 & $4,45 \mathrm{~d}$ & $2,96 \mathrm{~d}$ & $-0,17 \mathrm{ab}$ \\
\hline
\end{tabular}

Valores seguidos de la misma letra dentro de una columna no presentan diferencias significativas $(p<=0,05) .{ }^{1}$ Muestra Control: elaborada solo con harina de trigo sin el agregado de ningún modificador. A: almidón, G: gluten.

Contrariamente a lo esperado, la muestra control presentó menores valores de firmeza que A5 y A10. Probablemente se debió a que el agua agregada durante la elaboración de las masas, se ajustó experimentalmente a la muestra control, pero no al resto de las muestras. De hecho, todas las muestras fueron preparadas con la misma cantidad de agua $(37,5 \mathrm{~mL} / 100 \mathrm{~g}$ harina) que la muestra control. De acuerdo a Park \& Baik (2002), para un menor contenido de proteínas, se requiere mayor cantidad de agua para el completo desarrollo de la masa. En este sentido, la incorporación de almidón, al diluir proporcionalmente las proteínas, provocó que se necesitara más agua para elaborar la masa de la que le fue agregada, por lo que resultaron masas más firmes para $\mathrm{A} 5$ y $\mathrm{A} 10$. En el caso de la masticabilidad, solo A5 resultó significativamente mayor que la muestra control.

Al comparar la textura medida entre las pastas sustituidas con almidón respecto a las sustituidas con gluten, se observó que estas últimas presentaron mayores valores de firmeza que las muestras sustituidas con almidón. Respeto a la masticabilidad, si bien se encontró una tendencia similar a lo observado para firmeza, A5 no presentó diferencias significativas con G3.

De acuerdo a trabajos previos (Pagani et al., 1986; De Noni \& Pagani, 2010), cuando las interacciones entre las proteínas de la red continua prevalecen durante la cocción, el material almidonoso, el cual hidrata lentamente, queda atrapado dentro de la red, y en consecuencia la pasta cocida será firme. Por el contrario, cuando la red de proteínas no es lo suficientemente fuerte y elástica, el almidón se hincha y gelatiniza antes que tenga lugar la coagulación de las proteínas, afectando negativamente la textura de la pasta. 


\section{Evaluación sensorial de las pastas}

Los parámetros evaluados por el panel sensorial se hicieron por comparación de la mayor o menor intensidad de una determinada propiedad de la pasta cocida, con respecto a la muestra control (Tabla 2.4). Los evaluadores encontraron a las muestras sustituidas con gluten más firmes y a las muestras sustituidas con almidón menos firmes que la muestra control.

Con respecto a la masticabilidad, solo las muestras A10 y G6 fueron diferenciadas de la muestra control, con menor y mayor masticabilidad respectivamente. En cuanto a la pegajosidad, solo A10 fue calificada como más pegajosa que la muestra control, mientras que para el resto de las muestras no se encontraron diferencias significativas.

Tabla 2.4 - Evaluación sensorial de las pastas elaboradas con harina sustituida con almidón y con gluten

\begin{tabular}{ccccc}
\hline Muestra & Firmeza & Masticabilidad & Pegajosidad & Color Amarillo \\
\hline Control $^{1}$ & $0 \mathrm{~b}$ & $0 \mathrm{bc}$ & $0 \mathrm{bc}$ & $0 \mathrm{a}$ \\
$\mathrm{A} 5$ & $-0,8 \mathrm{a}$ & $-0,9 \mathrm{ab}$ & $-0,4 \mathrm{ab}$ & $-0,5 \mathrm{a}$ \\
$\mathrm{A} 10$ & $-1,0 \mathrm{a}$ & $-1,1 \mathrm{a}$ & $-1,0 \mathrm{a}$ & $-0,6 \mathrm{a}$ \\
$\mathrm{G} 3$ & $1,1 \mathrm{c}$ & $0,7 \mathrm{~cd}$ & $0,6 \mathrm{c}$ & $0,8 \mathrm{~b}$ \\
$\mathrm{G} 6$ & $1,9 \mathrm{~d}$ & $1,6 \mathrm{~d}$ & $0,4 \mathrm{bc}$ & $2,0 \mathrm{c}$ \\
\hline
\end{tabular}

Además, las pastas sustituidas con gluten presentaron un color más amarillo, mientras que las adicionadas con almidón resultaron con menor color amarillo que la muestra control. Resultados que se correspondieron con los valores de $b^{*}$ medidos por medio del espectrofotómetro de reflectancia.

El panel sensorial también fue invitado a ordenar las muestras por preferencia en una escala de 1 (menos preferida) a 4 (más preferida) en relación a la muestra control. En este sentido la muestra G6 fue la mejor calificada (Figura 2.3). 


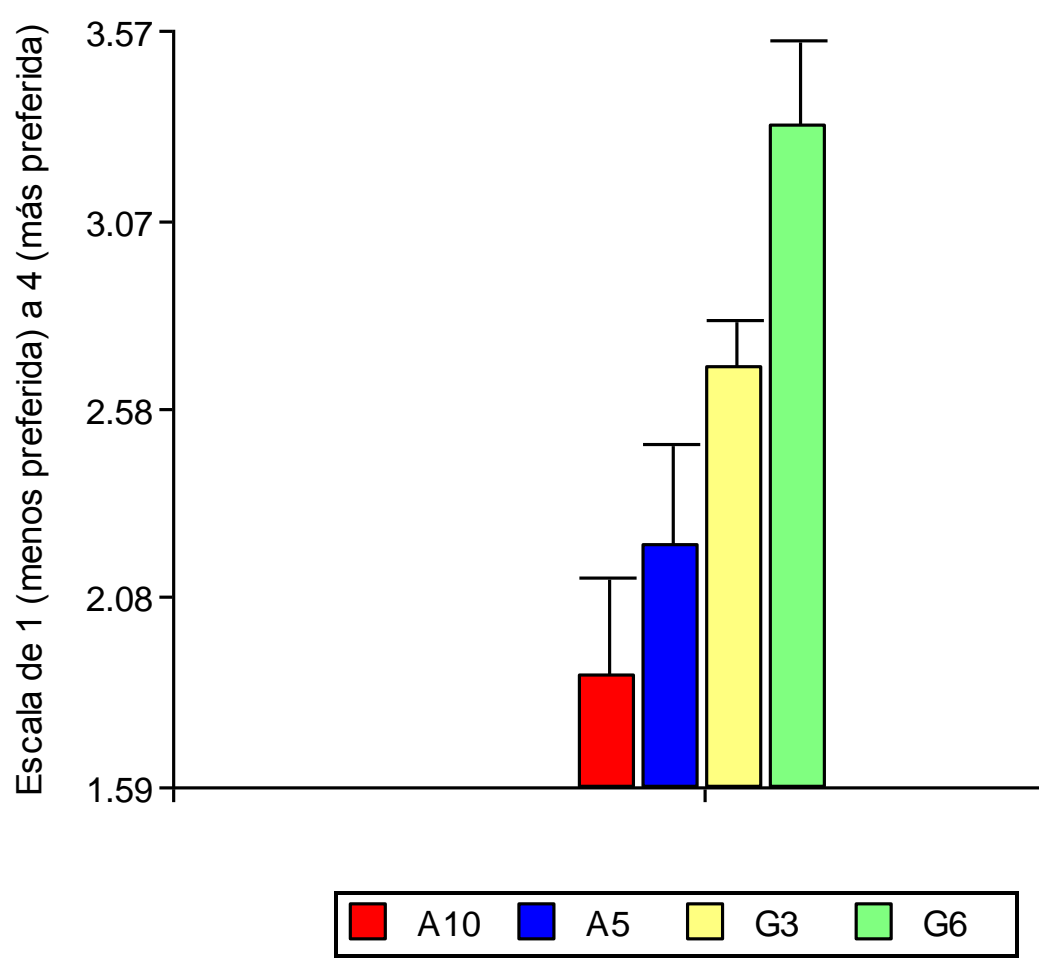

Figura 2.3 - Orden de preferencia dado por los evaluadores para las pastas cocidas elaboradas con harina sustituida con almidón (A5, A10) y con gluten $(G 3, G 6)$.

Al realizar un análisis de Friedman para la evaluación de preferencia, como era de esperar, G6 obtuvo el valor de la suma de rangos más alto $(27,5)$, con una media de rangos de 3,4 ; al tiempo que $\mathrm{A} 10$ fue la muestra menos preferida con una suma de rangos igual a 14,0 y una media igual a 1,8; encontrándose diferencias significativas $(p<0,05)$ para G6 respecto a A5 y A10 (Tabla 2.5).

Tabla 2.5 - Prueba de Friedman para la evaluación preferencia de las pastas elaboradas con harina de trigo pan sustituida con almidón y con gluten

\begin{tabular}{ccc}
\hline Muestra & Suma de Rangos & Media de Rangos \\
\hline A5 & 16,0 & $2,0 \mathbf{a b}$ \\
A10 & 14,0 & $1,8 \mathbf{a}$ \\
G3 & 22,5 & $2,8 \mathbf{~ b c}$ \\
G6 & 27,5 & $3,4 \mathbf{c}$ \\
\hline
\end{tabular}

Letras distintas indican diferencias significativas $(p<=0,050)$. Mínima diferencia significativa entre la suma de rangos 7,951. A: almidón, G: gluten. 


\section{Conclusión}

La sustitución de la harina de trigo pan con diferentes cantidades de almidón y de gluten afectó la calidad de las pastas frescas obtenidas. En efecto, al no someter a las pastas a un proceso de secado posterior, donde puede suceder una desnaturalización parcial de las proteínas que favorezca la calidad de las pastas cocidas, en las pastas frescas la calidad es una función tanto del contenido y la calidad de las proteínas como de las características del almidón.

Los mayores niveles de proteínas extraíbles en SDS medidos en las mezclas de harina de trigo más gluten respecto a los equivalente obtenidos con almidón, significó mayor proporción de proteínas que pudieron unirse por puentes disulfuro, facilitando la formación de una red más continua, limitando el hinchamiento del almidón durante la cocción y su lixiviación posterior, resultando en pastas de mejor calidad.

Consecuentemente, mientras que la adición de gluten favoreció la formación de una estructura más firme, produciendo pastas con menor residuo de cocción, mayor color amarillo, mayor firmeza y masticabilidad, la adición de almidón produjo el efecto contrario, debilitando la estructura de las muestras y por ende empeorando su calidad. La preferencia por la muestra G6 dada por el panel sensorial corroboró estos resultados. 


\section{TERCERA SECCIÓN}

\section{Evaluación del efecto de harinas con}

diferentes características sobre el color

de pastas frescas 
Para evaluar el efecto de diferentes harinas sobre el color de las pastas frescas laminadas, éstas se caracterizaron en términos de la composición química y de las fracciones proteicas, a fin de estudiar la posible relación entre cada uno de sus compontes con el color de las pastas resultantes. Con igual propósito se ensayaron formulaciones con distintas cantidades de agua añadida.

\section{Caracterización de las harinas utilizadas}

Las harinas de trigo pan que se utilizaron fueron: una harina comercial (MCA), una proveniente del cultivar Baguete (BAG) y otra del cultivar Buck Guapo (BUK). Además se estudió una harina de triticale, (Triticosecale Wittmack) var. Tatú (TRI).

\section{Composición de las harinas}

Los valores de humedad, proteínas y cenizas medidos en las harinas estudiadas se muestran en la Tabla 3.1. El mayor contenido de humedad encontrado para las muestras BAG, BUK y TRI respecto a MCA, se debió al agua agregada para el acondicionamiento de los granos antes de ser sometidos a su molienda, la que fue realizada con un molino experimental. En tanto que MCA fue provista al laboratorio ya en forma de harina obtenida por molienda industrial.

Respecto al contenido de proteínas, BUK presentó el valor más alto, seguida por MCA y $B A G$, en tanto que TRI presentó el valor más bajo. Los valores de cenizas dividieron las muestras en dos grupos, por un lado las harinas MCA y BAG con los valores más pequeños y por el otro BUK y TRI las que mostraron un mayor contenido de cenizas.

Tabla 3.1 - Humedad, proteínas y cenizas de las harinas

\begin{tabular}{cccc}
\hline Harina & $\begin{array}{c}\text { Humedad } \\
\mathbf{\%}, \mathbf{p} / \mathbf{p}\end{array}$ & $\begin{array}{c}\text { Proteínas } \\
\mathbf{\%} \mathbf{p} / \mathbf{p}, \mathbf{b s} *\end{array}$ & $\begin{array}{c}\text { Cenizas } \\
\mathbf{\%} \mathbf{p} / \mathbf{p}, \mathbf{b s} \boldsymbol{\text { s }}\end{array}$ \\
\hline MCA & $12,2 \pm 0,1 \mathbf{a}$ & $11,4 \pm 0,3 \mathbf{b}$ & $0,56 \pm 0,03 \mathbf{a}$ \\
BAG & $13,3 \pm 0,1 \mathbf{c}$ & $10,4 \pm 0,2 \mathbf{a}$ & $0,59 \pm 0,01 \mathbf{a}$ \\
BUK & $12,9 \pm 0,0 \mathbf{b}$ & $15,6 \pm 0,0 \mathbf{c}$ & $0,78 \pm 0,02 \mathbf{b}$ \\
TRI & $12,3 \pm 0,1 \mathbf{a}$ & $10,1 \pm 0,3 \mathbf{a}$ & $0,80 \pm 0,01 \mathbf{b}$ \\
\hline
\end{tabular}

*bs: base seca. Valores seguidos de la misma letra dentro de una columna no presentan diferencias significativas $(p<=0,05)$. 


\section{Determinación del índice de sedimentación en SDS y de la capacidad de retención de agua}

Sobre las harinas estudiadas se determinó el índice de sedimentación en SDS (I-SDS) y la capacidad de retención de agua (WRC) (Tabla 3.2). Dentro de las harinas de trigo, BUK presentó el mayor valor de I-SDS, mientras que BAG mostró el valor más pequeño. La harina de triticale, de la cual no se esperaba una buena calidad panadera, mostró ciertamente el menor valor de I-SDS de todas las harinas evaluadas.

Considerando que el I-SDS es una medida indirecta de la capacidad del gluten en formar una red, por lo que a mayor valor de I-SDS mejor será la calidad de la harina, y teniendo en cuenta que las harinas con propiedades de gluten fuerte tienden a producir pastas de superior calidad, se podría considerar a BUK como la harina más adecuada para la elaboración de pastas de buena calidad.

Respecto a la capacidad de retención de agua, dentro de las harinas de trigo, el mayor valor lo obtuvo BUK, seguida de BAG y por ultimo MCA. El valor obtenido para TRI estuvo comprendido entre BUK y BAG. La capacidad de retención de agua es un parámetro que depende de la cantidad de pentosanos, de proteínas, de glicoproteínas y de complejos proteína-polisacáridos, y presenta correlaciones significativas con el contenido de almidón dañado ( $r=0,90 ; p<0,01$ ) (Moiraghi et. al., 2005).

Tabla 3.2 - I-SDS y WRC de las harinas

\begin{tabular}{ccc}
\hline Harina & I-SDS, $\mathbf{~ m L}$ & WRC, $\% \mathbf{p} / \mathbf{p}$ \\
\hline MCA & $9,8 \pm 0,4 \mathrm{c}$ & $60 \pm 1 \mathrm{a}$ \\
BAG & $9,2 \pm 0,2 \mathrm{~b}$ & $69 \pm 0 \mathrm{~b}$ \\
BUK & $17,5 \pm 0,1 \mathrm{~d}$ & $85 \pm 0 \mathrm{~d}$ \\
TRI & $7,1 \pm 0,2 \mathrm{a}$ & $79 \pm 0 \mathrm{c}$ \\
\hline \multicolumn{2}{l}{ Valores seguidos de la misma letra dentro de una columna } \\
no presentan diferencias significativas ( $p<=0,05$ ).
\end{tabular}

Como otra medida indirecta de la calidad de las proteínas, se puede esperar que las harinas con mayores valores de WRC sean las más apropiadas para elaborar pastas de buena calidad, pero se debe tener en cuenta que la WRC también correlaciona positivamente con el contenido de almidón dañado, el cual es perjudicial para la calidad de la pastas por la competencia por el agua con las proteínas durante el amasado, limitando la formación de la masa y durante la cocción, por la gran capacidad de absorción de agua favoreciendo el 
debilitamiento de la estructura de la pasta. Por consiguiente la utilidad de la WRC para predecir la calidad de la harina para la elaboración de pastas puede ser limitada.

\section{Caracterización de las fracciones proteicas de las harinas}

Sobre las harinas estudiadas se realizaron extracciones secuenciales con diferentes solventes, de modo de separar las distintas fracciones proteicas en base a sus solubilidades en los solventes de extracción empleados. De este modo se obtuvo una fracción enriquecida en albúminas y globulinas a partir de la extracción con $\mathrm{NaCl} 5 \% \mathrm{p} / \mathrm{v}$, otra de gliadinas obtenida por la extracción con isopropanol $70 \% \mathrm{v} / \mathrm{v}$, otra de gluteninas solubles por extracción con dodecil sulfato de sodio (SDS) $1,5 \%$ p/v y por último, el remanente de la última extracción, considerado como gluteninas insolubles. A cada fracción resultante, por un lado se determinó proteínas totales por Kjeldahl (Tabla 3.3) y por otro, se analizó mediante electroforesis en gel de poliacrilamida (SDS-PAGE).

Tabla 3.3 - Fracciones proteicas (F) obtenidas a partir de la extracción secuencial

\begin{tabular}{|c|c|c|c|c|c|c|c|c|}
\hline \multirow[t]{2}{*}{ Harina } & \multicolumn{2}{|c|}{$\begin{array}{l}\text { F1-Albúminas } \\
\text { y Globulinas }\end{array}$} & \multicolumn{2}{|c|}{ F2- Gliadinas } & \multicolumn{2}{|c|}{$\begin{array}{l}\text { F3-Gluteninas } \\
\text { Solubles }\end{array}$} & \multicolumn{2}{|c|}{$\begin{array}{l}\text { F4-Gluteninas } \\
\text { Insolubles }\end{array}$} \\
\hline & $\mathrm{g}^{1}$ & P.R. $^{2}$ & $\mathrm{~g}^{1}$ & P.R. $^{2}$ & $\mathrm{~g}^{1}$ & P.R. $^{2}$ & $\mathrm{~g}^{1}$ & P.R. $^{2}$ \\
\hline MCA & $1,7 \pm 0,2 \mathrm{a}$ & 13,9 & $3,3 \pm 0,3 a$ & 26,9 & $2,1 \pm 0,2 \mathrm{a}$ & 16,6 & $5,3 \pm 0,1 b$ & 42,6 \\
\hline BAG & $1,7 \pm 0,0 \mathrm{a}$ & 13,5 & $3,2 \pm 0,2 \mathrm{a}$ & 25,8 & $2,3 \pm 0,2 a$ & 18,6 & $5,2 \pm 0,1 b$ & 42,1 \\
\hline BUK & $2,5 \pm 0,1 c$ & 13,1 & $5,3 \pm 0,2 c$ & 27,3 & $3,4 \pm 0,4 b$ & 17,4 & $8,2 \pm 0,9 c$ & 42,2 \\
\hline TRI & $2,2 \pm 0,0 \mathrm{~b}$ & 18,2 & $4,5 \pm 0,0 b$ & 36,1 & $2,1 \pm 0,0 \mathrm{a}$ & 16,6 & $3,6 \pm 0,2 a$ & 29,1 \\
\hline
\end{tabular}

La harina que presentó mayor contenido, en valor absoluto, de las cuatro fracciones extraídas fue BUK, pero hay que tener en cuenta que esta harina presentó el mayor contenido de proteínas totales. Es por eso que en la Tabla 3.3 también se incluyó el porcentaje relativo obtenido para cada fracción en relación al total de proteínas extraídas. En este sentido, entre las harinas de trigo, la harina MCA fue la que presentó mayor porcentaje de albúminas y globulinas, seguida de BAG. En el caso de la fracción correspondiente a gliadinas, BUK fue la que obtuvo el mayor valor, seguida por MCA. Para la fracción de gluteninas solubles, la harina BAG obtuvo el mayor porcentaje relativo, mientras que el segundo valor más alto fue para BUK. Finalmente, para la fracción de gluteninas insolubles, el mayor porcentaje relativo fue para MCA. 
Al comparar la harina de triticale con las harinas de trigo, se encontró tanto para la fracción de albúminas y globulinas como para la de gliadinas, que TRI mostró, en términos absolutos, el segundo valor más alto; sin embargo, el porcentaje relativo de estas fracciones respecto al total de proteínas extraídas fue el más alto de todas las proteínas estudiadas. En el caso de la fracción de gluteninas solubles, TRI presentó un valor similar a la harina MCA tanto en valor absoluto como en porcentaje relativo. Para la fracción de gluteninas insolubles, TRI presentó el valor más bajo de todas las muestras analizadas.

\section{Electroforesis en SDS-PAGE}

Las corridas electroforéticas de la fracción de albúminas y globulinas, de gliadinas y de gluteninas solubles obtenidas para las diferentes harinas estudiadas se muestran en las Figuras $3.1,3.2$ y 3.3 respectivamente.

En el perfil electroforético correspondiente a la fracción de albúminas y globulinas de las harinas de trigo, se pudo observar que las bandas de mayor intensidad correspondieron a las zonas de 14,5 y $21,0 \mathrm{kD}$; de $31,0 \mathrm{kD}$; entre 31,0 y $45,0 \mathrm{kD}$ y entre 45,0 y $66,0 \mathrm{kD}$. Si bien el perfil de la harina de triticale fue similar al de las harinas de trigo, se observó una segunda banda a la altura de los $31,0 \mathrm{kD}$, semejante a las harinas de trigo, pero de mayor intensidad (Figura 3.1, marca 1) y una banda a los $45,0 \mathrm{kD}$ de muy marcada intensidad (Figura 3.1, marca 2), que si bien estaba presente en las harinas de trigo, era de intensidad muy leve.

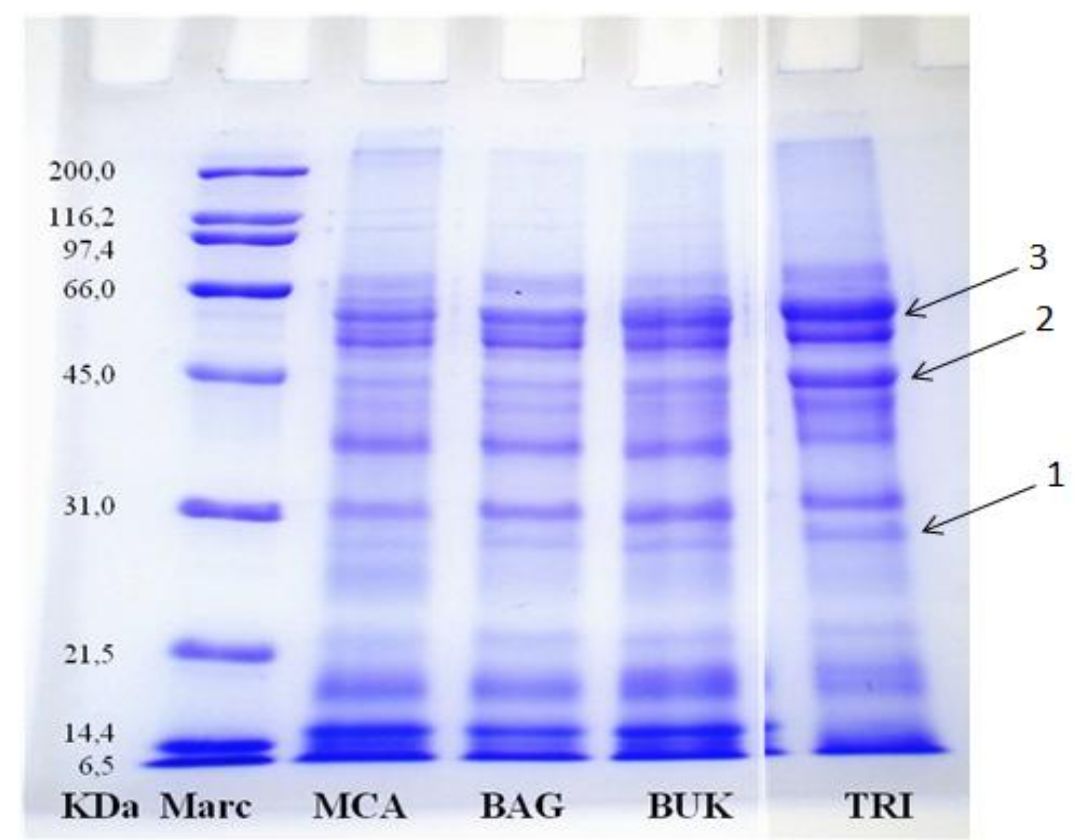

Figura 3.1 - Perfil electroforético de las proteínas extraídas con $\mathrm{NaCl} 5 \% \mathrm{p} / \mathrm{v}$, correspondiente a albúminas y globulinas. 
También, entre los 45,0 kD y 66,0 kD se encontraron bandas de mayor intensidad que las observadas en las harinas de trigo (Figura 3.1, marca 3). Se debe tener presente que TRI fue la harina que presentó mayor porcentaje relativo de albuminas y globulinas en relación al resto de las harinas lo que se correlacionó con la mayor cantidad e intensidad de las especies polipeptídicas.

En el perfil electroforético de la fracción extraída con isopropanol $70 \% \mathrm{v} / \mathrm{v}$ de las harinas de trigo, se encontró una tenue banda en la zona 6,5 y 14,0 kD, mientras que en la región entre 31,0 y $45,0 \mathrm{kD}$ aparecieron varias bandas de mayor intensidad, pudiendo observarse diferencias entre la harina BAG respecto a MCA y BUK. En BAG y BUK también se distinguen bandas tenues a 45 kD (Figura 3.2, marca 1 y 2). Si bien la harina de TRI presentó, al igual que las harinas de trigo, bandas en la región entre 31,0 y 45,0 kD, se encontraron además bandas en la región entre 66,0 y 97,4kD (Figura 3.2, marca 3).

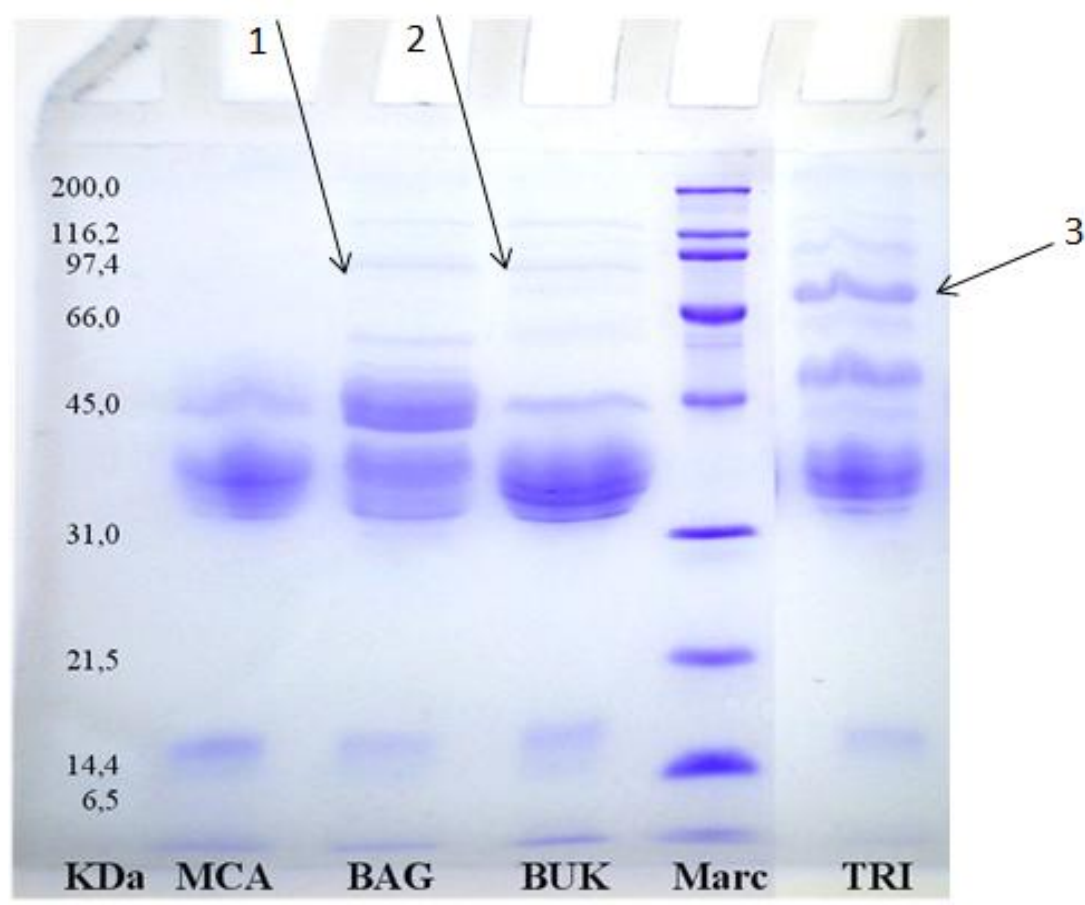

Figura 3.2 - Perfil electroforético de las proteínas extraídas con isopropanol $70 \% \mathrm{v} / \mathrm{v}$, correspondiente a la fracción de gliadinas.

En el caso de la fracción de gluteninas solubles, el perfil electroforético mostró las bandas de mayor intensidad en la zona de 31,0 a 45,0 kD (Figura 3.3, marca 1), aunque en la región de pesos moleculares más altos, también se observaron numerosas bandas. En cuanto a la harina de triticale, se encontraron además dos bandas de marcada intensidad en la zona de 66,0 kD (Figura 3.3, marca 2). 


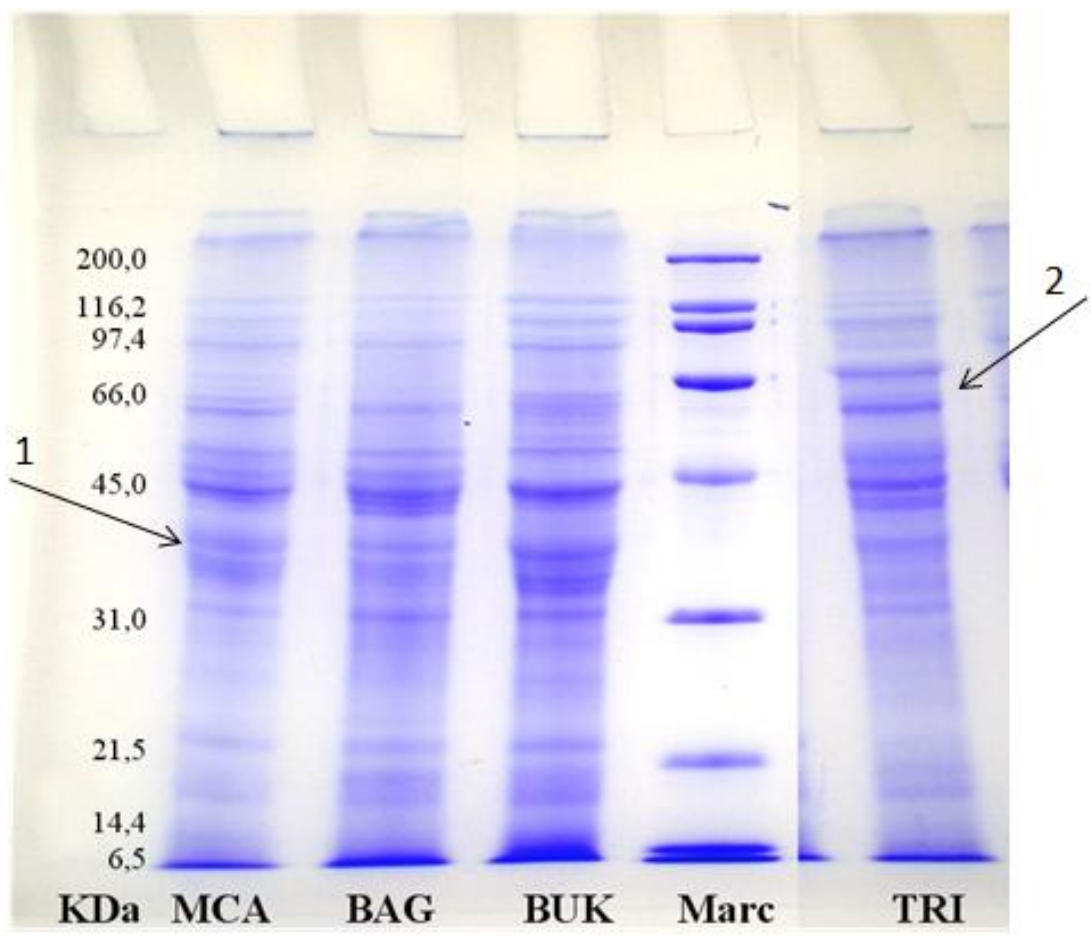

Figura 3.3 - Perfil electroforético de las proteínas extraídas con SDS 1,5\% p/v, correspondiente a la fracción de gluteninas solubles.

\section{Determinación del color de las harinas}

El color de las harinas, en términos de $L^{*}, a^{*}$ y $b^{*}$ se muestra en la Tabla 3.4. Entre las harinas de trigo, MCA presentó el mayor valor de $L^{*}$, seguido por las harinas BAG y BUK. En cuanto a la medición del espacio de color rojo-verde, todas las harinas presentaron valores negativos (verde), siendo MCA la muestra que resultó con el valor más negativo de a* de todas las harinas de trigo evaluadas. El mayor valor de b* se observó en la muestra BAG, seguida de BUK y MCA.

Tabla 3.4 - Color de las harinas

\begin{tabular}{cccc}
\hline Harina & $\mathrm{L}^{*}$ & $\mathrm{a}^{*}$ & $\mathbf{b}^{*}$ \\
\hline MCA & $91,6 \pm 0,1 \mathrm{~d}$ & $-0,42 \pm 0,02 \mathrm{c}$ & $8,96 \pm 0,06 \mathrm{c}$ \\
BAG & $90,4 \pm 0,1 \mathrm{c}$ & $-0,40 \pm 0,03 \mathrm{c}$ & $10,69 \pm 0,10 \mathrm{e}$ \\
BUK & $89,4 \pm 0,2 \mathrm{~b}$ & $-0,21 \pm 0,06 \mathrm{~d}$ & $9,96 \pm 0,17 \mathrm{~d}$ \\
TRI & $89,5 \pm 0,2 \mathrm{~b}$ & $-0,62 \pm 0,05 \mathrm{~b}$ & $8,18 \pm 0,10 \mathrm{~b}$ \\
\hline
\end{tabular}

Valores seguidos de la misma letra dentro de una columna no presentan diferencias significativas $(p<=0,05)$. 
En el caso de la harina de triticale, el valor de $L^{*}$ medido no mostró diferencias significativas con la harina de trigo BUK, mientras que los valores de $a^{*}$ y de b* fueron el más alto y el más bajo respectivamente, en relación al resto de las harinas estudiadas.

\section{Determinación del color de las pastas}

El color de las pastas elaboradas con las diferentes harinas fue significativamente (ANAVA, $p<0,05)$ diferente tanto en términos de $L^{*}$, como de $a^{*}$ y de $b^{*}$ (Tabla 3.5).

Tabla 3.5 - Color de las pastas frescas ${ }^{1}$

\begin{tabular}{ccccc}
\hline Pastas & L* $^{*}$ & $\mathbf{a}^{*}$ & $\mathbf{b}^{*}$ & Calificación del color $^{2}$ \\
\hline MCA & $82,1 \pm 0,5 \mathrm{~d}$ & $1,4 \pm 0,1 \mathrm{a}$ & $13,6 \pm 0,3 \mathrm{a}$ & $5,46 \pm 0,01 \mathrm{~b}$ \\
BAG & $78,1 \pm 0,6 \mathrm{c}$ & $2,1 \pm 0,0 \mathrm{~b}$ & $16,0 \pm 0,0 \mathrm{c}$ & $5,50 \pm 0,02 \mathrm{~b}$ \\
BUK & $74,7 \pm 0,8 \mathrm{~b}$ & $2,7 \pm 0,0 \mathrm{c}$ & $19,3 \pm 0,0 \mathrm{~d}$ & $5,66 \pm 0,04 \mathrm{c}$ \\
TRI & $70,7 \pm 0,5 \mathrm{a}$ & $2,7 \pm 0,0 \mathrm{c}$ & $14,2 \pm 0,2 \mathrm{~b}$ & $4,96 \pm 0,01 \mathrm{a}$ \\
\hline
\end{tabular}

Valores seguidos de la misma letra dentro de una columna no presentan diferencias significativas $(p<=0,05) .{ }^{1}$ Masa preparada con $37,5 \mathrm{~mL}$ de agua $/ 100 \mathrm{~g}$ harina. ${ }^{2}$ Calificación del Color: $\left(\mathrm{L}^{*}+\left(\mathrm{b}^{*} \mathrm{x}\right.\right.$ 2))/20, escala: 1-10, siendo 10 la calificación más favorable (Hareland et al., 1995).

La luminosidad $\left(\mathrm{L}^{*}\right)$ de las pastas mostró un perfil similar al medido en las harinas correspondientes; es decir la muestra preparada con MCA mostró el mayor valor de L*, seguida por las pastas elaboradas con BAG y BUK. Pero en el caso de los parámetros a* y b*, se encontró una situación diferente. Todos los valores de a* cambiaron de negativos en la harina a positivos en la masa. De este modo, la muestra elaborada con BUK mostró el mayor valor de $a^{*}$, mientras que MCA presentó el valor más bajo. Para el parámetro b*, la masa elaborada con BUK, seguida de la preparada con harina BAG, fueron las que presentaron los mayores valores de $b^{*}$, a pesar que la harinas correspondientes mostraron los valores más bajos para el mismo espacio de color. De igual modo, el valor de $a^{*}$ medido en la masa elaborada con harina de triticale fue positivo mientras que en la harina fue negativo. Estos resultados sugieren que la hidratación de las partículas y la elaboración de la masa afectó el color de la harina en términos de $a^{*} y$ de $b^{*}$.

En la Tabla 3.5 se muestra la calificación del color calculada para cada masa. Considerando la preferencia del color amarillo y de la luminosidad en las pastas, se encontró que la pasta elaborada con harina BUK resultó como la mejor calificada, seguida de las muestras BAG y MCA, mientras que la pasta preparada con harina TRI fue la peor calificada. 
Teniendo en cuenta que en el cálculo para la calificación del color, el componente b* tiene el doble de peso que el componente $L^{*}$, los bajos valores encontrados en general para todas las muestras no fueron sorprendentes, dado que esta calificación fue propuesta para las pastas elaboradas a partir de sémola de trigo candeal, en donde el contenido de pigmentos amarillos es cuantitativamente superior al encontrado en las harinas de trigo pan.

\section{Relación entre la composición química y el color de las harinas y de las pastas}

A través de un análisis de correlación de Pearson, se evaluó la relación entre las proteínas, las cenizas, el I-SDS y la WRC, con el color medido en las harinas y en las pastas frescas elaboradas con ellas. En este sentido, el contenido de cenizas de las harinas presentó una correlación negativa con el componente $L^{*}$ tanto de la harina $\left(r:-0,90^{* *}\right)$, como de las pastas ( $\left.r:-0,92^{* *}\right)$, resultado acorde a trabajos previos (Baik et al., 1995; Borrelli et al., 2003; Wang et al., 2004; Zhang et al., 2005). Esta correlación negativa fue encontrada también en productos horneados, tales como galletitas, para las cuales el contenido de cenizas es uno de los principales factores que afectan la luminosidad (Ribotta et al., 2002). Además, el contenido de cenizas mostró una correlación positiva con el componente $a^{*}$ del color de las pastas ( $r$ : $\left.0,93^{* *}\right)$.

Con respecto a las proteínas presentes en las harinas, se encontró una significante correlación positiva con el componente $b^{*}$ de las pastas $\left(r: 0,84^{* *}\right)$, también acorde a resultados previos (Wang et al., 2004), pero no con el medido en las harinas. Asimismo, al igual que las proteínas, el I-SDS también mostró una correlación positiva con el espacio de color amarillo-azul ( $r: 0,89 * *)$ medido en la masa, debido a su capacidad de comportarse como una medida indirecta de las proteínas presentes en la muestra. En general, más allá de los efectos en el color de las pastas relacionados con las variaciones en las proteínas de la harina, estos son independientes de, y adicionales a los conocidos efectos de los pigmentos de la harina o de la actividad de la enzima polifenoloxidasa (Ohm et al., 2008). En cuanto a la WRC, esta mostró una correlación negativa con la luminosidad de la harina $\left(r:-0,85^{* *}\right)$ y de la masa ( $r$ : $\left.0,85^{* *}\right)$, aunque para los componentes $a^{*}$ y $b^{*}$ solo presentó correlación con los valores medidos en la masa $\left(a^{*}, r: 0,97^{* *}\right.$ y $\left.b^{*}, r: 0,71^{*}\right)$. 


\section{Relación entre las fracciones proteicas y el color de las harinas y de las pastas}

Más allá del efecto del contenido de proteínas totales sobre el color de las pastas, se estudió además cómo las fracciones proteicas provenientes de la extracción secuencial realizada con solventes de diferente polaridad, podían incidir sobre el color de las pastas frescas. Al respecto, la fracción recuperada a partir de $\mathrm{NaCl} 5 \% \mathrm{p} / \mathrm{v}$, rica principalmente en albúminas y globulinas, mostró correlación negativa con el componente $L^{*}$ de la harina ( $r$ : $\left.0,73^{*}\right)$ y positiva con el componente $a^{*}$ de la masa ( $r$ : $0,74 *$. En la fracción extraída con isopropanol $70 \% \mathrm{v} / \mathrm{v}$, enriquecida en gliadinas, solo se encontró correlación con el componente $b^{*}$ medido en la masa $\left(r: 0,76^{*}\right)$. Este aporte significativo de las albúminas, globulinas y gliadinas sobre el color de las pastas, sugiere que las condiciones de molienda pueden afectar el color de las pastas dado que estas fracciones solubles se encuentran principalmente en la capa de aleurona del grano (Ohm et al., 2008).

Además, la fracción recuperada y la residual de la extracción con SDS 1,5\% p/v, correspondiente a las gluteninas solubles e insolubles respectivamente, mostró correlación positiva con $a^{*}$ de la harina $\left(r=0,74^{*} ; r=0,90^{* *}\right)$ y con $b^{*}$ medido en la masa $\left(r=0,91^{* *}\right.$; $r=0,82^{* *}$ ) Sin embargo, de acuerdo a Kim et al. (1991), el color de la gliadina y glutenina puras, recién extraídas es blanco, y la acción enzimática (polifenoloxidasa) y la reacción de Maillard son los responsables del desarrollo del color gris o amarillo durante el procesamiento y almacenamiento de la harina.

\section{Relación entre diferentes cantidades de agua añadida a la masa y el color de las pastas}

Para evaluar el efecto del agua utilizada en la preparación de las pastas frescas sobre el color, se aumentó la cantidad de agua añadida a la masa desde 37,5 a 43,8 mL /100 g de harina.

La luminosidad de las pastas frescas fue afectada negativamente por la mayor cantidad de agua añadida a la masa, encontrándose diferencias significativas $(p<0,05)$ en todas las muestras, a excepción de la pastas elaborada con harina BAG (Figura 3.4). 


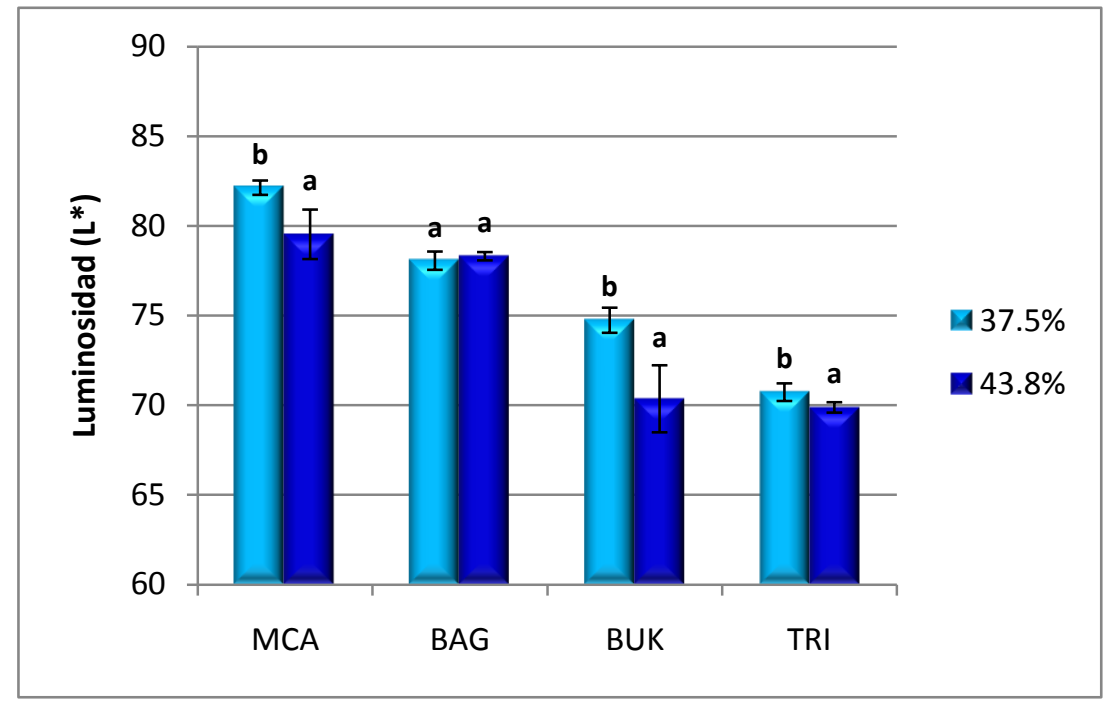

Figura 3.4 - Efecto de la adición de diferentes cantidades de agua a la masa sobre la luminosidad ( $L^{*}$ ) de las pastas frescas. Barras con la misma letra, para la misma muestra, no presentan diferencias significativas $(p \leq 0,05)$.

En el caso del componente a* (Figura 3.5), a pesar que se observó una tendencia a aumentar con la mayor cantidad de agua añadida a la masa, solo se encontraron diferencias significativas para las muestras elaboradas con harina BUK y TRI.

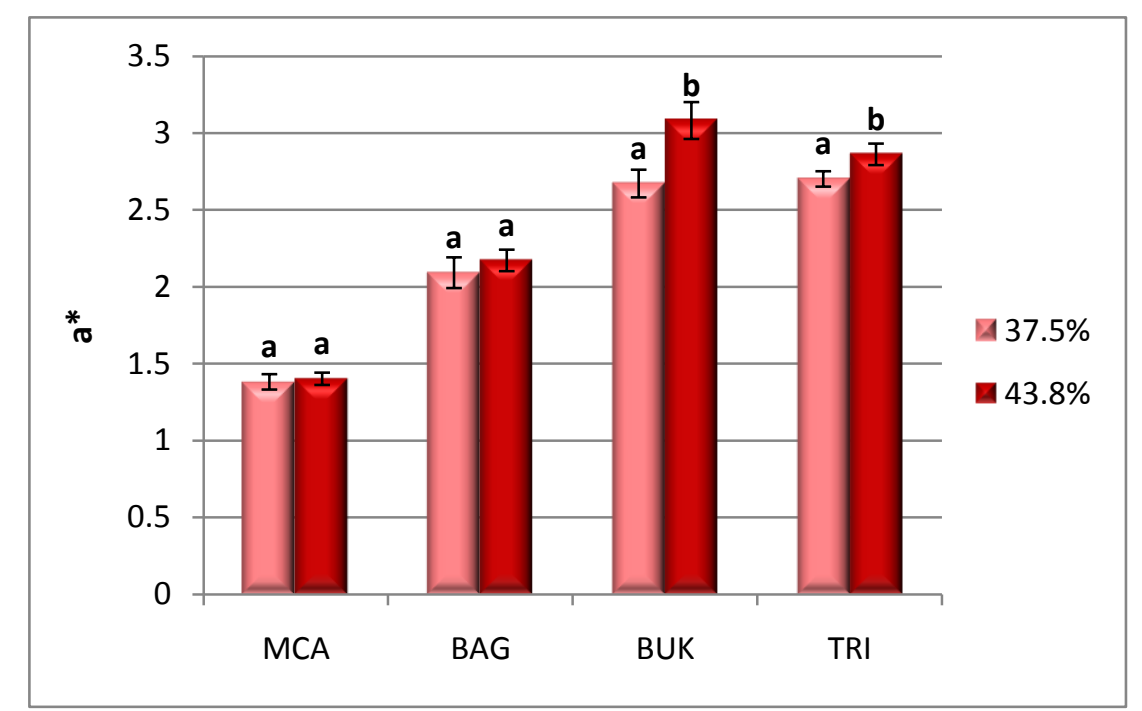

Figura 3.5 - Efecto de la adición de diferentes cantidades de agua a la masa sobre el espacio de color rojo-verde $\left(\mathrm{a}^{*}\right)$ de las pastas frescas. Barras con la misma letra, para la misma muestra, no presentan diferencias significativas $(p \leq 0,05)$. 


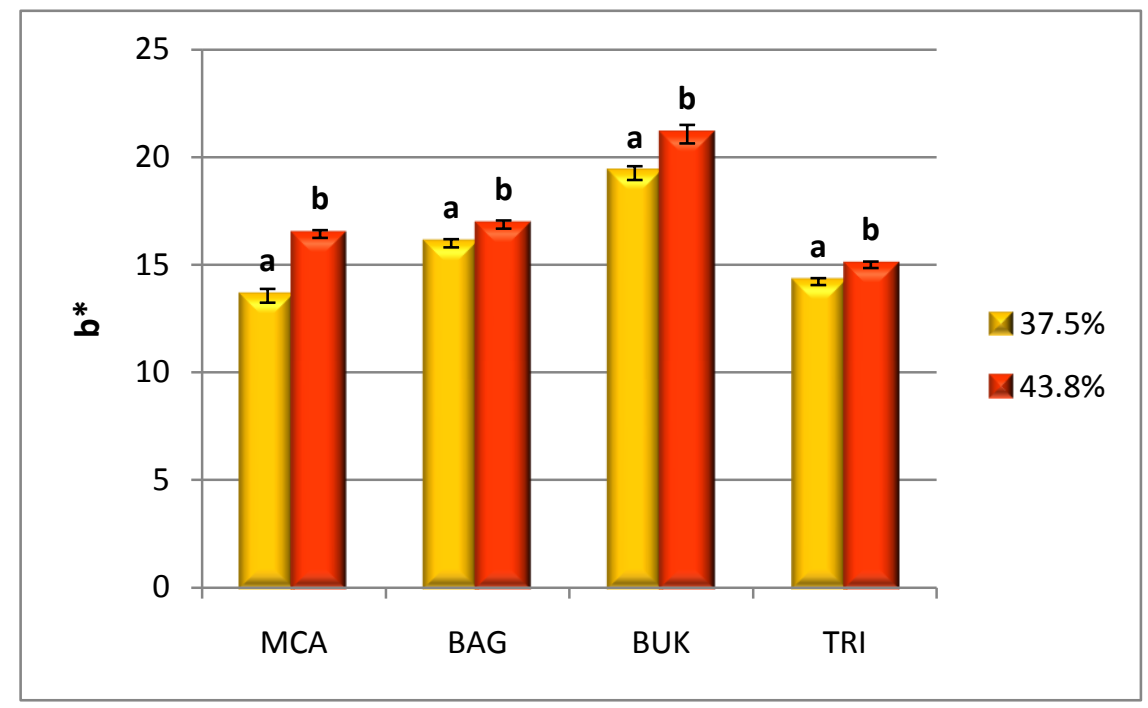

Figura 3.6 - Efecto de la adición de diferentes cantidades de agua a la masa sobre el espacio de color amarillo-azul (b*) de las pastas frescas. Barras con la misma letra, para la misma muestra, no presentan diferencias significativas $(p \leq 0,05)$.

Por el contrario, el componente $b^{*}$ del color fue significativamente afectado por la mayor adición de agua (Figura 3.6) en todas las pastas evaluadas. Resultados similares fueron observados en trabajos previos realizados sobre noodles (Hatcher et al., 1999; Humphries et al., 2004; Wang et al., 2004; Solah et al., 2007; Ohm et al., 2008).

Para cuantificar el efecto de las diferentes harinas y de la adición de distintas cantidades de agua a la masa sobre el color de las pastas frescas, se realizó un ANAVA incluyendo en los términos del modelo a las harinas y al agua añadida a la masa (Tabla 3.6).

Tabla 3.6 - ANAVA para evaluar el efecto de las diferentes harinas y de las distintas cantidades de agua usada para preparar la masa, sobre el color de las pastas frescas

\begin{tabular}{|c|c|c|c|c|c|}
\hline Tratamiento & & $\begin{array}{l}\text { Fuente de } \\
\text { variación }\end{array}$ & $\mathbf{L}^{*}$ & $a *$ & $\mathbf{b}^{*}$ \\
\hline Harinas & & $\begin{array}{l}\text { Ajuste del } \\
\text { modelo }\end{array}$ & 0,96 & 0,99 & 0,99 \\
\hline \multirow[t]{5}{*}{ Agua } & Valor $\mathrm{F}^{1}$ & & & & \\
\hline & & Modelo & 264,49 & 691,52 & 963,98 \\
\hline & & Harina(H) & 568,14 & 1567,75 & 1929,28 \\
\hline & & Agua(A) & 74,56 & 65,29 & 739,36 \\
\hline & & $\mathrm{H} \times \mathrm{A}$ & 24,15 & 24,04 & 73,57 \\
\hline
\end{tabular}

${ }^{1}$ Todos los valores mostraron un nivel de significancia $p \leq 0,001$.

Para el modelo propuesto, se encontró que la variación experimental pudo ser explicada al menos en un $96 \%$. Se observó que las diferentes harinas fueron claramente la mayor fuente de variación en el color de las pastas frescas, especialmente en lo que respecta al componente b* 
y a* del color. El efecto de las distintas cantidades de agua añadida a la masa, fue particularmente importante para el espacio de color amarillo-azul $\left(b^{*}\right)$, mientras que para el resto de los componentes del color, el efecto fue mucho menor. La interacción entre harinas y agua solo mostró un pequeño efecto y al igual que el resto de los términos del modelo, fue más pronunciado sobre el componente $b^{*}$ del color de las pastas.

\section{Conclusiones}

Considerando que las harinas estudiadas provienen de cereales que no sufren una presión de selección por un mayor contenido de pigmentos ni por una menor presencia de enzimas oxidantes, se puede decir que la luminosidad y el componente rojo-verde de color de las pastas, fue afectado principalmente por el contenido de cenizas, mientras que el componente amarillo-azul fue afectado por el contenido de proteínas de las harinas evaluadas. Además, a partir de la calificación de color calculada, en donde el componente $b^{*}$ de color tiene el mayor peso en la fórmula, se encontró que aquellas pastas elaboradas con harinas de mayor contenido de proteínas, fueron las mejores calificadas.

Además se observó que el perfil de color medido en las harinas, en términos de $a^{*}$ y de b*, fue diferente al encontrado en las pastas correspondientes, indicando que la hidratación de las partículas de la harina y el proceso de amasado modificaron el color de las harinas.

A partir del estudio de las fracciones proteicas, se encontró que las albúminas y globulinas correlacionaron con el componente ${ }^{*}$ de las pastas, mientras que las gliadinas y las gluteninas solubles e insolubles lo hicieron con el componente $b^{*}$.

EI ANAVA realizado para las harinas y al agua añadida a la masa, mostró que el efecto de las diferentes harinas fue cuantitativamente el más importante sobre el color de las pastas frescas en comparación con las diferentes cantidades de agua añadidas a la masa. 


\section{CUARTA SECCIÓN}

Obtención de pastas de calidad tecnológica y sensorial aceptables, elaboradas con harina de amaranto y harina de soja a fin de otorgarles propiedades funcionales y mejorar su calidad nutricional 
A partir de las propiedades nutricionales y funcionales que poseen las harinas de amaranto y de soja, ambas fueron usadas para reemplazar la harina de trigo en la elaboración de pastas. Se ensayaron diferentes niveles de sustitución, para estudiar cómo estas harinas no panaderas afectaban la estructura de la pasta de modo de determinar la cantidad máxima en la que pueden ser usadas manteniendo una calidad tecnológica y sensorial aceptable.

\section{Caracterización de las harinas}

La harina utilizada como base de la formulación, fue una harina de trigo pan comercial. La harina de amaranto fue obtenida por molienda de los granos crudos enteros, por lo que resultó harina integral. La harina de soja usada en este trabajo era desgrasada y micronizada.

\section{Composición química}

Tanto la harina de soja como la harina de amaranto presentaron mayores valores de proteínas, de cenizas, de materia grasa, de fibra cruda y de fibra dietética que la harina de trigo pan (Tabla 4.1). La harina de soja presentó un contenido de proteínas muy superior a la harina de amaranto, de hecho esta leguminosa se caracteriza por un alto contenido de proteínas, pero al ser la harina utilizada desgrasada, el contenido relativo de proteínas resultó aún mayor. La harina de amaranto mostró un valor de materia grasa prácticamente un orden de magnitud mayor que el de las harinas de trigo y de soja. Los valores de fibra dietética resultaron también mayores para las harinas de amaranto y de soja respecto del de la harina trigo pan, siendo en la harina de soja prácticamente el doble que el de la harina de amaranto.

Tabla 4.1 - Proteínas, cenizas, materia grasa, fibra cruda y fibra dietética de las harinas

\begin{tabular}{cccccc}
\hline Harina & $\begin{array}{c}\text { Proteínas } \\
\% \mathbf{p} / \mathbf{p}\end{array}$ & $\begin{array}{c}\text { Cenizas } \\
\% \mathbf{p} / \mathbf{p}\end{array}$ & $\begin{array}{c}\text { Materia } \\
\text { Grasa } \\
\mathbf{\%} \mathbf{p} / \mathbf{p}\end{array}$ & $\begin{array}{c}\text { Fibra Cruda } \\
\% \mathbf{p} / \mathbf{p}\end{array}$ & $\begin{array}{c}\text { Fibra } \\
\text { Dietética } \\
\mathbf{\%} \mathbf{p} / \mathbf{p}\end{array}$ \\
\hline Trigo & $12,2 \pm 0,1 \mathrm{a}$ & $0,76 \pm 0,03 \mathrm{a}$ & $0,9 \pm 0,2 \mathrm{a}$ & $0,3 \pm 0,0 \mathrm{a}$ & $3,7 \pm 0,1 \mathrm{a}$ \\
Amaranto & $17,5 \pm 0,1 \mathrm{~b}$ & $3,33 \pm 0,05 \mathrm{~b}$ & $7,8 \pm 0,1 \mathrm{~b}$ & $3,3 \pm 0,1 \mathrm{~b}$ & $12,2 \pm 0,5 \mathrm{~b}$ \\
Soja & $45,5 \pm 0,6 \mathrm{c}$ & $7,00 \pm 0,00 \mathrm{c}$ & $0,7 \pm 0,0 \mathrm{a}$ & $4,3 \pm 0,1 \mathrm{c}$ & $23,7 \pm 0,3 \mathrm{c}$ \\
\hline
\end{tabular}

Valores expresados como $\mathrm{g} / 100 \mathrm{~g}$ de harina, en base seca.

\section{Contenido de almidón, amilosa y amilopectina}

La Tabla 4.2 muestra el contenido de almidón total, de amilosa y de amilopectina (calculada por diferencia entre el almidón y la amilosa) de las harinas de trigo y amaranto. La harina de trigo pan presentó el mayor contenido de almidón y de sus componentes en valor absoluto respecto a la harina de amaranto. En esta última se encontró una cantidad 
importante de almidón, con un contenido de amilosa de 14,8\% p/p, siendo proporcionalmente la cantidad de amilosa y de amilopectina menor y mayor respectivamente, que lo medido en la harina de trigo.

De acuerdo a Inouchi et al. (1999), en el género Amaranthus se han encontrado tres tipos de almidones basado en el contenido de amilosa: normal (19,4-27,8\% p/p de amilosa) waxy o glutinoso ( 0 a $1 \%$ de amilosa) y no waxy o no-glutinoso (6,6 - 12,6\% de amilosa). Asimismo, en un trabajo realizado por Wu \& Corke (1999), donde evaluaron 243 genotipos de 26 especies de amaranto, encontraron que el contenido promedio de amilosa fue $19,2 \%$, variando entre 7,8 a $34,3 \%$. En el caso de la harina de soja desgrasada, se determinó el contenido de hidratos de carbonos totales resultando $16,6 \pm 1,1 \% \mathrm{p} / \mathrm{p}$, en base seca.

Tabla 4.2 - Contenido de almidón, amilosa y amilopectina ${ }^{1}$ en las harinas de trigo y amaranto

\begin{tabular}{cccccc}
\hline Harina & $\begin{array}{c}\text { Almidón } \\
\% \mathrm{p} / \mathrm{p}^{\mathbf{2}}\end{array}$ & $\begin{array}{c}\text { Amilosa } \\
\% \mathrm{p} / \mathrm{p}^{\mathbf{2}}\end{array}$ & $\begin{array}{c}\text { Amilopectina } \\
\% \mathrm{p} / \mathrm{p}^{\mathbf{2}}\end{array}$ & $\begin{array}{c}\text { Amilosa } \\
\% \mathrm{p} / \mathrm{p}^{3}\end{array}$ & $\begin{array}{c}\text { Amilopectina } \\
\% \mathrm{p} / \mathrm{p}^{3}\end{array}$ \\
\hline Trigo & $76,0 \pm 0,4 \mathrm{c}$ & $24,2 \pm 0,6 \mathrm{~b}$ & $51,8 \pm 0,9 \mathrm{c}$ & $31,8 \mathrm{~b}$ & $68,2 \mathrm{~b}$ \\
Amaranto & $60,5 \pm 0,8 \mathrm{~b}$ & $14,8 \pm 0,2 \mathrm{a}$ & $45,7 \pm 0,6 \mathrm{~b}$ & $24,5 \mathrm{a}$ & $75,5 \mathrm{c}$ \\
\hline
\end{tabular}

${ }^{1}$ Cantidad estimada por diferencia: Almidón -Amilosa. ${ }^{2} \mathrm{~g} / 100 \mathrm{~g}$ de harina, base seca. ${ }^{3} \mathrm{~g} / 100 \mathrm{~g}$ de almidón, base seca. Valores seguidos de la misma letra dentro de una columna no presentan diferencias significativas ( $p \leq 0,05)$, según el test de Fisher.

\section{Propiedades de pasting}

Las propiedades de pasting fueron evaluadas a cada una de las harinas de manera individual, y a las mezclas entre la harina de trigo y la harina de amaranto, y entre la harina de trigo y la harina de soja, en las diferentes cantidades utilizadas para la elaboración de las pastas.

\section{Mezcla de harinas de trigo y de amaranto}

La harina de amaranto presentó menores valores de temperatura media de gelatinización, de viscosidad de pico, de breakdown, de viscosidad media, de viscosidad final y de setback que la harina de trigo (Tabla 4.3). Consecuentemente, el agregado de harina de amaranto a la harina de trigo, provocó también una disminución de la viscosidad de pico, de la viscosidad media, del breakdown y del tiempo de pico (facilidad de cocción de la pasta) (Figura 4.1).

La baja viscosidad de pico observada para la harina de amaranto pudo deberse a su menor contenido de amilosa en comparación con la harina de trigo (14,8\%g vs. $24,4 \% \mathrm{p} / \mathrm{p})$, resultando en una menor capacidad de hinchamiento y menor liberación de amilosa al medio. 
Además, el bajo valor de breakdown medido para la harina de amaranto, provocó una disminución de este valor a medida que mayor cantidad de harina de amaranto estaba presente en la mezcla. A juzgar por los resultados, la velocidad de lixiviación de la amilosa proveniente del almidón de amaranto podría ser mucho menor que la correspondiente al almidón de trigo. De hecho Gunaratne y Corke (2007), describieron que ante la presencia de dos almidones, la velocidad de liberación de amilosa de uno de ellos puede inhibir el breakdown del otro.

Tabla 4.3- Valores de RVA obtenidos para la harina de trigo, de amaranto y de las mezclas usadas en la elaboración de las pastas

\begin{tabular}{cccccccc}
\hline Muestra & $\begin{array}{c}\text { TMG } \\
\left({ }^{\circ} \mathbf{C}\right)\end{array}$ & $\begin{array}{c}\text { V.P. } \\
(\mathbf{r v u})\end{array}$ & $\begin{array}{c}\text { V.M. } \\
(\mathbf{r v u})\end{array}$ & $\begin{array}{c}\text { B.D, } \\
(\text { rvu })\end{array}$ & $\begin{array}{c}\text { V.F. } \\
\text { (rvu) }\end{array}$ & $\begin{array}{c}\text { SB } \\
(\text { rvu })\end{array}$ & $\begin{array}{c}\text { P.T. } \\
\text { (min) }\end{array}$ \\
\hline Harina de Trigo 100\% & 87,3 & 210,8 & 125,4 & 85,3 & 243,3 & 117,8 & 6,2 \\
Harina de Amaranto 100\% & 83,3 & 123,3 & 113,9 & 9,3 & 129,1 & 15,2 & 6,3 \\
H. Amaranto 15\% - H. Trigo 85\% & 88,3 & 189,5 & 113,9 & 75,6 & 248,9 & 135,0 & 6,1 \\
H. Amaranto 30\% - H. Trigo 70\% & 88,1 & 169,7 & 111,0 & 58,7 & 256,1 & 145,1 & 5,9 \\
H. Amaranto 40\% - H. Trigo 60\% & 87,3 & 155,3 & 105,1 & 50,3 & 239,3 & 134,3 & 5,8 \\
H. Amaranto 50\% - H. Trigo 50\% & 85,7 & 140,3 & 101,8 & 38,5 & 210,1 & 108,3 & 5,7 \\
\hline
\end{tabular}

TMG: Temperatura de la pasta (temperatura de gelatinización), V.P.: Viscosidad Pico, V.M.: Viscosidad Media, BD: Breakdown, V.F.: Viscosidad Final, SB: Setback, P.T.: Tiempo de pico (facilidad de cocción de la pasta).

El incremento de la viscosidad que ocurre al finalizar la curva de pasting, se relaciona con el enfriamiento de la pasta y con el fenómeno de retrogradación y por lo tanto con el contenido de amilosa (Alvis et al., 2008); ya que un menor contenido de amilosa significa una menor susceptibilidad a retrogradar (Gunaratne \& Corke, 2007; Zuleta \& Araya, 2009). De este modo, el menor contenido de amilosa presente en la harina de amaranto, resultaría en una menor tendencia a retrogradar, lo que explica los menores valores de viscosidad final encontrados para las mezclas con mayor porcentaje de harina de amaranto. 


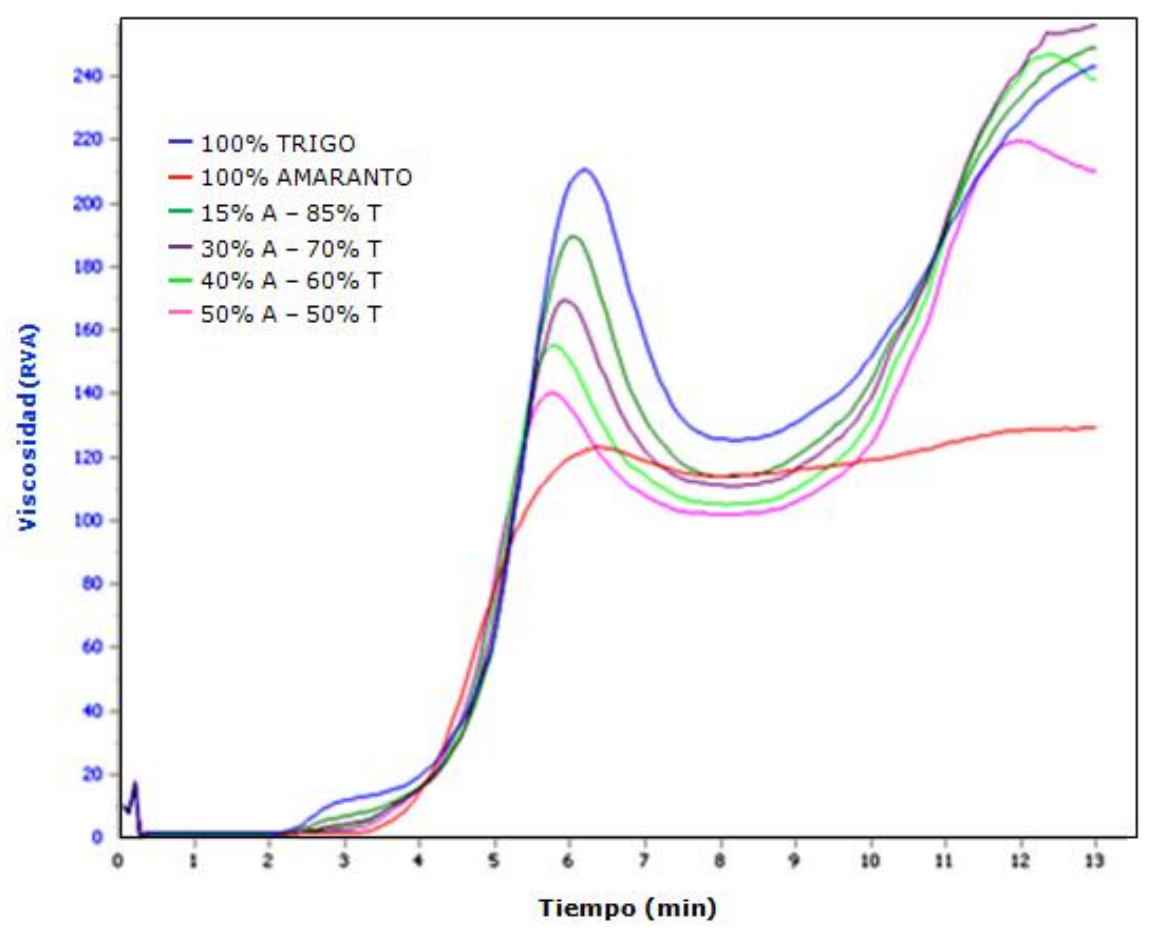

Figura 4.1 - Propiedades de pasting de la harina de trigo, de la harina de amaranto y de sus mezclas.

\section{Mezcla de harinas de trigo y de soja}

La Tabla 4.4 muestra los valores obtenidos de las curvas de pasting para la harina de trigo, la harina de soja y para las mezclas de harina de trigo - harina de soja usadas para elaborar las pastas.

Tabla 4.4- Valores de RVA obtenidos para la harina de trigo, de soja y de las mezclas entre éstas usadas en la elaboración de las pastas

\begin{tabular}{cccccccc}
\hline Muestra & $\begin{array}{c}\text { TMG } \\
\left({ }^{\circ} \mathbf{C}\right)\end{array}$ & $\begin{array}{c}\text { V.P. } \\
\text { (rvu) }\end{array}$ & $\begin{array}{c}\text { V.M. } \\
\text { (rvu) }\end{array}$ & $\begin{array}{c}\text { B.D. } \\
\text { (rvu) }\end{array}$ & $\begin{array}{c}\text { V.F. } \\
\text { (rvu) }\end{array}$ & $\begin{array}{c}\text { S.B. } \\
\text { (rvu) }\end{array}$ & $\begin{array}{c}\text { P.T. } \\
\text { (min) }\end{array}$ \\
\hline Harina de Trigo 100\% & 87,3 & 210,8 & 125,4 & 85,3 & 243,3 & 117,8 & 6,2 \\
Harina de Soja 100\% & ND & 1,6 & 1,5 & 0,1 & 2,3 & 0,8 & 6,5 \\
H. Soja 15\% - H. Trigo 85\% & 87,4 & 156,2 & 92,0 & 64,2 & 180,8 & 88,8 & 6,0 \\
H. Soja 30\% - H. Trigo 60\% & 88,2 & 102,9 & 61,9 & 41,0 & 117,3 & 55,3 & 5,7 \\
H. Soja 40\% - H. Trigo 60\% & 88,2 & 70,7 & 42,8 & 27,8 & 79,3 & 36,4 & 5,3 \\
H. Soja 50\% - H. Trigo 50\% & 88,2 & 42,2 & 26,6 & 15,6 & 53,9 & 27,3 & 5,1 \\
\hline
\end{tabular}

TMG: Temperatura de la pasta (temperatura de gelatinización), V.P.: Viscosidad Pico, V.M.: Viscosidad Media, BD: Breakdown, V.F.: Viscosidad Final, SB: Setback, P.T.: Tiempo de pico (facilidad de cocción de la pasta), ND: no disponible.

La harina de soja prácticamente no mostró cambios en su viscosidad bajo las condiciones del ensayo, fenómeno que se explica porque la soja se caracteriza por la escasa presencia de 
gránulos de almidón en la semilla madura (Stevenson et al., 2007), con un contenido de almidón de 0,19-0,91\%; mientras que en la harina, el almidón constituye sólo 0,56-0,58\%; en donde la amilosa representa entre el $15-20 \%$, es decir menor a $0,1 \%$ respecto de la harina (Wilson et. al., 1978). De hecho su perfil de viscosidad prácticamente resultó una línea recta (Figura 4.2).

Consecuentemente se encontró que la incorporación creciente de la harina de soja a la harina de trigo, disminuyó todos los valores de la curva de pasting (viscosidad pico, viscosidad media, viscosidad final, breakdown, setback, y tiempo de pico).

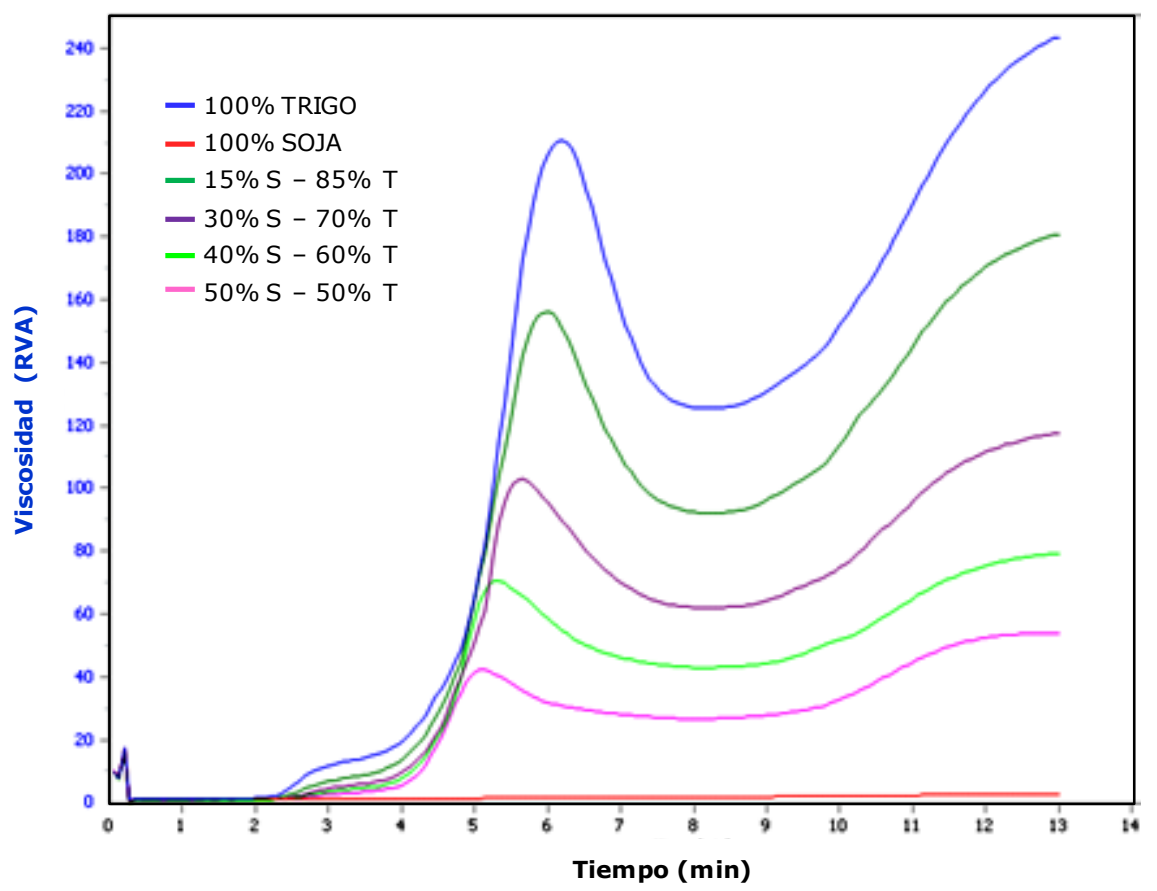

Figura 4.2- Propiedades de pasting de la harina de trigo, de la harina de soja y de sus mezclas.

Si bien la temperatura de gelatinización para la harina de soja, debido al escaso contenido de almidón, no pudo ser medida bajo las condiciones del ensayo, en un trabajo realizado por transmitancia óptica, se encontró que los gránulos comenzaron a hincharse a $50{ }^{\circ} \mathrm{C}$ y que la pérdida de birrefringencia se inició a los $73^{\circ} \mathrm{C}$ y se completó a los $81{ }^{\circ} \mathrm{C}$ (Wilson et al., 1978).

\section{Elaboración de las pastas}

Para elaborar las pastas, la harina de trigo fue reemplazada con cantidades crecientes de harina de amaranto y harina de soja, con el propósito de lograr pastas con la mayor sustitución 
posible, dadas las propiedades nutricionales y funcionales que presentan estas dos últimas harinas. No obstante, debido a que ninguna de estas harinas presenta capacidad de formar gluten, la cantidad que pudo ser incorporada de cada una de ellas estuvo sujeta a que las pastas resultantes alcanzaran una calidad sensorial y tecnológica aceptable.

En este sentido se elaboraron pastas en donde la harina de trigo fue reemplazada en un $15,30,40$ y $50 \% \mathrm{p} / \mathrm{p}$ tanto con la harina de amaranto ( $\mathrm{A} 15, \mathrm{~A} 30, \mathrm{~A} 40$ y $\mathrm{A} 50)$ como con la harina de soja (S15, S30, S40 y S50). Todos los ensayos realizados sobre estas pastas se compararon con una muestra elaborada solo con harina de trigo pan, considerada como muestra control (Co).

Para cada uno de los porcentajes de sustitución de la harina de trigo con la harina de amaranto y con la de soja, se determinó experimentalmente la cantidad de agua óptima necesaria para preparar la masa de las pastas. En la Tabla 4.5 se puede observar que las muestras sustituidas con harina de soja necesitaron más agua para formar la masa que las muestras sustituidas con harina de amaranto, siendo mayor cuanto más alto era el porcentaje de sustitución. Considerando que la harina de soja le aporta proporcionalmente más proteínas a las pastas que la harina de amaranto, probablemente sean éstas las responsables de la mayor cantidad de agua requerida para formar la masa de las pastas con soja.

Tabla 4.5 - Agua necesaria para elaborar las pastas

\begin{tabular}{cccc}
\hline $\begin{array}{c}\text { Nivel de } \\
\text { sustitución }\end{array}{ }^{1}$ & $\begin{array}{c}\text { Pastas con harina } \\
\text { de amaranto, } \mathbf{~ L L}^{2}\end{array}$ & $\begin{array}{c}\text { Pastas con harina } \\
\text { de soja, } \mathbf{~ L L}^{2}\end{array}$ & $\begin{array}{c}\text { Pasta control con } \\
\text { harina de trigo } \mathbf{~ p a n , ~} \mathbf{~ L L}^{\mathbf{2}}\end{array}$ \\
\hline 0 & --- & -- & 40 \\
15 & 40 & 44 & --- \\
30 & 40 & 46 & --- \\
40 & 42 & 48 & -- \\
50 & 44 & 54 & --- \\
\hline \multicolumn{4}{c}{}
\end{tabular}

Las distintas cantidades de agua que fueron necesarias para elaborar las pastas, hizo que las muestras tuvieran que ser secadas, para poder obtener muestras comparables y poder evaluar el efecto de la incorporación de estas harinas alternativas, más allá de las distintas cantidades de agua con que resultaron las pastas.

El secado de las pastas se realizó en condiciones de laboratorio, por medio de dos ciclos, el primero de presecado, durante $30 \mathrm{~min}$, a $30^{\circ} \mathrm{C}$ y con una humedad relativa (HR) aproximada de $40 \%$, en una estufa con circulación de aire, por medio del cual se logró bajar la humedad de la muestra hasta $26 \pm 2 \% \mathrm{p} / \mathrm{p}$; seguido de un segundo ciclo de secado, durante $17 \mathrm{~h}$, a $30^{\circ} \mathrm{C} \mathrm{y}$ 
con una HR inicial de $~ 65 \%$ en una estufa sin circulación de aire, en la cual la carga de pastas a secar regulaba la HR durante el tiempo de secado y en general, la HR final presentó valores semejantes a los iniciales. Bajo estas condiciones de secado, los valores de humedad final de las pastas estuvieron alrededor de $10 \pm 1 \% \mathrm{p} / \mathrm{p}$.

La sustitución de la harina de trigo con harina de amaranto tuvo un mayor efecto en la apariencia de las pastas que la correspondiente a la harina de soja. La incorporación creciente de harina de amaranto provocó además de un oscurecimiento, una notoria alteración de la superficie de la pasta (Figura 4.3), mientras que aquellas elaboradas con harina de soja (Figura 4.4), si bien resultaron más oscuras que la muestra control, el aspecto superficial fue menos afectado que en las pastas con amaranto.

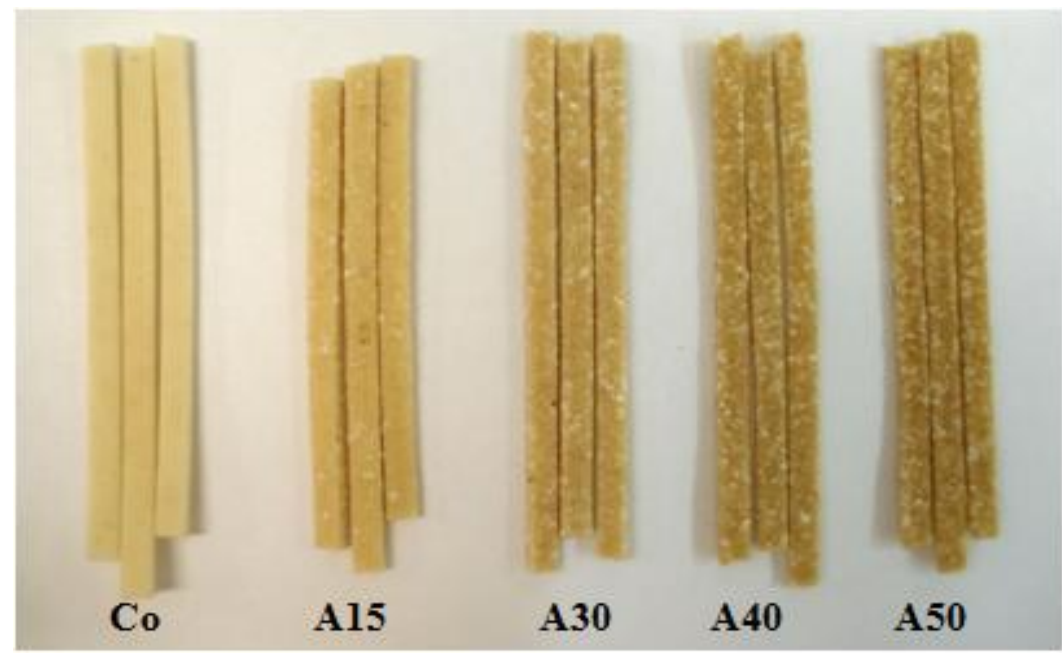

Figura 4.3 - Pastas secas sustituidas con harina de amaranto.

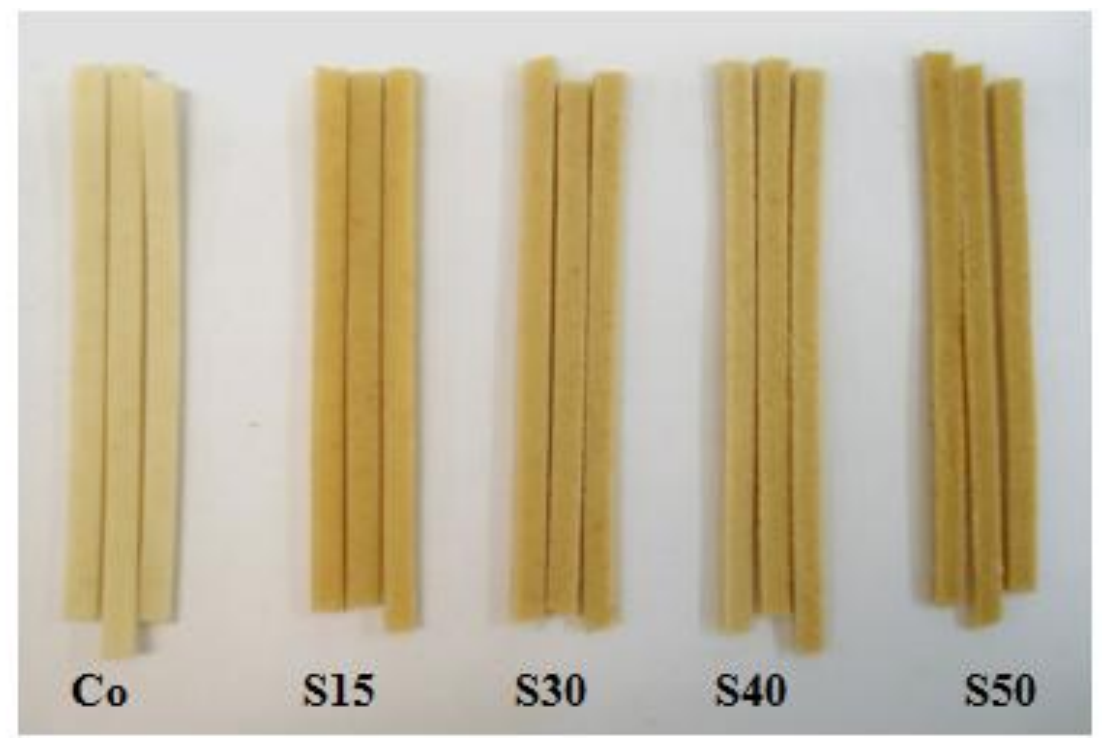

Figura 4.4 - Pastas secas sustituidas con harina de soja. 


\section{Comportamiento durante la cocción}

En la Tabla 4.6 se muestra el tiempo óptimo de cocción (TOC), el residuo de cocción, la absorción de agua y el índice de hinchamiento de las muestras. Tanto para las pastas elaboradas con harina de amaranto como para aquellas elaboradas con harina de soja, se observó que a medida que el porcentaje de sustitución aumentaba, el TOC disminuía, resultando menor para las pastas sustituidas con harina de amaranto respecto a las sustituidas con harina de soja.

Los valores de residuo de cocción de las pastas con amaranto y con soja fueron significativamente mayores al de la muestra control para todos los porcentajes de sustitución, siendo aún mayores para las pastas con soja respecto a las pastas con amaranto. A partir de los resultados obtenidos se puede estimar que a medida que el gluten proveniente de la harina de trigo se fue "diluyendo" por la sustitución con estas harinas alternativas, el retículo proteico se tornó más débil, facilitando una mayor difusión del agua hacia el interior de la pasta, disminuyendo los tiempos óptimos y aumentando el residuo de cocción.

Los valores de absorción de agua de las muestras sustituidas con harina de amaranto resultaron significativamente menores al de la muestra control. Dado que la absorción de agua depende fuertemente del tiempo de cocción (Zweifel et al., 2003), el hecho que los TOC de las muestras de amaranto resultaran menores que el del control, pudo explicar los menores valores de absorción de agua medidos en estas muestras.

Tabla 4.6 - TOC, Residuo de cocción, absorción de agua y índice de hinchamiento de las pastas

\begin{tabular}{ccccc}
\hline Pasta & $\begin{array}{c}\text { TOC } \\
(\mathbf{m i n})\end{array}$ & $\begin{array}{c}\text { Residuo de cocción } \\
(\% \mathbf{p} / \mathbf{p})^{\mathbf{1}}\end{array}$ & $\begin{array}{c}\text { Absorción de agua } \\
\% \mathbf{p} / \mathbf{p}^{\mathbf{2}}\end{array}$ & $\begin{array}{c}\text { Índice de } \\
\text { hinchamiento }\end{array}$ \\
\hline Co & 8 & $6,1 \pm 0,1 \mathrm{a} \mathrm{A}$ & $160 \pm 5 \mathrm{c} \mathrm{B}$ & $2,1 \pm 0,1 \mathrm{~d} \mathrm{~A}$ \\
& & & & \\
A15 & 7 & $6,6 \pm 0,1 \mathrm{~b}$ & $144 \pm 5 \mathrm{~b}$ & $1,9 \pm 0,1 \mathrm{~b}$ \\
A30 & 5 & $6,7 \pm 0,1 \mathrm{~b}$ & $133 \pm 3 \mathrm{a}$ & $1,8 \pm 0,1 \mathrm{a}$ \\
A40 & 5 & $7,3 \pm 0,2 \mathrm{c}$ & $149 \pm 4 \mathrm{~b}$ & $2,0 \pm 0,1 \mathrm{bc}$ \\
A50 & 4 & $7,9 \pm 0,1 \mathrm{~d}$ & $151 \pm 1 \mathrm{~b}$ & $2,0 \pm 0,0 \mathrm{~cd}$ \\
& & & & \\
S15 & 9 & $8,4 \pm 0,4 \mathrm{~B}$ & $158 \pm 3 \mathrm{~B}$ & $2,2 \pm 0,0 \mathrm{~A}$ \\
S30 & 8 & $10,4 \pm 0,4 \mathrm{C}$ & $153 \pm 2 \mathrm{AB}$ & $2,2 \pm 0,0 \mathrm{~A}$ \\
S40 & 7 & $11,7 \pm 0,4 \mathrm{D}$ & $148 \pm 8 \mathrm{~A}$ & $2,2 \pm 0,1 \mathrm{~A}$ \\
S50 & 7 & $14,0 \pm 0,2 \mathrm{E}$ & $172 \pm 2 \mathrm{C}$ & $2,6 \pm 0,0 \mathrm{~B}$ \\
\hline
\end{tabular}

${ }^{1} \mathrm{~g}$ de residuo/100 $\mathrm{g}$ de pasta seca. ${ }^{2} \mathrm{~g}$ de agua/ $100 \mathrm{~g}$ de pasta seca. Letras minúsculas distintas indican diferencias significativas $(p<=0,05)$ entre el control y las pastas con harina de amaranto. Letras mayúsculas distintas indican diferencias significativas $(p<=0,05)$ entre el control y las pastas con harina de soja. 
Además, considerando que la harina de amaranto usada para elaborar las pastas fue del tipo integral, la presencia de fibra insoluble, podría resultar en una harina con menor capacidad de absorción de agua que la harina refinada de trigo.

En el caso de las pastas elaboradas con harina de soja, si bien las muestras S15, S30 y S40 mostraron una tendencia a presentar menores valores de absorción de agua con los crecientes porcentajes de sustitución, solo S40 fue significativamente menor que Co, y por el contrario S50 resultó con un valor de absorción de agua mayor a Co. Este comportamiento no pudo ser explicado por los tiempos de cocción, dado que las muestras presentaron tiempos mayores, iguales y menores que la muestra control, y más aún, S40 y S50 que tuvieron los mismos TOC y mostraron valores de absorción de agua muy diferentes. Probablemente la capacidad de gelificar de estas proteínas pudo contrarrestar el efecto adverso sobre la estructura de la pasta que pudo ejercer una harina sin capacidad de formar gluten como lo es la harina de soja, conservando así la integridad de la pasta aún a niveles de sustitución más altos en comparación con la harina de amaranto. Sin embargo, para el mayor nivel de sustitución, el grado de deterioro del retículo proteico fue tal que superó el efecto de atenuante de las proteínas de soja, resultando en una estructura que no pudo ofrecer demasiada resistencia a la difusión de agua al interior de la pasta, dando elevados valores de absorción de agua como lo observado para S50.

Si se considera que el índice de hinchamiento es la relación entre el peso de la muestra cocida y el peso de la muestra cocida secada, al haber encontrado menores valores de absorción de agua a mayor nivel de sustitución, se puede esperar menores índices de hinchamiento para las muestras más sustituidas. De esta forma se explica que los valores encontrados para A15, A30 y A40 sean significativamente menores que la muestra control. Sin embargo A50, S15, S30 y S40 no mostraron diferencias significativas con Co. Esto pudo deberse a que, si bien la absorción de agua disminuyó con el mayor nivel de sustitución, hubo también mayor pérdida de sólidos durante la cocción; con lo cual el valor de la pasta cocida seca fue menor, reduciendo así el efecto de la menor absorción de agua sobre el índice de hinchamiento.

\section{Evaluación instrumental de la textura de las pastas secas}

La textura de la pasta seca se evaluó en términos de fracturabilidad; parámetro que indica la resistencia de la pasta a fracturarse, por ejemplo al ser manipulada durante una operación 
de envasado. Para ello se empleó una sonda de tres puntos y se midió la fuerza necesaria para quebrar un segmento de fideo, de modo que, a mayor fuerza medida, menor fracturabilidad.

Las pastas sustituidas con harina de amaranto mostraron una clara tendencia a hacerse más frágiles con los crecientes porcentajes de sustitución, encontrándose diferencias significativas para todos los niveles de adición (Figura 4.5). Estos resultados, indicaron un evidente debilitamiento de la estructura de la pasta provocado por la incorporación de la harina de amaranto.

Una tendencia diferente se encontró para las pastas sustituidas con harina de soja (Figura 4.5), donde se puede observar que la incorporación de esta harina no afectó demasiado la resistencia a la fractura; incluso hasta un $30 \%$ de sustitución se verificó un aumento de ésta respecto a Co. Recién a partir del $40 \%$ de sustitución, los valores de fuerza medidos resultaron menores que la muestra control. A partir de los datos obtenidos, se interpretó que la incorporación de la harina de soja, hasta cierto límite, conformó una estructura más firme de la pasta seca respecto a la pasta elaborada sólo con harina de trigo. Durante el proceso de obtención de la harina de soja, debido al calor, las proteínas de soja pueden sufrir una parcial desnaturalización parcial, que de acuerdo a Ryan et al. (2002), podría favorecer las interacciones proteína-proteína con mecanismos similares a los observados para los agentes tensioactivos. La desnaturalización de las proteínas de soja, podría exponer grupos hidrofóbicos anteriormente ocultos, que le dan a sus proteínas la habilidad de formar puentes entre los lípidos y las interfaces acuosas del mismo modo que lo hacen los glicolípidos.

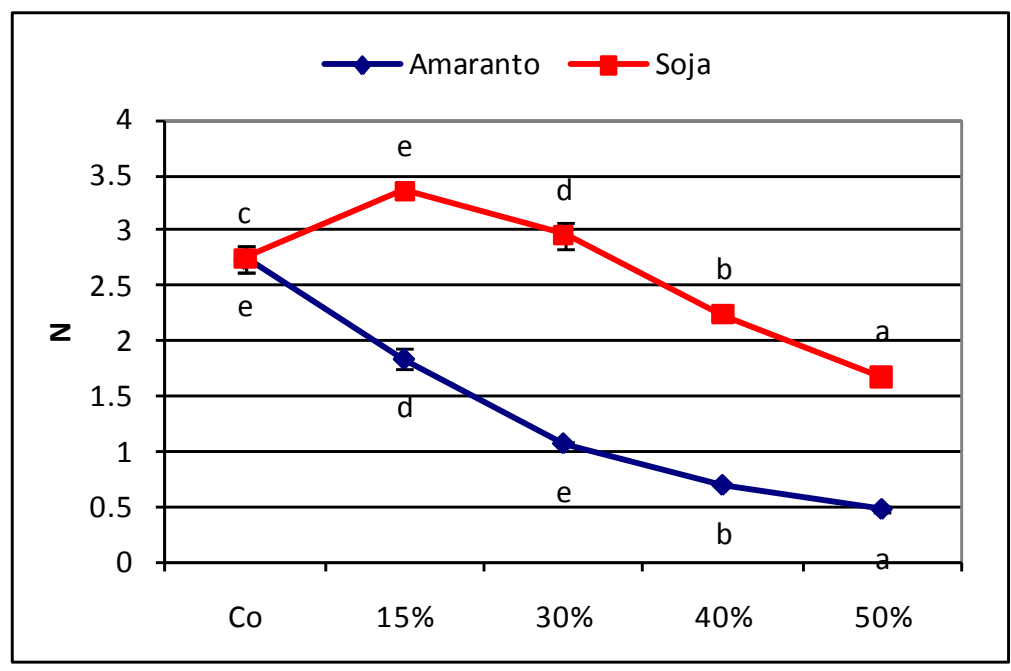

Figura 4.5 - Fracturabilidad de las pastas secas elaboradas con harina de amaranto y harina de soja (\%: porcentaje peso en peso). 


\section{Evaluación instrumental de la textura de las pastas cocidas}

Los parámetros de firmeza, pegajosidad, cohesividad, elasticidad, masticabilidad (chewiness) y resiliencia fueron calculados a partir de un análisis de perfil de textura (dos ciclos de $70 \%$ de deformación), sobre tres segmentos de fideos cocidos; resultados que se muestran en la Tabla 4.7. Además, en la misma tabla se puede observar el espesor de los fideos una vez cocidos. En este sentido, se encontró que la altura de las muestras adicionadas con harina de amaranto, a excepción de A15, disminuyó a medida que aumentó el nivel de sustitución, encontrándose diferencias significativas respecto del control para A30, A40 y A50. Un comportamiento diferente mostraron las muestras adicionadas con harina de soja. La altura obtenida para S15 y S30 fue significativamente mayor que Co, mientras que S40 no mostró diferencias significativas con Co; solo S50 mostró una altura menor que Co.

La firmeza medida en las muestras adicionadas con harina de amaranto mostró una tendencia a disminuir con los mayores niveles de sustitución, aunque solo se obtuvieron diferencias significativas para A40 y A50. En el caso de las muestras sustituidas con harina de soja, S15 y S30 mostraron un valor de firmeza significativamente mayor que la muestra control, en tanto que S40 no se diferenció estadísticamente de Co y solo S50 resultó con una menor firmeza que Co.

Tabla 4.7 - Análisis de Textura de las pastas elaboradas con harina de amaranto y con harina de soja

\begin{tabular}{cccccccc}
\hline Muestra & Altura, mm & Firmeza, N & Pegajosidad, N & Cohesividad & Elasticidad & Masticabilidad, N & Resiliencia \\
\hline Control & $1,3 \pm 0,1 \mathrm{c} \mathrm{B}$ & $1,42 \pm 0,11 \mathrm{c} \mathrm{B}$ & $-0,12 \pm 0,01 \mathrm{c} \mathrm{C}$ & $0,69 \pm 0,02 \mathrm{c} \mathrm{C}$ & $0,87 \pm 0,01 \mathrm{c} \mathrm{C}$ & $0,84 \pm 0,04 \mathrm{~d} \mathrm{D}$ & $0,09 \pm 0,01 \mathrm{~b} \mathrm{AB}$ \\
& & & & & & \\
A15 & $1,3 \pm 0,0 \mathrm{c}$ & $1,38 \pm 0,04 \mathrm{bc}$ & $-0,15 \pm 0,01 \mathrm{~b}$ & $0,66 \pm 0,01 \mathrm{bc}$ & $0,83 \pm 0,01 \mathrm{~b}$ & $0,76 \pm 0,03 \mathrm{c}$ & $0,07 \pm 0,01 \mathrm{a}$ \\
A30 & $1,0 \pm 0,1 \mathrm{~b}$ & $1,39 \pm 0,08 \mathrm{bc}$ & $-0,18 \pm 0,02 \mathrm{a}$ & $0,64 \pm 0,01 \mathrm{ab}$ & $0,82 \pm 0,02 \mathrm{ab}$ & $0,73 \pm 0,05 \mathrm{c}$ & $0,07 \pm 0,01 \mathrm{a}$ \\
A40 & $1,0 \pm 0,1 \mathrm{~b}$ & $1,26 \pm 0,08 \mathrm{~b}$ & $-0,19 \pm 0,02 \mathrm{a}$ & $0,61 \pm 0,02 \mathrm{a}$ & $0,81 \pm 0,02 \mathrm{a}$ & $0,62 \pm 0,01 \mathrm{~b}$ & $0,07 \pm 0,01 \mathrm{ab}$ \\
A50 & $0,7 \pm 0,0 \mathrm{a}$ & $1,08 \pm 0,09 \mathrm{a}$ & $-0,15 \pm 0,02 \mathrm{~b}$ & $0,63 \pm 0,02 \mathrm{ab}$ & $0,80 \pm 0,01 \mathrm{a}$ & $0,55 \pm 0,05 \mathrm{a}$ & $0,08 \pm 0,00 \mathrm{ab}$ \\
& & & & & & & \\
S15 & $1,5 \pm 0,1 \mathrm{C}$ & $1,58 \pm 0,02 \mathrm{C}$ & $-0,14 \pm 0,01 \mathrm{~B}$ & $0,66 \pm 0,02 \mathrm{BC}$ & $0,83 \pm 0,02 \mathrm{~B}$ & $0,86 \pm 0,04 \mathrm{D}$ & $0,08 \pm 0,01 \mathrm{AB}$ \\
S30 & $1,5 \pm 0,0 \mathrm{C}$ & $1,62 \pm 0,08 \mathrm{C}$ & $-0,16 \pm 0,01 \mathrm{~A}$ & $0,60 \pm 0,01 \mathrm{~A}$ & $0,79 \pm 0,01 \mathrm{~A}$ & $0,77 \pm 0,04 \mathrm{~B}$ & $0,07 \pm 0,01 \mathrm{~A}$ \\
S40 & $1,3 \pm 0,1 \mathrm{~B}$ & $1,49 \pm 0,07 \mathrm{BC}$ & $-0,15 \pm 0,01 \mathrm{AB}$ & $0,64 \pm 0,01 \mathrm{~B}$ & $0,83 \pm 0,01 \mathrm{~B}$ & $0,80 \pm 0,05 \mathrm{BC}$ & $0,07 \pm 0,01 \mathrm{~A}$ \\
S50 & $1,1 \pm 0,1 \mathrm{~A}$ & $1,20 \pm 0,06 \mathrm{~A}$ & $-0,13 \pm 0,01 \mathrm{C}$ & $0,58 \pm 0,03 \mathrm{~A}$ & $0,79 \pm 0,01 \mathrm{~A}$ & $0,56 \pm 0,01 \mathrm{~A}$ & $0,10 \pm 0,03 \mathrm{~B}$ \\
\hline
\end{tabular}

Letras minúsculas distintas indican diferencias significativas $(p<=0,05)$ entre el control y las pastas con harina de amaranto. Letras mayúsculas distintas indican diferencias significativas $(p<=0,05)$ entre el control y las pastas con harina de soja. 
A excepción de S50, tanto las pastas elaboradas con harina de amaranto como con harina de soja, presentaron mayor pegajosidad que la muestra control, siendo aún mayor para las muestras adicionadas con harina de amaranto que para las muestras con harina de soja.

Para los parámetros cohesividad, elasticidad y masticabilidad, en general todas las muestras presentaron la misma tendencia; a mayor nivel de sustitución, menor valor encontrado para el parámetro medido, aunque no se encontraron diferencias significativas para todos los niveles de sustitución en relación al control.

Con respecto a la resiliencia, las muestras A15 y A30 fueron las únicas que mostraron valores significativamente menores que $\mathrm{Co}$, mientras que el resto de las muestras, incluyendo a las de soja, no presentaron diferencias respecto a Co.

Si bien el comportamiento durante la cocción de las muestras elaboradas con harina de amaranto y con harina de soja, fue afectado significativamente con el nivel de sustitución, a partir del análisis de textura, se observó que la calidad de las pastas elaboradas con harina de soja fue menos afectada que en las pasta elaboradas con harina de amaranto, al menos hasta el $40 \%$ de sustitución. Si bien el retículo proteico se fue debilitando con la incorporación creciente de estas harinas alternativas, la harina de amaranto afectó en mayor medida la estructura de la red de gluten que la harina de soja.

\section{Propiedades reológicas de las pastas cocidas}

Para evaluar las propiedades reológicas de las pastas, se elaboraron cintas de pastas de 2,8 $\mathrm{cm}$ de ancho, las que se secaron y cocinaron al igual que el resto de las muestras utilizadas en este trabajo. Desde el momento de la cocción hasta la realización del ensayo, las pastas fueron conservadas en agua destilada a una temperatura de $2-5{ }^{\circ} \mathrm{C}$ a fin de evitar tanto como fuera posibles cambios en su estructura.

\section{Barrido de deformación}

Para evaluar el intervalo en el cual el esfuerzo era linealmente proporcional a la deformación aplicada, se realizó un barrido de deformación desde 0,05 hasta 30\%, en tres muestras diferentes aleatoriamente elegidas (Control, S30 y S50), encontrando que hasta una deformación de $0,1 \%$, el esfuerzo presentaba un comportamiento lineal en todas las muestras analizadas (Figura 4.6). 


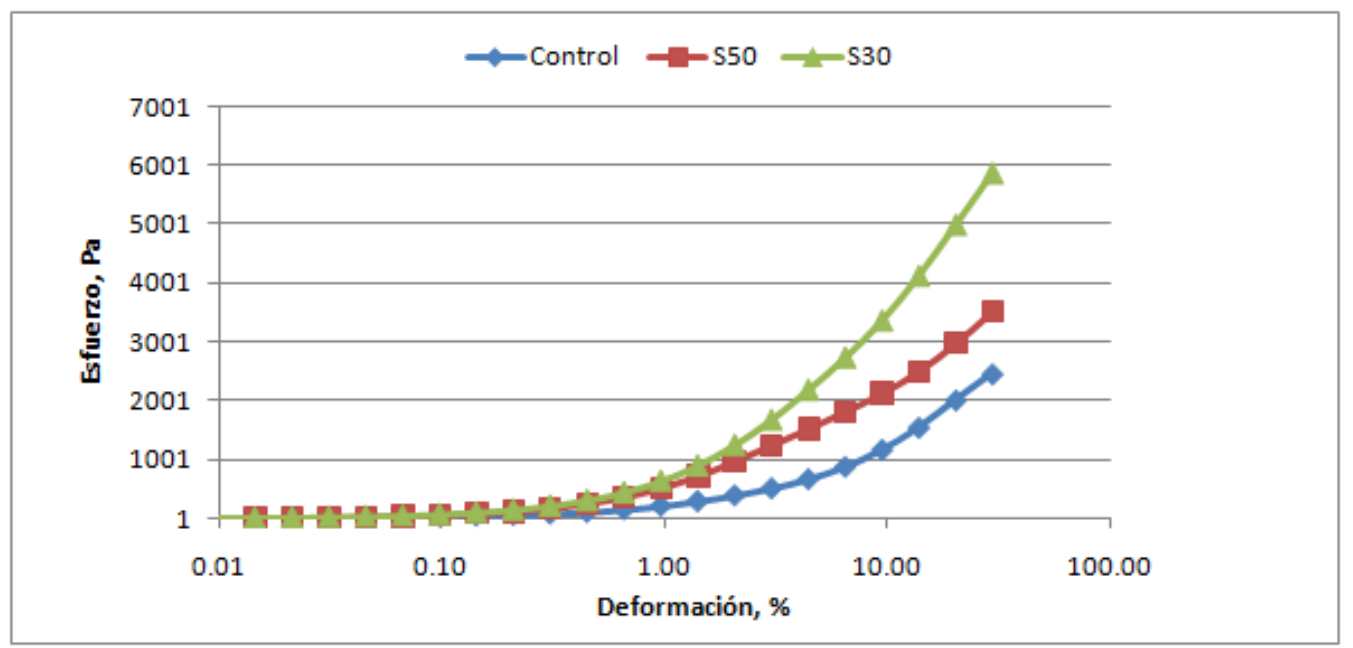

Figura 4.6 - Barrido de deformación de las pastas cocidas.

\section{Barrido de frecuencia}

\section{Pastas elaboradas con harina de amaranto}

El comportamiento reológico de las pastas elaboradas con proporciones crecientes de harina de amaranto mostró mayores valores de G' (Figura 4.7), G" (Figura 4.8) y de tan $\delta$ (Figura 4.9), respecto a la muestra control, lo que sugirió que la harina de amaranto acentuó un comportamiento sólido-elástico, resultando en un material más rígido y con mayor tendencia a fracturarse (Ross, 2006). También se observó una importante dependencia con la frecuencia tanto para $G^{\prime}$ como para $G^{\prime \prime}$, siendo en esta última, más marcada para las mayores frecuencias evaluadas.

Bejosano \& Corke (1998), en un trabajo realizado sobre masas y pastas a las que le adicionaron aislados proteicos de amaranto y de soja, encontraron que éstos provocaban un aumento del componte elástico, sugiriendo que las proteínas, especialmente las insolubles, fortalecían la masa generando un comportamiento más sólido - elástico. Si bien en este trabajo, también se encontraron mayores valores de $\mathrm{G}^{\prime}$ con la incorporación creciente de harina de amaranto, en este caso no se pudo explicar por un fortalecimiento de la pasta. 


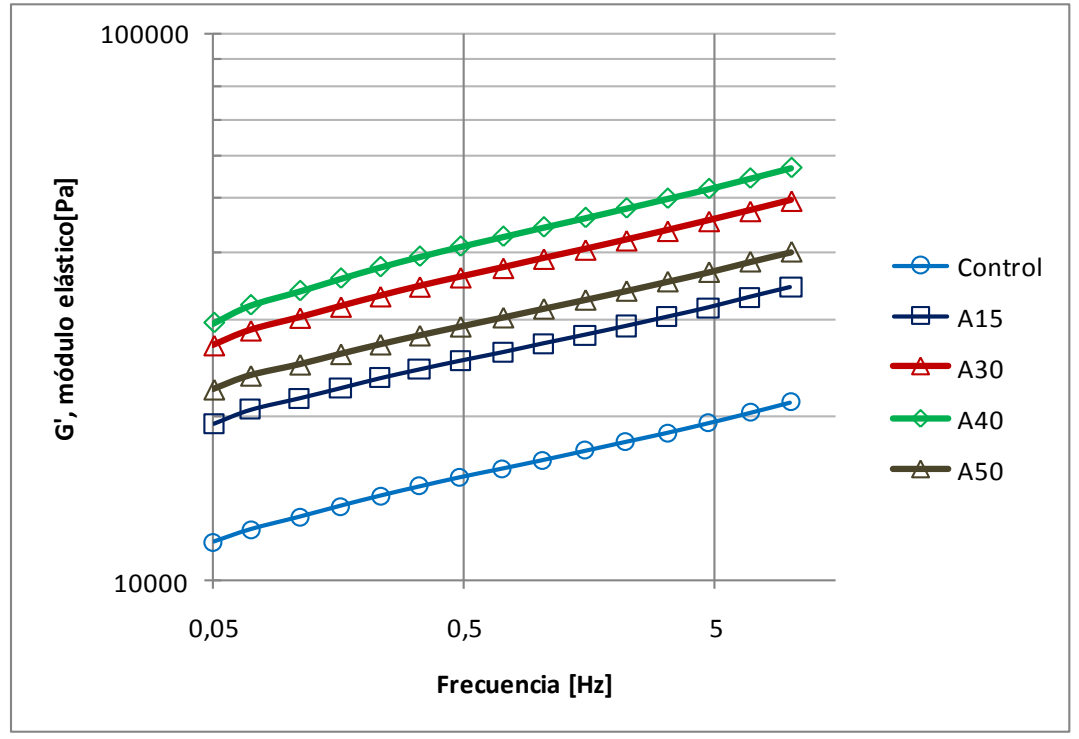

Figura 4.7- Módulo elástico, G', de las pastas cocidas elaboradas con harina de amaranto.

La harina de amaranto debilitó la estructura de la pasta, no solo por el efecto de dilución sobre el gluten aportado por la harina de trigo, responsable principal de la estructura de la pasta, si no que al ser una harina integral, las partículas de tegumento favorecieron la discontinuidad de la red de gluten, lo que se corroboró con el mayor residuo de cocción, la menor firmeza y la mayor pegajosidad obtenida para estas muestras.

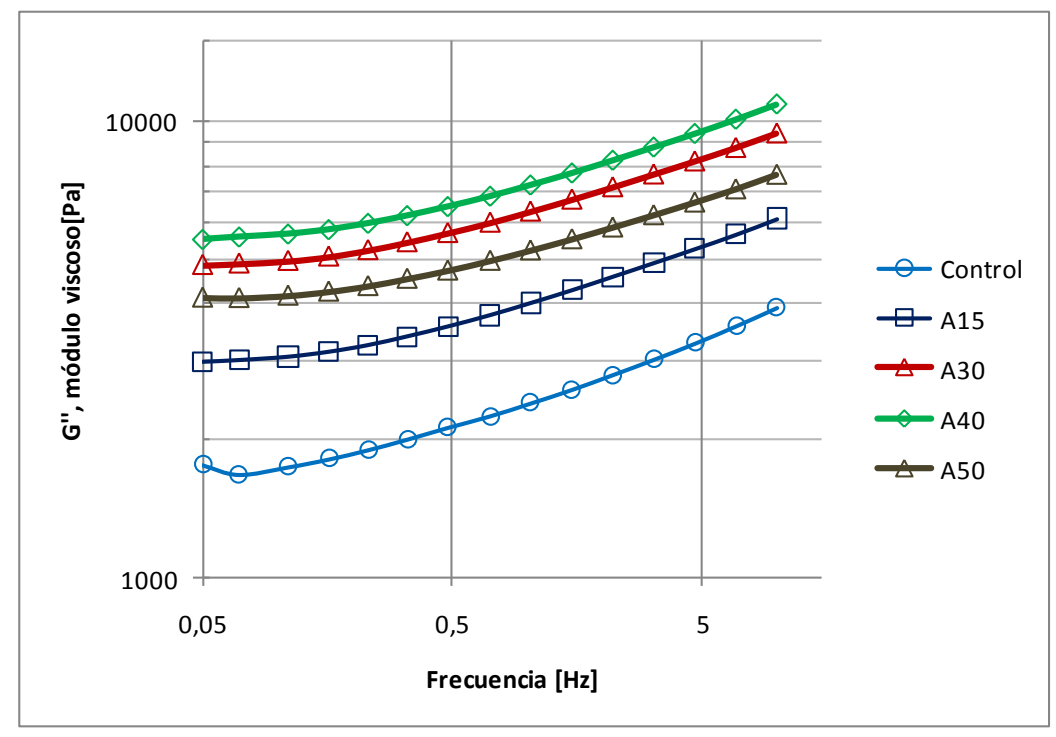

Figura 4. 8- Módulo viscoso, G", de las pastas cocidas elaboradas con harina de amaranto.

Un comportamiento particular presentaron los valores de Tan $\delta$ medidos en las pastas elaboradas con harina de amaranto. Desde 0,05 hasta $0,10-0,15 \mathrm{~Hz}$, se observó una 
disminución de los valores de $\operatorname{Tan} \delta$ para todas las muestras, luego hasta $0,48 \mathrm{~Hz}$ para las muestras Control, $A 15$ y $A 30$ y hasta $0,71 \mathrm{~Hz}$ para las muestras $A 40$ y A50, los valores de Tan $\delta$ se mantuvieron prácticamente constantes y finalmente éstos aumentaron linealmente con la frecuencia. Esto indicó que en la primera porción de la curva, el aumento de componente elástico fue mayor que el del componente viscoso, luego ambos componentes se mantuvieron constantes y finalmente se produjo un aumento proporcional de $\mathrm{G}^{\prime}$ y $\mathrm{G}^{\prime \prime}$ hasta alcanzar los 10 $\mathrm{Hz}$.

De acuerdo a Ross (2006) el contenido de amilosa se correlaciona negativamente con Tan ס. Esto podría explicar el comportamiento que se observó para muestras a partir de $0,5 \mathrm{~Hz}$, considerando que el aporte de amilosa por la harina de amaranto es mucho menor que el de la harina de trigo y por lo tanto la primera pudo ejercer un efecto de dilución sobre la amilosa aportada por la harina de trigo. Sin embargo los menores valores de Tan $\delta$ encontrados desde 0,05 hasta $0,5 \mathrm{~Hz}$ no pudieron explicarse con el concepto anterior.

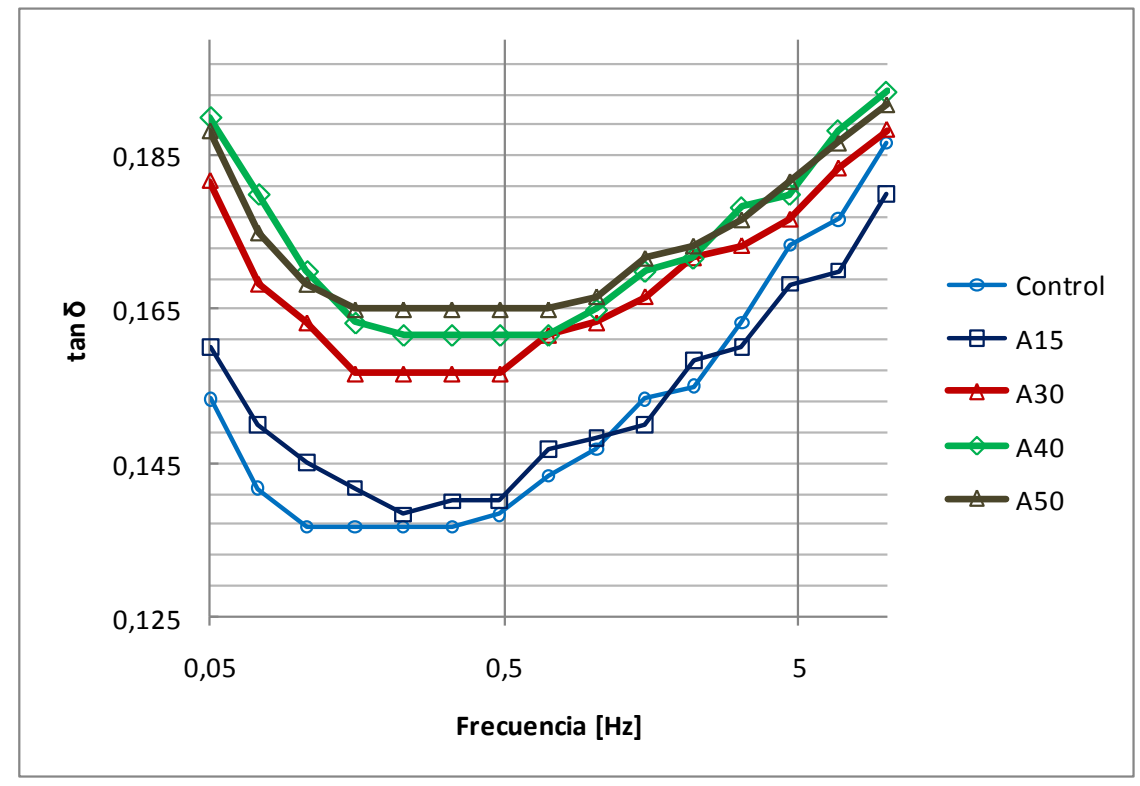

Figura 4.9- Tan $\delta$ de las pastas cocidas elaboradas con harina de amaranto.

A pesar de las variaciones observadas el comportamiento siempre fue de tipo elástico, propiedad que disminuyó (elasticidad) al aumentar el grado de sustitución. 


\section{Pastas elaboradas con harina de soja}

El comportamiento reológico de las pastas elaboradas con proporciones crecientes de harina de soja mostró un incremento tanto del módulo elástico $\mathrm{G}^{\prime}$, como del módulo viscoso, G" (Figura 4.10 y 4.11). Se encontró además, una gran dependencia con la frecuencia, siendo para el módulo elástico constante durante todo el rango analizado, mientras que para el módulo viscoso, esta dependencia se acentuó aún más para los valores más altos.

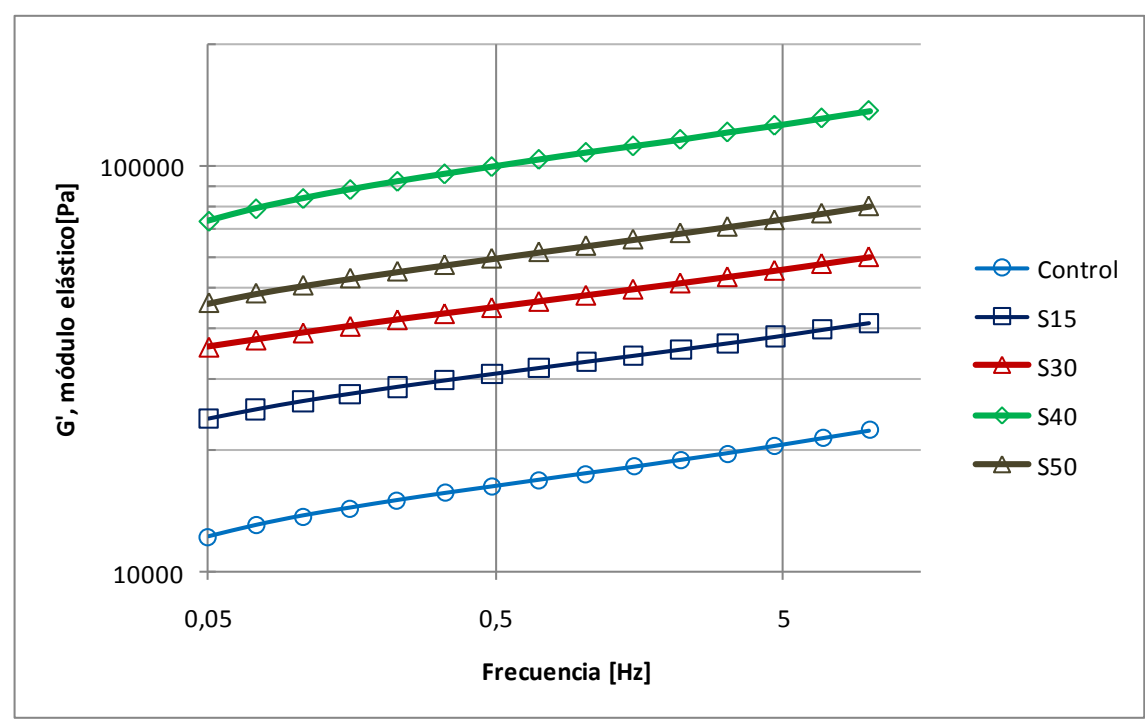

Figura 4.10 - Módulo elástico, G', de la pastas elaboradas con harina de soja.

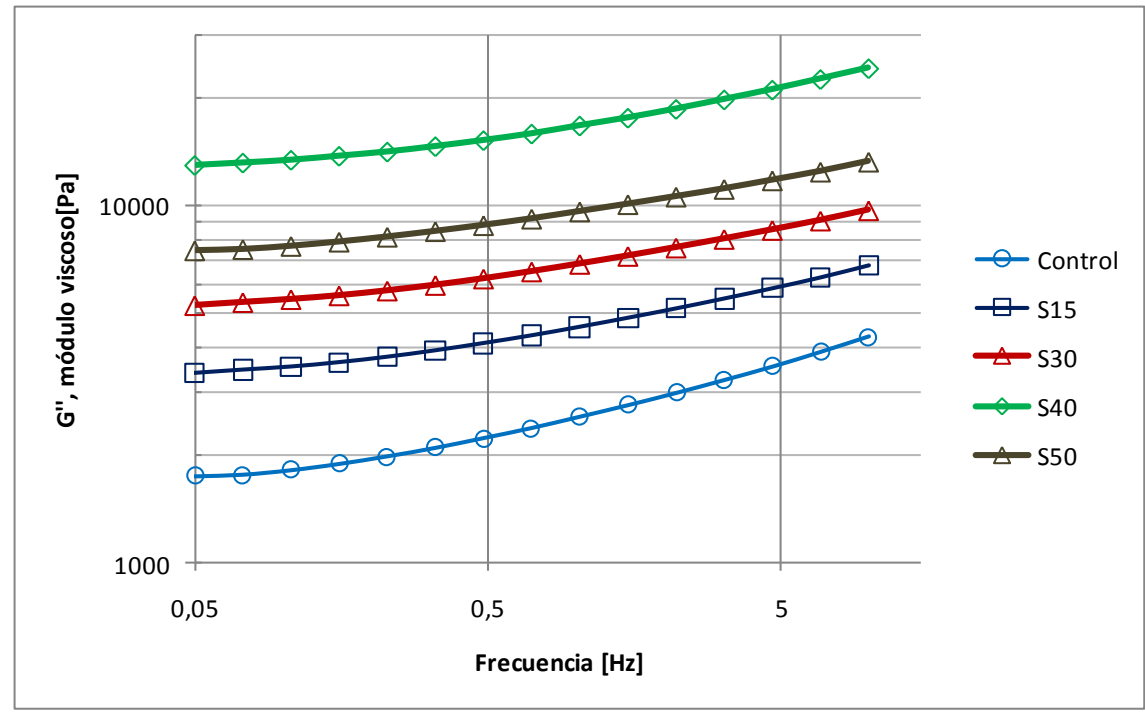

Figura 4.11- Módulo viscoso, G", de las pastas elaboradas con harina de soja.

Además se observó, que en general, los valores de Tan $\delta$ disminuyeron hasta los $0,25 \mathrm{~Hz}$, para luego aumentar linealmente con la frecuencia (Figura 4.12), presentado mayores valores 
las muestras con mayor nivel de sustitución, a excepción de los valores de $\mathrm{S50}$, los que se encontraron comprendidos entre los de S30 y S40. En el caso de la muestra control, a partir de $0,25 \mathrm{~Hz}$, se diferenció del resto de las muestras, debido a un mayor aumento de Tan $\delta$ con la frecuencia, presentado a partir de $0,7 \mathrm{~Hz}$ los mayores valores de Tan $\delta$.

Esta disminución inicial de Tan $\delta$ hasta los $0,25 \mathrm{~Hz}$, observada para todas las muestras, indicó que el componente elástico aumentó en mayor proporción que el componente viscoso, significando una mayor rigidez a bajas frecuencias.

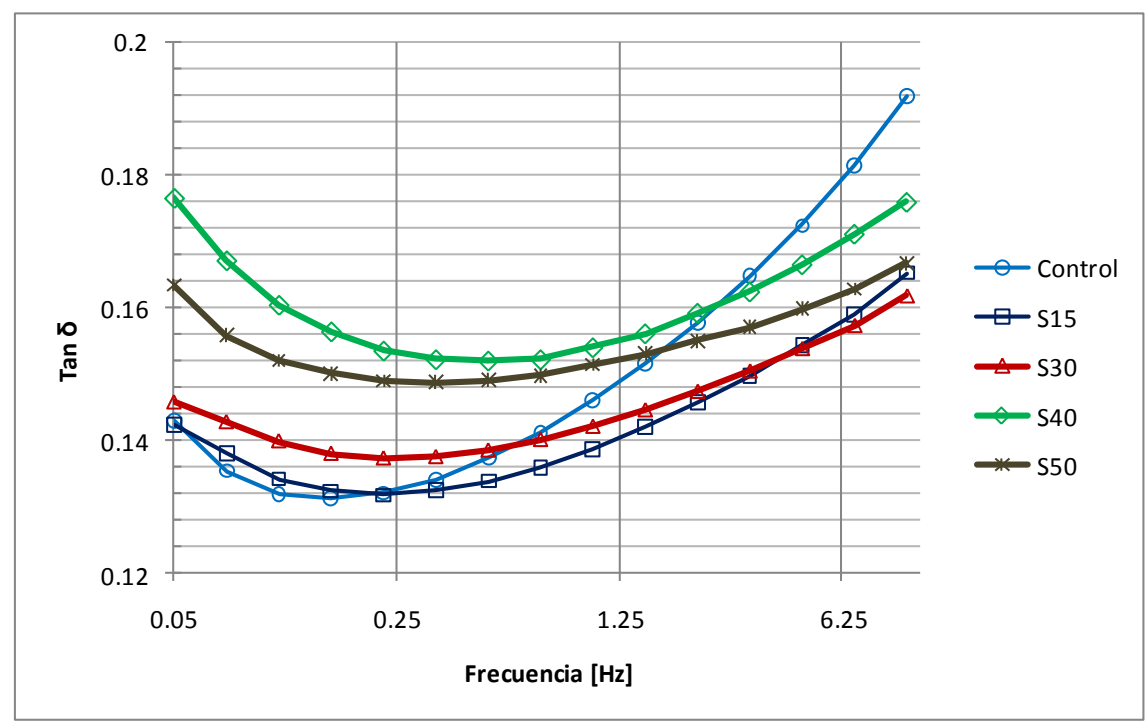

Figura 4.12- Tan $\delta$ de las pastas cocidas elaboradas con harina de soja.

Las discordancias encontradas en el comportamiento reológico de las pastas elaboradas con harina de amaranto y de soja pueden explicarse en parte, por ser un material heterogéneo, en donde el comportamiento viscoelástico puede ser diferente entre la superficie y el interior de la pasta cocida. De acuerdo a Ross (2006), los fideos cocidos presentan heterogeneidad en una serie de escalas y la falta de homogeneidad en los productos alimenticios es una causa importante de desajuste entre las consideraciones teóricas y el comportamiento en el mundo real cuando éste alimento es sometido a una deformación. En una macro escala, los fideos cocidos presentan una heterogeneidad desde el exterior respecto al interior como consecuencia del gradiente de humedad generado durante la cocción. En una meso escala, también se observa una heterogeneidad: una fase discontinua de gránulos de almidón hinchados, pero que aún no se han dispersado, especialmente en el centro de la pasta y una fase continua de proteínas y amilosa lixiviada de los gránulos de almidón. Asimismo se describe una heterogeneidad en una micro escala, a nivel molecular, donde se encuentran 
asociaciones de amilosa/amilosa, y enredos de amilosa/proteína en cercanía de la superficie de los gránulos de almidón, dada la poca capacidad de los polímeros lineales para participar en el movimiento de traslación, excepto reptación, en entornos altamente concentrados (Ross, 2006).

\section{Color de las pastas cocidas}

Tanto la harina de amaranto como la harina de soja afectaron el color de las pastas cocidas, generando un aspecto más oscuro y en especial para aquellas elaboradas con harina de amaranto una superficie más discontinua (Figura 4.13 y Figura 4.14).

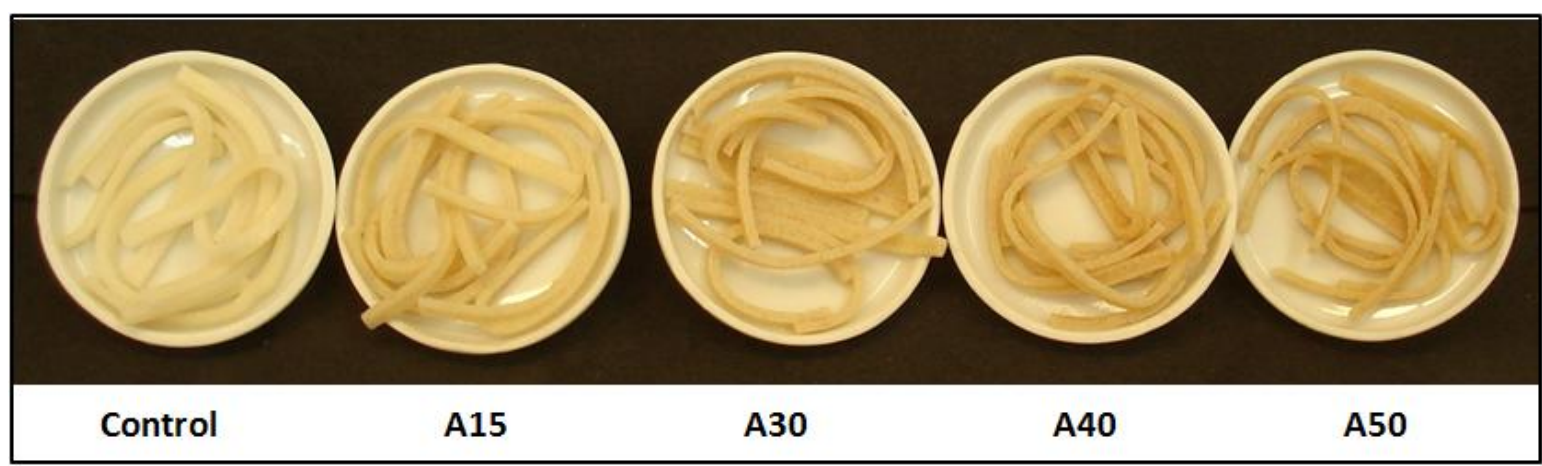

Figura 4.13 - Aspecto de las pastas cocidas elaboradas con harina de amaranto.

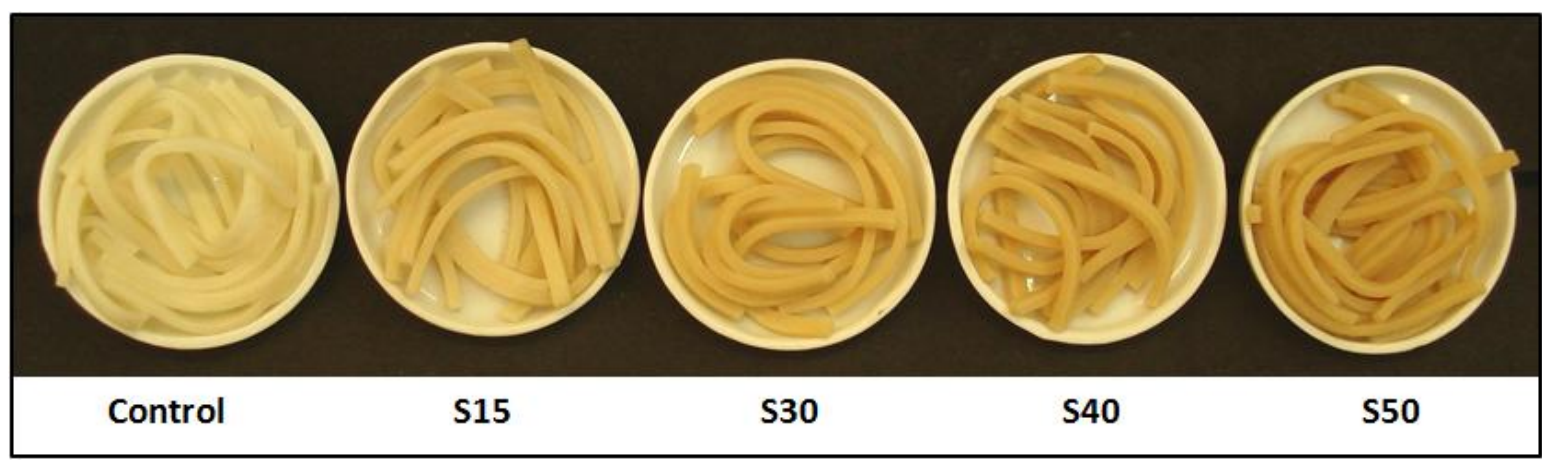

Figura 4.14 - Aspecto de las pastas cocidas elaboradas con harina de soja.

A través de la reflectancia medida en las pastas cocidas, se pudo observar que tanto el agregado de la harina de amaranto como el de soja, disminuyeron el valor $L^{*}$ y aumentaron los valores a* y b* (Figura 4.15 y Figura 4.16 ). 

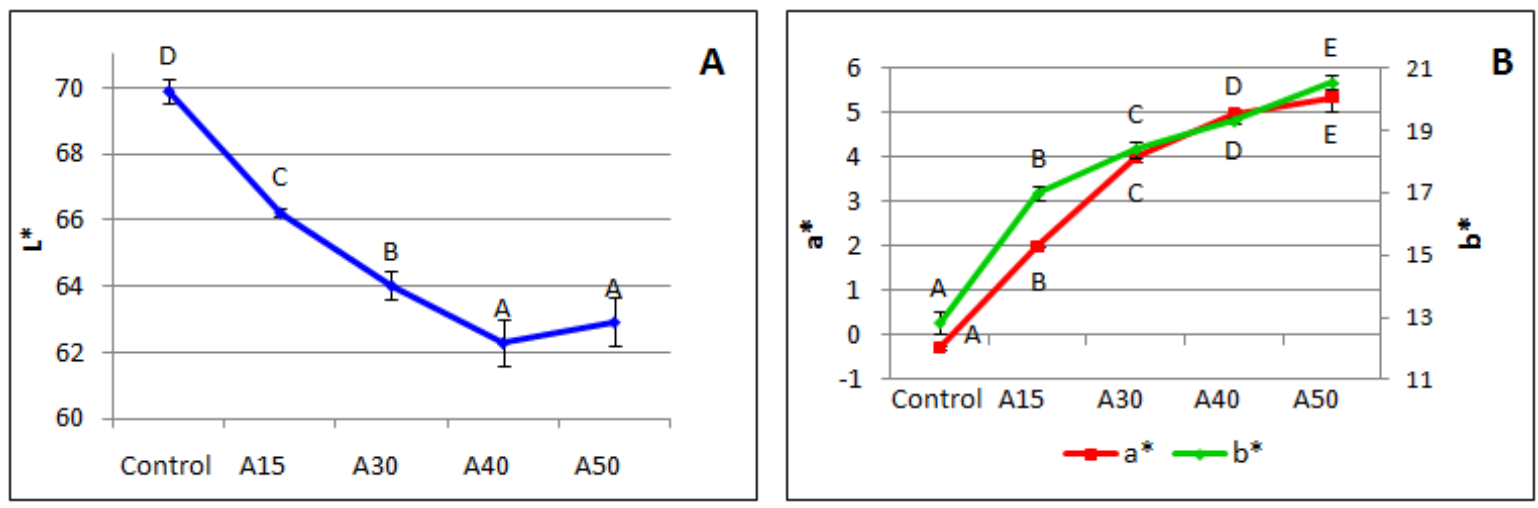

Figura 4.15 - Efecto sobre el color provocado por la sustitución con harina de amaranto a la harina de trigo utilizada la elaborar las pastas, sobre la luminosidad $\left(\mathrm{L}^{*}\right),[\mathrm{A}]$; y sobre los espacios de color rojoverde $\left(a^{*}\right)$ y $\left(b^{*}\right),[B]$. Letras distintas indican diferencias significativas $(p<=0,05)$.
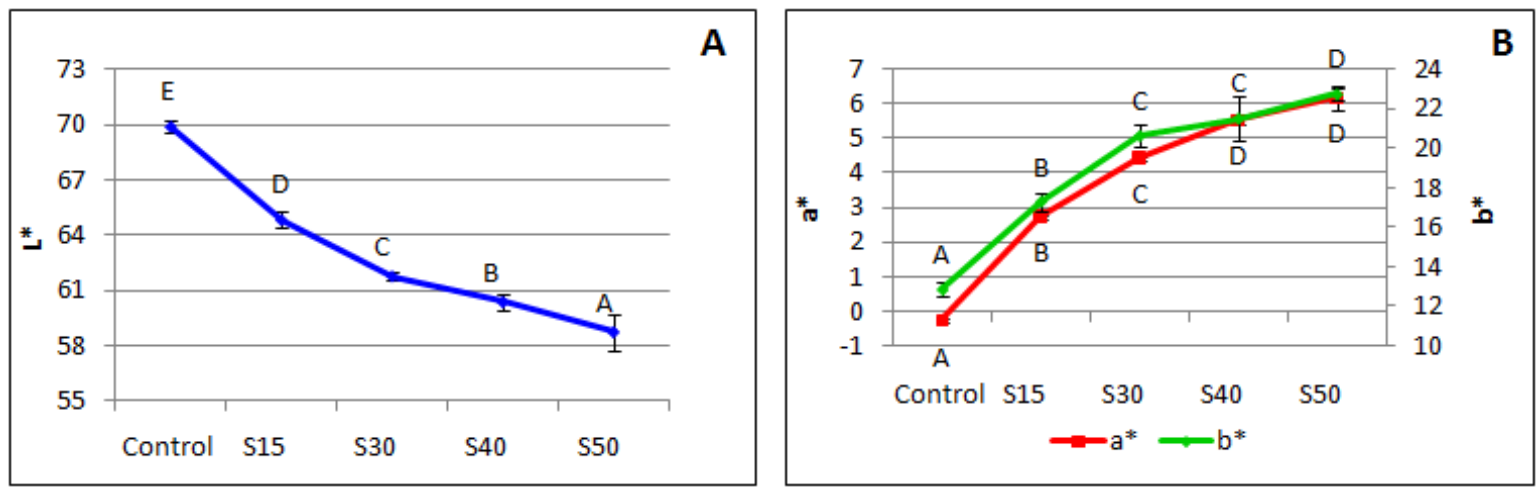

Figura 4.16 - Efecto sobre el color provocado por la sustitución con harina de soja a la harina de trigo utilizada para elaborar las pastas, sobre la luminosidad $\left(L^{*}\right),[A]$ y sobre los espacios de color rojoverde $\left(a^{*}\right)$ y $\left(b^{*}\right),[B]$. Letras distintas indican diferencias significativas $(p<=0,05)$.

En la Tabla 4.8 además se muestran las diferencias de color encontradas en las pastas sustituidas con la harina de amaranto y de soja respecto al de la muestra control, en términos de $\Delta L^{*}, \Delta a^{*}, \Delta b^{*}$, y $\Delta E$, siendo este último calculado como $\Delta E=\left(\Delta L^{2}+\Delta a^{2}+\Delta b^{2}\right)^{1 / 2}$. Los resultados indican que la pasta perdió claridad y se volvió más rojiza y más amarillenta, conforme aumentaron los porcentajes de sustitución de ambas harinas; no obstante, las pastas sustituidas con harina de soja presentaron mayores diferencias respecto a la muestra control, que las pastas sustituidas con harina de amaranto. Además, a partir los valores $\Delta \mathrm{E}$ obtenidos, utilizando la escala de National Bureau Standard (NBS), se calificaron las diferencias obtenidas. Para las pastas sustituidas con harina de soja se encontraron las mayores diferencias, especialmente para los valores $\Delta L^{*}$ y $\Delta b^{*}$; resultados consecuentes con la calificación NBS. 
Tabla 4.8 - Diferencias de color observadas en las pastas cocidas con harina de amaranto y de soja

\begin{tabular}{cccccc}
\hline Muestras & $\mathbf{\Delta L}^{*}$ & $\mathbf{\Delta} \mathbf{a}^{*}$ & $\mathbf{\Delta} \mathbf{b}^{*}$ & $\mathbf{\Delta} \mathbf{E}^{*}$ & $\mathbf{N B S}, \boldsymbol{\Delta \mathbf { E } ^ { \mathbf { 1 } }}$ \\
\hline A15 & $-3,6$ & 2,3 & 4,1 & 5,9 & Notoria \\
A30 & $-5,7$ & 4,2 & 5,5 & 9,0 & Marcadamente notoria \\
A40 & $-7,5$ & 5,3 & 6,8 & 11,5 & Marcadamente notoria \\
A50 & $-7,3$ & 5,5 & 7,6 & 11,9 & Marcadamente notoria \\
& & & & & \\
S15 & $-5,1$ & 2,9 & 4,4 & 7,3 & Marcadamente notoria \\
S30 & $-8,3$ & 4,7 & 7,9 & 12,3 & Extremadamente notoria \\
S40 & $-9,6$ & 5,7 & 8,6 & 14,1 & Extremadamente notoria \\
S50 & $-11,2$ & 6,4 & 10,0 & 16,4 & Extremadamente notoria \\
\hline
\end{tabular}

${ }^{1} \mathrm{NBS}, \Delta \mathrm{E}$ : prácticamente imperceptible: 0-0,5; ligeramente perceptible: 0,5-1,5;

apreciable: 1,5-3,0; notoria: 3,0-6,0; marcadamente notoria: 6,0-12,0; extremadamente notoria $>12$.

\section{Microscopía electrónica de barrido (SEM) de las pastas secas y cocidas}

\section{Pastas elaboradas con harina de amaranto}

A través de la microscopía electrónica de barrido se pudo observar cómo la incorporación de la harina de amaranto afectó la estructura de las pastas. Si bien los pequeños gránulos de almidón del amaranto $(\varnothing: 0,5$ a $2 \mu \mathrm{m})$ poseen la características de formar aglomerados de hasta $80 \mu \mathrm{m}$, pudiendo actuar en conjunto con las proteínas como un relleno en la matriz de las pastas favoreciendo su estructura (Mariotti et al., 2009), al haber usado en el trabajo una harina del tipo integral, la presencia de tegumentos en grandes cantidades y de gran tamaño (placas que pueden superar $600 \mu \mathrm{m}$ de acuerdo a Mariotti et al., 2009) (Figura 4.17), generaron una marcada discontinuidad en la matriz proteica afectando negativamente la calidad de las pastas. Resultados coincidentes con lo observado en el comportamiento durante la cocción y la textura medida.

En la Figura 4.18-SS, se puede observar como la superficie de la pasta seca perdió continuidad por el agregado de la harina de amaranto, generándose poros cada vez mayores, los que facilitaron significativamente la difusión del agua hacia su interior durante la cocción, favoreciendo la gelatinización del almidón y disminuyendo los tiempos de cocción. 


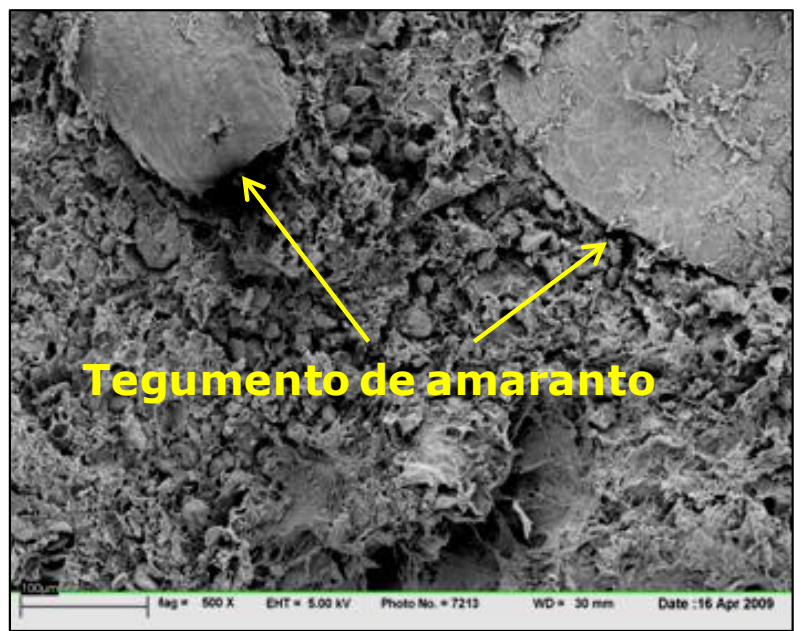

Figura 4.17-Superficie de la pasta cocida elaborada con $50 \mathrm{~g}$ de harina de amaranto/100 $\mathrm{g}$ harina de trigo.
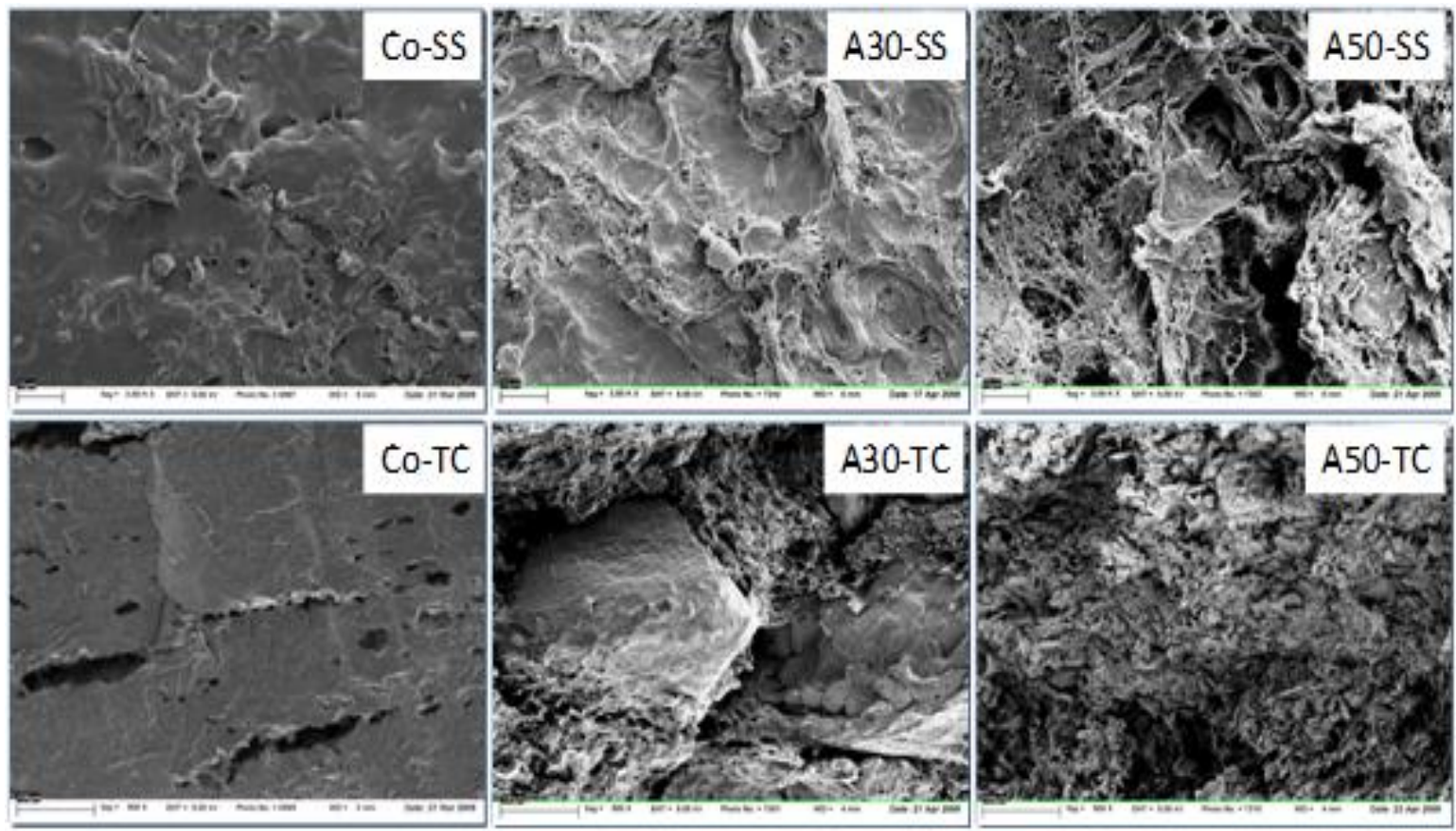

Figura 4.18- SEM de la superficie (SS) y de la sección transversal (TC) de las pastas cocidas elaboradas con harina de amaranto.

En el corte transversal de la pasta cocida (Figura 4.18-TC), también se observó una estructura debilitada y heterogénea, en donde posiblemente las proteínas solo estaban agregadas sin ninguna organización, interrumpidas por grandes placas de tegumento (Figura 4.18-A30 TC). 


\section{Pastas elaboradas con de harina de soja}

La ultra-estructura de la superficie de la pasta seca sólo se vio ligeramente afectada por el agregado de harina de soja (Figura 4.19-SS), aunque sobre la pasta cocida (Figura 4.19-SC) se encontraron cambios notables. El aspecto homogéneo que presentó la muestra control (Figura 4.19-CoSC), progresivamente fue desapareciendo ante la incorporación de la harina de soja, resultando en una pasta con una superficie cada vez más heterogénea y discontinua.
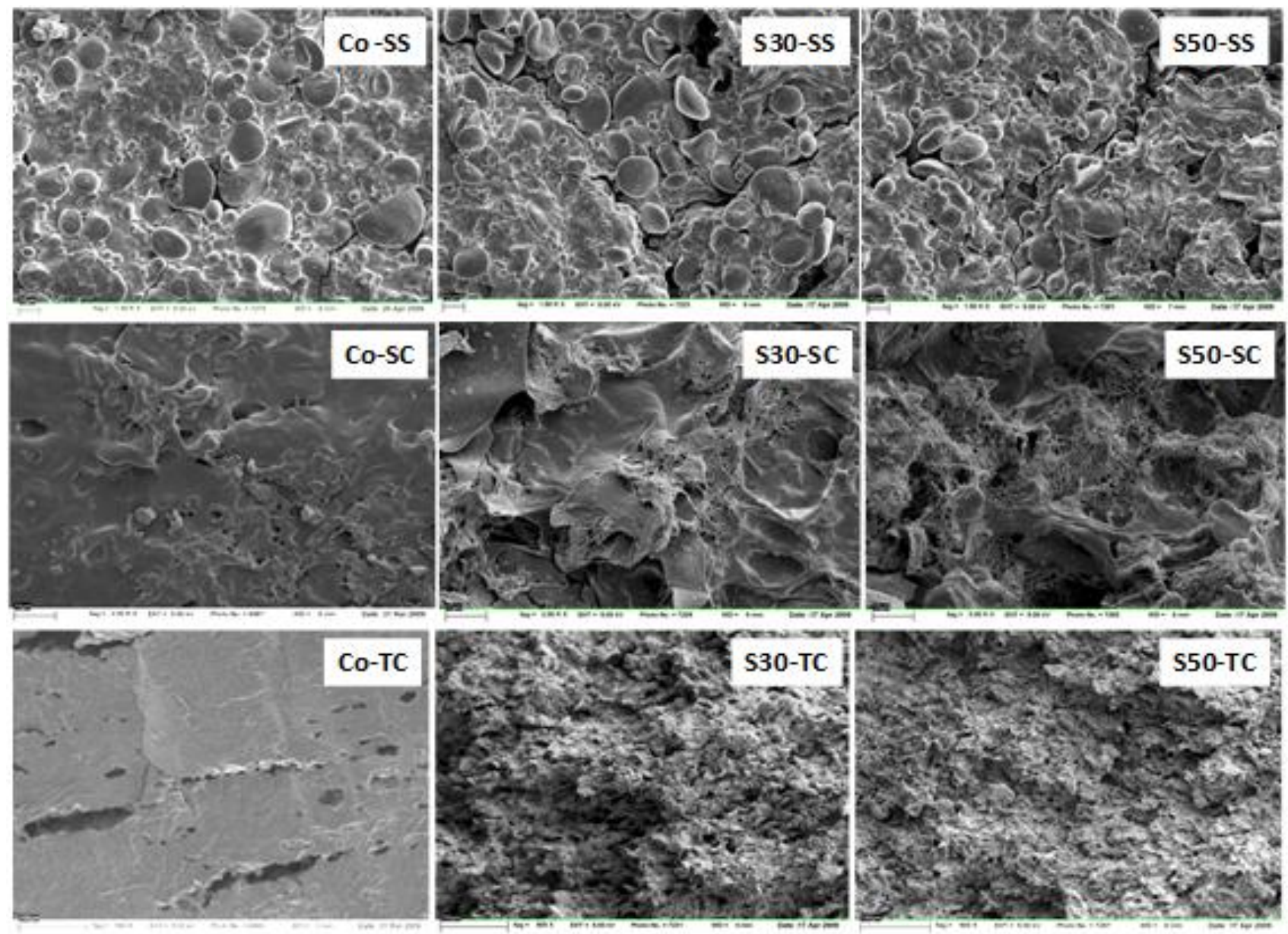

Figura 4.19- SEM sobre la superficie de la pasta seca (SS), de la superficie (SC) y del corte transversal (TC) de la pasta cocida elaborada con harina de soja.

Sobre el corte transversal de la pasta cocida (Figura 4.19-TC), la muestra control se diferenció notablemente de las muestras $\mathbf{S 3 0}$ y $\mathbf{S 5 0}$, mientras que estas dos últimas se mostraron similares. El agregado de harina de soja, generó una pasta cocida de aspecto heterogéneo, donde probablemente las proteínas de soja fueron parte importante de esa estructura enredada. 
El deterioro observado en la ultra-estructura de las pastas elaboradas con harina de soja, estuvo acorde con los mayores residuos de cocción y mayor pegajosidad medidas en estas pastas, pero se contradijo con los valores de firmeza medidos, dado que solo S50 presentó menor firmeza que la muestra control. Este comportamiento sugirió que, si bien la red de proteínas del gluten, proveniente de la harina de trigo se vio notablemente deteriorada, las proteínas de soja, aportaron una cierta firmeza, probablemente debido a su capacidad de gelificar, reduciendo el deterioro de la calidad final de la pasta, a pesar de ser una harina carente de gluten sin propiedades panaderas.

\section{Evaluación sensorial de pastas cocidas}

Las pastas cocidas identificadas con tres números aleatorios, fueron presentadas a un panel de evaluadores semi-entrenados, junto con una muestra señalada como muestra control (elaborada solo con harina de trigo pan). El ensayo se hizo por comparación de la intensidad de cada una de las propiedades evaluadas, entre las muestras problemas respecto y la muestra control. Además los panelistas realizaron una evaluación de preferencia, calificando las muestras desde extremadamente agradable hasta extremadamente desagradable a través de una escala de nueve puntos.

\section{Evaluación sensorial de las pastas elaboradas con harina de amaranto}

Para el análisis de los datos resultantes de la evaluación sensorial, se planteó un diseño en bloques completamente aleatorizados donde los 8 evaluadores fueron considerados como bloques y las cinco muestras ( $\mathrm{Co}, \mathrm{A} 15, \mathrm{~A} 30, \mathrm{~A} 40$ y $\mathrm{A} 50$ ) fueron tomadas como los tratamientos. Primero se realizó un ANAVA incluyendo la interacción bloque (evaluadores) x tratamiento (niveles de sustitución), para comprobar que ésta no era significativa, ya que un supuesto importante de un diseño en bloques es que los efectos de los bloques sean aditivos (Tabla 4.9).

Como la interacción resultó no significativa, valores $F>$ Fcrit $(F c r i t ~(4 ; 7 ; 0,95)=4,12)$ y p>0,05; para las cuatro propiedades evaluadas, se realizó un nuevo análisis con un modelo que no incluyera la interacción, a los fines de aumentar los grados de libertad del error experimental (Tabla 4.10). 
Tabla 4.9 - Análisis estadístico (ANAVA) de la evaluación sensorial de las pastas sustituidas con harina de amaranto incluyendo la interacción bloque (evaluadores) $x$ tratamiento (niveles de sustitución)

\begin{tabular}{ccccccc}
\hline Propiedad & Fuente de Variación & $\begin{array}{c}\text { Suma de } \\
\text { cuadrados }\end{array}$ & $\begin{array}{c}\text { Grados de } \\
\text { Libertad }\end{array}$ & $\begin{array}{c}\text { Cuadrado } \\
\text { medio }\end{array}$ & Estadístico F & valor p \\
\hline Firmeza & Nivel de sustitución (NS) & 85,45 & 4 & 21,36 & 10,71 & $<0,0001$ \\
& Evaluador (E) & 83,04 & 7 & 11,86 & 5,95 & 0,0001 \\
Pegajosidad & NS x E & 43,52 & 28 & 1,55 & 0,78 & 0,7532 \\
& Nivel de sustitución (NS) & 19,89 & 4 & 4,97 & 2,28 & 0,0778 \\
& Evaluador (E) & 84,21 & 7 & 12,03 & 5,51 & 0,0002 \\
Masticabilidad & Nivel de sustitución (NS) & 63,63 & 28 & 2,27 & 1,04 & 0,4468 \\
& Evaluador (E) & 35,55 & 4 & 15,89 & 13,95 & $<0,0001$ \\
& NS x E & 32,69 & 7 & 5,13 & 4,5 & 0,0009 \\
Elasticidad & Nivel de sustitución (NS) & 238,61 & 4 & 1,17 & 1,03 & 0,4633 \\
& Evaluador (E) & 69,76 & 7 & 99,65 & 30,85 & $<0,0001$ \\
& NS x E & 33,95 & 28 & 1,21 & 0,63 & 0,0003 \\
& & & & & & 0,9007 \\
\hline
\end{tabular}

Tabla 4.10 - ANAVA de la evaluación sensorial de las pastas sustituidas con harina de amaranto de los componentes Nivel de Sustitución y Evaluador

\begin{tabular}{ccccccc}
\hline \multirow{2}{*}{ Propiedad } & \multirow{2}{*}{ Fuente de Variación } & $\begin{array}{c}\text { Suma de } \\
\text { cuadrados }\end{array}$ & $\begin{array}{c}\text { Grados de } \\
\text { Libertad }\end{array}$ & $\begin{array}{c}\text { Cuadrado } \\
\text { medio }\end{array}$ & $\begin{array}{c}\text { Estadístico } \\
\mathbf{F}\end{array}$ & valor $\mathbf{p}$ \\
\hline Firmeza & Nivel de sustitución (NS) & 85,45 & 4 & 21,36 & 11,78 & $<0,0001$ \\
& Evaluador (E) & 83,04 & 7 & 11,86 & 6,54 & $<0,0001$ \\
Pegajosidad & Nivel de sustitución (NS) & 19,89 & 4 & 4,97 & 2,24 & 0,0738 \\
& Evaluador (E) & 84,21 & 7 & 12,03 & 5,42 & 0,0001 \\
Masticabilidad & Nivel de sustitución (NS) & 63,55 & 4 & 15,89 & 13,81 & $<0,0001$ \\
& Evaluador (E) & 35,9 & 7 & 5,13 & 4,46 & 0,0004 \\
Elasticidad & Nivel de sustitución (NS) & 238,61 & 4 & 59,65 & 36,45 & $<0,0001$ \\
& Evaluador (E) & 69,76 & 7 & 9,97 & 6,09 & $<0,0001$ \\
\hline
\end{tabular}

A partir del análisis de la varianza para firmeza, se encontró que el efecto bloque (evaluadores), como el efecto tratamiento (niveles de sustitución) resultaron significativos, de modo que la variabilidad total se dividió entre tres diferentes fuentes; la variabilidad debida a los evaluadores, la variabilidad debida a los distintos niveles de sustitución con harina de amaranto y la variabilidad remante no explicada por las anteriores (error experimental). Mediante el test de DGC de comparaciones múltiples (Tabla 4.11) se observó que solo A40 y A50 resultaron significativamente menos firmes que el resto de las muestras.

En el caso de la pegajosidad, solo el efecto bloque (evaluadores) resultó significativo como fuente de variabilidad total, más allá de la explicada por el error experimental. Si bien para esta evaluación se modificó la técnica de medición, por la dificultad que habían expresado los evaluadores para medir esta propiedad en ensayos previos realizados con las pastas elaboradas con harina de soja, no se logró disminuir la dispersión en los resultados. De hecho 
se consideró que la variabilidad generada por los evaluadores, fue la que soslayó las posibles diferencias de pegajosidad entre los diferentes niveles de sustitución (Tabla 4.11). Cabe destacar que cuando esta propiedad fue medida en el texturómetro, si bien A15, no presentó diferencias con Co, A30, A40 y A50 resultaron más pegajosas que la muestra control.

Tabla 4.11 - Evaluación sensorial de pastas cocidas sustituidas
con harina de amaranto
\begin{tabular}{ccccc}
\hline Muestra & Firmeza & Pegajosidad & Masticabilidad & Elasticidad \\
\hline Co & $0 \mathrm{~b}$ & $0 \mathrm{a}$ & $0 \mathrm{~b}$ & $0 \mathrm{c}$ \\
A15 & $-0,21 \mathrm{~b}$ & $0,72 \mathrm{a}$ & $-0,39 \mathrm{~b}$ & $-3,41 \mathrm{~b}$ \\
A30 & $-0,72 \mathrm{~b}$ & $0,56 \mathrm{a}$ & $-0,52 \mathrm{~b}$ & $-3,17 \mathrm{~b}$ \\
A40 & $-1,77 \mathrm{a}$ & $1,07 \mathrm{a}$ & $-1,88 \mathrm{a}$ & $-4,37 \mathrm{a}$ \\
A50 & $-2,76 \mathrm{a}$ & $1,49 \mathrm{a}$ & $-2,26 \mathrm{a}$ & $-5,01 \mathrm{a}$ \\
\hline
\end{tabular}
Valores seguidos de la misma letra dentro de una columna no presentan
diferencias significativas $(\mathrm{p}<=0,05)$, según el test de DGC.

Respecto a la masticabilidad y a la elasticidad, tanto el nivel de sustitución como los evaluadores resultaron ser fuentes de variación ( $F>F$ crit; $p>0,05)$ al igual que lo observado para la firmeza. A partir del test de comparaciones múltiples DGC (Tabla 4.11), ambas propiedades solo se diferenciaron del control las muestras A40 y A50, presentando menor masticabilidad y elasticidad que el resto de las muestras.

Al plantear un análisis de correlación de Pearson de las variables firmeza, pegajosidad, elasticidad y masticabilidad entre la medición instrumental (texturómetro TA-XT2i Texture Analyzer, Stable Micro Systems, Inglaterra) y la evaluación sensorial, se encontraron correlaciones significativas $(p<0,05)$ para la firmeza $(r: 0,99 ; p: 0,001)$ y para la masticabilidad ( $r: 0,91 ; p: 0,03$ ). Puede que las propiedades elasticidad y pegajosidad le hayan resultado a los panelistas más difíciles de evaluar generando una alta dispersión en los resultados y afectando consecuentemente el análisis de correlación. 


\section{Evaluación de preferencia}

Para la evaluación de preferencia se observó que la muestra control fue la mejor calificada y que toda incorporación de harina de amaranto perjudicó la aceptación del producto.

A partir de un análisis de Friedman (Tabla 4.12), se encontraron diferencias significativas para todos los niveles de sustitución respecto a la muestra control. Las muestras A15 y A30 fueron las que presentaron los mayores valores de la suma y media de rangos, mientras que la muestra A50 fue la menos preferida de todas, con una media de rangos de 1,31.

Tabla 4.12 - Prueba de Friedman para la evaluación de preferencia de las pastas elaboradas con harina de amaranto

\begin{tabular}{ccc}
\hline Tratamiento & Suma de Rangos & Media de Rangos \\
\hline Co & 40,0 & $5,00 \mathrm{e}$ \\
A15 & 26,5 & $3,31 \mathrm{c}$ \\
A30 & 29,0 & $3,63 \mathrm{~cd}$ \\
A40 & 14,0 & $1,75 \mathrm{ab}$ \\
A50 & 10,5 & $1,31 \mathrm{a}$ \\
\hline
\end{tabular}

Letras distintas indican diferencias significativas $(p \leq 0,05)$. Mínima diferencia significativa entre la suma de rangos 4,042 .

Además a partir de la media aritmética (Figura 4.20) se encontró que tanto A15 como A30 resultaron con una calificación de 5, es decir ni agradable ni desagradable, mientras que A40 y A50 fueron las más castigadas quedando en la zona de lo desagradable.

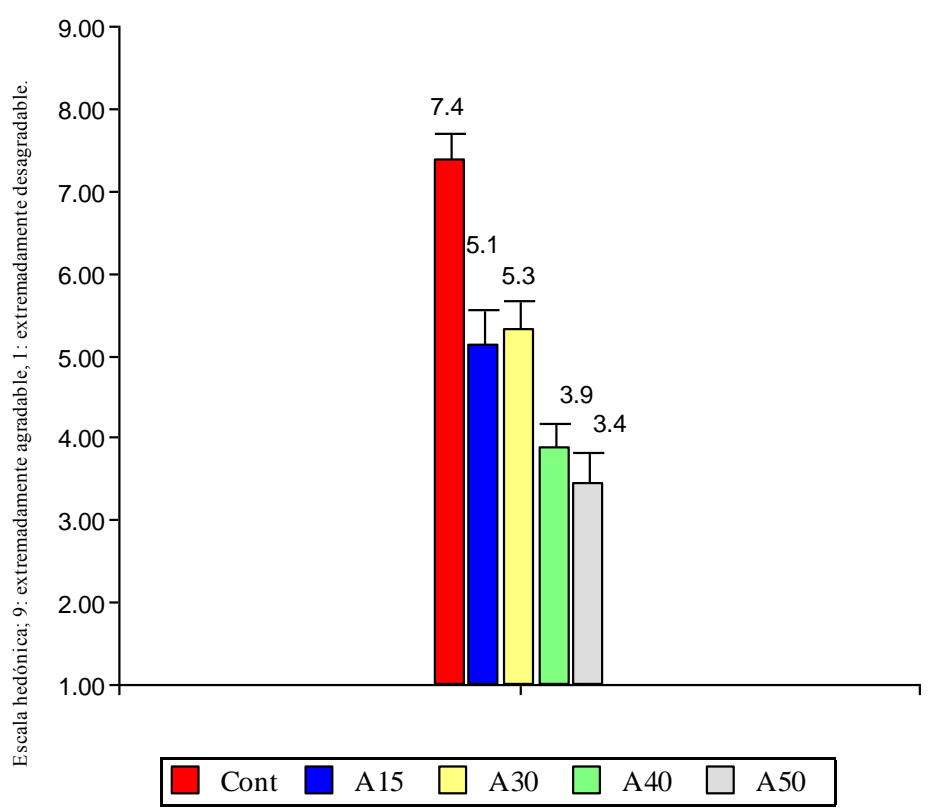

Figura 4.20 - Evaluación de preferencia de pastas cocidas elaboradas con harina de amaranto. Las barras de error corresponden al error estándar). 


\section{Evaluación sensorial de pastas elaboradas con harina de soja}

Al igual que para la evaluación sensorial de las pastas sustituidas con harina de amaranto, también se planteó un diseño de bloques completamente aleatorizados, donde los 8 evaluadores (E) fueron considerados como bloques y las cinco muestras (Co, S15, S30, S40 y S50) (NS) fueron tomadas como los tratamientos. De igual modo que para el análisis anterior, primero se realizó un ANAVA para evaluar si la interacción bloque $\mathrm{x}$ tratamiento era significativa.

En la Tabla 4.13 se puede observar que la interacción NS x E no resultó significativa, dado que todos los valores del estadístico $F$ fueron menores al Fcrit $(4 ; 7 ; 0,95)=4,12$ para las cuatro propiedades evaluadas. La misma conclusión se obtuvo al observar los valores $p$, los que resultaron todos mayores a 0,05 . De modo que al no encontrar evidencias para rechazar la aditividad de los efectos de los bloques; se realizó un nuevo análisis para un modelo sin esta interacción a los fines de aumentar los grados de libertad del error experimental (Tabla 4.14).

Tabla 4.13 - Análisis estadístico (ANAVA) de la evaluación sensorial de las pastas sustituidas con harina de soja incluyendo la interacción bloque (evaluadores) $x$ tratamiento (niveles de sustitución).

\begin{tabular}{ccccccc}
\hline Propiedad & Fuente de Variación & $\begin{array}{c}\text { Suma de } \\
\text { cuadrados }\end{array}$ & $\begin{array}{c}\text { Grados de } \\
\text { Libertad }\end{array}$ & $\begin{array}{c}\text { Cuadrado } \\
\text { medio }\end{array}$ & Estadístico F & valor $\mathbf{p}$ \\
\hline Firmeza & Nivel de sustitución (NS) & 96,46 & 4 & 24,12 & 9,03 & $<0,0001$ \\
& Evaluador (E) & 142,08 & 7 & 20,3 & 7,6 & $<0,0001$ \\
Pegajosidad & NS x E & 115,64 & 28 & 4,13 & 1,55 & 0,1015 \\
& Nivel de sustitución (NS) & 2,23 & 4 & 0,56 & 0,47 & 0,7545 \\
& Evaluador (E) & 47,77 & 7 & 6,82 & 5,8 & 0,0001 \\
Masticabilidad & Nivel de sustitución (NS) & 34,82 & 28 & 1,24 & 1,06 & 0,4287 \\
& Evaluador (E) & 58,76 & 4 & 14,69 & 6,01 & 0,0007 \\
& NS x E & 74,07 & 7 & 13,3 & 5,44 & 0,0002 \\
Elasticidad & Nivel de sustitución (NS) & 180,04 & 28 & 2,66 & 1,09 & 0,3954 \\
& Evaluador (E) & 47,47 & 7 & 45,01 & 15,69 & $<0,0001$ \\
& NS x E & 93,76 & 28 & 6,78 & 2,36 & 0,0405 \\
& & & & 3,35 & 1,17 & 0,3219 \\
\hline
\end{tabular}

Para firmeza se encontró que el estadístico F (Fcrit $(4 ; 8 ; 0,95)=4,12)$, resultó significativo tanto para el nivel de sustitución como para los evaluadores, indicando que la variabilidad total se dividió entre la variabilidad debida a los distintos niveles de sustitución (efecto de los tratamientos), la variabilidad debida a los evaluadores (efecto de bloque) y la variabilidad remanente no explicada por las dos anteriores, es decir del error experimental. Mediante el test de DGC de comparaciones múltiples (Tabla 4.15) se encontró que solo S30 y S50 resultaron significativamente diferentes al control presentando menor firmeza que el resto de las muestras. 
Tabla 4.14 - ANAVA de la evaluación sensorial de las pastas sustituidas con harina de soja de los componentes Nivel de Sustitución y Evaluador

\begin{tabular}{ccccccc}
\hline \multirow{2}{*}{ Propiedad } & Fuente de Variación & $\begin{array}{c}\text { Suma de } \\
\text { cuadrados }\end{array}$ & $\begin{array}{c}\text { Grados de } \\
\text { Libertad }\end{array}$ & $\begin{array}{c}\text { Cuadrado } \\
\text { medio }\end{array}$ & $\begin{array}{c}\text { Estadístico } \\
\text { F }\end{array}$ & valor p \\
\hline Firmeza & Nivel de sustitución (NS) & 96,46 & 4 & 24,12 & 7,37 & 0,0001 \\
& Evaluador (E) & 142,08 & 7 & 20,3 & 6,2 & $<0,0001$ \\
Pegajosidad & Nivel de sustitución (NS) & 2,23 & 4 & 0,56 & 0,46 & 0,7625 \\
& Evaluador (E) & 47,77 & 7 & 6,82 & 5,67 & $<0,0001$ \\
Masticabilidad & Nivel de sustitución (NS) & 58,76 & 4 & 14,69 & 5,8 & 0,0004 \\
& Evaluador (E) & 93,07 & 7 & 13,3 & 5,25 & 0,0001 \\
Elasticidad & Nivel de sustitución (NS) & 180,04 & 4 & 45,01 & 14,68 & $<0,0001$ \\
& Evaluador (E) & 47,47 & 7 & 6,78 & 2,21 & 0,0438 \\
\hline
\end{tabular}

En el caso de la pegajosidad, solamente el efecto bloque (evaluadores) resultó significativo $(F>4,12 ; p<0,05)$; es decir que los distintos niveles de sustitución no afectaron la pegajosidad de las muestras. De hecho, a partir del test DGC (Tabla 4.15) ninguna de las muestras mostró diferencias con la muestra Control. Aquí los evaluadores manifestaron dificultad en medir esta propiedad y a partir de los resultados obtenidos, se dedujo que las diferencias que pudieran haber presentado las muestras quedaron soslayadas por la dispersión generada por los evaluadores.

Tabla 4.15 - Evaluación sensorial de las pastas cocidas sustituidas con harina de soja

\begin{tabular}{ccccc}
\hline Muestra & Firmeza & Pegajosidad & Masticabilidad & Elasticidad \\
\hline Co & $0,0 \mathrm{~b}$ & $0,0 \mathrm{a}$ & $0,0 \mathrm{~b}$ & $0,0 \mathrm{c}$ \\
S15 & $-0,3 \mathrm{~b}$ & $-0,1 \mathrm{a}$ & $-0,6 \mathrm{~b}$ & $-2,3 \mathrm{~b}$ \\
S30 & $-1,9 \mathrm{a}$ & $-0,0 \mathrm{a}$ & $-1,9 \mathrm{a}$ & $-3,6 \mathrm{a}$ \\
S40 & $-0,6 \mathrm{~b}$ & $0,3 \mathrm{a}$ & $-1,2 \mathrm{a}$ & $-4,2 \mathrm{a}$ \\
S50 & $-2,9 \mathrm{a}$ & $0,3 \mathrm{a}$ & $-2,4 \mathrm{a}$ & $-3,6 \mathrm{a}$ \\
\hline
\end{tabular}

Valores seguidos de la misma letra dentro de una columna no presentan diferencias significativas $(p<=0,05)$, según el test de DGC.

Respecto a la masticabilidad, resultaron significativos tanto el nivel de sustitución como los evaluadores. A partir del test DGC (Tabla 4.15), a excepción de S15, para el resto de las muestras se encontraron diferencias significativas respecto de la muestra control, presentando menor masticabilidad cuanto mayor era el agregado de harina de soja a la formulación.

La elasticidad fue la única propiedad en donde los evaluadores no afectaron significativamente la variabilidad total $(F<F c r i t)$, solo los diferentes niveles de sustitución junto con el error experimental fueron las fuentes de variación. Consecuentemente, en este caso en particular, se podría omitir el considerar a los evaluadores como bloque. De acuerdo a DGC 
(Tabla 4.15), todas las muestras resultaron significativamente menos elásticas que el control, siendo más acentuada la diferencia para S30, S40 y S50.

Además se planteó una análisis de correlación de Pearson con un nivel de significancia $p<0,05$, entre la evaluación sensorial e instrumental de las propiedades evaluadas, encontrando solo correlación significativa para la elasticidad ( $r: 0,91 ; p: 0,03$ ). Se estima que la dispersión generada por los evaluadores al calificar las muestras fue la responsable de la falta de correlación entre la medición instrumental y la evaluación sensorial.

\section{Evaluación de preferencia}

Respecto a la evaluación de preferencia de las muestras, todas las pastas elaboradas con soja resultaron con menor calificación que la muestra control. De acuerdo al test de Friedman, los panelistas encontraron diferencias de preferencia para todos los niveles de sustitución respecto de la muestra control (Tabla 4.16), resultando S15 la mejor calificada (suma de rangos: 31,5; media de rango: 3,9); mientras que $\$ 40$ resultó la menos preferidas de todas (suma de rango 10 , media de rango 1,3 ).

\begin{tabular}{|c|c|c|}
\hline Tratamiento & Suma de Rangos & Media de Rango \\
\hline Cont & 40 & $5,0 \mathrm{e}$ \\
\hline S15 & 31,5 & $3,9 d$ \\
\hline S30 & 23 & $2,9 \mathrm{c}$ \\
\hline S40 & 10 & $1,3 a$ \\
\hline S50 & 15,5 & $1,9 \mathrm{~b}$ \\
\hline
\end{tabular}

Además, a partir de la media aritmética (Figura 4.21) S15 resultó calificada como ligeramente agradable, mientras que S30 fue considerada como ni agradable ni desagradable. Tanto para S40 como para S50, los evaluadores las ubicaron dentro de la zona de desagradable.

Está claro que el agregado de harina de soja afectó la preferencia del consumidor negativamente. 


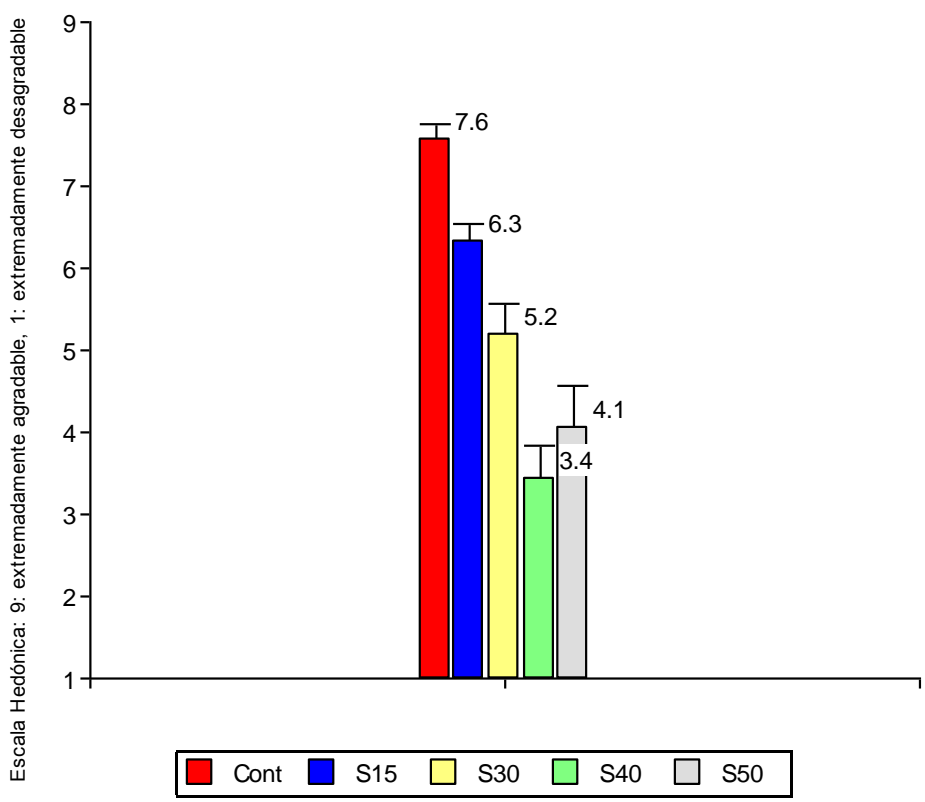

Figura 4.21 - Evaluación de preferencia de pastas cocidas elaboradas con harina de soja. (Las barras de error corresponden al error estándar)

\section{Conclusiones}

El haber tenido que mantener el diseño en bloques para los evaluadores significó, que éstos resultaron una fuente de variación extra a la proveniente de los distintos niveles de sustitución de la harina de trigo con la harina de amaranto y con la harina de soja.

Si bien los panelistas contaban con experiencia previa en la cata de pastas, manifestaron relativa dificultad en la evaluación de estas muestras particularmente, generando dispersión en los valores obtenidos para cada propiedad analizada. Esta variabilidad aportada por los panelistas posiblemente provocó la falta de correlación entre la evaluación sensorial e instrumental.

Es importante considerar que más allá de las propiedades funcionales y nutricionales que se le pueden aportar a las pastas con la incorporación de harinas de amaranto y soja, hay que tener en cuenta que estas harinas carecen de gluten el que tiene un papel primordial en calidad de las pastas. Asimismo, en el caso de la harina de amaranto, si bien la harina integral puede favorece la calidad nutricional por el aporte de fibras, las grandes partículas de tegumento generaron discontinuidades en la estructura de la pastas, favoreciendo su debilitamiento.

Fue necesario entonces definir una situación de equilibrio entre la incorporación de estas harinas alternativas y la calidad tecnológica y sensorial de las pastas resultantes. A partir de los 
resultados del comportamiento durante la cocción, del análisis instrumental de textura, de la medición del color y de la evaluación sensorial, se propuso como límite para las pastas elaboradas con harina de amaranto un porcentaje de sustitución no mayor al 30\% p/p, mientras que para las pastas preparadas con harina de soja, un porcentaje no mayor al $40 \%$ $\mathrm{p} / \mathrm{p}$. 


\section{QUINTA SECCIÓN}

Determinación de los componentes con propiedades funcionales aportados por la harina de amaranto y la harina de soja y evaluación de la calidad nutricional de las pastas 
Los compuestos con propiedades funcionales aportados por la harina de amaranto y por la harina de soja, fueron aislados, identificados y cuantificados tanto en las harinas como en las pastas elaboradas con ellas. Sobre estas últimas, además se evaluó la calidad nutricional.

El compuesto identificado y cuantificado en las pastas elaboradas con harina de amaranto fue el escualeno, mientras que en las elaboradas con harina de soja se hizo lo propio con las isoflavonas.

\section{Determinación del escualeno}

A partir de fracción lipídica extraída por Soxhlet de la harina liofilizada de amaranto, al igual que la harina de trigo y de las pastas elaboradas con estas harinas, se recuperó el escualeno por extracción en fase sólida (SPE), al que se identificó y cuantificó por HPLC por medio de un patrón de referencia.

\section{Identificación}

La Figura 5.1 muestra el perfil cromatográfico obtenido para la solución patrón de escualeno, para la harina de amaranto y para la pasta elaborada con $40 \mathrm{~g}$ harina de amaranto/100 g de harina de trigo. El tiempo de retención que presentó el escualeno, bajo de la condiciones de ensayo, fue de 9,9 min.

La identificación del escualeno se realizó por la similitud en los tiempo de retención de la corrida cromatográfica y también por comparación del espectro de absorción (PDA-UV) en el rango de $190 \mathrm{~nm}$ a $400 \mathrm{~nm}$, obtenido a partir del escualeno recuperado de las muestras, respecto al espectro del escualeno utilizado como referencia (Figura 5.2). El espectro del escualeno patrón presentó un mínimo de absorbancia a los 199 nm y un máximo a los 205 nm.

Asimismo, se evaluó la pureza de pico de la solución patrón de escualeno y de las muestras analizadas.

Bajo condiciones óptimas de separación y detección, un compuesto puro genera un pico cuyo espectro presenta la misma forma a lo largo del pico. Por el contrario, cuando hay analitos interferentes que coeluyen con el pico de interés, se producen espectros con diversos grados de asimetría espectral a lo largo del pico. Esta es la base para la determinación de la pureza de pico (SSI-AP-LC-0213). Un pico homogéneo tiene un índice de pureza de pico del $100 \%$, lo que indica que todos los espectros son similares. Por el contrario un índice de pureza de pico menor a 100, sugiere que sólo una fracción del número total de los espectros coincide con el espectro obtenido en la cima del pico (SSI-AP-LC-0213). 

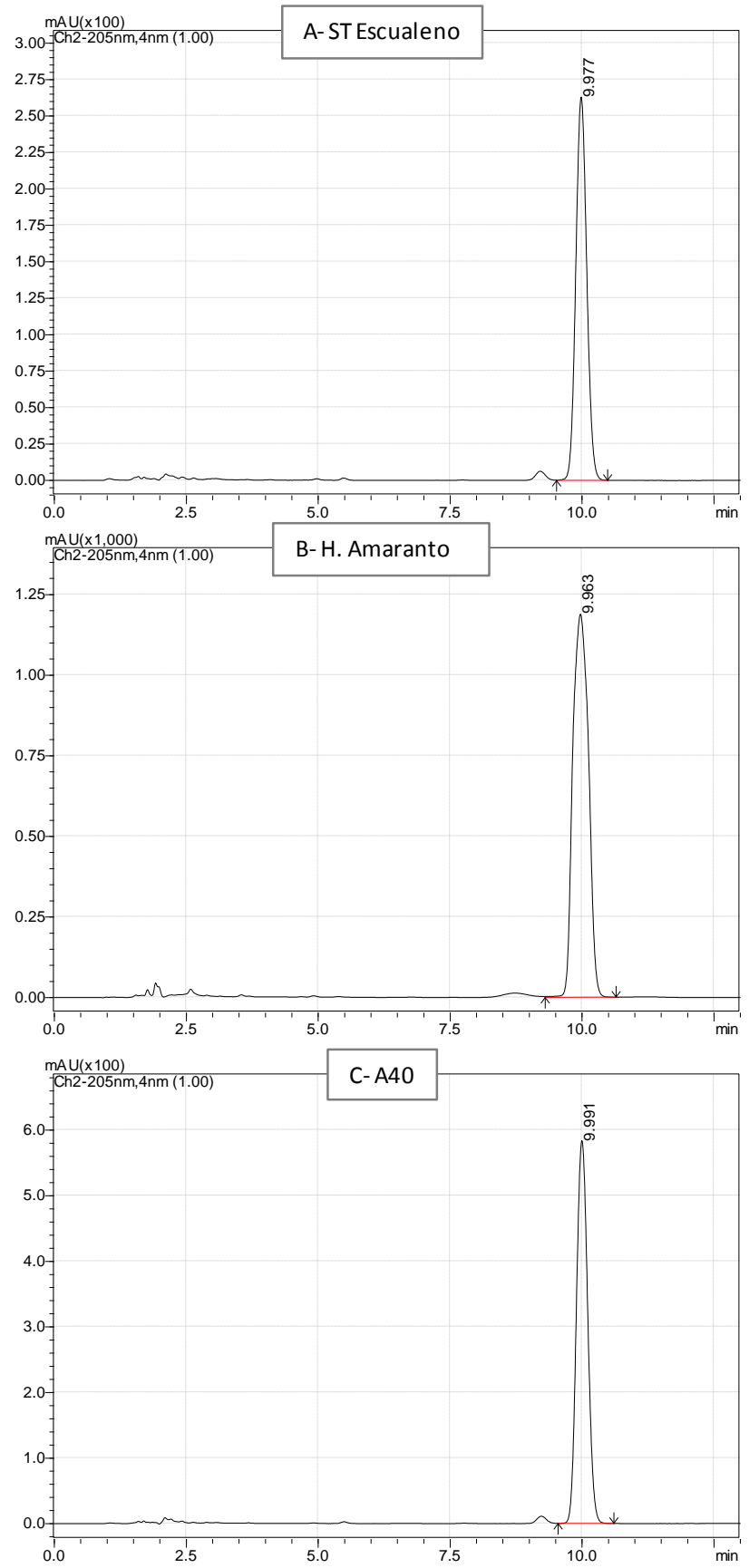

Figura 5.1- Perfil cromatográfico del escualeno. A: solución patrón de $46,68 \mu \mathrm{g} / \mathrm{mL}$, B: harina de amaranto y $\mathrm{C}$ : pasta elaborada con $40 \mathrm{~g}$ de harina de amaranto $/ 100 \mathrm{~g}$ de harina de trigo. 

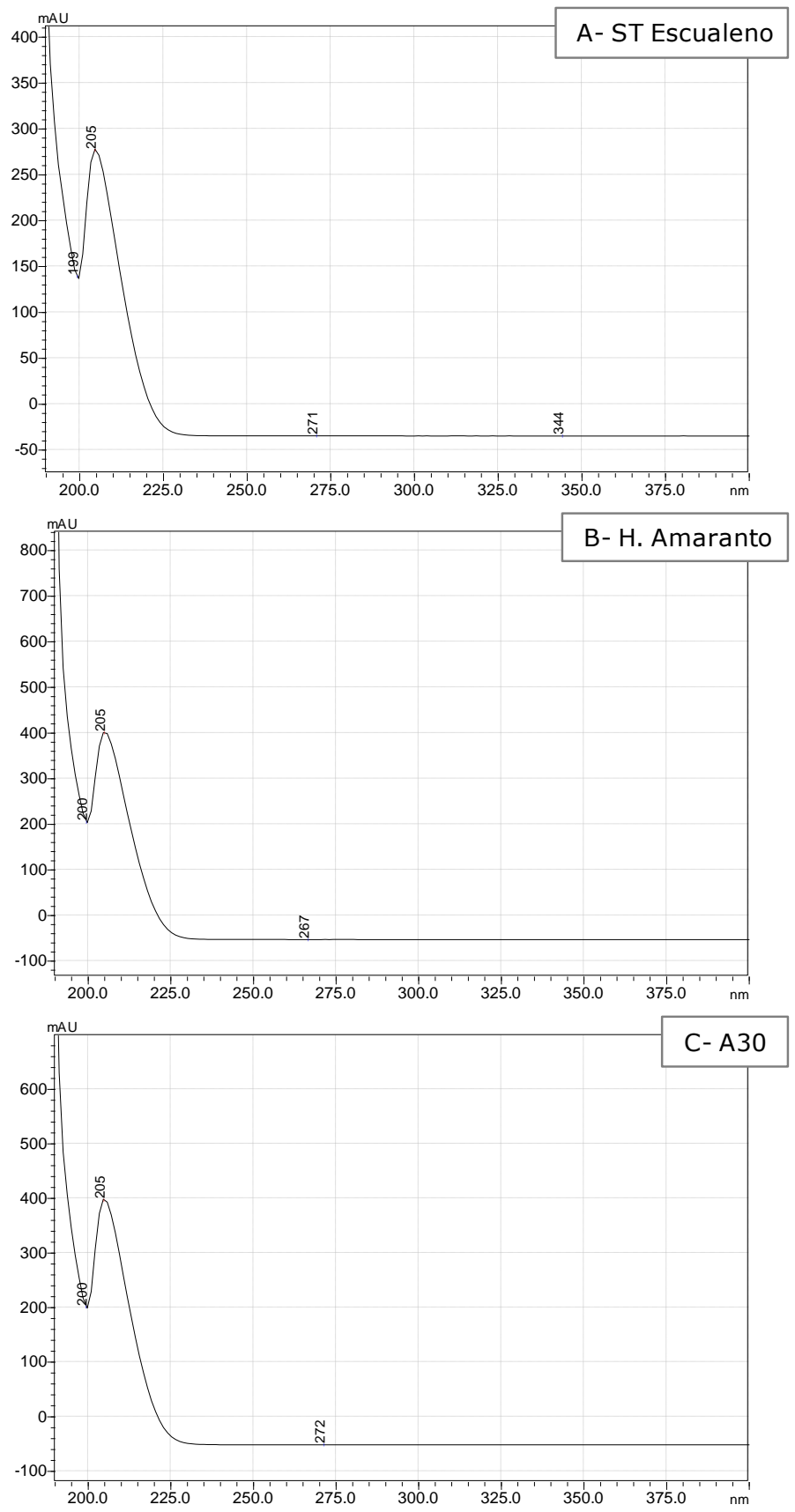

Figura 5.2 - Espectros de absorción entre $190 \mathrm{~nm}$ y $400 \mathrm{~nm}$; A: solución patrón de escualeno de 46,68 $\mu \mathrm{g} / \mathrm{mL}$, B: harina de Amaranto, C: pasta sustituida con $30 \mathrm{~g}$ de harina de amaranto $/ 100 \mathrm{~g}$ harina de trigo.

La Figura 5.3-A muestra la pureza del pico considerado como escualeno, donde se observó que éste no coeluyó con ningún compuesto interferente o impureza que pudiera contribuir a la respuesta del pico, lo que se corroboró con el índice de pureza de pico obtenido igual a 1.000.000 (por un artificio del software, un índice de pureza igual a 100\% se expresa como $\left.10^{6}\right)$ 
Además, la pureza de pico se puede evaluar a través del grado de superposición de los espectros obtenidos a diferentes longitudes de onda para el compuesto de interés. Una buena superposición, en donde la forma del pico y el tiempo de retención coinciden, indica un pico puro, mientras que una pobre superposición indica presencia de impurezas (HP Product Note, 1993).

En la Figura 5.3-B, se observa la superposición encontrada para el pico del escualeno, el cual coincidió con la forma y el tiempo de retención de los espectros obtenidos a las diferentes longitudes de onda evaluadas.

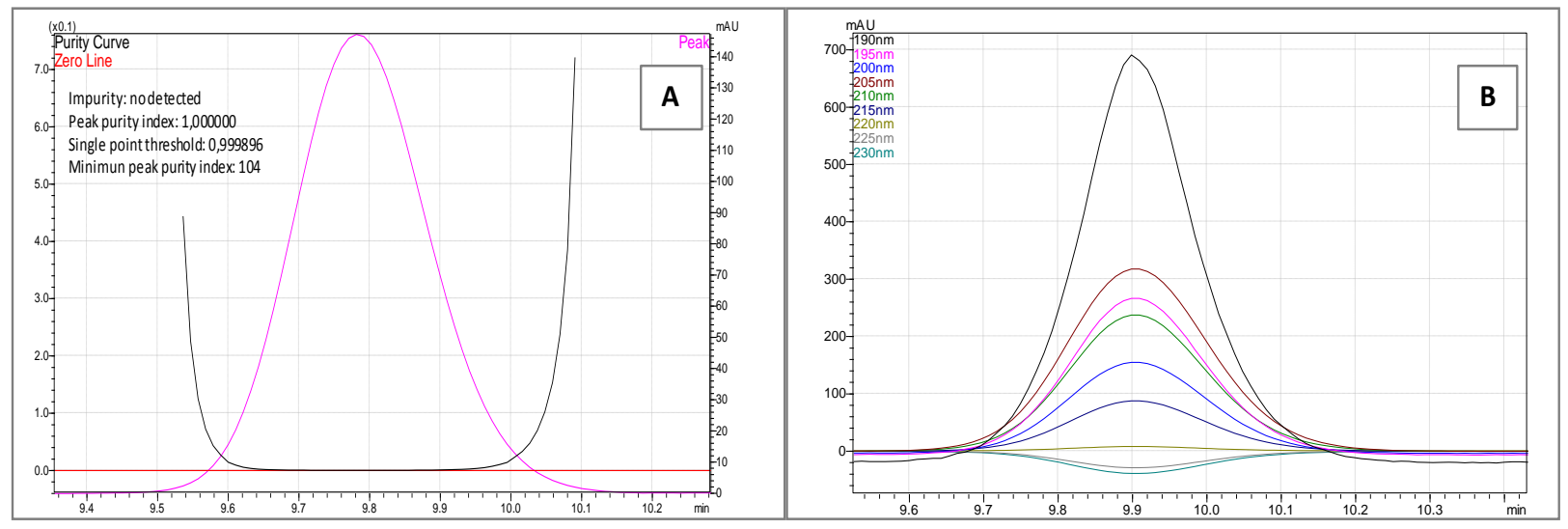

Figura 5.3 - Identificación del pico considerado como escualeno, pureza de pico calculada (A), perfil de los picos a diferentes longitudes de onda.

\section{Cuantificación}

Para la cuantificación del escualeno en la harina de amaranto, en la de trigo y en las pastas elaboradas con ellas, se realizó un análisis de regresión lineal, a partir de las áreas provenientes de la integración de cada pico cromatográfico dado por las soluciones de diferente concentración, preparadas con el patrón de escualeno (Figura 5.4).

La cantidad de aceite encontrado en la harina de amaranto (A. mantegazzianus Pass.), en base seca, fue 7,8 $\pm 0,1 \mathrm{~g} / 100 \mathrm{~g}$, mientras que la cantidad de escualeno fue 4,56 $\pm 0,14 \mathrm{~g} / 100 \mathrm{~g}$ de aceite presente en la harina; lo que equivale a 0,35 $\pm 0,01 \mathrm{~g} / 100 \mathrm{~g}$ de harina. Los resultados obtenidos fueron consistentes con trabajos previos donde determinaron el contenido de escualeno en diferentes especies de amaranto. León-Camacho et al. (2001), informaron para A. cruentus L., una concentración de aceite de 6,34 g/100 g de semilla y un contenido de escualeno de 4,16 g/1000 g de semillas. He et al. (2002), evaluaron las variedades, A. cruentos, hybridus, hypochondriacus y tricolor, y encontraron en promedio, un contenido de materia grasa de $6,43 \mathrm{~g} / 100 \mathrm{~g}$ de granos de amaranto, mientras que el escualeno medido resultó 4,88 
$\mathrm{g} / 100 \mathrm{~g}$ de materia grasa. Además Berganza et al. (2003), informaron un contenido de escualeno en A. mantegazzianus de $5,21 \mathrm{~g} / 100 \mathrm{~g}$ de aceite.

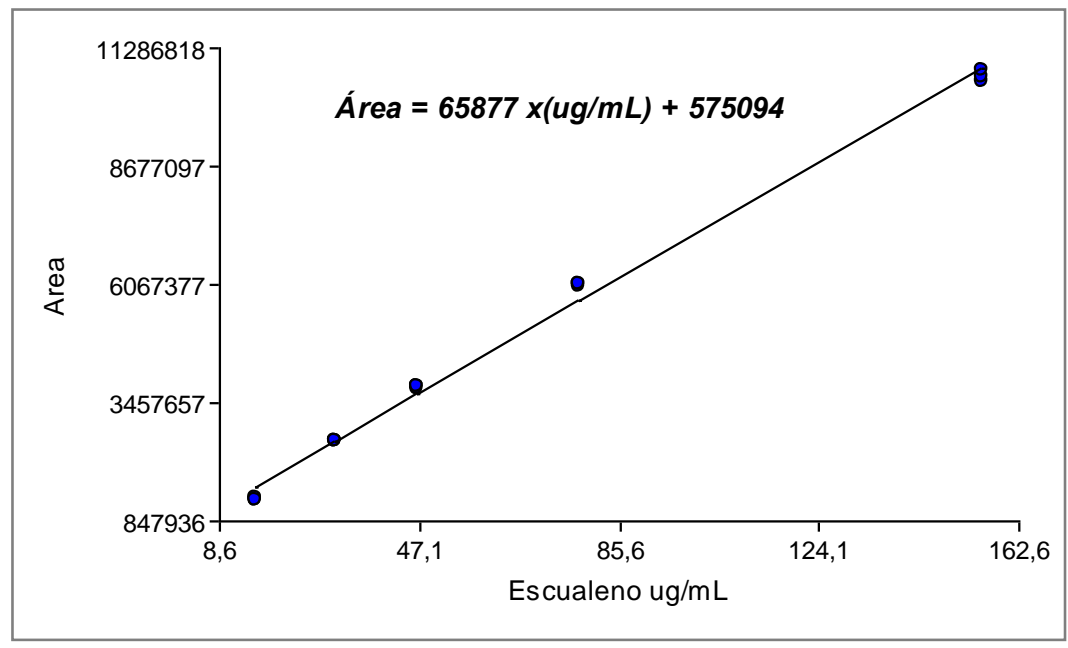

Figura 5.4 - Curva de calibración de escualeno y ecuación de la recta.

La cantidad de escualeno encontrada en los fideos cocidos varió desde $15 \mathrm{mg} / 100 \mathrm{~g}$ para la pasta sustituida con $15 \mathrm{~g}$ de harina de amaranto/100 g de harina de trigo, hasta $68 \mathrm{mg} / 100 \mathrm{~g}$ para aquella sustituida con $50 \mathrm{~g}$ de harina de amaranto; encontrándose diferencias significativas para todos los niveles de sustitución ensayados (Figura 5.5).

La importancia de la presencia de escualeno en las pastas sustituidas con harina de amaranto, radica en los efectos beneficiosos que se han demostrado de este compuesto sobre la salud del ser humano. Qureshi et al. (1996), en un trabajo realizado en pollos, demostró que una dieta que contenía $20 \mathrm{~g} / 100 \mathrm{~g}$ de dieta de amaranto y otra que contenía $5 \mathrm{~g} / 100 \mathrm{~g}$ de dieta de aceite de amaranto, disminuyeron los niveles sanguíneos de colesterol total, del LDLcolesterol y de los triglicéridos, con un mínimo efecto sobre el HDL-colesterol. Plate \& Areas (2002), en un estudio realizado sobre conejos alimentados con dietas suplementadas con amaranto extrudido y aceite de amaranto, también observaron disminución en los niveles de LDL-colesterol, VLDL-colesterol y triacilglicéridos, sin modificar los niveles de HDL-colesterol. 


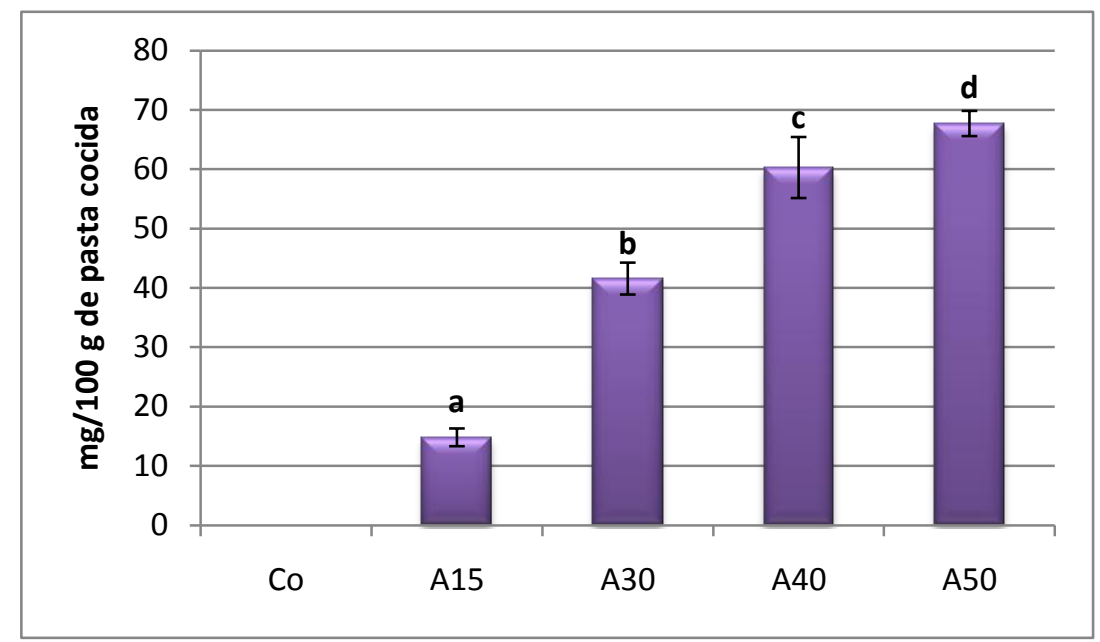

Figura 5.5- Concentración de escualeno presente en las pastas cocidas elaboradas con harina de amaranto, $\mathrm{mg} / 100 \mathrm{~g}$. Letras distintas indican diferencias significativas $(p<=0,05)$

Martirosyan et al. (2007), también estudiaron el efecto del aceite de amaranto en 125 pacientes que sufrían enfermedades cardiovasculares, hipertensión y obesidad, encontrando que la inclusión de aceite de amaranto en la dieta mostró un efecto beneficioso sobre las afecciones cardiovasculares y la hipertensión; que el aceite de amaranto disminuyó significativamente la cantidad de colesterol total, triacilglicéridos y LDL y VLDL-colesterol; que contribuyó a incrementar la concentración de ácidos grasos poliinsaturados del tipo omega-3 de cadena larga y por último, que el aceite de amaranto podía ser considerado como un efectivo antioxidante natural capaz de proteger la membrana celular contra oxidaciones nocivas.

\section{Extracción de las isoflavonas de la harina de soja y de las pastas sustituidas con ésta y su determinación por HPLC}

Uno de los propósitos de incorporar harina de soja a las pastas, más allá de mejorar la calidad nutricional en relación al contenido de fibras, de proteínas y aminoácidos esenciales, fue sumarle propiedades funcionales a través del enriquecimiento en fitosteroles del tipo de las isoflavonas. La soja es fuente de isoflavonas, incluyendo la familia genisteína y sus derivados (genistina, malonil genistina, acetil genistina y genisteína) y la daidzeína y sus derivados (malonil-daidzina, daidzina y daidzeína). 
Si bien la harina de amaranto contiene fitosteroles (Berger et al., 2003; Marcone et al., 2004; Mendonça et al., 2009), para evaluar si estos pertenecían a la familia de las isoflavonas, también fue analizada.

A través de una extracción hidro-alcohólica de las harinas y de las pastas (previamente cocidas secadas y molidas) se recuperaron las isoflavonas, las que fueron analizadas por HPLC. Por comparación con patrones externos pertenecientes a la familia de la daidzeína y genisteína, se realizó la identificación y cuantificación de las isoflavonas.

En la Figura 5.6, donde se muestran los cromatogramas obtenidos para la harina de amaranto y la harina de soja, se puede observar la ausencia de las isoflavonas estudiadas en la harina de amaranto. En consecuencia, la determinación de isoflavonas por HPLC se redujo a la harina de soja y a las pastas elaboradas a partir de la mezcla de esta última con la harina de trigo.

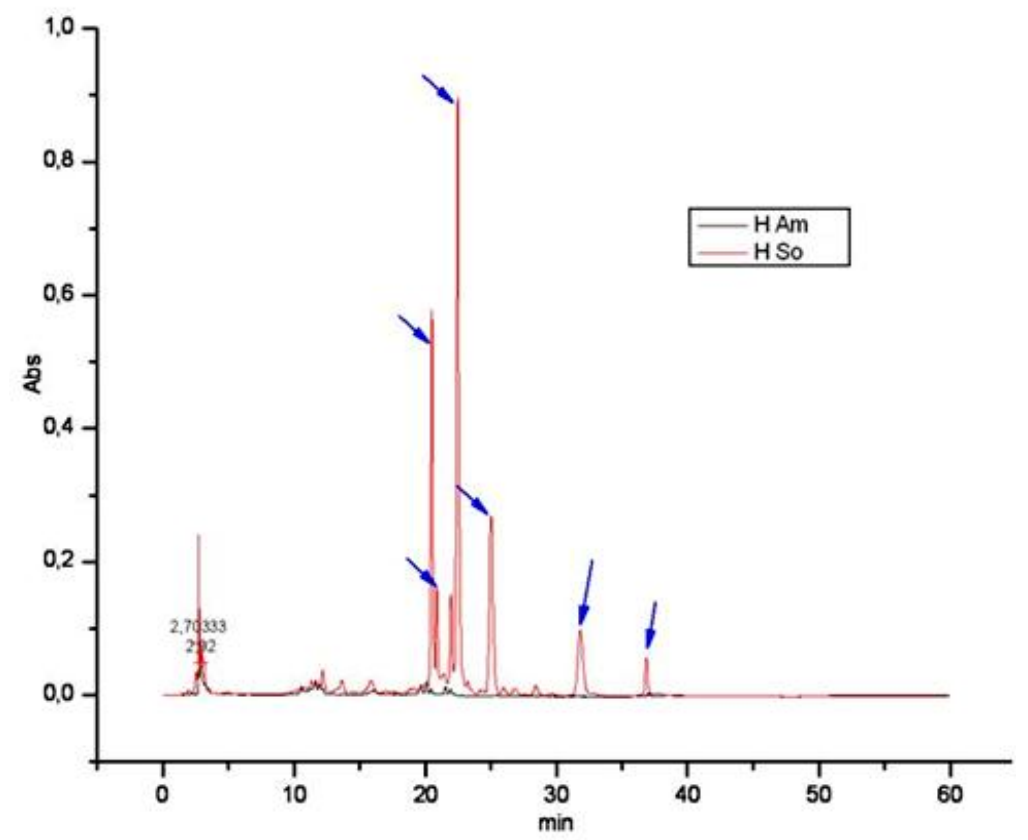

Figura 5.6 - Cromatograma correspondiente a la determinación de Isoflavonas en la harina de amaranto (H Am) comparada con la harina de soja (H So). Las flechas indican las isoflavonas encontradas en la harina de soja, ausentes en la harina de amaranto.

La Figura 5.7 muestra el perfil cromatográfico obtenido a partir de una muestra elaborada con $50 \mathrm{~g}$ de harina de soja/100 g de harina de trigo, pudiendo identificarse, por comparación con isoflavonas patrones, de acuerdo al orden de elución, malonil-daidzina, daidzina, genistina, malonil genistina, daidzeína, acetil genistina y genisteína. 


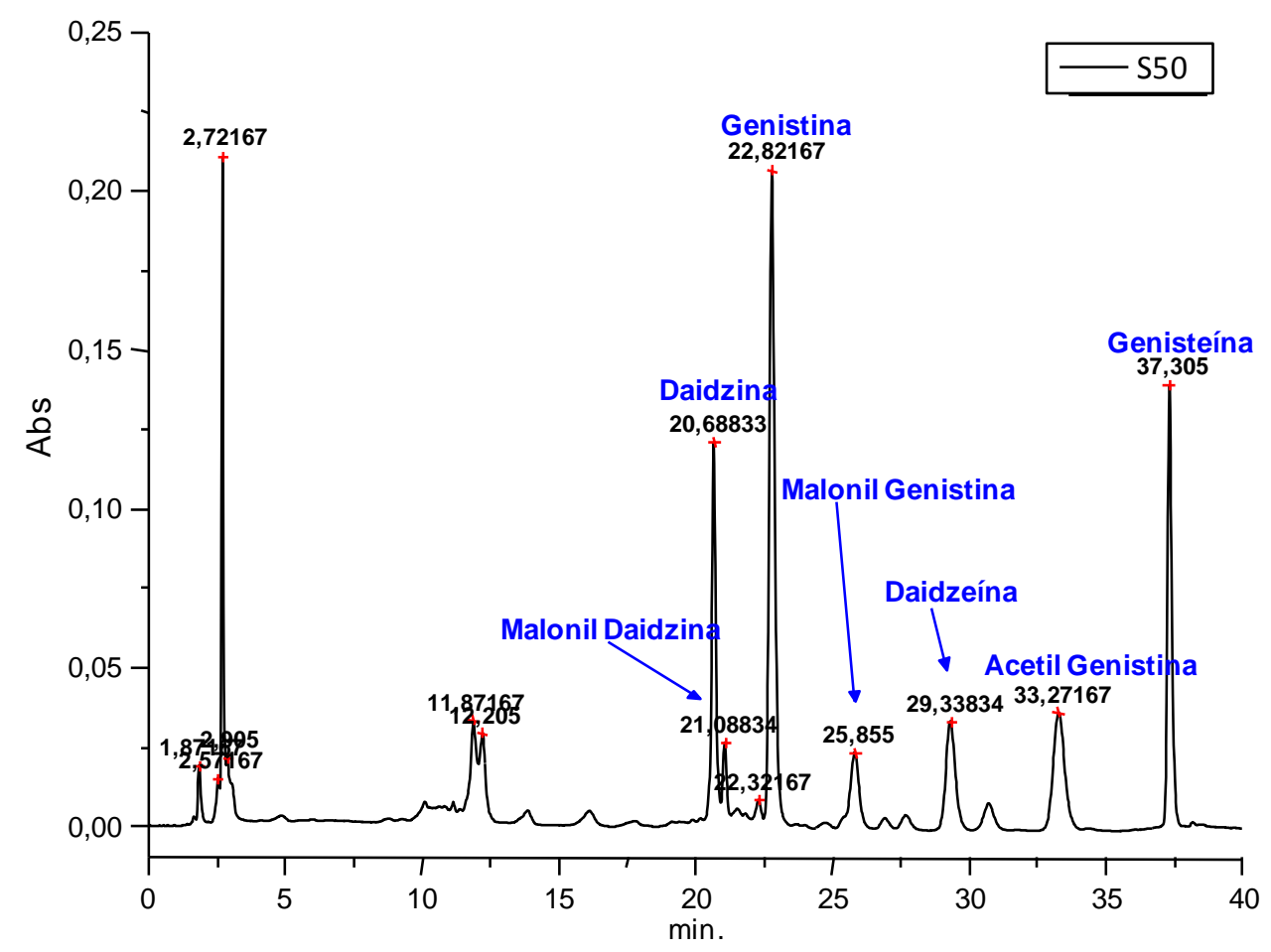

Figura 5.7 -Isoflavonas recuperadas en las pastas elaboradas con $50 \mathrm{~g}$ de harina de soja/100 g de harina de trigo.

El contenido total de isoflavonas medido en la harina de soja, expresado como agliconas, resultó $308,4 \mathrm{mg} / 100 \mathrm{~g}$ de harina en base seca. En cuanto a las pastas elaboradas con ésta harina, se encontró que cuanto mayor fue el porcentaje de sustitución, mayor contenido de isoflavonas totales presentaron las pastas cocidas (Tabla 5.1).

Tabla 5.1 - Contenido de isoflavonas totales, expresado como agliconas, de las pastas cocidas elaboradas con harina de soja

\begin{tabular}{cc}
\hline Muestras & Isoflavonas totales, $\mathbf{~ m g} / \mathbf{1 0 0 g}^{\mathbf{1}}$ \\
\hline S15 & $10,5 \pm 0,5 \mathrm{a}$ \\
S30 & $19,9 \pm 0,9 \mathrm{~b}$ \\
S40 & $24,2 \pm 2,1 \mathrm{c}$ \\
S50 & $26,7 \pm 1,5 \mathrm{c}$ \\
\hline
\end{tabular}

${ }^{1} \mathrm{mg}$ de isoflavonas, expresadas como agliconas/100 $\mathrm{g}$ de pasta cocida. Letras distintas indican diferencias significativas $p<=0,05$.

Al discriminar las isoflavonas correspondiente a la familia de la genisteína (Figura 5.8) y de la daidzeína (Figura 5.9), se encontró que los valores de isoflavonas correspondiente a ambas series, en general, aumentaron conforme aumentaron los niveles de sustitución. 


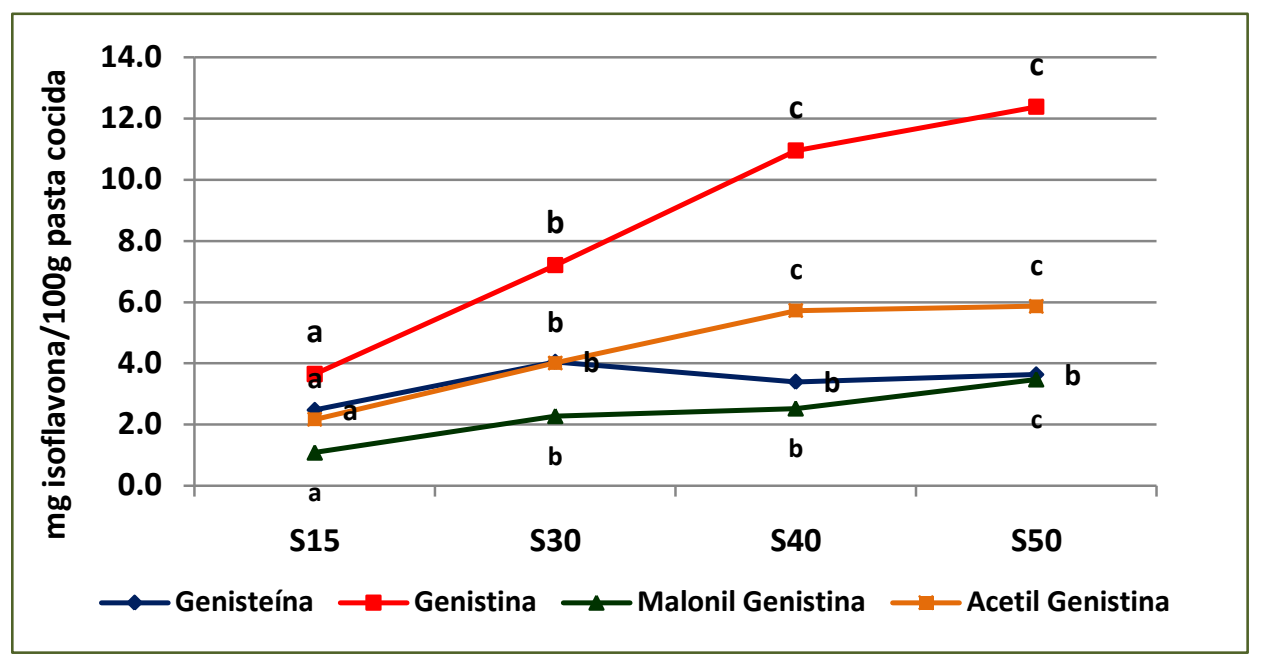

Figura 5.8 - Isoflavonas pertenecientes a la serie genisteína cuantificadas en las pastas elaboradas con harina de soja. Test de LSD Fisher, letras distintas indican diferencias significativas $p<=0,05$.

Sin embargo, S40 y S50 no siempre mostraron un mayor enriquecimiento de cada una de las isoflavonas a pesar de la mayor cantidad de harina de soja agregada. Considerando el debilitamiento de la estructura de la pasta que se observó en las muestras con altos niveles de adición y el consecuente aumento en los residuos de cocción, es esperable que las isoflavonas pasen al agua de cocción como parte del residuo.

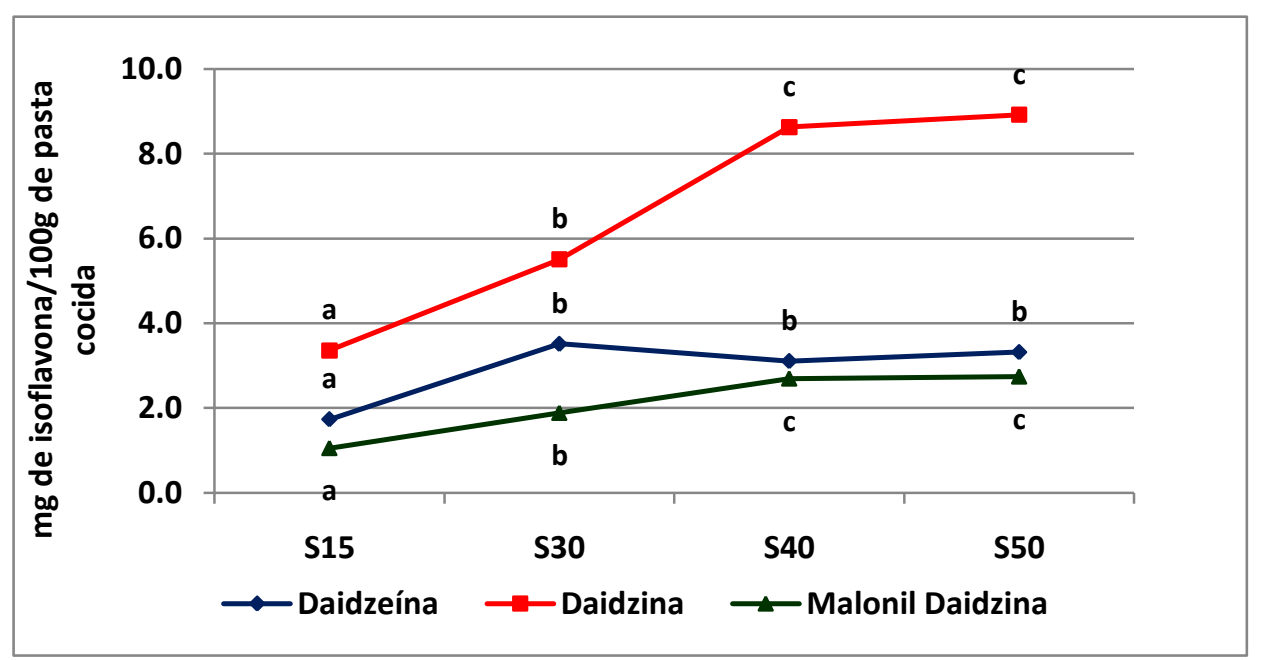

Figura 5.9 - Isoflavonas pertenecientes a la serie daidzeína cuantificadas en las pastas elaboradas con harina de soja. Test de LSD Fisher, letras distintas indican diferencias significativas $p<=0,05$. 


\section{Evaluación de la calidad nutricional de las pastas elaboradas con harina de amaranto y harina de soja}

\section{Determinación del contenido de proteínas y de fibra dietética}

Las pastas elaboradas con harina de amaranto y con harina de soja mostraron valores significativamente mayores de proteínas que la muestra control (Tabla 5.2), acorde con los mayores contenidos de proteínas medidos en ambas harinas alternativas (Tabla 4.1) en relación a la harina de trigo.

Con respecto a la fibra dietética, también se obtuvieron valores significativamente mayores al de la muestra control para todos los niveles de sustitución, tanto para las muestras elaboradas con amaranto como para las muestras preparadas con soja (Tabla 5.2).

Tabla 5.2 - Contenido de proteínas y fibra dietética en las pastas cocidas listas para el consumo

\begin{tabular}{ccc}
\hline Muestras & Proteínas, $\% \mathbf{p} / \mathbf{p}^{\mathbf{1}}$ & Fibra Dietética, $\% \mathbf{p} / \mathbf{p}^{\mathbf{1}}$ \\
\hline Co & $4,3 \pm 0,0 \mathrm{aA}$ & $1,4 \pm 0,0 \mathrm{aA}$ \\
& & \\
Am15 & $4,7 \pm 0,1 \mathrm{~b}$ & $1,7 \pm 0,1 \mathrm{~b}$ \\
Am30 & $5,3 \pm 0,1 \mathrm{c}$ & $2,1 \pm 0,1 \mathrm{c}$ \\
Am40 & $5,3 \pm 0,0 \mathrm{c}$ & $2,2 \pm 0,1 \mathrm{~d}$ \\
Am50 & $5,3 \pm 0,0 \mathrm{c}$ & $2,3 \pm 0,0 \mathrm{e}$ \\
& & \\
S15 & $6,0 \pm 0,1 \mathrm{~B}$ & $2,2 \pm 0,1 \mathrm{~B}$ \\
S30 & $7,7 \pm 0,1 \mathrm{C}$ & $3,2 \pm 0,1 \mathrm{C}$ \\
S40 & $8,9 \pm 0,0 \mathrm{D}$ & $3,9 \pm 0,1 \mathrm{D}$ \\
S50 & $9,3 \pm 0,1 \mathrm{E}$ & $4,0 \pm 0,0 \mathrm{E}$ \\
\hline${ }^{1}$ Letras minúsculas distintas indican diferencias significativas ( $\left.\mathrm{p}<=0,05\right)$ entre \\
el control y las pastas con harina de amaranto. Letras mayúsculas distintas \\
indican diferencias significativas ( $<<=0,05$ ) entre el control y las pastas con \\
\multicolumn{3}{c}{ harina de soja. Test de LSD Fisher. }
\end{tabular}

Si se comparan los valores de proteínas y de fibra dietética de las muestras sustituidas con harina de soja respecto a las sustituidas con harina de amaranto, como resultado de los mayores valores de proteína y de fibra dietética encontrados en la harina de soja, S15, S30, S40 y S50 mostraron mayores valores para ambos parámetros que sus pares elaborados a partir de harina de amaranto. 


\section{Determinación de almidón resistente, soluble y total en las pastas cocidas}

Para las pastas sustituidas con harina de amaranto se observó una disminución en los valores de almidón resistente respecto a la muestra control, resultando entre 0,5 y 0,2 g/100 g de pasta (Tabla 5.3). Respecto al contenido de almidón soluble y total, se observó que, mientras A15 y A30 no mostraron diferencias significativas con Co, A40 y A50 presentaron un menor contenido tanto de almidón soluble como de almidón total (Tabla 5.3). Dado que la incorporación de harina integral de amaranto afectó negativamente la calidad de las pastas cocidas, provocando mayores valores de residuo de cocción con los mayores niveles de sustitución, se estimó que parte del almidón de las pastas más afectadas quedó en el agua de cocción.

Tabla 5.3 - Almidón Resistente (AR), Almidón Soluble (AS) y Almidón Total (AT) de las pastas cocidas sustituidas con harina de amaranto

\begin{tabular}{cccc}
\hline Muestra & $\mathbf{A R}, \% \mathbf{p} / \mathbf{p}^{\mathbf{1}}$ & $\mathbf{A S}, \% \mathbf{p} / \mathbf{p}^{\mathbf{1}}$ & $\mathbf{A T}, \% \mathbf{p} / \mathbf{p}^{\mathbf{1}}$ \\
\hline Co & $0,7 \pm 0,1 \mathrm{~b}$ & $64,7 \pm 0,3 \mathrm{~b}$ & $65,4 \pm 0,2 \mathrm{~b}$ \\
A15 & $0,5 \pm 0,0 \mathrm{a}$ & $65,8 \pm 0,0 \mathrm{~b}$ & $66,3 \pm 0,0 \mathrm{~b}$ \\
A30 & $0,4 \pm 0,1 \mathrm{a}$ & $63,1 \pm 2,6 \mathrm{~b}$ & $63,5 \pm 2,6 \mathrm{~b}$ \\
A40 & $0,2 \pm 0,0 \mathrm{a}$ & $60,8 \pm 0,7 \mathrm{a}$ & $61,1 \pm 0,7 \mathrm{a}$ \\
A50 & $0,3 \pm 0,1 \mathrm{a}$ & $59,4 \pm 0,4 \mathrm{a}$ & $59,7 \pm 0,5 \mathrm{a}$ \\
\hline
\end{tabular}

${ }^{1} \mathrm{~g} / 100 \mathrm{~g}$ de pasta, base seca. Test de DGC; letras distintas indican diferencias significativas $(p \leq 0,05)$

La Tabla 5.4 muestra el contenido de almidón resistente, almidón soluble y almidón total en las pastas sustituidas con harina de soja.

El agregado de esta harina provocó una disminución en el contenido de almidón resistente en las pastas cocidas respecto a la muestra control, siendo menor a 0,8 g/100 g de pastas cocidas, en todos los casos.

Asimismo, tanto los valores de almidón soluble como los de almidón total resultaron menores a medida que el porcentaje de sustitución fue mayor. Considerando que la harina de soja no presenta un contenido significativo de almidón, era esperable que su incorporación en la pasta no hiciera más que diluir al almidón provisto por la harina de trigo. En este sentido, cuanto mayor fue la cantidad de harina de soja incorporada a la formulación, menor resultó la cantidad del almidón total y de almidón soluble que presentaron las muestras. Además hay que considerar las pérdidas ocurridas durante la cocción (Tabla 4.6), en donde parte del almidón pasó al agua de cocción. 
Tabla 5.4 - Almidón Resistente (AR), Almidón Soluble (AS) y Almidón Total (AT) de las pastas cocidas sustituidas con harina de soja

\begin{tabular}{cccc}
\hline Muestra & $\mathbf{A R}, \% \mathbf{p} / \mathbf{p}^{\mathbf{1}}$ & $\mathbf{A S}, \% \mathbf{p} / \mathbf{p}^{\mathbf{1}}$ & $\mathbf{A T}, \% \mathbf{p} / \mathbf{p}^{\mathbf{1}}$ \\
\hline Co & $0,76 \pm 0,04 \mathrm{c}$ & $64,5 \pm 0,0 \mathrm{~d}$ & $65,3 \pm 0,0 \mathrm{~d}$ \\
S15 & $0,59 \pm 0,02 \mathrm{~b}$ & $60,2 \pm 0,8 \mathrm{c}$ & $60,8 \pm 0,7 \mathrm{c}$ \\
S30 & $0,52 \pm 0,01 \mathrm{a}$ & $49,5 \pm 0,7 \mathrm{~b}$ & $50,0 \pm 0,7 \mathrm{~b}$ \\
S40 & $0,63 \pm 0,01 \mathrm{~b}$ & $42,0 \pm 2,8 \mathrm{a}$ & $42,6 \pm 2,7 \mathrm{a}$ \\
S50 & $0,75 \pm 0,02 \mathrm{c}$ & $38,1 \pm 1,7 \mathrm{a}$ & $38,8 \pm 1,7 \mathrm{a}$ \\
${ }^{1} \mathrm{~g} / 100$ g de pasta, base seca. Test de DGC; letras distintas indican diferencias significativas \\
\multicolumn{4}{c}{$(\mathbf{p} \leq 0,05)}$.
\end{tabular}

\section{Determinación de la digestibilidad in vitro del almidón}

\section{Digestibilidad de almidón in vitro de las pastas cocidas sustituidas con harina de amaranto}

La Figura 5.10 muestra el curso de la hidrólisis in vitro del almidón de las pastas cocidas elaboradas con harina de amaranto, de la muestra control y de una muestra de pan blanco elaborada con la misma harina de trigo utilizada para la preparación de las pastas.

A partir de las curvas de hidrólisis se puede observar que la cantidad de almidón hidrolizado de la muestra de pan fue muy superior a lo medido en las muestras de pastas durante todo el tiempo del ensayo.

Asimismo, se encontró que los porcentajes de hidrólisis aumentaron rápidamente para todas las muestras estudiadas hasta el tiempo $30 \mathrm{~min}$, pero luego la cantidad de almidón hidrolizado medido en función del tiempo fue mucho menor. Para la muestra de pan, la velocidad de hidrólisis fue tan pequeña a partir de los $30 \mathrm{~min}$, que después de los $90 \mathrm{~min}$ la curva se asemejó a una meseta. En el caso de las muestras de pastas, si bien la velocidad de hidrólisis fue mucho menos pronunciada después de los primeros $30 \mathrm{~min}$, se sostuvo hasta los 180 min evaluados.

Esta marcada diferencia que se observó entre la curva de hidrólisis obtenida para el pan respecto a la encontrada para las pastas, corroboró que la accesibilidad de las enzimas a una estructura compacta como la de las pastas retarda el tiempo de hidrólisis (Fardet et al., 1998; Sung \& Stone, 2005; Kim et al., 2008). De acuerdo a Giacco et al. (2001) el pan presenta una estructura de gran porosidad debido el entrampamiento de las burbujas de gas que se expanden durante la cocción, lo que produce un incremento de la superficie expuesta a la actividad enzimática. 
En las curvas de hidrólisis de las pastas, se encontró que la cantidad de almidón hidrolizado a los 30 min fue significativamente mayor para las muestras A40 y A50 respecto a la muestra control $(p \leq 0,05)$, mientras que A30 no mostró diferencias con Co y A15 presentó una menor cantidad de almidón hidrolizado. Para los tiempos 60, 90 y 120 min, se encontraron diferencias significativas para todos los niveles de sustitución, siendo la A15 la más resistente a la hidrólisis, seguida por la muestra Co, luego A30, A40 y A50, de acuerdo a la mayor sensibilidad a la hidrólisis encontrada. En tanto que los tiempos 150 y 180 min presentaron un patrón similar de hidrólisis que a los $30 \mathrm{~min}$, siendo A15 la menos y A50 la más susceptible a la hidrólisis respectivamente.

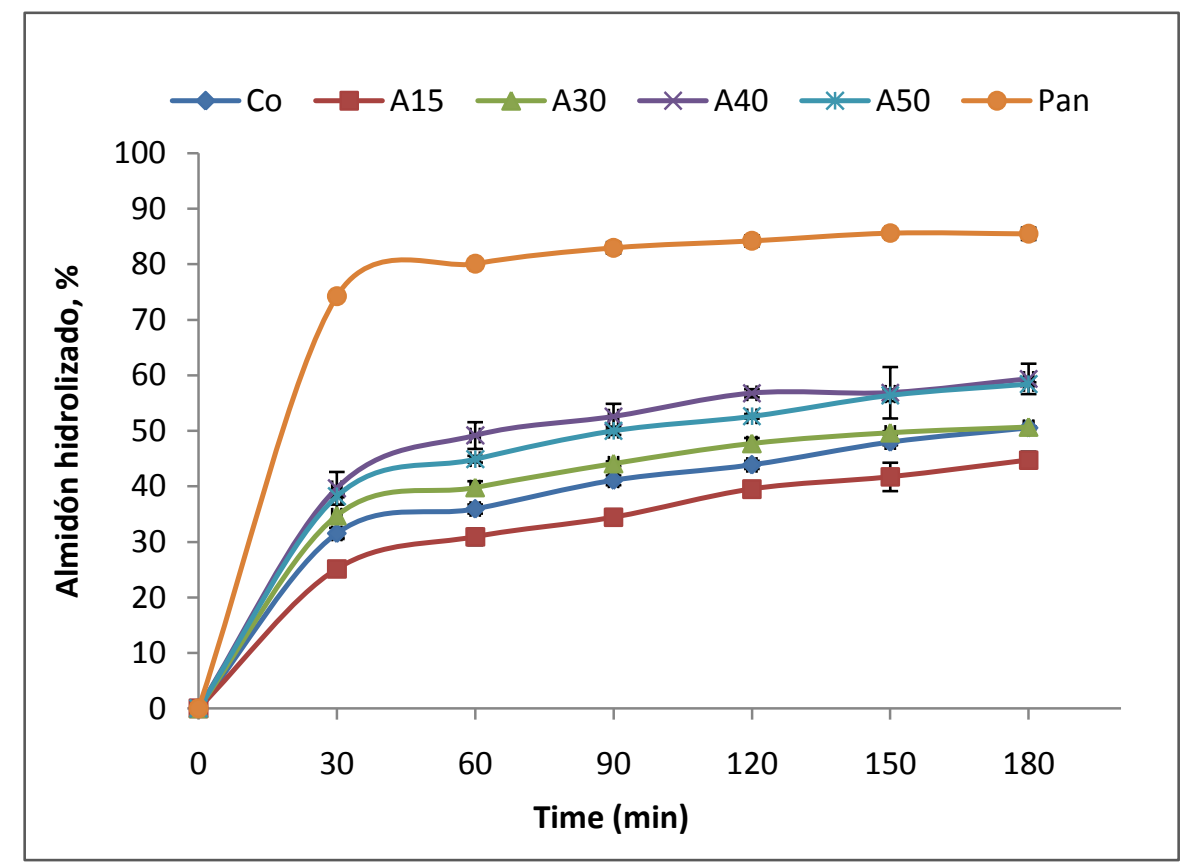

Figura 5.10- Porcentaje de almidón hidrolizado respecto al almidón total de las pastas cocidas sustituidas con harina de amaranto.

Las propiedades de cocción analizadas previamente para estas pastas (Tabla 4.6) , indicaron que existe una situación de equilibrio: por un lado los tiempos de cocción más cortos permitieron un menor tiempo de contacto con el agua y, por ende, menores posibilidades de que el agua difunda al interior de la pasta; pero por otro lado la incorporación de harina de amaranto integral produjo un debilitamiento de la estructura favoreciendo que más sólidos alcanzaran el agua de cocción aumentando los residuos aun con tiempos de cocción más breves.

La misma situación de equilibrio fue la que afectó la digestibilidad de almidón en las pastas cocidas. En el caso de A15, el menor tiempo de exposición en el agua de cocción pesó más que 
el debilitamiento de la estructura; menor tiempo para que el agua difunda dentro de la pasta, menor absorción de agua, menor posibilidad de que el almidón gelatinice y por ende menor capacidad de las enzimas hidrolíticas de digerir el almidón. Pero a medida que los niveles de sustitución aumentaron, el debilitamiento de la estructura fue compensado los menores tiempos de exposición en el agua de cocción, lo que resultó en una estructura más porosa y por ende más fácil de hidratar, esto favoreció la actividad de las enzimas hidrolíticas, encontrándose valores de almidón hidrolizado similares para A30 respecto a Co y mayores para $\mathrm{A} 40$ y $\mathrm{A} 50$.

Esta alteración en la estructura también se corroboró al observar las fotos de microscopía electrónica de las pastas cocidas sustituidas con harina de amaranto (Figura 4.18).

Además, para las curvas de hidrólisis de cada muestra se calculó la ecuación de primer orden: $C=C \infty\left(1-e^{-k t}\right)$ de acuerdo a Goñi et al. (1997), donde $C$ corresponde al porcentaje de hidrólisis al tiempo t, $\mathrm{C}^{\infty}$ es la concentración en equilibrio del almidón hidrolizado después de $180 \mathrm{~min}$, k es la constante cinética y t es el tiempo seleccionado. Los valores experimentales obtenidos para cada muestra, fueron ajustados a la ecuación de manera de obtener k y Co y con la ecuación resultante se realizaron nuevas curvas teóricas, las que fueron integradas para calcular el área bajo la curva (AUC) entre 0 y $180 \mathrm{~min}$. La relación entre los valores de AUC de la muestras de pasta respecto a la muestra de pan (muestra tomada como referencia) fue definida como Índice de Hidrólisis (HI). Además se estimó un índice glucémico a partir del HI, según Goñi et al. (1997) utilizando la ecuación GI= 39,71 + (0,549 × HI) (Tabla 5.5).

Tabla 5.5 - Índice de Hidrólisis (HI), Índice Glucémico (IG) y clasificación respecto al IG estimado de las pastas cocidas elaboradas con harina de amaranto y de la muestra de pan

\begin{tabular}{cccc}
\hline Muestra & $\mathbf{H I}^{\mathbf{1}}$ & $\mathbf{I G}^{\mathbf{2}}$ & Clasificación (vs.pan) $^{\mathbf{3}}$ \\
\hline Co & $50,2 \pm 0,8 \mathrm{~b}$ & $67 \pm 1 \mathrm{~b}$ & IG Bajo \\
A15 & $43,1 \pm 1,8 \mathrm{a}$ & $64 \pm 1 \mathrm{a}$ & IG Bajo \\
A30 & $53,6 \pm 1,5 \mathrm{c}$ & $69 \pm 1 \mathrm{~b}$ & IG Bajo \\
A40 & $63,3 \pm 2,6 \mathrm{~d}$ & $74 \pm 2 \mathrm{c}$ & IG Bajo \\
A50 & $60,3 \pm 0,5 \mathrm{~d}$ & $73 \pm 0 \mathrm{c}$ & IG Bajo \\
Pan & 100 & $95 \pm 1 \mathrm{~d}$ & IG Moderado \\
\hline
\end{tabular}

${ }^{1} \mathrm{HI}=$ Área bajo la curva (AUC) de la pasta / AUC del pan, tomada entre 0 y $180 \mathrm{~min}$, utilizando la ecuación $\mathrm{C}=\mathrm{C} \infty$ (1-e(-kt)) para graficar dichas curvas y luego integrarlas. ${ }^{2}$ IG: calculado como $\mathrm{Gl}=39,71$ $+\left(0,549 \times\right.$ HI) de acuerdo a Goñi et al. (1997). ${ }^{3}$ De acuerdo a Schakel et al. (2008). Test de LSD Fisher; letras distintas indican diferencias significativas $(p \leq 0,05)$.

De acuerdo a Schakel et al. (2008), los alimentos pueden ser clasificados como de bajo, medio y alto índice glucémico. Si se utiliza como alimento de referencia a la glucosa, estos valores son: IG bajo $\leq 55$, IG moderado entre 56 y 69 e IG alto $\geq 70$; pero cuando se usa como 
alimento de referencia al pan, los valores IG (vs. glucosa) se deben multiplicar por 1,43 $\left(I G_{v s . p a n}=1,43 \times 1 G_{v s . g l u c o s a}\right)$, de manera tal que la clasificación respecto del pan resulta: IG bajo $\leq$ 79; IG moderado entre 80 y 99 e IG alto $\geq 100$. En este sentido se observó que los mayores índices de hidrólisis correspondieron a las muestras A40 y A50, mientras que el menor valor de HI fue observado para A15; y que de acuerdo al IG estimado, todas las muestras de pastas se clasificaron como de bajo índice glucémico.

Para evaluar el grado de ajuste de la ecuación $C=C \infty\left(1-\mathrm{e}^{-k t}\right)$ calculada para las muestras ensayadas y desde de allí dar validez al valor HI obtenido, se realizó un análisis de correlación de Pearson $(p \leq 0,05)$ entre los valores experimentales y los valores estimados a cada tiempo de ensayo para el conjunto de las muestras evaluadas (Tabla 5.6). Se encontraron coeficientes de correlación significativos para todos los tiempos del ensayo, corroborando la validez así a los HI calculados.

Tabla 5.6 - Coeficiente de correlación de Pearson, entre los valores de hidrólisis experimental y los teóricos ${ }^{1}$ para el conjunto de las muestras analizadas, a los diferentes tiempos de ensayo

\begin{tabular}{ccc}
\hline Tiempo, $\boldsymbol{m i n}$ & $\mathbf{r}^{\mathbf{1}}$ & $\mathbf{p}^{\mathbf{2}}$ \\
\hline 30 & 0,9989 & $<0,001$ \\
60 & 0,9987 & $<0,001$ \\
90 & 0,9988 & $<0,001$ \\
120 & 0,9978 & $<0,001$ \\
150 & 0,9990 & $<0,001$ \\
180 & 0,9973 & $<0,001$ \\
\hline
\end{tabular}

${ }^{1}$ Valores calculados a partir de la ecuación $\mathrm{C}=\mathrm{C} \infty\left(1-\mathrm{e}^{(-\mathrm{kt})}\right) \cdot{ }^{1} \mathrm{r}$ : coeficiente de correlación de Pearson. ${ }^{2}$ p: probabilidad.

\section{Digestibilidad de almidón in vitro de las pastas cocidas sustituidas con harina de} soja

La Figura 5.11 muestra el curso de la hidrólisis in vitro del almidón para las pastas sustituidas con harina de soja, la muestra control y la muestra de pan utilizada como referencia. Como era de esperar la muestra de pan presentó el mayor porcentaje de hidrólisis, y dentro de las muestras de pastas, se encontró que todas las muestras elaboradas con harina de soja presentaron mayores valores de hidrólisis que la muestra control. Como se explicó anteriormente, la susceptibilidad a las enzimas hidrolíticas en la muestra de pan es mucho mayor que en las muestras de pastas. 
El curso de las curvas de hidrólisis mostró un aumento muy rápido en los primeros 30 min para todas las muestras y a partir de allí la velocidad de hidrólisis disminuyó progresivamente hasta los 180 min evaluados.

En las curvas de hidrólisis de las pastas, se encontró que la cantidad de almidón hidrolizado a los 30 min fue significativamente mayor para las muestras S15, S30 y S40 respecto a de la muestra control $(p \leq 0,05)$, mientras que S50 no mostró diferencias con Co. Para los tiempos $60,90,120$ y $150 \mathrm{~min}$, todas las pastas elaboradas con harina de soja presentaron mayor porcentaje de hidrólisis que Co; encontrándose diferencias significativas para todos los niveles de sustitución, siendo S30 y S50 las muestras con mayor y con menor nivel de hidrólisis respectivamente. A los 180 min se encontró un patrón similar de hidrólisis que a los $30 \mathrm{~min}$, S50 no se diferenció de Co y las muestras S15, S30 y S40 presentaron mayor cantidad de almidón hidrolizado que Co.

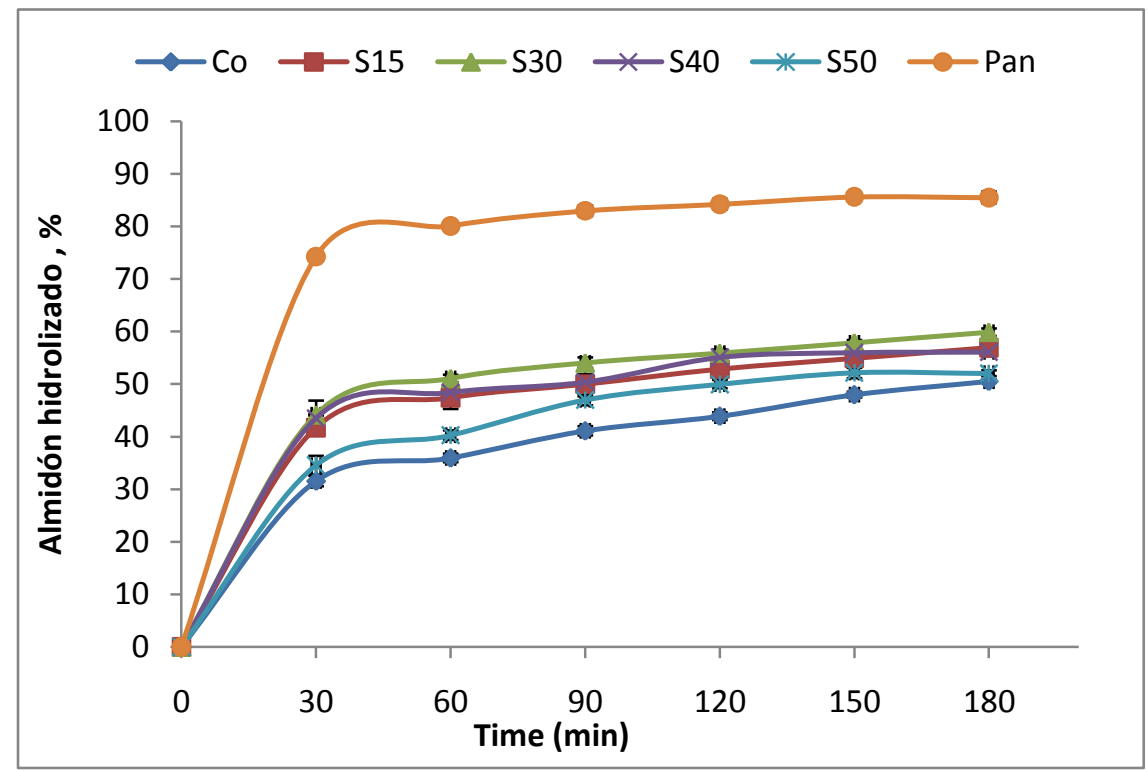

Figura 5.11- Porcentaje de almidón hidrolizado respecto al almidón total de las pastas cocidas sustituidas con harina de soja.

Para explicar las diferencias observadas en el grado de hidrólisis de las pastas, nuevamente se debe considerar una situación de equilibrio: por un lado, a medida que se fue incorporando harina de soja, harina carente de gluten, la estructura de las pastas se debilitó y por ende las enzimas hidrolíticas pudieron actuar más libremente; pero por otro lado, el almidón total de las muestras fue disminuyendo ya que la harina de soja carece prácticamente de almidón. Consecuentemente, a medida que las pastas presentaron mayor cantidad de harina de soja, las muestras mostraron un mayor grado de hidrólisis del almidón, pero en S30 se observó un 
punto de inflexión en donde el efecto dilución del almidón comenzó a ser más importante que el daño sobre la estructura de la pasta, al punto que S50 fue la muestra que presentó menor porcentaje de almidón hidrolizado.

Por medio de la microscopía electrónica de barrido (SEM) también se observó que el aspecto homogéneo y compacto presentado por la muestra control, progresivamente fue transformándose en más poroso y discontinuo con los mayores niveles de adición de harina de soja usados para elaborar las pastas (Figura 4.19).

A partir de las curvas de hidrólisis de las muestras, se calculó la ecuación de primer orden: $C=C \infty\left(1-e^{-k t}\right)$ de acuerdo a Goñi et al. (1997) y de igual manera que para las pastas elaboradas con harina de amaranto, los valores experimentales obtenidos para cada muestra, fueron ajustados a la ecuación para obtener $\mathrm{k}$ y $\mathrm{C} \infty$. Con la ecuación resultante se realizaron nuevas curvas teóricas, las que fueron integradas para calcular el área bajo la curva (AUC) entre 0 y 180 min; para así obtener el índice de hidrólisis (HI) de las muestras y estimar el IG de acuerdo a Goñi et al. (1997), tal que IG=39,71 + $(0,549 \times \mathrm{HI})$, clasificando las muestras por los IG resultantes de acuerdo a Schakel et al. (2008) (Tabla 5.7).

Tabla 5.7 - Índice de Hidrólisis (HI), Índice Glucémico (IG) y Clasificación respecto al IG estimado de las pastas cocidas sustituidas con harina de amaranto y de la muestra de pan

\begin{tabular}{cccc}
\hline Muestra & $\mathbf{H I}^{\mathbf{1}}$ & $\mathbf{I G}^{\mathbf{2}}$ & Clasificación (vs.pan) $^{\mathbf{3}}$ \\
\hline Co & $50,2 \pm 0,8 \mathrm{a}$ & $67 \pm 1 \mathrm{a}$ & IG Bajo \\
S15 & $61,2 \pm 2,2 \mathrm{c}$ & $73 \pm 2 \mathrm{c}$ & IG Bajo \\
S30 & $65,1 \pm 0,4 \mathrm{~d}$ & $76 \pm 1 \mathrm{~d}$ & IG Bajo \\
S40 & $62,5 \pm 1,1 \mathrm{c}$ & $74 \pm 1 \mathrm{~cd}$ & IG Bajo \\
S50 & $55,6 \pm 0,6 \mathrm{~b}$ & $70 \pm 0 \mathrm{~b}$ & IG Bajo \\
Pan & 100 & $95 \pm 1 \mathrm{e}$ & IG Moderado \\
\hline
\end{tabular}

${ }^{1} \mathrm{HI}=$ Área bajo la curva (AUC) de la pasta / AUC del pan, tomada entre 0 y 180 min, utilizando la ecuación $\mathrm{C}=\mathrm{C} \infty\left(1-\mathrm{e}^{(-\mathrm{kt})}\right)$ para graficar dichas curvas y luego integrarlas. ${ }^{2} \mathrm{IG}$ : calculado como $\mathrm{Gl}=39,71+$ $(0,549 \times \mathrm{HI})$ de acuerdo a Goñi et al. (1997). ${ }^{3}$ De acuerdo a Schakel et al. (2008). Test de LSD Fisher; letras distintas indican diferencias significativas $(p \leq 0,05)$.

Se puede observar que todas las pastas sustituidas presentaron mayores valores de $\mathrm{HI}$ que Co, siendo mayor para S30, seguido de S15 y S40, mientras que S50 fue la muestra sustituida con harina de soja con menor HI. A partir de IG estimado, todas las pastas resultaron como alimentos de bajo IG.

También en este caso se realizó un análisis de correlación de Pearson para evaluar el ajuste de la ecuación $\mathrm{C}=\mathrm{C} \infty\left(1-\mathrm{e}^{(-\mathrm{kt})}\right)$, dado que a partir de esta ecuación derivan los $\mathrm{HI}$ calculados. Nuevamente se obtuvieron coeficientes de correlación $r>0,99$ ( $p<0,001)$ (Tabla 5.8). 
Tabla 5.8 - Coeficiente de correlación de Pearson, entre los valores de hidrólisis experimental y los teóricos ${ }^{1}$ para el conjunto de las muestras analizadas, a los diferentes tiempos de ensayo.

\begin{tabular}{ccc}
\hline Tiempo, min & $\mathbf{r}^{\mathbf{1}}$ & $\mathbf{P}^{\mathbf{2}}$ \\
\hline 30 & 0,9989 & $<0,001$ \\
60 & 0,9987 & $<0,001$ \\
90 & 0,9988 & $<0,001$ \\
120 & 0,9978 & $<0,001$ \\
150 & 0,9990 & $<0,001$ \\
180 & 0,9973 & $<0,001$ \\
\hline${ }^{1}$ Valores calculados a partir de la ecuación $\mathrm{C}=\mathrm{C} \infty\left(1-\mathrm{e}^{(-k \mathrm{kt})}\right) .{ }^{1}{ }^{1}$ : coeficiente \\
\multicolumn{2}{c}{ de correlación de Pearson. ${ }^{2} \mathrm{p:} \mathrm{probabilidad.}$}
\end{tabular}

\section{Determinación de la digestibilidad in vitro de las proteínas}

La digestibilidad de las proteínas es el porcentaje de proteína consumida que es absorbida por el tracto gastrointestinal y que no es recuperada como $\mathrm{N}$ fecal (Brody, 1999). Las proteínas vegetales en su forma natural, son en general menos digeribles que las proteínas de origen animal (Johnston, 1999).

La digestibilidad de las proteínas de las pastas elaboradas con harina de amaranto resultó significativamente mayor para todos los niveles de sustitución respecto a lo observado para la muestra control (Tabla 5.9).

Tabla 5.9 - Digestibilidad de las proteínas de las pastas elaboradas con harina de amaranto

\begin{tabular}{cc}
\hline Muestra & Digestibilidad Proteínas, ${ }^{1}{ }^{1}$ \\
\hline Co & $76,1 \pm 3,7 \mathrm{a}$ \\
A15 & $89,7 \pm 6,9 \mathrm{~b}$ \\
A30 & $89,7 \pm 1,8 \mathrm{~b}$ \\
A40 & $84,7 \pm 4,2 \mathrm{~b}$ \\
A50 & $84,9 \pm 5,7 \mathrm{~b}$ \\
\hline Porcentaje de proteínas digeridas respecto del total de proteínas \\
presentes en la pasta cocida lista para el consumo Test de DGC; letras \\
distintas indican diferencias significativas ( $\mathrm{p} \leq 0,05)$.
\end{tabular}

Mientras que Co presentó un valor de digestibilidad de proteínas de $76,1 \%$ p/p respecto al total de proteínas presentes en la pasta cocida, las muestras elaboradas con harina de amaranto mostraron valores comprendidos entre 84,7 y $89,7 \% \mathrm{p} / \mathrm{p}$, comparables a aquellos obtenidos por Nur Herhen et al. (2006) y Rayas-Duarte et al. (1996) en macarrones de sémola de trigo candeal y en espaguetis sustituidos con harina de amaranto, respectivamente. 
La Tabla 5.10 muestra la digestibilidad de proteínas medida en las pastas elaboradas con harina de soja, las cuales mostraron mayores valores de digestibilidad que la muestra control, aunque sin presentar diferencias significativas entre los distintos niveles de sustitución, variando entre $81,2 \%$ p/p y $86,8 \%$ p/p. En un trabajo previo (Hsu et al., 1977) en donde se determinó la digestibilidad in vitro de las proteínas en fideos extrusados tipo "coditos", elaborados con sémola y sustituidos con $8,6 \% \mathrm{p} / \mathrm{p}$ de aislado proteico de soja, obtuvieron un valor de $79,8 \% \mathrm{p} / \mathrm{p}$.

\begin{tabular}{|c|c|}
\hline Muestra & Digestibilidad Proteínas, $\%^{1}$ \\
\hline Co & $76,1 \pm 3,7 a$ \\
\hline S15 & $81,2 \pm 2.8 b$ \\
\hline S30 & $86,8 \pm 6,5 b$ \\
\hline S40 & $86,6 \pm 2,6 b$ \\
\hline S50 & $82,0 \pm 4,0 \mathrm{~b}$ \\
\hline
\end{tabular}

El mayor porcentaje de digestibilidad de proteínas in vitro encontrado en las pastas elaboradas con harina de amaranto y de soja, se puede explicar por el mayor grado de disgregación que sufrieron las muestras durante el proceso de simulación de la masticación realizado el ensayo. El debilitamiento de la estructura observado en estas pastas por la incorporación de estas harinas carentes de gluten respecto a la muestra elaborada solo con harina de trigo, facilitó el acceso de la proteasa responsable de la digestibilidad de las proteínas presentes en las pastas.

Además de la estructura y conformación de las proteínas, otros factores que pueden afectar su digestibilidad son los inhibidores de proteasas, el ácido fítico, los polifenoles y los taninos (Jenkins et al., 1999), los que dependen de la naturaleza del alimento y del tipo y grado de procesamiento al que haya sido sometido.

Tanto el amaranto como la soja poseen factores antinutricionales que dificultan su digestibilidad (Svensson et al., 2004). En el caso de la harina de amaranto, si bien se obtuvo a partir de granos crudos, se considera al proceso de cocción de las pastas suficiente como para inactivar los factores antinutricionales que pudieran estar presentes en estas muestras.

Para la cocción de las pastas se utiliza agua a ebullición en una relación mínima 1:10 (pasta:agua), lo que asegura que al agregar la pasta se producirá solo un ligero descenso de la 
temperatura, aproximadamente hasta $95{ }^{\circ} \mathrm{C}$ y dado el pequeño espesor de los fideos, la transferencia calórica es muy alta y alcanzan rápidamente la misma temperatura del agua (Calvelo, 2008). De este modo, las pastas durante la cocción fueron sometidas al menos durante 5 min (menor tiempo óptimo de cocción de las muestras elaboradas con harina de amaranto) a $95^{\circ} \mathrm{C}$, descartando así actividad remanente de algún factor antinutricional.

En el caso de las pastas elaboradas con harina de soja, más allá que las muestras fueron también sometidas a un proceso de cocción similar, para su elaboración se utilizó harina de soja previamente inactivada.

Debido a que el secado de las pastas se realizó a bajas temperaturas $\left(30^{\circ} \mathrm{C}\right)$, se descartó además la presencia de agregados proteicos resultantes de la reacción de Maillard, característicos de las pastas secadas a altas temperaturas, los que pueden llegar a afectar la digestibilidad de las proteínas hasta en un 10\% (De Zorzi et al., 2007; Petitot et al., 2009b).

\section{Conclusiones}

De acuerdo al contenido de escualeno cuantificado en las pastas elaboradas con harina de amaranto, teniendo en cuenta los efectos hipocolesterolémicos de este triterpeno demostrado en los trabajos antes mencionados y considerando que altos niveles de colesterol incrementan el riesgo de las enfermedades cardiovasculares e infarto (Martirosyan et al., 2007), es que se proponen a estas pastas como parte de una dieta saludable, especialmente para aquellas personas que presentan un alto riesgo de sufrir cardiopatías.

La población asiática ha tenido históricamente baja incidencia de enfermedades cardiovasculares, de síntomas menopáusicos, de cáncer de mama (así como de otros tipos de cáncer hormona dependientes), diabetes y obesidad, respecto a la población occidental (Patisaul \& Jefferson, 2010). En una dieta tradicional japonesa la concentración plasmática de daidzeína, genisteína y equol en una persona adulta está comprendida entre $50-800 \mathrm{ng} / \mathrm{mL}$, la cual es alcanzada al consumir solo una modesta cantidad de alimentos en base a soja conteniendo $50 \mathrm{mg} /$ día de isoflavonas (Setchell \& Cassidy, 1999). En una porción de pastas elaboradas con $40 \mathrm{~g}$ de harina de soja/100 g de harina de trigo, correspondiente a $80 \mathrm{~g}$ de pasta seca de acuerdo a lo recomendado en la resolución MERCOSUR/GMC/RES. № 47/03) (CAA, 2009/10b), se estarían consumiendo 19,4 mg de isoflavonas, es decir el 39\% de lo usualmente consumido en una dieta japonesa. En este sentido, es que se también se proponen a las pastas elaboradas con harina de soja como parte de una dieta beneficiosa para la salud. 
El valor diario de referencia (VDR) de proteínas de acuerdo al Reglamente Técnico MERCOSUR sobre el rotulado nutricional de alimentos envasados (CAA, 2009/10b) es $75 \mathrm{~g}$ y en caso que el alimento aporte un 10\% del VDR/100 g de sólidos, podrá ser considerado como fuente de proteínas. Respecto al contenido de fibra dietética, el valor diario de referencia (CAA, 2009/10b) es $25 \mathrm{~g}$ y para aquellos alimentos que aporten un mínimo de $3 \mathrm{~g} / 100 \mathrm{~g}$ de sólidos podrán ser declarados como fuente de fibras. De manera que para las pastas elaboradas con harina de soja, a partir del $30 \%$ de sustitución en adelante, podrían ser consideradas tanto como fuente de proteínas como de fibra dietética.

Además, para las proteínas de soja la FDA en 1999 autorizó una alegación de salud (health claim) para la rotulación de alimentos que la contengan, debido a la existencia de evidencia científica suficiente para relacionar el consumo de proteínas de soja con la reducción de los niveles plasmáticos de colesterol total y LDL colesterol. La alegación hace referencia a que, incluyendo proteínas de soja en una dieta baja en grasas saturadas y colesterol se puede reducir el riesgo de enfermedades coronarias. La FDA propuso una ingesta diaria de $25 \mathrm{~g} / \mathrm{d} i ́ a$, es decir que para que un alimento pueda llevar la alegación de salud, deberá contener 6,25 g de proteína de soja por porción (es decir 25 g de proteína dividida en 4 porciones diarias) (CFR, 2010a). De manera que aquellas pastas elaboradas con $40 \% \mathrm{p} / \mathrm{p}$ de harina de soja, pueden aportar 6,31 g de proteínas de soja /porción, correspondiente al $40 \%$ del total de proteínas $(22,96 \%)$ presentes en una porción de $55 \mathrm{~g}$ de pastas secas (CFR, 2010b), resultando con la cantidad suficiente como para llevar esta alegación de salud en lo que respecta su contenido de proteínas de soja.

Asimismo, la FDA tiene aprobada una alegación de salud respecto a la fibra dietética, de acuerdo con la asociación entre la reducción de algunos tipos de cáncer y el consumo de este macronutriente (CFR, 2010c). Para que un alimento pueda llevar esta alegación debe contener una cantidad de fibra comprendida entre el 10 y el $19 \%$ del valor diario de referencia por porción (CFR, 2010d), el cual para fibra dietética es 25 g (CFR, 2010e); es decir entre 2,5 y 4,75 $\mathrm{g}$ de fibra dietética/porción. Tanto las pastas elaboradas con $30 \% \mathrm{p} / \mathrm{p}$ de harina de amaranto, como aquellas preparadas con $40 \% \mathrm{p} / \mathrm{p}$ de harina de soja pueden llevar esta alegación, dado que en una porción de $55 \mathrm{~g}$ de pasta seca (CFR, 2010b), contienen 3,24 g y 6,93 g de fibra dietética, respectivamente.

Las pastas elaboradas con harina de amaranto y con harina de soja resultaron además como alimentos de bajo índice glucémico, con los beneficios de salud asociados a esta propiedad tales como la menor excreción urinaria del péptido $C$ en pacientes sanos y el mejor 
control glucémico en pacientes diabéticos; por lo cual se trata de alimentos de elección para personas diabéticas y para reducir los lípidos en suero en sujetos hiperlipidémicos.

Finalmente, la digestibilidad de proteínas medida en las pastas elaboradas con ambas harinas alternativas fue mayor a aquella preparada solo con harina de trigo, asegurando así su asimilación y aprovechamiento por el organismo. 


\section{CONCLUSIONES} GENERALES 
Las pastas alimenticias son productos que se consumen en todo el mundo, que se caracterizan por ser un alimento tradicional y de gran aceptación debido a su conveniencia, palatabilidad y cualidades nutricionales.

El ingrediente de elección por excelencia de la pasta es la sémola de trigo candeal (Triticum durum Desf.), pero desafortunadamente, el trigo durum requiere de condiciones climáticas relativamente estrictas, representado solo el $1 \%$ de la cosecha triguera total en nuestro país. Cuando el trigo candeal presenta un precio elevado, poca oferta y disponibilidad, o en regiones alejadas de las zonas donde se cultiva, éste es reemplazado parcial o totalmente por el trigo pan (Triticum aestivum L.). De modo que, es frecuente encontrar pastas elaboradas a partir de harinas de trigo pan, especialmente en aquellos productos destinados a consumidores que priorizan el costo sobre la calidad.

En los últimos años las pastas se han vuelto más atractivas por sus propiedades nutricionales ya que se trata de un producto de bajo índice glucémico y con escaso aporte de grasa y de sodio. La Organización Mundial de la Salud y la Food and Drug Administration de Estados Unidos, han considerado a la pasta como un alimento apropiado para el agregado de nutrientes. Mejorar la calidad nutricional de las pastas involucra principalmente aumentarles la cantidad de proteínas y de fibra dietética, y fortificarlas con vitaminas y minerales. Además, las pastas son consideradas como un buen vehículo para incorporarles ingredientes beneficiosos para la salud, transformándose así en alimentos funcionales. Tanto la harina de amaranto como la harina de soja pueden ser consideradas como ingredientes funcionales, debido a los elementos beneficiosos para la salud que pueden aportar a las formulaciones donde se las incorpore.

La harina de amaranto posee un alto valor nutritivo por ser buena fuente de proteínas y de lípidos, con una composición en aminoácidos esenciales bien balanceada. Además se caracteriza por la presencia de escualeno, al cual se le atribuyen propiedades hipocolesterolémicas, quimio-preventivas del cáncer y efectos beneficiosos sobre la hipertensión.

La harina de soja se caracteriza por su alto contenido de proteínas, ricas en lisina, las que además presentan efectos cardioprotectores. Asimismo, la soja es una fuente de isoflavonas incluyendo genisteína y daidzeína, las que son reconocidas como compuestos con propiedades preventivas y terapéuticas del cáncer, de la osteoporosis y de los síntomas de la menopausia.

En este trabajo se evaluó la posibilidad de elaborar pastas con harina de trigo pan, sustituidas con diferentes cantidades de harina de amaranto y de harina de soja, con una 
calidad tecnológica y sensorial aceptables, a fin de otorgarles propiedades funcionales y mejorar su calidad nutricional.

Con el propósito de evaluar los parámetros que definen la calidad de las pastas, primero se realizaron diferentes ensayos instrumentales y sensoriales en muestras de pastas secas comerciales, a fin de estudiar la aptitud de estos métodos como indicadores de calidad. Además, se analizó la posible asociación entre las mediciones sensoriales e instrumentales en las muestras ensayadas. El análisis químico, el comportamiento de las pastas durante la cocción (tiempo óptimo de cocción, absorción de agua, residuo de cocción y contenido de amilosa en el agua de cocción), el color de las pastas secas y cocidas, las mediciones instrumentales de textura (firmeza, cohesividad, masticabilidad, elasticidad, resiliencia y pegajosidad) y la evaluación sensorial y de preferencia de las muestras, mostraron buena sensibilidad para ser utilizados como parámetros de calidad de las pastas. Entre las mediciones instrumentales y sensoriales se encontró una significativa correlación para la mayoría de las variables según se observó a través de los coeficientes de Pearson y el análisis de componentes principales.

Para determinar cómo influyen los principales componentes de la harina en la calidad, se elaboraron pastas frescas en donde la harina de trigo pan fue sustituida con 5 y $10 \% \mathrm{p} / \mathrm{p}$ de almidón y de 3 y $6 \%$ p/p de gluten. Ante el agregado de almidón se observó un detrimento en la calidad de las pastas, mientras que el agregado de gluten produjo el efecto contrario. De hecho, al no someter a las pastas a un proceso de secado posterior, donde puede suceder una desnaturalización parcial de las proteínas que favorezca la calidad de las pastas cocidas, en las pastas frescas la calidad es una función tanto del contenido y la calidad de las proteínas como de las características del almidón.

Los mayores niveles de proteínas extraíbles en SDS medidos en las mezclas de harina de trigo con más gluten, respecto a los equivalentes obtenidos con almidón, significó mayor proporción de proteínas que pudieron unirse por puentes disulfuro, facilitando la formación de una red más continua, limitando el hinchamiento del almidón durante la cocción y su lixiviación posterior, resultando de este modo en pastas de mejor calidad. Mientras que la adición de gluten favoreció la formación de una estructura más firme, produciendo pastas con menor residuo de cocción, mayor color amarillo, mayor firmeza y masticabilidad, la adición de almidón produjo el efecto contrario, debilitando la estructura de las muestras y por ende empeorando su calidad. La preferencia por la muestra con la mayor cantidad de gluten agregado dada por el panel sensorial corroboró estos resultados. 
Además, se evaluó el efecto de diferentes harinas sobre el color de las pastas frescas laminadas. Las harinas se caracterizaron en términos de su composición química y de las fracciones proteicas, a fin de estudiar la posible relación entre cada uno de sus compontes con el color de las pastas resultantes. Con igual propósito se ensayaron formulaciones con distintas cantidades de agua añadida. Considerando que las harinas estudiadas provienen de cereales que no sufren una presión de selección por un mayor contenido de pigmentos ni por una menor presencia de enzimas oxidantes, se puede decir que la luminosidad y el componente rojo-verde de color de las pastas, fue afectado principalmente por el contenido de cenizas, mientras que el componente amarillo-azul fue afectado por el contenido de proteínas de las harinas evaluadas. Además, a partir de la calificación de color calculada, en donde el componente $b^{*}$ de color tiene el mayor peso en la fórmula, se encontró que aquellas pastas elaboradas con harinas de mayor contenido de proteínas, fueron las que obtuvieron mejor calificación. También se observó que el perfil de color medido en las harinas, en términos de $a^{*}$ y de $b^{*}$, fue diferente al encontrado en las pastas correspondientes, indicando que la hidratación de las partículas de harina y el proceso de amasado modificaron el color de las masas. A partir del estudio de las fracciones proteicas, se encontró que las albúminas y globulinas correlacionaron con el componente $a^{*}$ de las pastas, mientras que las gliadinas y las gluteninas solubles e insolubles lo hicieron con el componente b*. El ANAVA realizado para las harinas y al agua añadida a la masa, mostró que el efecto de las diferentes harinas fue cuantitativamente el más importante sobre el color de las pastas frescas en comparación con las diferentes cantidades de agua añadidas a la masa.

A fin de obtener pastas elaboradas con harina de amaranto y con harina de soja de una calidad tecnológica y sensorial aceptables, se ensayaron diferentes niveles de sustitución, para estudiar cómo estas harinas no panaderas afectaban la estructura de la pasta de modo de determinar la cantidad máxima en las que podían ser usadas.

En primer lugar se evaluaron las propiedades de las harinas utilizadas, encontrándose que tanto la harina de soja como la harina de amaranto presentaron un contenido de proteínas y de fibra dietética muy superior a la harina de trigo, siendo más acentuado en la harina de soja respecto a la de amaranto. Además se observó que esta última harina presentaba una importante cantidad de materia grasa.

También se encontró a partir de la evaluación de amilosa, de amilopectina y de almidón de las harinas, que la de amaranto presentó una cantidad importante de almidón, con un contenido de amilosa de $14,8 \% \mathrm{p} / \mathrm{p}$, siendo proporcionalmente la cantidad de amilosa y de amilopectina menor y mayor respectivamente, que lo determinado en la harina de trigo. 
En cuanto a las propiedades de pasting evaluadas se observó que el agregado de harina de amaranto a la harina de trigo, provocó una disminución de la viscosidad de pico, de la viscosidad media, del breakdown y del tiempo de pico (facilidad de cocción de la pasta). Asimismo, el menor contenido de amilosa presente en la harina de amaranto, generó una menor tendencia a retrogradar, lo que explicó los menores valores de viscosidad final encontrados para las mezclas con mayor porcentaje de harina de amaranto. En el caso de la harina de soja, su incorporación creciente a la harina de trigo, disminuyó todos los valores de la curva de pasting (viscosidad pico, viscosidad media, viscosidad final, breakdown, setback, y tiempo de pico) debido a que la soja se caracteriza por una escasa presencia de almidón y de hecho su perfil de viscosidad prácticamente resultó una línea recta.

Al evaluar la apariencia de las pastas elaboradas con harina de amaranto y harina de soja, se encontró que la primera tuvo un mayor efecto negativo respecto a la harina de soja, provocando además de un oscurecimiento, una notoria alteración de la superficie de la pasta. A través de la reflectancia medida en las pastas cocidas, se pudo observar que tanto el agregado de la harina de amaranto como el de harina de soja, disminuyeron el valor $L^{*} y$ aumentaron los valores $a^{*} \mathrm{y}^{*}$.

En cuanto al comportamiento durante la cocción, las pastas elaboradas con harina de amaranto y con harina de soja, presentaron menores tiempos óptimos de cocción, siendo aún menores para las pastas sustituidas con harina de amaranto respecto a las sustituidas con harina de soja, y mayores residuos de cocción que la muestra control. A partir de los resultados obtenidos se pudo estimar que a medida que el gluten proveniente de la harina de trigo se fue "diluyendo" por la sustitución con estas harinas alternativas, el retículo proteico se tornó más débil, facilitando una mayor difusión del agua hacia el interior de la pasta, deteriorando la calidad de los productos obtenidos.

También la textura tanto de las pastas secas, en término de fracturabilidad, como de las pastas cocidas (firmeza, pegajosidad, elasticidad, masticabilidad y resilencia), se vio afectada negativamente con la incorporación de estas harinas alternativas, aunque cabe destacar que el efecto de la harina de soja fue mucho más atenuado que el de la harina de amaranto, especialmente en términos de firmeza en donde solo el mayor porcentaje de sustitución con harina de soja resultó significativamente menor que la muestra control.

El comportamiento reológico de las pastas mostró mayores valores de $G^{\prime}, G^{\prime \prime}$ y de $\tan \delta$, respecto a la muestra control, lo que sugirió que ambas harinas acentuaron un comportamiento sólido-elástico. También se observó una importante dependencia con la 
frecuencia tanto para $G^{\prime}$ como para $G^{\prime \prime}$, siendo en esta última, más marcada para las mayores frecuencias evaluadas.

A través de la microscopía electrónica de barrido se pudo observar como la incorporación de estas harinas no panaderas modificaron la estructura de las pastas, especialmente para aquellas elaboradas con harina de amaranto, en donde la característica de harina integral, favoreció la presencia de tegumentos en grandes cantidades y de gran tamaño, generando una marcada discontinuidad en la matriz proteica, afectando negativamente la calidad de las pastas. Resultados coincidentes con lo observado en el comportamiento durante la cocción y con las mediciones de textura. En el caso de las pastas elaboradas con harina de soja, si bien la red de proteínas del gluten, proveniente de la harina de trigo, se vio notablemente deteriorada, las proteínas de soja, aportaron una cierta firmeza; probablemente debido a su capacidad de gelificar, reduciendo el deterioro de la calidad final de la pasta, a pesar de ser una harina carente de gluten sin propiedades panaderas.

Respecto a la evaluación sensorial, el haber tenido que mantener el diseño en bloques para los evaluadores significó, que éstos resultaron una fuente de variación extra a la proveniente de los distintos niveles de sustitución de la harina de trigo con la harina de amaranto y con la harina de soja. Si bien los panelistas contaban con experiencia previa en la cata de pastas, manifestaron relativa dificultad en la evaluación de estas muestras en particular generando dispersión en los valores obtenidos para cada propiedad analizada. Esta variabilidad aportada por los panelistas posiblemente provocó la falta de correlación entre la evaluación sensorial e instrumental.

Es importante considerar que más allá de las propiedades funcionales y nutricionales que se le puede aportar a las pastas por la incorporación de harina de amaranto y harina de soja, hay que tener en cuenta que estas harinas carecen de gluten el que tiene un papel primordial en calidad de las pastas. Fue necesario entonces definir una situación de equilibrio entre la incorporación de estas harinas alternativas y la calidad tecnológica y sensorial de las pastas resultantes. A partir de los resultados del comportamiento durante la cocción, del análisis instrumental de textura, de la medición del color y de la evaluación sensorial, se propuso como límite para las pastas elaboradas con harina de amaranto un porcentaje de sustitución no mayor al $30 \% \mathrm{p} / \mathrm{p}$, mientras que para las pastas preparadas con harina de soja, un porcentaje no mayor al $40 \% \mathrm{p} / \mathrm{p}$. 
Los compuestos con propiedades funcionales aportados por la harina de amaranto y por la harina de soja fueron aislados, identificados y cuantificados tanto de las harinas como de las pastas elaboradas con ellas.

Se encontró que la harina de amaranto aportó cantidades significativas de escualeno a las pastas y dado los efectos hipocolesterolémicos que presenta este compuesto, es que se propone que las pastas elaboradas con harina de amaranto pueden formar parte de una dieta saludable, especialmente para aquellas personas que presentan un alto riesgo de sufrir cardiopatías, considerando que altos niveles de colesterol incrementan el riesgo de las enfermedades cardiovasculares e infarto.

Respecto a las pastas elaboradas con soja, en base a los resultados obtenidos en la Sección $\mathrm{IV}$, en donde las pastas elaborados hasta con $40 \mathrm{~g}$ de harina de soja/100 $\mathrm{g}$ de harina de trigo, habían resultado con una calidad tecnológica aceptable, en una porción de éstas ( $80 \mathrm{~g}$ de pasta seca) se estarían consumiendo $19,4 \mathrm{mg}$ de isoflavonas, es decir el $39 \%$ de lo usualmente consumido en una dieta japonesa. En este sentido, es que se proponen también a estas pastas como parte de una dieta beneficiosa para la salud.

En relación con la calidad nutricional evaluada, de acuerdo a los valores diarios de referencia de proteínas y de fibra dietética, las pastas elaboradas con harina de soja, a partir del $30 \%$ de sustitución en adelante, podrían ser consideradas como fuente de proteínas y de fibra dietética.

Además para las proteínas de soja, de acuerdo a la alegación de salud aprobada por la FDA para aquellos alimentos con contengan $6,25 \mathrm{~g}$ de proteína de soja por porción y la existencia de evidencia científica suficiente para relacionar el consumo de proteínas de soja con la reducción de los niveles plasmáticos de colesterol total y LDL colesterol; aquellas pastas elaboradas $40 \mathrm{~g}$ de harina de soja/100 $\mathrm{g}$ de harina de trigo, que pueden aportar 6,31 $\mathrm{g}$ de proteína de soja /porción, resultan con la cantidad suficiente como para llevar esta alegación de salud en lo que respecta su contenido de proteínas de soja.

De igual modo, respecto a la alegación de salud para fibra dietética que tiene aprobada la FDA, por la asociación entre la reducción de algunos tipos de cáncer y el consumo de este macronutriente; tanto las pastas elaboradas con $30 \% \mathrm{p} / \mathrm{p}$ de harina de amaranto, como aquellas preparadas con $40 \% \mathrm{p} / \mathrm{p}$ de harina de soja pueden llevar esta alegación, dado que en una porción, contienen $3,24 \mathrm{~g}$ y 6,93 g de fibra dietética respectivamente, superior a lo requerido para poder llevar esta alegación de salud. 
Adicionalmente, las pastas elaboradas con harina de amaranto y con harina de soja resultaron como alimentos de bajo índice glucémico, con los beneficios de salud asociados a esta propiedad tales como la menor excreción urinaria del péptido $C$ en pacientes sanos, el mejor control glucémico en pacientes diabéticos, y la reducción de los lípidos en suero de sujetos con hiperlipidemia. Asimismo, la digestibilidad de proteínas medida en las pastas elaboradas con ambas harinas alternativas fue mayor a aquella preparada solo con harina de trigo, asegurando así su asimilación y aprovechamiento por el organismo con el consecuente beneficio nutricional que eso significa. 


\section{CONCLUSIONES FINALES Y}

\section{PERSPECTIVAS FUTURAS}


Se obtuvieron pastas con harina de trigo pan de una calidad tecnológica y sensorial aceptables por medio de un proceso de laminado. La utilización de éste sistema de elaboración ayudó a contrarrestar las conocidas falencias que presenta este tipo de materia prima para la elaboración de pastas (tales como la menor cantidad y calidad de gluten), respecto a la sémola de trigo de candeal.

Se elaboraron pastas laminadas en donde la harina de trigo pan fue sustituida hasta $30 \%$ $\mathrm{p} / \mathrm{p}$ con harina integral de amaranto y hasta $40 \% \mathrm{p} / \mathrm{p}$ por harina desgrasada y micronizada de soja, las cuales resultaron con una calidad tecnológica y sensorial aceptables y con una calidad nutricional notablemente mejorada.

En el caso de las pastas elaboradas con harina de amaranto, el aporte de proteínas no solo fue cuantitativo, sino cualitativo dado el equilibrado balance de aminoácidos esenciales que esta harina presenta. Además, estas pastas resultaron enriquecidas con cantidades significativas de escualeno, compuesto con demostradas propiedades hipocolesterolémicas, quimio-preventivas del cáncer y efectos beneficiosos sobre la hipertensión. De este modo es que se proponen a estos productos como parte de una dieta saludable, especialmente para aquellas personas con posibilidad de sufrir cardiopatías, dado que los elevados niveles de colesterol incrementan el riesgo de padecer enfermedades cardiovasculares e infarto.

Las pastas elaboradas con harina de soja obtenidas en el presente trabajo, pueden ser calificadas como fuente de proteínas y, al ser ricas en lisina, son capaces de suplementar la deficiencia de este aminoácido en los productos elaborados a partir de trigo. Además, de acuerdo a la cantidad proporcional de proteínas de soja que presentan estas pastas, pueden llevar la alegación de salud aprobada por al FDA en relación el consumo de este tipo de proteínas y la reducción de los niveles plasmáticos de colesterol total y LDL colesterol. De igual modo, una porción de estas pastas contienen el $39 \%$ de isoflavonas de lo que habitualmente se consume en una dieta japonesa y considerando la asociación entre el consumo de estos compuestos flavonoides con la menor incidencia de enfermedades cardiovasculares, de síntomas menopáusicos, de cáncer de mama (así como de otros tipos de cáncer hormona dependientes), de diabetes y de obesidad, es que se las propone como parte de una dieta beneficiosa para la salud.

En el mismo sentido, tanto las pastas elaboradas con harina de amaranto como con harina de soja, pueden llevar la alegación de salud aprobada por la FDA para fibra dietética, sumando otro efecto beneficioso para la salud dada la asociación entre la reducción de algunos tipos de cáncer y el consumo de este macronutriente. 
Adicionalmente, las pastas elaboradas con harina de amaranto y con harina de soja resultaron como alimentos de bajo índice glucémico, con los beneficios de salud asociados a esta propiedad tales como la menor excreción urinaria del péptido $C$ en pacientes sanos, el mejor control glucémico en pacientes diabéticos, y la reducción del contenido de lípidos en suero de personas con hiperlipidemia.

Finalmente la digestibilidad de proteínas medida en las pastas elaboradas con ambas harinas alternativas fue mayor a aquella preparada solo con harina de trigo, asegurando así su asimilación y aprovechamiento por el organismo con el consecuente beneficio nutricional que eso significa.

Las perspectivas que se abren a partir de este trabajo comprenden:

- Ampliar el número de variedades de trigo pan, para estudiar la influencia de estas sobre la calidad de las pastas obtenidas.

- Ensayar diferentes temperaturas de secado con el propósito de fortalecer la estructura de las pastas laminadas elaboradas con harina de trigo, harina de amaranto y harina de soja.

- Evaluar el comportamiento térmico del almidón sobre las pastas secas y cocidas elaboradas con harina de amaranto y de soja.

- Evaluar el efecto del tamaño de partícula de la harina de amaranto sobre el daño en la estructura de las pastas.

- Profundizar el estudio sobre la interacción entre las proteínas de soja y las proteínas de trigo en las pastas elaboradas con harina de soja. 


\section{BIBLIOGRAFÍA}


AACC. American Association of Cereal Chemistry. 1995. Approved Methods of the American Association of Cereal Chemists, 9th Ed., American Association of Cereal Chemists, St. Paul, MN. USA.

Abecassis J., Abbou R., Chaurand M., Morel M.H., Vernoux P. 1994. Influence of extrusion conditions on extrusion speed, temperature, and pressure in the extruder and on pasta quality. Cereal Chemistry, 71: 247-253.

ADA, American Diet Association. 2004. Position of the American Dietetic Association: Functional foods. Journal of American Dietetic Association, 104: 814-826.

Alimentos Argentinos, 2002. Cadenas Alimentarias, Pastas secas. http://www.alimentosargentinos.gov.ar/03/farina/Pastas/pastas_secas/Pastas_secas.htm consultado diciembre, 2009.

Alvis A., Vélez C.A., Villada H.S., Rada-Mendoza M. 2008. Análisis físico-químico y morfológico de almidones de ñame, yuca y papa y determinación de la viscosidad de las pastas. Información Tecnológica, 19: 19-28.

Andrews J.L., Hay R.L., Skerritt J.H., Sutton K.H. 1994. HPLC and immunoassaybased glutenin subunit analysis: screening for dough properties in wheats grown under different environmental conditions. Journal of Cereal Science, 20: 203-215.

Añon M.C., Puppo M.C., Pedroza-Islas R., Oliete B., Villagómez-Zavala D. 2009. Valor nutricional y saludable de materias primas para la elaboración de productos de panificación; en Lutz M., León A.E., editores. Aspectos saludables y nutricionales de los productos de panificación. 1ra Edición. Universidad de Valparaíso-Editorial, España. Pág. 77.

AOAC International. Offical Methods of Analysis of AOAC International 1998. 16th edition, 4th revision. Vol II. Maryland. USA.

Atwell W.A. 1998. Method for reducing syruping in refrigerated dough. Patent Application WO $97 / 26794$.

Atwell W.A., Hood L.F., Lineback D.R., Varriano-Marston E., Zobel H.F. 1988. The terminology and methodology associated with basic starch phenomena. Cereal Foods World, 33: $306-311$. 
Ávila M. 2002. Incorporación del Rapid Visco Analizer (RVA) para la determinación de la calidad culinaria de arroz. Fundación para la Investigación Agrícola, Boletín Informativo Enero/Marzo: Año VII, Nº3.

Baik B.K., Czuchajowska Z., Pomeranz Y. 1995. Discoloration of dough for oriental noodles. Cereal Chemistry, 72: 198-205.

Barichelo V., Yada R.I., Coffin R.H., Stanley D.W. 1990. Low temperature sweetening in susceptible and resistant potatoes: starch structure and composition. Journal of Food Science, 55: 1054-1059.

Barkeling B., Granfelt Y., Bjiirck I., Rossner S. 1995. Effects of carbohydrates in the form of pasta and bread on food intake and satiety in man. Nutrition Research, 15: 467-476.

Bejosano F.P., Corke H. 1998. Effect of Amaranthus and buckwheat proteins on wheat dough properties and noodle quality. Cereal Chemistry, 75: 171-176.

Belitz H., Grosch W. 1999. Polysaccharides; en Belitz H, Grosch W. editores, Food Chemistry, second edition. Springer, Germany. Pág. 237-318.

Belitz H., Kieffer R., Seilmeier W., Wieser H. 1986. Structure and function of gluten protein. Cereal Chemistry, 63: 336-341.

Belton P.S. 1999. On the elasticity of wheat gluten. Journal of Cereal Science, 29: 103-107.

Belton P.S. 2005. New approaches to study the molecular basis of the mechanical properties of gluten. Journal of Cereal Science, 41: 203-211.

Belton P.S., Colquhoun I.J., Grant A., Wellner N., Field J.M., Shewry P.R., Tatham A.S. 1995. FTIR and NMR studies of a high-M $M_{r}$ subunit of glutenin. International Journal of Biological Macromolecules, 17: 74-80.

Berganza B.E., Moran A.W., Rodriguez M.G., Coto N.M., Santamaría M., Bressani R. 2003. Effect of variety and location on the total fat, fatty acids and squalene content of amaranth. Plant Foods for Human Nutrition, 58: 1-6.

Berger A., Monnard I., Dionisi F., Gumy D., Hayes K.G., Lambelet P. 2003. Cholesterollowering properties of amaranth flakes, crude and refined oils in hamsters. Food Chemistry, 81: 119-124. 
Berghofer E., y Schoenlechner R. 2002. Grain amaranth; en Belton P. y Taylor J. editores, Pseudocereals and less common cereals. Grain properties and utilization potential. Springer Verlag, Berlin Heidelberg. Alemania. Pág. 219-241.

Bettge A.D., Morris C.F. 2000 Relationships among grain hardness, pentosan fractions and end-use quality of wheat. Cereal Chemistry, 77: 241-247.

Bietz J., Wall J. 1980. Identity of high molecular weight gliadin and ethanol-soluble glutenin subunits of wheat: relation to gluten structure. Cereal Chemistry, 57: 415- 421.

Björck I., Granfeldt Y., Liljeberg H., Tovar J., Asp N.G. 1994. Food properties affecting the digestion and absorption of carbohydrates. The American Journal of Clinical Nutrition, 59(suppl): 699-705.

Bornet F.R.J., Bizais Y., Bruley Des Varannes S., Pouliquen B., Delort-Laval J., Galmiche J.P. 1990. Alpha- amylase (EC 3.2.1.1) susceptibility rather than viscosity or gastric emptying rate controls responses to starch in healthy humans. British Journal of Nutrition, 63: 207-220.

Bornet R., Fontvieille A.M., Rizkalla S., Colonna P., Blayo A., Mercier C., Slama G. 1989. Insulin and glycemic responses in healthy humans to native starches processed in different ways: correlation with in vitro alpha-amylase hydrolysis. The American Journal of Clinical Nutrition, 50: 315-323.

Borrelli G.M., De Leonardis A.M., Fares C., Platani C., Di Fonzo N. 2003. Effects of modified processing conditions on oxidative properties of semolina dough and pasta. Cereal Chemistry, 80: $225-231$.

Bourne M.C. 2002. Texture, Viscosity and Food; en Food Texture and Viscosity: Concept and Measurement. 2nd edition. Academic Press An Elsevier Science Imprint, London, UK. Pág. 1-30.

Brand-Miller J.C., Stockmann K., Atkinson F., Petocz P., Denyer G. 2009. Glycemic index, postprandial glycemia, and the shape of the curve in healthy subjects: analysis of a database of more than 1000 foods. The American Journal of Clinical Nutrition, 89: 97-105.

Brennan C.S., Kuri V., Tudoricâ C.M. 2004. Inulin-enriched pasta: effects on textural properties and starch degradation. Food Chemistry, 86: 189-193. 
Brighenti F., Casiraghi M.C., Baggio C. 1998. Resistant starch in the Italian diet. British Journal of Nutrition, 80: 333-341.

Brody T. 1999. Protein; en Brody T. editor, Nutritional Biochemistry 2nd edition. Academic Press, USA. Pág. 459.

Brunnel C., Pareyt B., Brijs K., Delcour J.A. 2010. The impact of the protein network on the pasting and cooking properties of dry pasta products. Food Chemistry, 120: 371-378.

CAA, Código Alimentario Argentino, Ley 18.284 18/07/69, Decreto 2126/71- Reglamentario de la Ley 18.284. 2009/10a. Alimentos Farináceos - Cereales, Harinas y Derivados. Capítulo IX. http://www.anmat.gov.ar/webanmat/codigoa/CAPITULO_IX_Harinas_actualiz_06-03.pdf http://www.anmat.gov.ar/codigoa, consultado en abril 2010.

CAA, Código Alimentario Argentino, Ley 18.284 18/07/69, Decreto 2126/71- Reglamentario de la Ley 18.284 . 2009/10b. Normas para la rotulación y publicidad de los alimentos, Capitulo V. http://www.anmat.gov.ar/webanmat/codigoa/Capitulo_V_Rotulacion_actualiz\%20200805.pdf, consultado en septiembre 2010.

Calvelo A. 2008. Material del curso Tecnología de elaboración de pastas secas. Universidad Nacional de La Plata. Maestría en tecnología de los alimentos.

Carr N.O., Daniels N.W.R., Frazier P.J. 1992. Lipid interactions in breadmaking. Critical Reviews in Food Science \& Nutrition, 31: 237-258.

Cauvain S., Young L. 2001. Flours; en Cauvain S., Young L. editores, Baking problems solved. Woodhead Publishing Limited and CRC Press LLC. England. Pág. 25.

CFR, Code Federal Regulation. 2010a. Health claims: Soy protein and risk of coronary heart disease (CHD). Sec. 101.82. 21CFR101.82. http://www.accessdata.fda.gov/scripts/cdrh/cfdocs/cfcfr/CFRSearch.cfm?fr=101.82. Consultado en septiembre, 2010.

CFR, Code Federal Regulation. 2010c. Health claims: fiber-containing grain products, fruits, and vegetables and cancer. Sec. 101.76. 21CFR101.76. http://www.accessdata.fda.gov/scripts/cdrh/cfdocs/cfcfr/CFRSearch.cfm?fr=101.76. Consultado en septiembre, 2010. 
CFR, Code Federal Regulation. 2010d. Nutrient content claims for "good source," "high," "more," and "high potency." Sec. 101.54. 21CFR101.54.

http://www.accessdata.fda.gov/scripts/cdrh/cfdocs/cfcfr/CFRSearch.cfm?fr=101.54.

Consultado en septiembre, 2010.

CFR, Code Federal Regulation. 2010e. Nutrition labeling of food. Sec. 101.9. 21CFR101.9.

http://www.accessdata.fda.gov/scripts/cdrh/cfdocs/cfcfr/CFRSearch.cfm?fr=101.9.

Consultado en septiembre, 2010.

CFR, Code of Federal Regulations. 2010b. Reference amounts customarily consumed per eating occasion. Sec. 101.12. 21CFR101.12.

http://www.accessdata.fda.gov/scripts/cdrh/cfdocs/cfcfr/CFRSearch.cfm?fr=101.12.

Consultado en septiembre, 2010.

Cheftel J.C., Cheftel H. 1992. Granos vegetales; en Introducción a la bioquímica y tecnología de los alimentos. 2da edición. Editorial Acribia S.A. España. Vol. I, Cap. II.3, Pág. 101104.

Chillo S., Laverse J., Falcone P.M., Del Nobile M.A. 2008. Quality of spaghetti in base Amaranthus wholemeal flour added with Quinoa, Broad Bean and Chick Pea. Journal of Food Engineering, 84: 101-107.

Chung O.K. 1986. Lipid-protein interactions in wheat flour, dough, gluten, and protein fractions. Cereal Food World, 31: 242-256.

Cornish G.B., Bekes F., Allen H.M., Martin D.J. 2001. Flour proteins linked to quality traits in an Australian doubled haploid wheat population. Australian Journal of Agricultural Research, 52: $1339-1348$.

Courtin C.M., Delcour J.A. 2002. Arabinoxylans and endoxylanases in wheat flour breadmaking. Journal of Cereal Science, 35: 225-243.

Courtin C.M., Roelants A., Delcour J.A. 1999. Fractionation reconstitution experiments provide insight into the role of endoxylanases in bread-making. Journal of Agricultural and Food Chemistry, 47: 1870-1877. 
D’Egidio M.G., Mariani B. M., Nardi S., Novaro P., Cubadda R. 1990. Chemical and technological variables and their relationships: a predictive equation for pasta cooking quality. Cereal Chemistry, 67: 275-281.

De Noni I., Pagani M.A. 2010. Cooking properties and heat damage of dried pasta as influenced by raw material characteristics and processing conditions. Critical Reviews in Food Science and Nutrition, 50: 465-472.

De Zorzi M., Curioni A., Simonato B., Giannattasio M., Pasini G. 2007. Effect of pasta drying temperature on gastrointestinal digestibility and allergenicity of durum wheat proteins. Food Chemistry, 104: 353-363.

Dexter J.E., Kilborn R.H., Morgan B.C., Matsuo R.R. 1983. Grain research laboratory compression tester: instrumental measurement of cooked spaghetti stickiness. Cereal Chemistry, 60: 139-142.

Dexter J.E., Matsuo R.R., Dronzek B.L. 1979. A scanning electron microscopy study of Japanese noodles I. Cereal Chemistry, 56: 202-208.

Dick J.W., Quick J.S. 1983. A modified screening test for rapid estimation of gluten strength in early generation durum wheat breeding lines. Cereal Chemistry, 60: 315-318.

Dick J.W., Youngs V.L. 1988. Evaluation of durum wheat, semolina and pasta in the United States; en Fabriani G. y Lintas C. editores, Durum Wheat Chemistry and Technology. American Association of Cereal Chemists, St. Paul, MN. Pág. 237-248.

Dillard C.J., German J.B. 2000. Review. Phytochemicals: nutraceuticals and human health. Journal of the Science of Food and Agriculture, 80: 1744-1756.

Don C., Lichtendonk W.J., Plijter J.J., Hamer R.J. 2003a. Glutenin macropolymer: a gel formed by particles. Journal of Cereal Science, 37: 1-7.

Don C., Lichtendonk W.J., Plijter J.J., Hamer R.J. 2003b. Understanding the link between GMP and dough: from glutenin particles in flour towards developed dough. Journal of Cereal Science, 38: 157-165.

Don C., Lichtendonk W.J., Plijter J.J., Hamer R.J. 2003c. Glutenin macropolymer is a gel formed by particles: average particle size determines the gel rigidity; en Dickinson E., van Vliet 
T., editores, Food Colloids-Biopolymers and Materials. Royal Society of Chemistry, Cambridge. Pág. 275-281.

Doxastakis G., Zafiriadis I., Irakli M., Marlani H., Tananaki C. 2002. Lupin, soya and triticale addition to wheat flour dough and their effect on rheological properties. Food Chemistry, 77: 219-227.

Edwards N.M., Mulvaney S.J., Scanlon M.G., Dexter J.E. 2003. Role of gluten and its components in determining durum semolina dough viscoelastic properties. Cereal Chemistry, 80: 755-763.

Eliasson A., Gudmundsson M. 1996. Starch: physicochemical and functional aspects; en Eliasson A., editor, Carbohydrates in Food. Marcel Dekker, USA. Pág. 431-503.

Eliasson A., Larsson K. 1993a. Bread; en Eliasson A, Larsson K. Marcel Dekker editores, Cereals in Breadmaking. Marcel Dekker Inc. USA. Pág. 325-363.

Eliasson A., Larsson K. 1993b. A molecular colloidal approach; en Eliasson A., Larson K. editors, Cereals in Breadmaling. Marcel Dekker, USA. Pág. 376.

Eliasson A.C. 2003. Starch structure and bread quality; en Cauvain S.P., editor, Bread making, improving quality. Woodhead Publishing Limited. England. Pág. 148.

Endres J.G. 2001a. Protein quality and human nutrition; en Endres J.G., editor, Soy protein products. Characteristics, nutritional aspects, and utilization. AOCS Press, Champaign, Illinois, USA. Pág. 10- 19.

Endres J.G. 2001b. Health and soy protein; en Endres J.G., editor, Soy protein products. Characteristics, nutritional aspects, and utilization. AOCS Press, Champaign, Illinois, USA. Pág. 20-25.

Endres J.G. 2001c. Uses in food systems; en Endres J.G., editor, Soy protein products. Characteristics, nutritional aspects, and utilization. AOCS Press, Champaign, Illinois, USA. Pág. 26-30.

Englyst K.N., Englyst H.N., Hudson G.J., Cole T.J., Cummings J.H. 1999. Rapidly available glucose in foods: an in vitro measurement that reflects the glycemic response. The American Journal of Clinical Nutrition, 69: 448-454. 
Ewart J.A.D. 1989. Hypothesis for how linear glutenin holds gas in dough. Food Chemistry, 32: $135-150$.

Fardet A., Hoebler C., Baldwin P.M., Bouchet B., Gallant D.J., Barry J.L. 1998. Involvement of the protein network in the in vitro degradation of starch from spaghetti and lasagne: $A$ microscopic and enzymic study. Journal of Cereal Science, 27: 133-145.

Figari A.C., Iturrizaga Atkins S., Nystrom J., Salas Ballester R. 2001. Seminario de Agronegocios, fideos enriquecidos con Kiwicha. Universidad del Pacífico, Facultad de Administración y Contabilidad. http://www.upbusiness.net/Upbusiness/docs/mercados/9.pdf, consultado en Julio, 2010.

Ford E.S., Liu S. 2001. Glycemic index and serum high-density lipoprotein cholesterol concentration among US adults. Archives of Internal Medicine, 161: 572-576.

Fortini S. 1988. Some specific aspects of durum wheat and pasta cooking quality evaluation in Europe; en Fabriani G. y Lintas C. editors, Durum Wheat Chemistry and Technology. American Association of Cereal Chemists, St. Paul, MN. USA. Pág. 231-232.

Friedman M., Brandon D.L. 2001. Nutritional and health benefits of soy proteins. Journal of Agricultural and Food Chemistry, 49: 1069-1086.

Fu B.X. 2008. Asian noodles: History, classification, raw materials, and processing. Food Research International, 41: 888-902.

Fu B.X., Assefaw, E.G., Sarkar A.K., Carson G.R. 2006. Evaluation of durum wheat fine flour for alkaline noodles processing. Cereal Foods World, 51: 178-183.

Fuerst E.P., Anderson J.V., Morris G.F. 2006. Delineating the role of polyphenol oxidase in the darkening of alkaline wheat noodles. Journal of Agricultural and Food Chemistry, 54: 23782384.

Funami T., Kataoka Y., Omoto T., Goto Y., Asai I., Nishinari K. 2005. Effects of non-ionic polysaccharides on the gelatinization and retrogradation behavior of wheat starch. Food Hydrocolloids, 19: 1-13.

Fundación Chile. 2005. Área Agroindustria. Una nueva versión para el sector triguero en Chile.http://ww2.fundacionchile.cl/portal/c/document_library/get_file?p_I_id=10504\&folderl d=12883\&name=DLFE-939.pdf; consultado en junio de 2010. 
Giacco R., Brighenti F., Parillo M., Capuano M., Ciardullo A.V., Rivieccio A., Rivellese A.A., Riccardi G. 2001. Characteristics of some wheat-based foods of the Italian diet in relation to their influence on postprandial glucose metabolism in patients with type 2 diabetes. British Journal of Nutrition, 85: 33-40.

Gnagnarella P., Gandini S., La Vecchi C., Maisonneuve P. 2008. Glycemic index, glycemic load, and cancer risk: a meta-analysis. The American Journal of Clinical Nutrition, 87: 17931801.

Goesaert H., Brijs K., Veraverbeke W.S., Courtin C.M., Gebruers K., Delcour J.A. 2005. Wheat flour constituents: how they impact bread quality, and how to impact their functionality. Trends in Food Science \& Technology, 16: 12-30.

Gómez Pallarés M., León A.E., Rosell C.M. 2007. Trigo; en León A.E., Rosell C.M., editores, De tales harinas, tales panes. Granos, harinas y productos de panificación en Iberoamérica. 1ra Edición. Hugo Baéz editor. Córdoba, Argentina. Pág. 19-33.

Goñi I., Garcia-Alonso A., Saura-Calixto F. 1997. A starch hydrolysis procedure to estimate glycemic index. Nutrition Research, 17: 427-437.

Grant L.A., Dick J.W., Shelton D.R. 1993. Effects of drying temperature, starch damage, sprouting, and additives on spaghetti quality characteristics. Cereal Chemistry, 70: 676-684.

Greenwood C. 1976. Starch; en Pomeranz Y. editor, Advances in Cereal Science and Technology, Vol. 1. American Association of Cereal Chemists. USA. Pág. 119-157.

Grosch W., Wieser H. 1999. Redox reactions in wheat dough as affected by ascorbic acid. Journal of Cereal Science, 29: 1-16.

Gunaratne A., Corke H. 2007. Gelatinizing, pasting, and gelling properties of potato and amaranth starch mixtures. Cereal Chemistry, 84: 22-29.

Gupta R.B., Paul J.G., Cornish G.B., Palmer G.A., Bekes F., Rathjen A.J. 1994. Allelic variation at glutenin subunit and gliadin loci, Glu-1, Glu-3 and Gli-1, of common wheats. I. Its additive and interaction effects on dough properties. Journal of Cereal Science, 19: 9-17.

Gupta R.B., Singh N.K., Shepherd K.W. 1989. The cumulative effect of allelic variation in LMW and HMW glutenin subunits on dough properties in the progeny of two bread wheats. Theoretical and Applied Genetics, 77: 57-64. 
Hamaker B.R., Kirleis A.W., Butler L.G., Axtell J.D., Mertz E.T. 1987. Improving the in vitro protein digestibility of sorghum with reducing agents. Proceedings of the National Academy of Sciences of the United States of America, 84: 626-628.

Hamer R.J., van Vliet T. 2000. Understanding the structure and properties of gluten: an overview; en Shewry P.R., Tatham A.S. editores, Wheat Gluten-Proceedings of the 7th International Workshop Gluten, Royal Society of Chemistry, Cambridge. Pág. 125-131.

Haralampu S.G. 2000. Resistant starch-a review of the physical properties and biological impact of RS3. Carbohydrate Polymers, 41: 285-292.

Hareland G.A., Puhr D., Wear J.G., Skunberg M. 1995. Color score: United States Department of Agriculture, agricultural research service in cooperation with the ND state agricultural experiment stations, quality evaluation of durum wheat cultivars. http://wheat.pw.usda.gov/ggpages/gopher/Quality/Durum/1995/95durum.txt.html

Harland J.I. 2001. Proceedings of 4th International symposium on the role of soy in preventing and treating chronic disease, San Diego, California, USA.

Hatcher D.W. 2001. Asian noodle processing; en Owens G., editors, Cereals processing technology. 1ra Edición. Woodhead Publishing Limited, Inglaterra. Cap. 7, Pág. 1.

Hatcher D.W., Anderson M.J., Desjardins R.G., Edwards N.M., Dexter J.E. 2002. Effects of flour particle size and starch damage on processing and quality of white salted noodles. Cereal Chemistry, 79: 64-71.

Hatcher D.W., Kruger J.E. 1993. Distribution of polyphenol oxidase in flour millstreams of Canadian common wheat classes milled to three extraction rates. Cereal Chemistry, 70: 51-55.

Hatcher D.W., Symons S.J., Kruger J.E. 1999. Measurement of the time dependent appearance of discolored spots in alkaline noodles by image analysis. Cereal Chemistry, 76: 189-194.

He H., Cai Y., Sun M., Corke H. 2002. Extraction and purification of Squalene from Amaranthus grain. Journal of Agricultural and Food Chemistry, 50: 368-372.

Heneen W.K., Brismar K. 2003. Structure of cooked spaghetti of durum and bread wheats. Starch, 55: 546-557. 
Heneman K.M., Chang H.C., Prior R.L., Steinberg F.M. 2007. Soy protein with and without isoflavones fails to substantially increase postprandial antioxidant capacity. Journal of Nutritional Biochemistry, 18: 46- 53.

Hoseney R.C. 1994a. Pasta and noodles; en Hoseney C. editor, Principles of Cereal Science and Technology, Second Edition. American Association of Cereal Chemists, USA. Pág. 321-334.

Hoseney R.C. 1994b. Gluten proteins; en Hoseney C. editor, Principles of Cereal Science and Technology, Second Edition. American Association of Cereal Chemists, USA. Pág. 197-211.

Hoseney RC. 1994c. Dry milling of cereal; en Hoseney C. editor, Principles of Cereal Science and Technology, Second Edition. American Association of Cereal Chemists, USA. Pág. 125-145.

HP Product Note. 1993. Peak purity analysis in HPLC and CE using diode-array technology. Publication Number 12-5091-7502E. Hewlett-Packard Company. Alemania.

Hsu H.W., Vavak D.L., Satterlee L.D., Miller G.A. 1977. A multienzyme technique for estimating protein digestibility. Journal of Food Science, 42: 1269-1273.

Humphries J.M., Graham R.D., Mares D.J. 2004. Application of reflectance colour measurement to the estimation of carotene and lutein content in wheat and triticale. Journal of Cereal Science, 40: 151-159.

Humphris A.D.L, McMaster T.J., Miles M.J., Gilbert S.M., Shewry P.R., Tatham A.S. 2000. Atomic force microscopy (AFM) study of interaction of HMW subunits of wheat glutenin. Cereal Chemistry, 77: 107-110.

Imhof M., Molzer S., Imhof M. 2008. Effects of soy isoflavones on 17b-estradiol-induced proliferation of MCF-7 breast cancer cells. Toxicology in Vitro, 22: 1452-1460.

Inouchi N., Nishi K., Tanaka S., Asai M., Kawase Y., Hata Y., Konishi Y., Yue S., Fuwa H. 1999. Characterization of Amaranth and Quinoa starches. Journal of Applied Glycoscience, 46: 233240.

ISO, International Organization for Standarization, 4121:1987. Sensory analysis -Methodology evaluation of food products by methods using scales.

Jackson E.A., Holt L.M., Payne P.I. 1983. Characterisation of high molecular weight gliadin and low-molecular-weight glutenin subunits of wheat endosperm by two dimensional 
electrophoresis and the chromosomal localization of their controlling genes. Theoretical and Applied Genetics, 66: 29-37.

Jeffrey G.A., Saenger W. 1994. Hydrogen Bonding in Biological Structures, Springer-Verlag, Berlin.

Jenkins D.J., Kendall C.W., Augustin L.S., Franceschi S., Hamidi M., Marchie A., Jenkins A.L., Axelsen M. 2002. Glycemic index: overview of implications in health and disease. The American Journal of Clinical Nutrition, 76(suppl): 266-273.

Jenkins D.J., Wolever T.M., Buckley G., Lam K.Y., Giudici S., Kalmusky J., Jenkins A.L., Patten R.L., Bird J., Wong G.S. 1988. Low-glycemic-index starchy foods in the diabetic diet. The American Journal of Clinical Nutrition, 48: 248-254.

Jenkins D.J., Wolever T.M., Kalmusky J., Guidici S., Giordano C., Patten R., Wong G.S., Bird J.N., Hall M., Buckley G. 1987. Low-glycemic index diet in hyperlipidemia: use of traditional starchy foods. The American Journal of Clinical Nutrition, 46: $66-71$.

Jenkins D.J., Wolever T.M., Taylor R.H., Barker H., Fielden H., Baldwin J.M., Bowling A.C., Newman H.C., Jenkins A.L., Goff D.V. 1981. Glycemic index of foods: a physiological basis for carbohydrate exchange. The American Journal of Clinical Nutrition, 34: 362-366.

Jenkins D.J.A., Wolever T.M.S., Jenkins A.L. 1999. Fiber and other dietary factors affecting nutrient absorption and metabolism; en Shils M.E., Olson J.A., Shike M., Ross A.C. editores, Modern Nutrition in Health and Disease, 9th edition. Lippincott, Williams \& Wilkins, USA. Chapter 43.

Johnston P.K. 1999. Nutritional Implications of vegetarian diets; en Shils M.E., Olson J.A., Shike M., Ross A.C. editores, Modern Nutrition in Health and Disease, 9th edition. Lippincott, Williams \& Wilkins, USA. Chapter 106.

Kasarda D.D. 1989. Glutenin structure in relation to wheat quality; en Pomeranz Y. editor, Wheat is Unique. American Association of Cereal Chemist, St Paul, MN. USA. Pág. 277-302.

Kasarda D.D. 1999. Glutenin polymers: the in vitro to in vivo transition. Cereal Food World, 44: 566-571. 
Kasarda D.D., Bernardin J., Nimmo C. 1976. Wheat proteins; en Advances in Cereal Science and Technology, Vol. 1. Ed. Pomeranz Y, American Association of Cereal Chemists. USA. Pág. 158-236.

Khatkar B.S., Fido R.J., Tatham A.S., Schofield J.D. 2002. Functional properties of wheat gliadins. II. Effects on dynamic rheological properties of wheat gluten. Journal of Cereal Science, 35: 307- 313.

Kim E.H.J., Petrie J.R., Motoi L., Morgenstern M.P., Sutton K.H., Mishra S., Simmons L.D. 2008. Effect of structural and physicochemical characteristics of the protein matrix in pasta on in vitro starch digestibility. Food Biophysics, 3: 229-234.

Kim S.K., D'Appolonia B.L. 1977a. Bread staling studies. III. Effect of pentosans on dough, bread and bread staling rate. Cereal Chemistry, 54: 225-229.

Kim W., Seib P.A., Chung, O.K. 1991. Origin of color in vital wheat gluten. Cereal Foods World, 36: 954-959.

Kok L., Kreijkamp-Kaspers S., Grobbee D.E., Lampe J.W., van der Schouw Y.T. 2005. Soy isoflavones, body composition, and physical performance. Maturitas, 52: 102-110.

Kovacs M.I.P., Poste L.M., Butler G., Woods S.M., Leisle D., Noll J.S., Dahlke G. 1997. Durum wheat quality: Comparison of chemical and rheological screening tests with sensory analysis. Journal of Cereal Science, 25: 65-75.

Krueger B.R., Knutson C.A., Inglett G.E., Walker C.E. 1987. A differential scanning calorimetry study on the effects of annealing on gelatinization behavior of corn starch. Journal of Food Science, 52: 715-718.

La Pasta. Un alimento básico de la dieta mediterránea. 2003. Cereales y Derivados. Consumer.es Erosky. (http://www.consumer.es/web/es/alimentacion/aprender_a_comer_bien/guia_alimentos/cer eales_y_derivados/2003/08/01/63875.php), consultado en diciembre 2009.

Laemmli U. 1970. Cleavage of structural proteins during the assembly of the head of bacteriophage T4. Nature, 227: 680-684. 
Larroque O., Gianibelli M., Gómez Sánchez M., MacRitchie F. 2000. Procedure for obtaining stable extracts of cereal flour and whole meal for size-exclusion HPLC analysis. Cereal Chemistry, 77: 448-450.

Lee M.R., Swanson B.G., Baik B.K. 2001. Influence of amylose content on properties of wheat starch and breadmaking quality of starch and gluten blends. Cereal Chemistry, 78:701706.

León-Camacho M., García-González D.L., Aparicio R. 2001. A detailed and comprehensive study of Amaranth (Amaranthus cruentus L.) Oil Fatty Profile. European Food Research and Technology, 213: 349-355.

Levis S., Strickman-Stein N., Doerge D.R., Krischer J. 2010. Design and baseline characteristics of the Soy phytoestrogens as replacement estrogen (SPARE) study - A clinical trial of the effects of soy isoflavones in menopausal women. Contemporary Clinical Trials, 31: 293-302.

Lezcano E. 2009. Pastas Alimenticias. Cadenas Alimentarias. Alimentos Argentinos, 46: 2028.

Limroongreungrata K., Huang Y.W. 2007. Pasta products made from sweetpotato fortified with soy protein. LWT- Food Science and Technology, 40: 200-206.

Lindahl L. 1990. Rheologycal properties in wheat flour systems. Molecular and interfacial basis. Thesis Doctoral. Lund University, Sweden.

Lindsay M.P., Skerritt J.H. 1999. The glutenin macropolymer of wheat flour dough: structure - function perspectives. Trends in Food Science and Technology, 10: 247-253.

Lindsay M.P., Skerritt J.H. 2000. Immunocytochemical localization of gluten proteins uncovers structural organization of glutenin macropolymer. Cereal Chemistry, 77: 360-369.

Liu J., Ho S.C., Su Y.X., Chen W.G., Zhang C.X., Chen Y.M. 2009. Effect of long-term intervention of soy isoflavones on bone mineral density in women: A meta-analysis of randomized controlled trials. Bone, 44: 948-953.

MacDonald R.S., Guo J.Y., Copeland J., Browning J.D., Sleper D., Rottinghaus G.E., Berhow M.A. 2005. Environmental influences on isoflavones and saponins in soybeans and their role in colon cancer. Journal of Nutrition, 135: 1239-1242. 
Malcolmson L.J., Matsuo R.R. 1993. Effects of cooking water composition on stickiness and cooking loss of spaghetti. Cereal Chemistry, 70: 272-275.

Malcomson, L.J., Matsuo R.R., Balshaw R. 1993. Textural optimization of spaghetti using response surface methodology: effects of drying temperature and durum protein level. Cereal Chemistry, 70: 417-423.

Marchylo B.A., Dexter J.E. 2001. Pasta production; en Owens G., editor. Cereals Processing Technology. 1ra Edición. Woodhead Publishing Limited, Inglaterra. Cap. 6, Pág. 1-3.

Marchylo B.A., Dexter J.E., Malcolmson L.J. 2004. Improving the texture of pasta; en Kilcast D. editor, Texture in food, Volume 2: Solid foods. Woodhead Publishing Ltd and CRC Press LLC.CRC Press Boca Raton Boston New York Washington, DC. Cap. 20.

Marcone M.F., KakudaY., Yada R.Y. 2004. Amaranth as a rich dietary source of $\beta$-sitosterol and other phytosterols. Plant Foods for Human Nutrition, 58: 207-211.

Marconi E., Carcea M. 2001. Pasta from non-traditional raw materials. Cereal Foods World, 46: $522-530$.

Mariotti M., Lucisano M., Ambrogina Pagani M., Ng P.K.W. 2009. The role of corn starch, amaranth flour, pea isolate, and psyllium flour on the rheological properties and the ultrastructure of gluten-free dough. Food Research International, 42: 963-975.

Martirosyan D.M., Miroshnichenko L.A., Kulakova S.N., Pogojeva A.V., Zoloedov V.I. 2007. Amaranth oil application for coronary heart disease and hypertension. Lipids in Health and Disease, 6: 1-12.

Matsuo R.R., Dexter J.E., Boudreau A., Daun J.E. 1986. The role of lipids in determining e spaghetti cooking quality. Cereal Chemistry, 63: 484-489.

Matsuo R.R., Dexter J.E., Dronzek B.L. 1978. Scanning electron microscopy study of spaghetti processing. Cereal Chemistry, 55: 744-753.

Matsuo R.R., Dexter J.E., MacGregor A.W. 1982. Effect of sprout damage on durum wheat and spaghetti quality. Cereal Chemistry, 59: 468-472.

Matz S. 1999. Ingredients from wheat; en Matz S. editor, Bakery Technology and Engineering, 3o Edition. Pan-Tech International, USA. Pág. 1-21. 
Mendonça S., Saldiva P.H., Cruz R.J., Arêas J.A.G. 2009. Amaranth protein presents cholesterol-lowering effect. Food Chemistry, 116: 738-742.

Messina M., Gugger E.T., Alekel D.L. 2001. Isoflavones, and bone health: a review of the animal and human data; en Wildman R.E.C editor, Handbook of Nutraceuticals and Functional Foods. CRC Press LLC, USA. Cap. 5.

Metakovskii E.V., Wrigley C.W., Bekes F., Gupta R.B. 1990. Gluten polypeptides as useful genetic markers of dough quality in Australian wheats. Australian Journal of Agricultural Research, 41: 289-306.

Meuser F., Suckow P. 1986. Chemistry and physics of baking. Ed. Blanshard MV, Frazier PJ, Galliard T. The Royal Society of Chemistry, London. Pág. 42-61.

Moiraghi M., Ribotta P.D., Aguirre A., Perez G.T., León A.E. 2005. Análisis de la aptitud de trigos pan para la elaboración de galletitas y bizcochuelos. Agriscientia, XXII, 2: 47-54.

Morrison W.R., Law R.V., Snape C.E. 1993. Evidence for inclusion complexes of lipids with V-amylose in maize, rice and oat starches. Journal of Cereal Science, 18: 107-109.

Nagata Y., Sonoda T., Mori M., Miyanaga N., Okumura K., Goto K., Naito S., Fujimoto K., Hirao Y., Takahashi A., Tsukamoto T., Akaza H. 2007. Dietary isoflavones may protect against prostate cancer in Japanese men. Journal of Nutrition, 137: 1974-1979.

Ng P., Bushuk W. 1987. Glutenin of marquish wheat as a reference for estimating molecular weights of glutenin subunits by sodium sulfate-polyacrylamide gel electrophoresis. Cereal Chemistry, 64: 324-327.

Ng P., Xu C., Bushuk W. 1991. Model of glutenin structure based on farinograph and electrophoretic results. Cereal Chemistry, 68: 231-235.

Nur Herken E., İbanoğlu Ș., Öner M.D., İbanoğlu E. 2006. The in vitro protein digestibility, microbiological quality and gelatinization behaviour of macaroni as affected by cowpea flour addition. Food Chemistry, 98: 664-669.

Oda M., Yasuda Y., Okazaki S., Yamauchi S., Yokohama Y. 1980. A method of flour quality assessment for Japanese noodles. Cereal Chemistry, 57: 253-254. 
Oh N.H., Seib P.A., Deyoe C.W., Ward A.B. 1983. Noodles I. Measuring the textural characteristics of cooked noodles. Cereal Chemistry, 60: 433-438.

Oh N.H., Seib P.A., Ward A.B., Deyoe C.W. 1985. Noodles IV. Influence of flour protein, extraction rate, particle size, and starch damage on the quality characteristics of dry noodles. Cereal Chemistry, 62: 441-446.

Ohm J.B., Ross A.S., Peterson C.J., Ong Y.L. 2008. Relationships of high molecular weight glutenin subunit composition and molecular weight distribution of wheat flour protein with water absorption and color characteristics of noodle dough. Cereal Chemistry, 85: 123-131.

Osborne T. 1907. Proteins of the wheat kernel. Publication of the Carnegie Institution Washington, 84: 1-119.

Ovando-Martinez M., Sáyago-Ayerdi S., Agama-Acevedo E., Goñi I., Bello-Pérez L.A. 2009. Unripe banana flour as an ingredient to increase the undigestible carbohydrates of pasta. Food Chemistry, 113: 121-126.

Pagani M.A., Gallant D.J., Bouchet B., Resmini P. 1986. Ultrastructure of cooked spaghetti. Food Microstructure, 5: 111-129.

Park C.S., Baik B.K. 2002. Flour characteristics related to optimum water absorption of noodle dough for making white salted noodles. Cereal Chemistry, 79: 867-873.

Park C.S., Baik B.K. 2004. Cooking time of white salted noodles and its relationship with protein and amylose contents of wheat. Cereal Chemistry, 81: 165-171.

Patisaul H.B., Jefferson W. 2010. The pros and cons of phytoestrogens. Front. Neuroendocrinol. doi:10.1016/j.yfrne.2010.03.003.

Payne P.I., Corfield K.G. 1979. Subunit composition of wheat glutenin proteins, isolated by gel filtration in a dissociating medium. Planta, 145: 83-88.

Payne P.I., Nightingale M.A., Krattiger A.F., Holt L.M. 1987. The relationship between HMW glutenin subunit composition and the bread-making quality in British-grown wheat varieties. Journal of Food Science and Agriculture, 40: 51-65. 
Petitot M., Abecassis J., Micard V. 2009a. Structuring of pasta components during processing: impact on starch and protein digestibility and allergenicity. Trends in Food Science \& Technology, 20: 521-532.

Petitot M., Brossard C., Barron C., Larré C., Morel M.H., Micard V. 2009b. Modification of pasta structure induced by high drying temperatures. Effects on the in vitro digestibility of protein and starch fractions and the potential allergenicity of protein hydrolysates. Food Chemistry, 116: 401-412.

Pezolet M., Bononfant S., Dousseau F., Popineau Y. 1992. Conformation of wheat gluten proteins. Comparison between functional and solution states as determined by infrared spectroscopy. Federation of European Biochemical Societies Letters, 299: 247-250.

Plate A.Y.A., Areas J.A.G. 2002. Cholesterol-lowering effect of extruded Amaranth (Amaranthus caudatus L.) in hypercholesterolemic rabbits. Food Chemistry, 76: 1-6.

Plucknett D.L., Blasé M.G., Campbell T.A., Feine L., Flores Merino H.E., et al. 1984. Grain Amaranths; en Ruskin F.R. editor, Amaranth modern prospects for ancient crop. National Academy Press, Washington DC. Pág. 27-38.

Pogna N., Redaelli R., Dachkevitch A., Dal Belin Peruffo A. 1994. Genetics of wheat quality and its improvement by conventional and biotechnological breeding; en Bushuk W., Rasper V., editores, Wheat Production, Properties and Quality. Chapman Hall. USA. Pág. 205-224.

Pogojeva A.V., Gono K.V., Kulakova S.N., Miroshnichenko L.A., Martirosyan D.M. 2006. Effect of amaranth oil on lipid profile of patients with cardiovascular diseases; en Martirosyan D.M. editor, Functional Foods for Chronic Diseases. The modern day cure without the side effects of traditional treatments. D\&A Inc. USA. Pág. 35.

Popineau Y., Bonenfant S., Cornec M., Pezolet M. 1994. A study by infrared spectroscopy of the conformations of gluten proteins differing in their gliadin and glutenin composition. Journal of Cereal Science, 20: 15-20.

Professional Pasta. General comment on pasta investigations into drying pasta. L1N06P044. www.professionalpasta.it, consultado en marzo de 2008. 
Puppo M.C., Gularte M.A., Pérez G., Ribotta P., Añón M.C. 2006. Soja; en León A.E., Rosell C.M., editores, De tales harinas, tales panes. Granos, harinas y productos de panificación en Iberoamérica. 1ra Edición. Hugo Baéz. Córdoba, Argentina. Pág. 322-354.

Qureshi A.A., Lehmann J.W., Peterson D.M. 1996. Amaranth and its oil inhibit cholesterol biosynthesis in 6 week old female chickens. The Journal of Nutrition, 126: 1972-1978.

Rahman S., Bird A., Regina A., Li Z., Ral J.P., McMaugh S., Topping D., Morell M. 2007. Resistant starch in cereals: exploiting genetic engineering and genetic variation. Journal of Cereal Science, 46: 251-260.

Ramírez Navas J.S. 2006. Fundamentos de la Reología en Alimentos. Ed. JSR e-books. Colombia. Pág. 5.

Rao C.V., Newmark H.L., Reddy B.S. 1998. Chemopreventive effect of squalene on colon cáncer. Carcinogenesis, 19: 287-290.

Rao V.K., Mulvanney S.J., Dexter J.E., Edwards N.M., Peressini D.J. 2001. Stress-relaxation properties of mixograph semolina-water doughs from durum wheat cultivars of variable strength in relation to mixing characteristics, bread- and pasta-making performance. Journal of Cereal Science, 34: 215- 232.

Rayas-Duarte P., Mock C.M., Satterlee L.D. 1996. Quality pf spaghetti containing Buckwheat, Amaranth, and Lupin flours. Cereal Chemistry, 73: 381-387.

Reed G., Thorn J.A. 1971. Enzymes; en Pomeranz Y. editor, Wheat: Chemistry and Technology. Vol. III. American Association of Cereal Chemistry. St. Paul, MN. USA. Pág. 453.

Repo-Carrasco-V R., Cortez G., Montes R.O., Quispe Villalpando L., Ramos I. 2006. Cultivos Andinos; en León A.E., Rosell C.M., editores, De tales harinas, tales panes. Granos, harinas y productos de panificación en Iberoamérica. 1ra Edición. Hugo Baéz. Córdoba, Argentina. Pág. 255.

Ribotta P.D., Arnulphi S.A., León A.E., Añón M.C. 2005a. Effect of soybean addition on the rheological properties and breadmaking quality of wheat flour. Journal of the Science of Food and Agriculture, 85: 1889-1896. 
Ribotta P.D., León A.E., Aguirre A.V., Beltramo D.M. 2002. Medición instrumental del color en galletitas dulces de triticale: influencia del contenido de cenizas. Información Tecnológica, 13: $171-174$.

Ribotta P.D., León A.E., Pérez G.T., Añón M.C. 2005b. Electrophoresis studies for determining wheat-soy protein interactions in dough and bread. European Food Research and Technology, 221: 48-53.

Rimbach G., Boesch-Saadatmandi C., Frank J., Fuchs D., Wenzel U., Daniel H., Hall W.L., Weinberg P.D. 2008. Dietary isoflavones in the prevention of cardiovascular disease - A molecular perspective. Food and Chemical Toxicology, 46: 1308-1319.

Riva M., Fessas D., Schiraldi A. 2000. Starch retrogradation in cooked pasta and rice. Cereal Chemistry, 77: 433-438.

Rodriguez Sandoval E., Fernandez Quintero A., Ayala Aponte A. 2005. Modelos reológicos aplicados a masas de trigo y maíz. Ingeniería e Investigación, 58: 87-93.

Roesler K.R., Rao A.G. 2001. Rapid gastric fluid digestion and biochemical characterization of engineered proteins enriched in essential amino acids. Journal of Agricultural and Food Chemistry, 49: 3443-3451.

Ross A.S. 2006. Instrumental measurement of physical properties of cooked Asian wheat flour noodles. Cereal Chemistry, 83: 42-51.

Ross A.S., Quail K.J., Crosbie G.B. 1997. Physicochemical properties of Australian flours influencing the texture of yellow alkaline noodles. Cereal Chemistry, 78: 814-820.

Ryan K.J., Homco-Ryan C.L., Jenson J., Robbins K.L., Prestat C., Brewer M.S. 2002. Lipid extraction process on texturized soy flour and wheat gluten protein-protein interactions in a dough matrix. Cereal Chemistry, 79: 434-438.

Sandstedt R. 1961. The function of starch in the baking of bread. The Bakers Digest, 35: 3641.

Schakel S., Schauer R., Himes J., Harnack L., Van Heel N. 2008. Development of a glycemic index database for dietary assessment. Journal of Food Composition and Analysis, 21: S50-S55. 
Schofield J.D., Bottomley R.C., Timms M.F., Booth M.R. 1983. The effect of heat on wheat gluten and the involvement of sulphydryl-disulphide interchange reactions. Journal of Cereal Science, 1: 241-253.

Setchell K.D.R., Cassidy A. 1999. Dietary isoflavones: biological effects and relevance to human health. Journal of Nutrition, 129: 758S-767S.

Shewry P.R., Halford N.G., Tatham A.S. 1992. High molecular weight subunits of wheat glutenin. Journal of Cereal Science, 15: 105-120.

Shewry P.R., Halford N.G., Tatham A.S., Popineau Y., Lafiandra D., Belton P.S. 2003. The high molecular weight subunits of wheat glutenin and their role in determining wheat processing properties. Advances in Food and Nutritional Research, 45: 219- 301.

Shewry P.R., Popineau Y., Lafiandra D., Belton P. 2001. Wheat glutenin subunits and dough elasticity: findings of the Eurowheat Project. Trend in Food Science \& Technology, 11: 433-441.

Shewry P.R., Tatham A.S. 1990. The prolamin storage proteins of cereal seeds: structure and evolution. Biochemical Journal, 267: 1-12.

Shewry P.R., Tatham A.S. 1997. Disulphide bonds in wheat gluten proteins. Journal of Cereal Science, 25: 207-227.

Shewry P.R., Tatham A.S., Forde J., Kreis M., Miflin B.J. 1986. The classification and nomenclature of wheat gluten proteins: A reassessment. Journal of Cereal Science, 4: 97-106.

Shibanuma K., Takeda Y., Hizukuri S., Shibata S. 1994. Molecular structures of some wheat starches. Carbohydrate Polymers, 25: 111-116.

Shogren R.L., Hareland G.A., Wu Y.V. 2006. Sensory evaluation and composition of spaghetti fortified with soy flour. Journal of Food Science, 71: 428-432.

Singh N., Shepherd K., Langridge P., Gruen L. 1991. Purification and biochemical characterization of triticin, a legume-like protein in wheat endosperm. Journal of Cereal Science, 13: 207-220.

Sissons M.J., Egan N.E., Gianibelli M.C. 2005. New insights into the role of gluten on durum pasta quality using reconstitution method. Cereal Chemistry, 82: 601-608. 
Soh H.N., Sissons M.J., Turner M.A. 2006. Effect of starch granule size distribution and elevated amylose content on durum dough rheology and spaghetti cooking quality. Cereal Chemistry, 83: 513-519.

Solah V.A., Crosbie G.B., Huang S., Quail K., Sy N., Limley H.A. 2007. Measurement of color, gloss, and translucency of white salted noodles: effects of water addition and vacuum mixing. Cereal Chemistry, 84: 145-151.

Sorrivas V., Yánez J.V. 2006. Apuntes de Microscopía Electrónica de Barrido (SEM). CRIBABB - CONICET. Bahía Blanca.

SSI-AP-LC-0213. Shimadzu Application Note. Assessing HPLC Peak Purity with Shimadzu Photodiode Detector SPD-M10Avp. Shimadzu. Columbia, USA.

Stable Micro Systems. 1995. TA-TX2 Application Study. Comparison of pasta stickiness cooked in hard and soft water. REF: PTA4/PFS. Stable Micro Systems LTD.

Steiner C., Peters W.H.M., Gallagher E.P., Magee P., Rowland I., Pool-Zobel B.L. 2007. Genistein protects human mammary epithelial cells from benzo(a)pyrene-7,8-dihydrodiol9,10-epoxide and 4-hydroxy-2-nonenal genotoxicity by modulating the glutathione/glutathione S-transferase system. Carcinogenesis, 28: 738-748.

Stevenson D.G., Jane J., George E. Inglett G.E. 2007. Structures and physicochemical properties of starch from immature seeds of soybean varieties (Glycine max (L.) Merr.) exhibiting normal, low-linolenic or low- saturated fatty acid oil profiles at maturity. Carbohydrate Polymers, 70: 149-159.

Sung W.C., Stone M. 2005. Microstructural studies of pasta and starch pasta. Journal of Marine Science and Technology, 13: 83-88.

Svensson B., Fukuda K., Nielsen P.K., Bønsager B.C. 2004. Proteinaceous a-amylase inhibitors. Biochimica et Biophysica Acta, 1696: 145-156.

Szczesniak A. S. 1963. Classification of textural characteristics. Journal of Food Science, 28: 385-389.

Tang C., Hsieh F., Heymann H., Huff H.E. 1999. Analyzing and correlating instrumental and sensory data: a multivariate study of physical properties of cooked wheat noodles. Journal of Food Quality, 22: 193-211. 
Tatham A.S. 1995. The structures of wheat protein; en Schofield editor, Wheat Structure. Biochemistry and Funccionality. Journal Royal society of Chemistry, England. Pág. 53-63.

Tatham A.S., Field J.M., Smith S.J., Shewry P.R. 1987. The conformations of wheat gluten proteins. II. Aggregated gliadins and low molecular subunits of glutenin. Journal of Cereal Science, 5: 203-214.

Tatham A.S., Shewry P.R. 1985. The conformation of wheat gluten proteins. The secondary structures and thermal stabilities of $\alpha-, \beta-, \gamma$ and $\omega$-gliadins. Journal of Cereal Science, 3: 104113.

The Oxford encyclopedia of ancient Egypt ISBN 0-19-510234-7. http://es.wikipedia.org/wiki/Archivo:Ramses_III_bakery.jpg\#filehistory, consultado en junio de 2010.

Thermo Fisher Scientific Inc.@. 2009. TR15103/1530-500, Fisher Diagnostics a division of Fisher Scientific Company. Middletown, VA 22645-1905 USA.

Thomson N.H., Miles M.J., Popineau Y., Harries J., Shewry P.R., Tatham A.S. 1999. Small angle $\mathrm{X}$-ray scattering of wheat seed storage proteins: $\alpha-, \nu^{-}$, and $\omega$-gliadins and the high molecular weight (HMW) subunits of glutenin. Biochimica et Biophysica Acta, 1430: 359-366.

Tudoricâ C.M., Kuri V., Brennan C.S. 2002. Nutritional and physicochemical characteristics of dietary fiber enriched pasta. Journal of Agricultural and Food Chemistry, 50: 347-356.

van Oort M., van Straaten F., Laane C. 1995. Pentosans and pentosanases in bread-making. International Food Ingredients, 2: 23-27.

Veraverbeke W.S., Delcour J.A. 2002. Wheat protein composition and properties of wheat glutenin in relation to breadmaking functionality. CRC Critical Reviews in Food Science and Nutrition, 42: 179-208.

Vidal-Escales E., Borrós S. 2004. New methodology to follow the evolution of squalene byproducts during model compound vulcanization studies. Talanta, 62: 539-547.

Vignaux N., Doehlert D.C., Elias E.M., McMullen M.S., Grant L.A., Kianian S.F. 2005. Quality of spaghetti made from full and partial waxy durum wheat. Cereal Chemistry, 82: 93-100. 
Vincent A., Fitzpatrick L. 2000. Soy isoflavones: are they useful in menopause? Mayo Clinic Proceedings, 75: 1174-1184.

Wang C., Kovacs M.I.P., Fowler D.B., Holley R. 2004. Effects of protein content and composition on white noodle making quality: color. Cereal Chemistry, 81: 777-784.

Waterborg J.H. 2009. The Lowry method for protein quantitation; en Walker J.M., editor. The protein protocols handbook I. Springer Protocols Handbooks. Humana Press Inc. USA. Pág. 7-10.

Weegels P.L., Hamer R.J, Schofield J.D. 1997a. Depolymerisation and repolymerisation of wheat glutenin during dough processing II. Changes in composition. Journal of Cereal Science, 25: $155-163$.

Weegels P.L., Hamer R.J., Schofield J.D. 1996b. Functional properties of wheat glutenin. Journal of Cereal Science, 23: 1-17.

Weegels P.L., Hamer R.J., Schofield J.D. 1997b. Functional properties of low molecular weight proteins III. Effects on composition of the glutenin macropolymer during dough mixing and resting. Journal of Cereal Science, 25: 165-173.

Weegels P.L., van der Pijpekamp A., Graveland A., Harmer R., Schofield J. 1996a. Depolymerisation and repolymerisation of wheat glutenin during dough processing $\mathrm{I}$. Relationships between glutenin macropolymer content and quality parameters. Journal of Cereal Science, 23: 103-111.

Wellner N., Mills E.N., Brownsey G., Wilson R.H., Brown N., Freeman J., Halford N.G., Shewry P.R., Belton P.S. 2005. Changes in protein secondary structure during gluten deformation studied by dynamic Fourier transform infrared spectroscopy. Biomacromolecules, 6: 255-261.

Whilster R., Daniel J. 1984. Molecular structure of starch; en Whilster R., BeMiller J., Paschal E. editores, Starch Chemistry and Technology. Academic Press. NY. USA. Pág. 153-182.

Wieser H. 2003. The use of redox agents. In: Cauvain S.P. editor, Bread MakingImproving Quality. Woodhead Publishing Ltd., Cambridge. Pág. 424-446.

Wieser H. 2007. Chemistry of gluten proteins. Food Microbiology, 24: 115-119. 
Wieser H., Mödl A., Seilmeier W., Belitz H. 1987. HPLC of gliadins from different wheat varieties: amino acid composition and $\mathrm{N}$-terminal amino acid sequence of components. Zeitschrift für Lebensmitteluntersuchung und -Forschung A, 185: 371-378.

Wilson L.A., Birmingham V.A., Moon D.P., Snyder H.E. 1978. Isolation and characterization of starch from mature soybean. Cereal Chemistry, 55: 661-670.

Wrigley C., Andrews J., Bekes F., Gras P., Gupta R., MacRitchie F., Skerritt J. 1998. Proteinprotein interactions-essential to dough rheology; en Hamer R., Hoseney R., editores, Interactions: The Keys to Cereal Quality. American Association of Cereal Chemists. USA. Pág. 18-20.

Wu H., Corke H. 1999. Genetic diversity in physical properties of starch from a world collection of Amaranthus. Cereal Chemistry, 76: 877-883.

Wuttke W., Jarry H., Seidlova'-Wuttke D. 2007. Isoflavones-Safe food additives or dangerous drugs? Ageing Research Reviews, 6: 150-188.

Yoo S.H., Jane J.L. 2002. Structural and physical characteristics of waxy and other wheat starches. Carbohydrate Polymers, 49: 297-305.

Yúfera E.P. 1998. Cereales; en Química de los alimentos. 1ra Edición. Editorial Síntesis S.A. Madrid. Cap. 3.

Zhang Y., Quail K., Mugford D.C., He Z. 2005. Milling quality and white salt noodle color of chinese winter wheat cultivars. Cereal Chemistry, 82: 633-638

Zhao L.F., Seib, P.A. 2005. Alkaline-carbonate noodles from hard winter wheat flours varying in protein, swelling power, and polyphenol oxidase activity. Cereal Chemistry, 82: 504516.

Zuleta A., Araya H. 2009. Hidratos de carbono como ingredientes funcionales; en Lutz M., León A.E., editores, Aspectos Saludables y Nutricionales de los Productos de Panificación. 1ra Edición. Universidad de Valparaíso-Editorial, España. Pág. 54.

Zweifel C., Handschin S., Escher F., Conde-Petit B. 2003. Influence of high-temperature drying on structural and textural properties of durum wheat pasta. Cereal Chemistry, 80: 159167. 